\title{
An Investigation of the Hazard Associated with the Alluvial Fans on the Kaikoura Coast, South Island, New Zealand
}

\author{
by \\ Erin Julia Baylis
}

\author{
A thesis submitted to \\ Victoria University of Wellington \\ as partial fulfilment of the requirements for the degree of \\ Master of Science (Honours) \\ In \\ Physical Geography
}

School of Geography, Environment and Earth Sciences,

Victoria University of Wellington

September 2009 


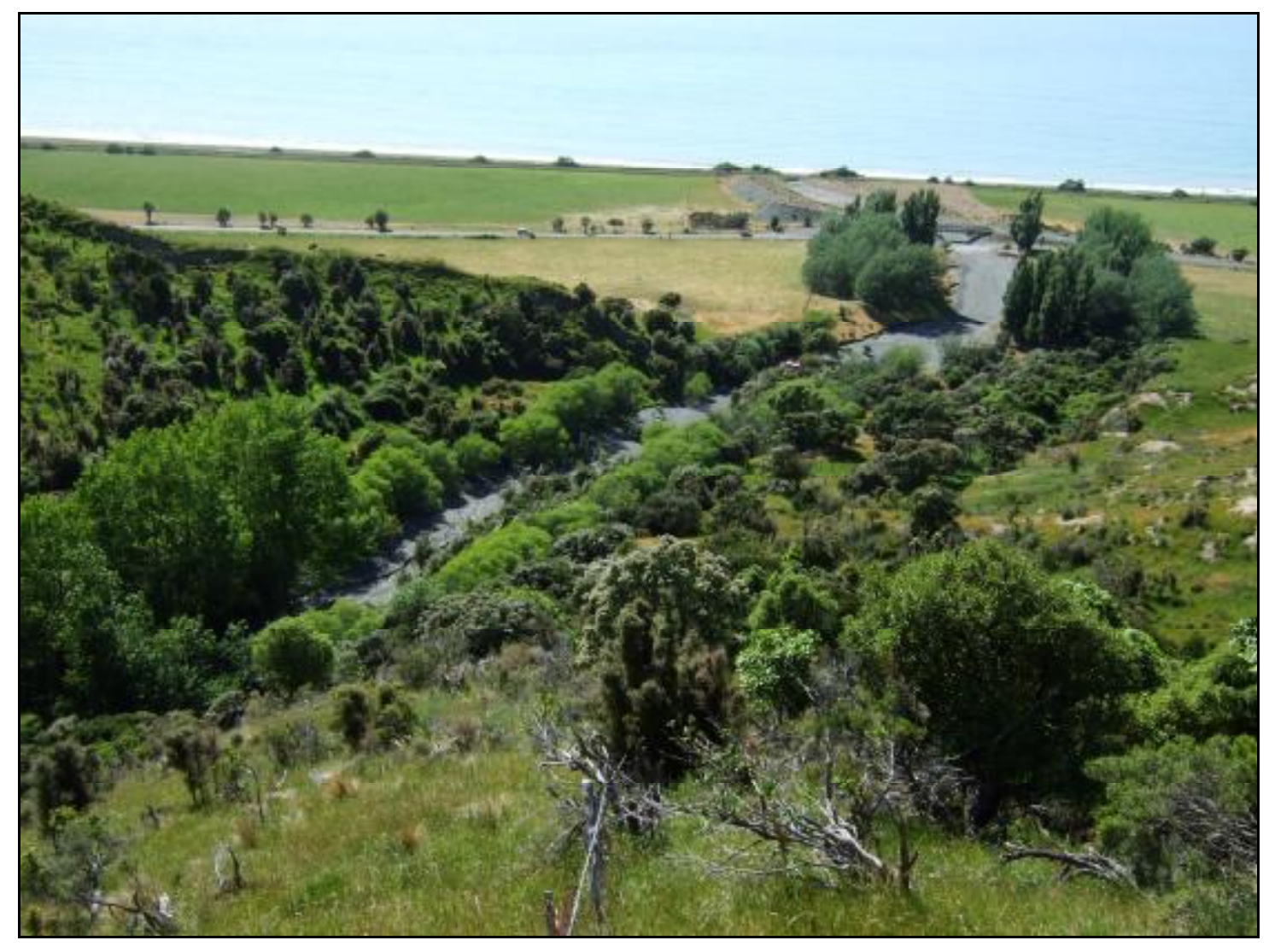

View to the east overlooking Fan 2 


\begin{abstract}
Three large alluvial fans on the northeast coast of the South Island between Kekerengu and the Clarence River mouth present a potential hazard to both State Highway 1 and the South Island Main Trunk Rail Line between Picton and Christchurch, which pass over top of them, and to their users. Climate changes are predicted in future for New Zealand, and may lead to longer warm dry weather periods with heavier rainfall occurrences for the east coast of the South Island. Locations of erosion, the streams' ability to transport sediment and the frequency and magnitude of hazardous fluvial sediment events associated with these alluvial fans could potentially alter due to these predicted future climatic changes, altering the potential hazard to the state highway and the railway line. The underlying purpose of this thesis is to understand the hazard posed by sediment events onto these three alluvial fans and how this may alter in relation to climate change.
\end{abstract}

Longitudinal profiles of the stream channels have been surveyed to determine if they are altering from artificial changes to base level and to establish if sediment is dominantly originating from the catchment walls or the stream channel itself. The potential for transporting sediment under varying return periods has been determined through the calculation of stream power and bed shear stress variables. Through a morphological interpretation of the fans, sedimentation rates have been estimated on both a geological scale and an event scale. The spatially distributed sediment transport model CAESAR was run to determine how the temporal frequency of hazardous events onto the fan could alter in relation to climatic changes.

The absence of any knickpoints located within the stream channel profiles implies that the redistribution of sediment through the stream channel is in a steady state and that the catchment and gully walls are the dominant contributor of sediment. Flow events equal to 10 - and 23-year return period events provide high amounts of available energy which can be used for sediment entrainment and transport, and ranges between 625.5 $\mathrm{W} / \mathrm{m} / \mathrm{s}$ to $4176.4 \mathrm{~W} / \mathrm{m} / \mathrm{s}$ and $789.7 \mathrm{~W} / \mathrm{m} / \mathrm{s}$ to $5366.2 \mathrm{~W} / \mathrm{m} / \mathrm{s}$ respectively. Values of unit stream power indicate that a constant amount of potential energy is available per unit area of the stream channel along its length. The comparison of the boundary shear stress and the critical shear stress indicate that all clasts within the stream channel can be entrained by $10-$ and $23-$ year return period flow events.

Annual geological sedimentation rates for Fan 2 are $181.1 \mathrm{~m}^{3} / \mathrm{yr}$, but it is recognised that individual sediment events may have a higher magnitude, with at least $1158.5 \mathrm{~m}^{3}$ sediment deposited on Fan 2 by two events in 2008 collectively. The model runs suggest that under an altered climatic regime sediment discharge events will generally occur less frequently but will be of a larger magnitude when they do occur. The supply of sediment is unlikely to be exhausted in the near geological future. Under high stream flow discharge events sediment stored in the stream channel is readily able to be entrained and transported, with potentially greater calibre clasts and/or a greater volume of sediment potentially able to be transported as rainfall events become less frequent but more intense. Further, under an altered climatic regime the potential hazard presented to State Highway 1 and the South Island Main Trunk Rail Line and their users is likely to remain unchanged or increase. 


\section{Acknowledgements}

Firstly I would like to thank my supervisor Dr Nicholas Preston for his guidance, patience, advice and many discussions through my time working on this thesis. Thank you for having an open door and answering my many questions. This would not have happened without your support.

Secondly I'd like to express my gratitude to Jeremy and Jane Stace and James and Becky Murray for kindly allowing me access to their land, especially at times of very short notice, and for sharing their local knowledge and history of the area and the alluvial fans. I'd also like to acknowledge Barry Stratton and Albert Su at Transit New Zealand for providing information regarding the fans. Thanks also go to Sam Dean and Brett Mullan from NIWA for providing RCM rainfall data for use in the CAESAR modelling.

Thirdly, thanks to all the staff and students at the School of Geography, Environment and Earth Sciences who I have been lucky enough to know, work with and learn from. A big thanks to my field assistants: Katie Jones, for her driving of the EDM, and Hamish McKoy, for carrying the engineering level through all that vegetation and braving to be in the catchments in the rain or hot sun. Many thanks to Andrew Rae for all his help with ArcMap and the ENVI software, and especially for trying to answer all those unanswerable questions. Thanks are owed to Dr Bethanna Jackson for help getting CAESAR running. Also thanks to Professor Michael Crozier for his assistance.

Thanks to the gymnasts, coaches and parents at Rimutaka Gymsports, who have provided me with another passion outside of my university life and helped me out over the last few years. Sorry girls (who think "all I do is measure rocks") for missing the last few months of training and competitions.

Thanks to all my family and friends for having an interest in my studies. I would particularly like to show my appreciation of the support and encouragement I've received from my parents Wendy and Stuart Baylis, and for always having an interest in whatever I do. Also thanks to grandma and grandad (my grandparents) for financially helping me to pursue my interests.

Finally I would like to give special thanks to Nick Krivan for all his lunch time distractions, support and patience, and for keeping me smiling through stressful times. Thank you also for proof reading my work and providing a place to stay after those late nights spent at uni. 


\section{Table of Contents}

Frontispiece

Abstract ii

Acknowledgements

Table of Contents iv

List of Figures viii

List of Tables $\quad$ xiii

List of Equations $\quad$ XV

Chapter 1: Introduction 1

1.1 Introduction 1

1.2 Aims and Objectives 3

1.3 Thesis Structure 5

$\begin{array}{ll}\text { Chapter 2: Background Theory } & 7\end{array}$

$\begin{array}{lll}2.1 & \text { Introduction } & 7\end{array}$

$\begin{array}{lll}2.2 & \text { Alluvial Fans } & 7\end{array}$

2.2.1 General Introduction to Fans 7

2.2.2 Conditions Required for Fan Formation 10

2.2.3 Additional Factors Influencing Fan Formation 12

2.2.4 Fan Types and Their Formation 21

2.2.5 Alluvial Fan Research in New Zealand 30

2.3 Hazard 31

2.3.1 An Introduction to Hazard 31

2.3.2 The Natural Hazards Associated with Fans 38

2.4 The Entrainment and Transport of Clasts in Stream Flows 41

Chapter 3: Regional Setting $\quad 48$

3.1 Introduction $\quad 48$

$\begin{array}{lll}3.2 & \text { Geology } & 50\end{array}$

3.2.1 Tectonic Setting $\quad 50$ 
3.3 Climate and Weather 53

3.3.1 Regional Climate and Weather 53

3.3.2 Climate Change 55

3.4 Vegetation and Land Use $\quad 59$

3.4.1 Vegetation $\quad 59$

3.4.2 Land Use $\quad 59$

$\begin{array}{lll}3.5 & \text { Geomorphology } & 61\end{array}$

3.6 Engineering of the Fans 63

3.7 Past Triggering Events $\quad 65$

3.7.1 Cyclone Alison $\quad 65$

3.7.2 The July and August 2008 Rainstorms 67

$\begin{array}{lr}\text { Chapter 4: Methods Overview } & \mathbf{7 0}\end{array}$

$\begin{array}{lll}4.1 & \text { Overview of Methods } & 70\end{array}$

4.2 Site Selection for Field Work $\quad 74$

$\begin{array}{lll}4.3 & \text { Methods Structure } & 76\end{array}$

Chapter 5: Likely Areas of Erosion: Longitudinal Profiles and Sediment

$\begin{array}{ll}\text { Transport } & 77\end{array}$

$\begin{array}{lll}5.1 & \text { Introduction } & 77\end{array}$

$\begin{array}{ll}5.2 & \text { Longitudinal Profiles }\end{array}$

5.2.1 Surveying with the Engineering Level 78

$\begin{array}{ll}\text { 5.2.2 Profile Collection } & 79\end{array}$

5.3 Longitudinal Profile Results 81

5.3.1 Unnamed Stream, Catchment 2

5.3.2 Southern Branch of Kawauiti Stream, Catchment 1

5.4 Stream Power $\quad 88$

5.4.1 Channel Slope $\quad 89$

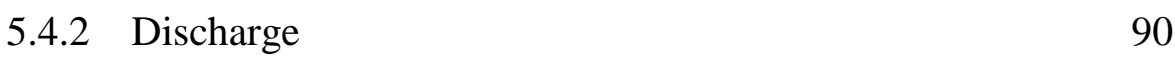

$\begin{array}{lll}\text { 5.4.3 Channel Width } & 104\end{array}$

5.5 Stream Power Results 104 
$\begin{array}{lll}5.6 & \text { Grain Size } & 107\end{array}$

5.6.1 Collection of Sediment Samples 108

5.6.2 Justification of Laboratory Procedures 109

$\begin{array}{lll}\text { 5.6.3 Laboratory Procedures } & 109\end{array}$

$\begin{array}{lll}5.7 & \text { Grain Size Results } & 110\end{array}$

$\begin{array}{lll}5.8 & \text { Calculation of Shear Stresses } & 111\end{array}$

5.8.1 Boundary Shear Stress 112

5.8.2 Critical Shear Stress 114

5.9 Shear Stress Results 117

5.9.1 Boundary Shear Stress Results 117

5.9.2 Critical Shear Stress Results 118

Chapter 6: Sediment Event Temporal Patterns: Sedimentation Rates and

$\begin{array}{ll}\text { Model Projections } & 120\end{array}$

$\begin{array}{lll}6.1 & \text { Introduction } & 120\end{array}$

$\begin{array}{lll}6.2 & \text { Sedimentation Rates } & 120\end{array}$

6.2.1 Field Surveying using the EDM and RTK 121

6.2.2 Stored Sediment Volume Calculation 123

6.2.3 Estimation of Geological Sedimentation Rates 124

6.2.4 Event Sedimentation Rates 124

6.3 Sedimentation Rates Results 126

6.3.1 Stored Sediment Volume 126

6.3.2 Geological Sedimentation Rates 127

6.3.3 Event Sedimentation Rates 128

$\begin{array}{lll}6.4 & 128\end{array}$

$\begin{array}{lll}\text { 6.4.1 CAESAR } & 129\end{array}$

6.4.2 How CAESAR Works 130

6.4.3 Data Collection 134

6.4.4 CAESAR Model Runs 143

6.5 CAESAR Results 144

6.5.1 Current Conditions Model Run 144

6.5.2 Climatically Altered Conditions Model Run 149 
$\begin{array}{lll}7.1 & \text { Introduction } & 154\end{array}$

7.2 Likely Areas of Erosion 154

7.2.1 Longitudinal Profiles 154

7.2.2 Stream Power 157

7.2.3 Likely Areas of Sediment Entrainment 159

$\begin{array}{lll}7.3 & \text { Sedimentation Rates } & 161\end{array}$

7.4 Sediment Event Frequency 164

7.4.1 Comparison of Sedimentation Event Occurrences 164

7.4.2 Model Projection Limitations, Errors and Uncertainties 168

7.4.3 Model Projections Summary 174

7.5 Implications for Potential Hazardous Events 174

$\begin{array}{ll}\text { Chapter 8: Conclusion } & 177\end{array}$

$\begin{array}{lll}8.1 & \text { Aims } & 177\end{array}$

8.2 Characterising the Hazard 178

8.3 Rates of Sediment Accumulation 179

8.4 Changes to the Potential Hazard in Relation to Changes in Climate 180

$\begin{array}{lll}8.5 & 181\end{array}$

8.6 Recommendations for Future Studies 182

$\begin{array}{ll}\text { References } & 184\end{array}$

\section{Appendices}

Appendix I: Longitudinal Profile Collection Data

Appendix II: Rainfall Intensity Data for Rational Method Calculations

Appendix III: Grain Size Results

Appendix IV: CAESAR Settings

Appendix V: Hourly Rainfall Data for CAESAR

Appendix VI: CAESAR Results 


\section{List of Figures}

2.1 Basic diagram of a fan deposit at the outlet of a steep sided valley 8

$\begin{array}{ll}2.2 & \text { Reworked and restricted fan morphologies } \\ \end{array}$

2.3 Transition-to-Drier-Climate model showing the processes leading to aggradation as the climate becomes drier

$\begin{array}{lll}2.4 & \text { The Paraglacial sediment model } & 19\end{array}$

$\begin{array}{ll}2.5 & \text { The Periglacial model } \\ & 20\end{array}$

2.6 The range of alluvial fan slope angles compared to colluvial fan slope angles reported within the literature

2.7 Common processes and deposits present on fluid-gravity dominated alluvial fans

2.8 Common processes and deposits present on sediment-gravity dominated colluvial fans

2.9 Natural phenomena can be natural resources which are useful to people but natural hazards can also result from the interaction of natural phenomena and the use of an area by humans

2.10 The relationship between the frequency and magnitude of hazard events 35

2.11 A shift right of the whole distribution curve of possible magnitudes increase the magnitude of the mean hazardous event that can be experienced resulting in potentially more, higher extreme hazardous events occurring

2.12 Greater variability of possible magnitudes could result in more extreme hazardous events

2.13 The main driving and resisting forces acting on individual clasts on the stream bed

2.14 The Hjulstrom Curve, outlining the flow velocity at certain size grain particles can be entrained, transported and deposited

2.15 The Shields Entrainment Diagram which shows the relationship between a dimensionless critical shear stress and the Reynolds number for a clast 47

3.1 Location of the field site in the South Island, New Zealand

3.2 The Marlborough Fault System 
3.3 Examples of the Great Marlborough Conglomerate rock type in the three catchments

3.4 Average monthly rainfall and temperatures of southeastern Marlborough and northern Canterbury

3.5 Projected mean annual temperature changes in ${ }^{\circ} \mathrm{C}$

3.6 Projected mean annual rainfall changes in percentages

3.7 The location of State Highway 1 and South Island Main Trunk Rail Line crossing the three alluvial fans

3.8 Photographs showing the terrain of Catchments 1 and 2

3.9 An example of erosion paths from water running down the catchment and gully walls.

3.10 The bypass bridge that currently allows access across Fan 2 during sediment and flood events.

3.11 Synoptic weather maps, at midnight (NZST) of Cyclone Alison's path over New Zealand from the $11^{\text {th }}$ of March to the $14^{\text {th }}$ of March 1975

3.12 Synoptic weather maps of the weather systems that produced the rainfall events during July and August 2008

3.13 Photographs of the three State Highway 1 fords passing over the alluvial fans under normal conditions and flood conditions during the $31^{\text {st }}$ July 2008 rainfall event.

4.1 Flow chart showing an overview of the methods employed in this study, and their interrelations

4.2 The fans north of the Clarence River mouth. Fan 2 and the corresponding catchment is the main site for field work to be carried out

4.3 Catchment 2 divided into sub-catchments A to $\mathrm{J}$

5.1 The engineering level in the foreground surveying the longitudinal profile of the stream channel in Catchment 1 to the measuring staff in the distance

5.2 Three cross-hairs are visible when sighting through the engineering level

5.3 The location of the longitudinal profile through Catchment 2 
5.4 The longitudinal profile of the unnamed stream located in Catchment 284

5.5 The location of the longitudinal profile through Catchment $1 \quad 86$

5.6 The longitudinal profile of the southern channel of the Kawauiti Stream located in Catchment 1

5.7 Vegetation cover types in Catchment $2 \quad 94$

5.8 The slope layer determined from the 20 metre DEM of Catchment 296

5.9 Graph displaying how stream power varies along the stream of Catchment 2 with distance from the headwaters to the catchment outlet 106

5.10 Unit stream power for a 10- and 23- year return period stream flow at the outlets of sub-catchments A, E, G, I and J

5.11 Map detailing the location of the nine sediment samples collected from the channel of Catchment 2

5.12 The sediment sieves used to sieve the fine portion of each sediment sample.

5.13 Boundary shear stress $\left(\mathrm{kg} / \mathrm{m}^{2}\right)$ for a $10-$ and $23-$ year return period stream flow discharge at the outlets of sub-catchments A, E, G, I and J

5.14 Critical shear stress $\left(\mathrm{kg} / \mathrm{m}^{2}\right)$ values required for the initiation of entrainment for eight different clast sizes in the sub-catchments, A to $\mathrm{J}$

6.1 Fan 4 showing a recently active fan superimposed upon a truncated relict fan.

6.2 Use of the RTK GPS unit to collect elevation and location coordinates on Fan 4.

6.3 Features near the apex of Fan 2 which were partially or completely buried during the two heavy rainfall events in July and August 2008

6.4 The clipped DEMs of A: Fan 2 and B: Fan 4 constructed in ArcMap from data collected in the field

6.5 Flow chart showing the operation processes carried out during the running of CAESAR

6.6 Schematic diagram of the scanning algorithm used to pass water through a catchment by the CAESAR model 
6.7 The epipolar image of the stereo pair images D23 and D24 generated in ENVI using tie points and the RPC information of the aerial photographs

6.8 The clipped DEM of Catchment 2 to be used in the CAESAR model

6.9 Mean monthly rainfall of the first ten years of the 1971 and 2071 rainfall data sets.

6.10 Time series of the hourly rainfall values used in the current conditions model run generated by the RCM for 1971 to 1980

6.11 Time series of the hourly rainfall values used in and the altered climatic conditions model run generated the RCM for 2071 to 2080

6.12 The approximate location from which the source sediment sample off a gully wall was taken from

6.13 Hourly water flow and sediment discharges produced for ten years under the current conditions model run

6.14 The relationship between the frequency of water hourly flow discharges and the size of hourly sediment discharges generated by each hourly water flow discharge under the current conditions model run

6.15 The size of the sediment discharge events produced for ten years in the current conditions model run using the 1971 rainfall data

6.16 Cumulative frequency of sediment events equal to or greater than a selected sediment event volume

6.17 Hourly water flow and sediment discharges produced for ten years under the altered climatic conditions model run

6.18 The relationship between the frequency of hourly flow discharges and the size of hourly sediment discharges generated by each hourly flow discharge under the altered climatic conditions model run

6.19 The size of the sediment discharge events produced for ten years in the altered climatic conditions model run

6.20 Cumulative frequency of sediment events equal to or greater than a selected sediment event volume for events produced from the altered climatic conditions model run

7.1 Evidence of the small channel degradation which occurred in the lower part of the stream channel in Catchment 2 during the July and August 2008 rainfall events. 
7.2 An increase in the mean amount of sediment, as indicated by the altered climatic conditions model run, would lead to a shift right of the hypothetical magnitude frequency curve, leading to an increased frequency of larger sediment events.

7.3 The water flow discharges produced in both CAESAR model runs, with the red line indicating the anomaly in the flow discharge 


\section{List of Tables}

5.1 Channel slope at the outlets of sub-catchments A to J.

5.2 Table describing the vegetation cover types and how they were identified on the 2004 aerial photograph.

5.3 Percentages of the bare soil, pasture and forest vegetation cover types within each of the sub-catchments A to J.

5.4 Mean slope angles of each of the sub-catchments A to J.

5.5 Frevert's runoff coefficient table, displaying adjusted values representative of the catchment concerned

5.6 Runoff coefficients calculated for sub-catchments A to J using Frevert's runoff coefficient table.

5.7 The length (in kilometres) of each of the sub-catchments A to J.

5.8 The area of each sub-catchment $\mathrm{A}$ to $\mathrm{J}$ and diameter of a circle equal to the area of each sub-catchment

5.9 Average fall of the stream channel for each of the sub-catchments A to $\mathrm{J}$

5.10 Concentration times for sub-catchments A to J.

5.11 The calculated rainfall intensity values 'I' required for the calculation of the stream discharge using the Rational Method.

5.12 Stream discharges $\left(\mathrm{m}^{3} / \mathrm{s}\right)$ for sub-catchments A to J over the $10-$ and 23- year return periods.

5.13 Channel width near the outlets of sub-catchments A, E, G, I and J

5.14 Stream power values calculated for sub-catchments A to J.

5.15 Unit stream power values calculated for sub-catchments A, E, G, I and $\mathrm{J}$.

5.16 Values of hydraulic radius for sub-catchments A to J for 10- and 23year return periods.

5.17 Boundary shear stress values calculated for sub-catchments A, E, G, I and $\mathrm{J}$.

5.18 Critical shear stress values calculated for sub-catchments A to J. 
6.1 Estimated volume of stored sediment and the geological sedimentation rates for Fan 2 and Fan 4

6.2 Grain size ranges and proportions of a sample of the source sediment from a gully wall of Catchment 2 to be used in CAESAR

6.3 The percentage of events of varying size ranges produced by the current conditions model run.

6.4 Cumulative frequency of sediment discharge events greater than or equal to varying event magnitudes.

6.5 The percentage of events of varying size ranges produced using the 2071 rainfall data

6.6 Cumulative frequency of sediment discharge events greater than or equal to varying event magnitudes.

7.1 Number of sedimentation events per year of the model run for the current and altered climatic conditions model runs. 


\section{List of Equations}

2.1 Fan area and catchment area relationship equation. 13

$\begin{array}{lll}2.2 & \text { Fan development equation. } & 17\end{array}$

2.3 Threshold of motion equation 44

$\begin{array}{lll}2.4 & \text { Shield's equation } & 46\end{array}$

$\begin{array}{llr}5.1 & \text { Stream power equation } & 88\end{array}$

$\begin{array}{ll}\text { 5.2 Unit stream power equation } & 89\end{array}$

$\begin{array}{ll}\text { 5.3 Rational method equation } & 92\end{array}$

$\begin{array}{lll}5.4 & \text { Frevert's runoff coefficient equation } & 98\end{array}$

$\begin{array}{lll}5.5 & \text { Bransby-Williams formula } & 100\end{array}$

$\begin{array}{lll}5.6 & \text { Boundary shear stress equation } & 112\end{array}$

$\begin{array}{lll}5.7 & \text { Stream discharge equation } & 113\end{array}$

5.8 Rearranged stream discharge equation to determine area of stream 113 channel

5.9 Rearranged stream channel area equation to determine stream channel 113 depth

$\begin{array}{lll}5.10 & \text { Critical shear stress equation } & 114\end{array}$

$\begin{array}{lll}5.11 & \text { Constant K equation } & 116\end{array}$ 


\section{Chapter 1}

\section{Introduction}

\subsection{Introduction}

Alluvial fans are a common landform found in many differing climatic regions (Bull, 1977; McArthur, 1987; Crosta and Frattini, 2004). The landscape of the South Island, New Zealand is very active. High rates of both uplift and weathering occur due to the tectonic and climatic location, and as a result there is a large amount of eroded sediment stored within catchments available for transport and deposition. Additionally New Zealand's location within the "roaring forties" provides weather systems capable of producing high intensity rainfall, required for the transport of this sediment (Davies and McSaveney, 2008). Thus the conditions required for alluvial and colluvial fan development are met, with many of these landforms existing in the South Island.

In New Zealand, and worldwide, the stability of alluvial fans is an important issue as fans can provide significant hazards to people, buildings and other infrastructure located on or near fans. Sediment movement through the alluvial fan system by debris flows, rock falls, rock avalanches or within stream flows produces a potential hazard as it flows out onto the fan surface and can lead to the additional hazards of flooding, aggradation or scouring of the stream channel and stream channel avulsions on the fan. Buildings and other infrastructure are commonly constructed on alluvial fans without a prior understanding of the processes that have actively led to the development of the fans. These processes may still be actively occurring on the fan even if an event has not occurred over a long time period. The Black Birch and Glencoe fans at Aoraki/Mount Cook Village provide a good example of development on fans, where large stop banks, dykes and land use zoning have been put in place to prevent the stream and debris flows from flowing out of the catchments, towards the village located on the fans (McSaveney and Whitehouse, 1989; Skermer et al., 2002). 
Climate is a key controlling variable on the formation and continued deposition of sediment onto alluvial fans (Bull, 1977; Blair and McPherson, 1994; Dorn, 1994). It provides both the preparatory and triggering factors for sediment movement through the catchment. The climate influences the weather conditions of an area, affecting the processes of physical and chemical weathering, vegetation growth and the resulting erosion and instability of the landscape, which provides an available sediment supply needed for fan formation. It also influences the occurrence and intensity of the rainfall events, which generate stream discharges able to entrain and transport the stored sediment onto the fans (Blair and McPherson, 1994). Alterations to the climatic situation, in particular the amount of rainfall and the intensity of the rainfall events, will therefore have an influence over the amount of sediment available within the catchment and rates of sediment accumulation onto the fan.

Like the rest of the world, New Zealand is predicted to be affected by climate change in the future (MfE, 2008). In New Zealand, the climate is predicted to get warmer and wetter especially in the western areas. Eastern areas are predicted to get drier but have more intense rainfall (Kinsella and McGurie, 2006; MfE, 2008). Current studies recognise the potential for more storms and that extreme rainfall events could become more intense and occur more frequently (MfE, 2008). Storm events with rainfall intensities similar to Cyclone Alison, in March 1975 (Bell, 1976), or the July and August 2008 events, which lead to large amounts of sediment being washed off the Seaward Kaikoura Ranges and deposited on the coastal area (Bell, 1976), could become a more common event. Intense periods of rainfall can lead to more energy being generated within stream channels for sediment entrainment and transport, allowing the larger calibre sediment and/or a larger amount of sediment to be moved onto the fan surface. This would alter the frequency and magnitude of hazardous events affecting development located on alluvial fans.

Many alluvial fans flow out of the Seaward Kaikoura Ranges and onto the coastal plain. The fan sequences between Kekerengu and the mouth of the Clarence River are encroaching on State Highway 1 and the South Island Main Trunk Rail Line between Picton and Christchurch. In some areas State Highway 1 and the railway line are already sitting on top of the alluvial fans. These fans have the potential to block or damage these 
key transport routes (Opus, 2008). Fan movement from Cyclone Alison, for example, caused damage to both State Highway 1 and the main railway line north of Kaikoura (Bell, 1976). As recently as July and August 2008 extreme rainfall triggered sediment movement onto the fans, extending over State Highway 1, blocking it for several days, thus resulting in the need for the bypass bridges to be used (pers. comm. Jeremy Stace, 16 November 2008).

Three large fans, in particular, located to the north of the Clarence River mouth, on the coast of the South Island, New Zealand, are the primary focus of this study. These fans are regularly active and extend from relatively small, easily eroded catchments. Both State Highway 1 and the railway line cross these fans, currently presenting a potential hazard to the road, rail and their users and consequently the fans are heavily maintained. The potential hazard could increase as a result of alterations in the climatic situation, with sediment build up increasing in the catchment and less frequent but more intense rainfall leading to greater sediment transport and deposition out of the catchments and onto the alluvial fans. This stretch of highway between the mouth of the Clarence River and Kekerengu is marked in Transit New Zealand's 10 year plan for the Canterbury Region, for improvements to the highway where the alluvial fans are affecting it, focusing on where these three alluvial fans are located (Transit New Zealand, 2007, 2008). Few records exist of sedimentation events on these alluvial fans or of the work undertaken to maintain the fans, the State Highway or the rail-line. Further, little research has been conducted on these fans to determine where the sediment is coming from, the rates of sediment transport and how climatic changes forecast for New Zealand could alter these sediment transport rates.

\subsection{Aims and Objectives}

Three main aims are involved in this study, each with the underlying purpose of understanding the hazard posed by sediment events onto the three alluvial fans located between Kekerengu and the Clarence River mouth. Each aim has key objectives established. 
The first main aim is to "spatially define the locations from which the erosion hazard originates, within the catchments of the alluvial fans".

Specifically this aim will be split into two objectives:

1: Construct longitudinal profiles of the stream channels to determine whether there is any evidence of the stream channel profiles altering as a result of artificial changes to base level.

This will help to determine what the current state and stage of the stream channel in 2008 implies about the location of areas of current and future potential erosion and sediment production within the catchments.

2: Evaluate which areas within the stream channels have the fluvial conditions required for sediment entrainment and transport of the sediment present within the stream channel out of the catchment and onto the alluvial fans at times when flow discharges are present in the stream channels.

The second aim for this study is "to understand the rates of sediment accumulation, in terms of both contemporary and geological sediment rates onto the alluvial fans".

This aim will be split into two objectives:

1: Estimate the volume of material deposited in the fans and the geological rates of sediment accumulation.

2: Estimate the amount of sediment deposited on the fans during the July and August 2008 rainfall events.

Aim three is to "investigate the likely changes to potential hazard on the alluvial fans, in relation to changes in climate". 
The objective for this aim is:

1: Estimate the potential change in frequency of sediment movement onto the alluvial fans as a result of a future rainfall/runoff regime, based on predicted climate change and by applying a spatially distributed sediment transport model.

The alluvial fans between the mouth of the Clarence River and the settlement of Kekerengu will be used for this study. The occasional, predominantly fluvial transport of sediment onto these fans presents a hazard to the State Highway and the rail line that cross these landforms and this hazard could increase with changes in climate. This study will go part way to addressing the current lack of knowledge about the spatial and temporal fluvial erosion and transport occurring in the fan catchments, due to the very limited existence of records of sedimentation events onto the fans.

\subsection{Thesis Structure}

This thesis is divided into eight chapters. Chapter two provides a theoretical background, reviewing alluvial fans, focusing on their development and morphology. Alluvial fans are further discussed in the context of the potential hazard which they present. This chapter also reviews the theory of fluvial sediment transport in order to provide an understanding of the methods to be undertaken. Chapter three will describe the regional setting of the three alluvial fans involved in this study.

Chapter four introduces the range of methods to be carried out within a field, laboratory or computer environment, putting each method in context with the other methods to be carried out, and relating them to the overall aim and objectives. Because of the wide range of methods applied, their detailed description is presented, alongside results, over the next two chapters. The methods undertaken for the collection of longitudinal profiles and the sediment transport data are outlined and the relevant results for these methods are presented in chapter five. Chapter six discusses the methods undertaken to determine sedimentation rates and in the collection of data required and the running of the CAESAR sediment transport model. The results obtained from the model will be 
detailed in this chapter additionally. Chapter seven aims to provide a discussion of the results presented in the previous two chapters. Lastly, in chapter eight, the conclusions of this study are drawn and presented. 


\title{
Chapter 2 \\ Background Theory
}

\subsection{Introduction}

\begin{abstract}
Alluvial fans can provide a number of differing hazards to people, buildings and infrastructure located on these active landforms. An understanding of alluvial fans and the processes leading to their formation and evolution is first required to fully understand the potential hazard presented by alluvial fans. The aim of this chapter is to provide a relevant background to the topics involved in this thesis and provide a review of literature currently available. It is divided into three sections. Section 2.2 provides an introduction to alluvial fans and the processes involved in their development. It provides a brief description of what alluvial fans are and the processes and controls related to their development. Section 2.3 introduces the ideas behind hazard theory, providing definitions. It then discusses the hazards associated with alluvial fans and their use by humans. The final section, section 2.4 , reviews the theory related to the fluvial entrainment and transport of sediment clasts and particles onto the fan surface.
\end{abstract}

\subsection{Alluvial Fans}

\subsubsection{General Introduction to Fans}

Alluvial fans are common in many different climatic locations. While a large proportion of the early study and enquiry into fans was concentrated on fans in drier arid or semiarid areas, for example the southwest United States, fans can develop in locations with humid, temperate, tropical, mountainous or coastal climates providing that the conditions required for fan development are met (McArthur, 1987; Blair and McPherson, 1994; Crosta and Frattini, 2004). Worldwide very few enquiries into fan formation and their deposits had been carried out prior to the 1960s (Dorn, 1994). Drew (1873) is thought to be the first author to use the term "alluvial fan" to describe a fan 
deposit (Bull, 1977; Blair and McPherson, 1994). In the 1960s, study of alluvial fans in the United States grew due to the need to look for water resources in the southwest as the population of this region grew. After this time the study of fans has rapidly expanded, still largely concentrating on fans located in arid and semi-arid areas, but additionally focusing on fans in other environments, their use in engineering and hydrology, their formative processes and morphodynamics and the hazards they present to their surrounding environment and users and development.

Alluvial fans are cone shaped sedimentary stores deposited at the base of slopes where a stream exits a steep sided valley to flow onto a gentle sloping valley surface (Figure 2.1; Selby, 1982; McSaveney and Whitehouse, 1989; Blair and McPherson, 1994; Dorn, 1994; Davies and McSaveney, 2008). Bull (1977, p 222) describes an alluvial fan as "a deposit whose surface forms a segment of a cone that radiates downslope from the point where the stream leaves the source area". A mountain valley stream is commonly restricted to the narrow mountain valley floor, becoming unconfined as it flows out of the mountain valley onto an open, gentle sloping valley, basin or coastal plain. As the stream becomes unconfined, the stream is allowed to freely avulse back and forth across the fan surface depositing sediment, while the stream at the apex of the fan stays in a fixed position, thus creating the semi-circular shape that fans commonly display. The deposition of sediment occurs due to the stream losing power to transport sediment as the stream flows onto a gentler slope. The stream is able to spread out over the fan surface and some water may disperse into groundwater in the fan deposit further decreasing the stream's ability to transport sediment.

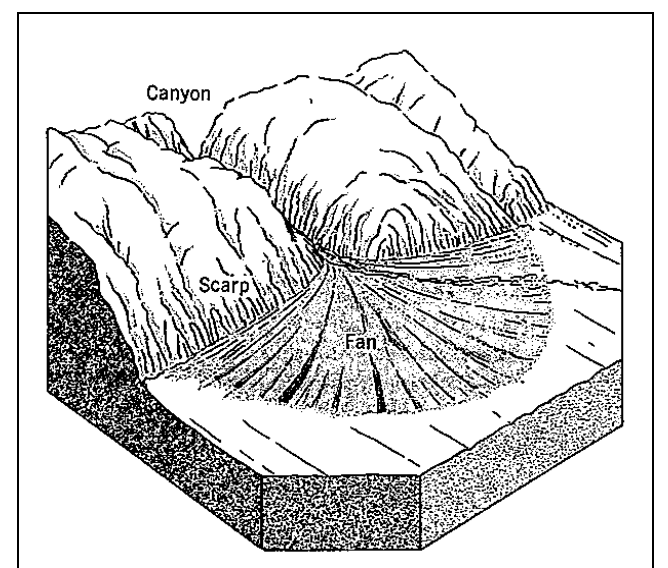

Figure 2.1: Basic diagram of a fan deposit at the outlet of a steep sided valley (Strahler, 1945) 
An environment with an available supply of sediment and where a stream becomes unrestricted as it leaves its catchment to flow onto a flatter surface and which receives rainfall events capable of generating flows to transport the sediment is required for the formation of fan landforms. Other variables, for example the tectonic, climatic and neighbouring environments and the catchment characteristics, also influence the formation of fans to some degree.

Alluvial fans are locations of temporary sediment storage within the movement of sediment from the catchment out to sea, acting as what Fryirs et al. (2007) term a barrier, longitudinally disconnecting the flow of sediment from the catchment onto the floodplain or the main river channel. The stream is the link between the erosional environment within the catchment and the depositional environment on the fan. Processes leading to fan development differ depending on the amount of water and sediment being transported, for example stream flows or debris flows, thus leading to different fan morphologies and therefore different fan types. While the term 'alluvial fan' is often generically used as an umbrella term by some authors (Bull, 1977; McArthur, 1987; Crosta and Frattini, 2004), fans can be divided into two main types, alluvial or colluvial, depending on the dominant processes leading to their formation and evolution. A range of secondary processes can act on alluvial fans altering the fan surface between forming events. Fans can develop in a variety of sizes and slope angles and the shape of the fan can be restricted by surrounding landforms. They often display a concave longitudinal profile and a convex cross section.

On a broad scale fans and the stability of them can be defined as active or inactive. Active fans are still forming, with formative processes occurring within living memory. They have streams or debris flows flowing and avulsing across them frequently, for example on daily to seasonal time scales, with little to moderate vegetation growing on them, especially along the recent channels. Inactive fans have not changed their form for a large amount of time, for example not within living memory, so their formative processes are considered to be finished. They generally have mature vegetation growing over the entire fan surface, including the stream channel. The stream channel may have dried up, with sediment only being transported by secondary processes. Dormant fans are considered as inactive; there have been no formative processes active for a period of 
time, but there may be reason to believe that these processes will become active again. Large amounts of sediment may be stored in the catchment and just require a triggering event for the movement of this material onto the fan to occur. Some parts of active fans can be converted to become dormant through control and mitigation structures placed on the fan. However, large events may not be completely controlled by these structures. The reactivation of dormant fans, both natural and man-made, will be unexpected due to the long period with no processes occurring on the fan or area. Fans which formed under different environmental conditions are termed relict fans. These are fans which formed when key factors influencing fan formation were different from the current conditions, for example a different climatic situation or a varying vegetation cover. Relict fans may be either active or inactive.

\subsubsection{Conditions required for Fan Formation}

Generally, there are three conditions that are required to be met for the formation of a fan to occur:

- A topographic environment which allows a stream to become unconfined as it exits a catchment to flow onto a lower, flatter floodplain or valley,

- An available sediment supply within the catchment,

- High-intensity rainfall events or snow/ice melt able to generate discharges capable of transporting sediment from the catchment (Blair and McPherson, 1994; Davies and McSaveney, 2008).

Alluvial fans typically form at the base of hillslopes where a stream flows out of a steep, narrow catchment onto a lower plain or valley allowing the stream to become unconfined and spread across the plain or valley. This topographic environment is common along hill and mountain front fault scarps where tectonic uplift processes have uplifted structural blocks elevating the catchments above the floodplain (Blair and McPherson, 1994; Davies and McSaveney, 2008). Further, this type of topographic environment can also be present where streams enter deglaciated valleys or where tributary streams enter incised stream or river channels (Blair and McPherson, 1994). 
The second condition for the development of a fan is an available sediment supply stored within the catchment that is sufficient for the build up of a fan. Allowing enough time, a sediment supply can be built up through both physical and chemical weathering. Relief can aid in the production of sediment by exposing the catchment to greater weathering processes such as more rain, ice or snow. Steep relief can also generate mass movements of sediment due to forces of gravity acting on the sediment on the slopes. Where rock is fractured and easily crumbled from faulting and folding processes, a greater surface area is exposed and can be easily weathered. Thus tectonic areas can continuously produce sufficient amounts of sediment for the build up of a fan due to their continued uplift creating relief and easily weathered rock (Blair and McPherson, 1994). Catchments without tectonically active processes are often able to rework sediment previously deposited by fluvial or glacial processes. However, unlike those catchments with a tectonic setting, catchments consisting of previously deposited sediments only supply a limited amount of sediment for a limited time and can be easily exhausted (Blair and McPherson, 1994). Once sediment supply has been generated through weathering processes it can be stored on the slopes or within the stream channel in the catchment, if it is not deposited straight onto the fan surface.

A means of transporting the sediment out of the catchment to be deposited onto the fan surface is the final requirement for fan development. High, sometimes catastrophic, stream discharges capable of entraining and transporting sediment can be produced by intense heavy rainfall events, prolonged rain events or fast ice or snow melt. These can all produce flash floods and can further act as a trigger to mass movement events such as debris flows, landslides and rock or debris avalanches. Blair and McPherson (1994) and Davies and McSaveney (2008) note that precipitation occurring over alluvial fan catchments can quickly flow into the main stream channel to produce these events due to the location of the catchments along mountain edges and their consequent relief inducing orographic rainfall. The catchment shape can further induce rapid flow into the main stream channel. Water has a short distance to flow from near the catchment headwaters to the catchment outlet in short, round catchments. The tributaries within the catchment are located close together and are able to contribute flow to the main stream channel rapidly and over a similar time frame inducing rapid, high flash flood. In longer, narrow catchments water is slower to flow from the catchment headwaters to the 
catchment outlet as the tributaries are spaced further apart and slowly add water to the main stream channel, leading to a lower flow over a longer duration (Fryirs and Brierley, 2001).

Davies and McSaveney (2008) recognise the need for a means of sediment deposition on the fan surface as an additional condition required for fan development. An abrupt change from a steep confined channel within the catchment to a gentle sloping unconfined area as the stream exits the catchment allows for deposition to occur. Deposition occurs from a sudden decrease in gradient which reduces the stream velocity and its ability to transport sediment (Bull, 1977). Stream flow is able to spread out as the stream becomes unconfined on the surface, or dissipates down into the fan surface, reducing the stream's capacity for sediment transport (Bull, 1977; Selby, 1982; Blair and McPherson, 1994).

\subsubsection{Additional Factors Influencing Fan Formation}

A number of other variables additionally have an influence over the morphology of fans and the processes that lead to their formation. These variables are either internal within the catchment or external variables from outside the catchment. Blair and McPherson (1994) list these additional key variables as:

- The characteristics of the catchment: lithology, area and size, shape, vegetation cover and relief

- Neighbouring environments and the restrictions they impose on the fan

- Tectonic effects

- Climatic effects

These variables can influence each other and can further enhance the effect each has on fan development. Bull (1977) and Selby (1982) note that changes in one or more of these variables can promote changes in other variables and therefore affect and alter the overall fan morphology. 


\section{Catchment Characteristics}

Catchment characteristics such as lithology, shape, area, size, relief and vegetation cover affect the supply of water and sediments to the fan, and in turn control the processes leading to fan formation and morphology (Bull, 1977; Blair and McPherson, 1994; Crosta and Frattini, 2004).

The type of lithology within the catchment can influence the size and volume of sediment generated and how easily the bedrock is weathered. Differing lithology is affected and responds differently to chemical and physical weathering processes, which is further enhanced by the structural properties of the rock mass, for example fractures, joints or faults (Blair and McPherson, 1994; Crosta and Frattini, 2004). When combined with slope angles, the lithology of the catchment has a large influence over the type of primary flow processes. Steep slopes with a lithology that can produce large amounts of clay typically lead to debris flows or landslides, while slopes with lithologies which produce lesser amounts of clay typically lead to rockfalls, rock avalanches or sheetfloods (Blair and McPherson, 1994). While both generate supplies of sediment within the catchment, lithologies which produce debris flows are better at supplying the sediment directly onto the fan surface.

Area can be related to almost every catchment characteristic in some way and is termed the "devil's own variable" by Anderson (1957) for this reason. It can have an influence on slope, relief, sediment storage and transport and the occurrence of flashfloods (Blair and McPherson, 1994). The relationship between catchment area and fan area has been expressed as:

$$
\mathrm{A}_{\mathrm{f}}=\mathrm{cA}_{\mathrm{b}}{ }^{\mathrm{n}}
$$

\section{Equation 2.1}

where $A_{b}$ is the area of the catchment $\left(\mathrm{km}^{2}\right)$ and $A_{f}$ is the area of the fan $\left(\mathrm{km}^{2}\right)(\mathrm{Bull}$, 1977; Crosta and Frattini, 2004). This is due to water discharge and therefore sediment discharge increasing as the catchment area gets bigger. Crosta and Frattini (2004) note that the exponents $\mathrm{c}$ and $\mathrm{n}$ can vary between fans in differing climatic zones and this can further be associated with climate change, the tectonic setting, the erodibility of the lithology and the capacity for sediment storage within the catchment. The ratio of the 
size of the fan to the size of the catchment may not be constant, however, due to sediment storage within the catchment. Larger catchments are able to store sediment which is later transported by stream flow processes whereas sediment from smaller catchments may be deposited straight onto the fan (Crosta and Frattini, 2004). Generally, however, the relationship between catchment area and fan area has implications for distinguishing between fans that have formed due to dominantly alluvial or colluvial processes. De Scally and Owens (2004) note that smaller catchments develop smaller fans that are usually developed by debris flow processes, while the larger fans are developed by alluvial processes flowing from larger catchments.

Catchment shape determines the rate at which water and sediment is transported to the main stream channel and out to the fan (Blair and McPherson, 1994). Elongation of the catchment can slow the rate of water converging in the main stream channel and allows for sediment storage as high flows are needed to transport sediment through the longer catchment (Fryirs and Brierley, 2001). Flash floods are more likely to be generated in catchments with a rounded shape rather than a long narrow shape (Strahler, 1957) as the tributaries are located closer together and the flow in each has a similar distance to travel from the headwaters of the catchment to the catchment outlet. The flow can converge quicker and produces a short duration, high flood peak (Fryirs and Brierley, 2001). These high flood peaks are also more capable of transporting greater volumes of sediment.

The relief of the catchments can influence which sediment transport processes are active within the catchment and the size of these events. High relief combined with steep slopes and easily eroded soil and rock types tend to aid in the generation of mass movements. Steep slopes also increase the rate of overland flow towards the channels. The overall relief and elevation of the catchment affect the likelihood of the catchment receiving large precipitation events. The geographic location and the orientation of the catchment additionally determine the influence rainfall can have on the catchment in generating floods or mass movements (Blair and McPherson, 1994). 
Garfi et al. (2006) recognise vegetation cover as a significant control on the sediment generation processes acting within fan catchments. Vegetation aids in stabilising slopes. Once this vegetation is removed slopes increasingly become prone to erosion through mass movements or water flows. Conversely, the presence of vegetation can alter the severity of debris flows by contributing additional vegetative debris to the flow (Selby, 1974).

\section{Neighbouring Environments}

The size and morphology of the receiving site can influence fan shape (Sorriso-Valvo et al., 1998; Crosta and Frattini, 2004). The nature of neighbouring environments (fluvial, marine, lacustrine, and aeolian) or the presence of other fan deposits can have some bearing on the processes of fan formation (Bull 1977; Blair and McPherson, 1994). The overall shape of the fan can be reworked or restricted laterally or distally and conditions under which sediment is deposited can be changed as a result of this (Figure 2.2).

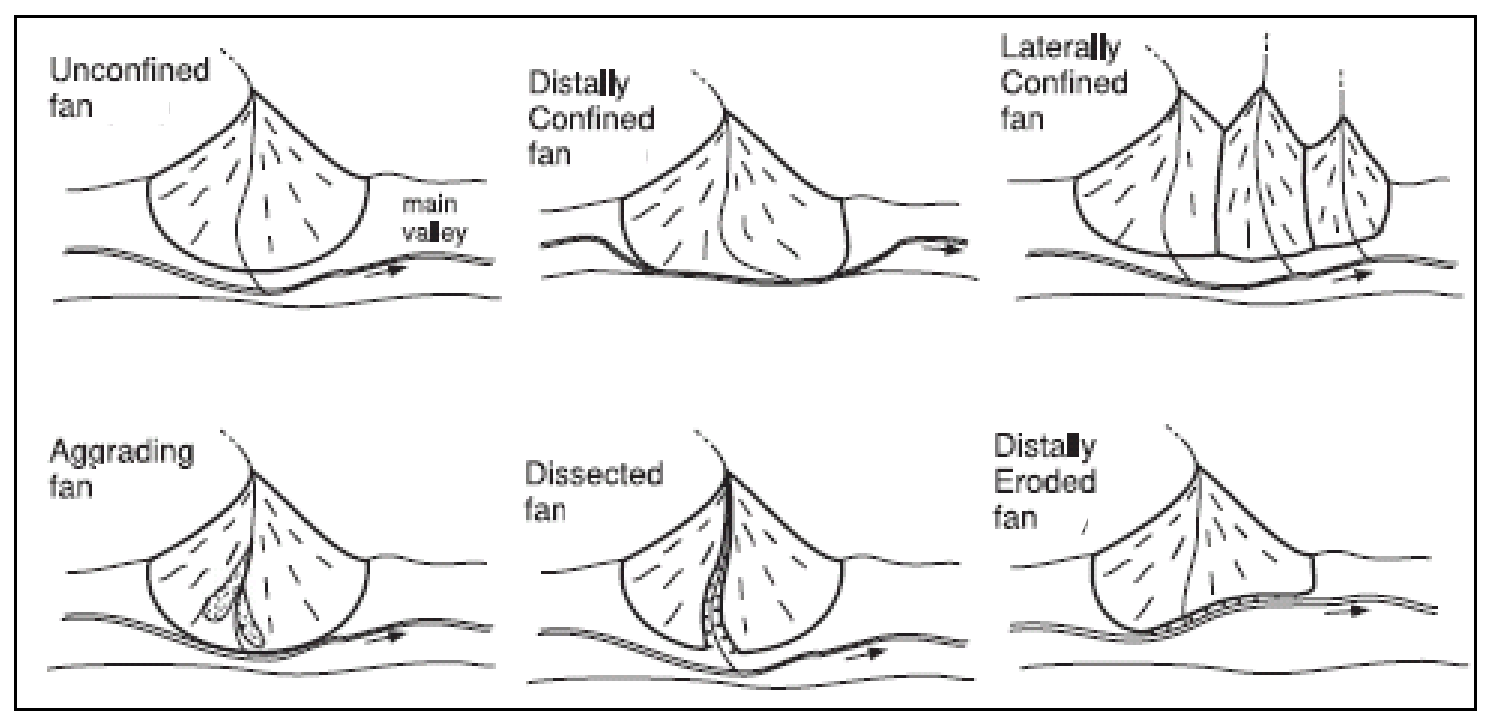

Figure 2.2: Reworked and restricted fan morphologies (Crosta and Frattini, 2004).

Marine and lacustrine environments distally restrict alluvial fan development. Processes involved with aggradation, degradation or deposition on alluvial fans can be altered by near by marine and lacustrine environments. Beach ridges, delta formation or long shore drift processes can hamper the flow of water and debris to the toe of the fan, leading to a steepening of the overall fan surface. Erosion at the toe of the fan by inundation from lake and marine water bodies can further lead to steeper distal fan slopes. Alternatively a drop in lake or sea level can lead to an increased rate of primary deposition at the fan 
toe, as primary sedimentary flows accelerate due to the steepened surface left by the withdrawal of the water level (Blair and McPherson, 1994).

Streams or rivers flowing adjacent to the toe of alluvial fans can erode back the distal margins of the fan resulting in a steepening of the overall fan slope as the fan adjusts (Bull, 1977; Blair and McPherson, 1994). However, as discussed by Bull (1977) and Davies and Korup (2007), alluvial fan deposits can extend out onto the floodplain, displacing the river, if the rate of fan deposition exceeds the rate that sediment is removed from the fan. This will continue until the rates of deposition and removal are equal.

Wind blown deposits such as dune formations and sand sheets located at the toe of fans further act to limit distal fan formation. Blair and McPherson (1994) note that these aeolian deposits can migrate onto the fan surface changing the way in which primary deposition can occur by restricting the location and run out distance of debris and water flow on the fan.

Fans exiting from adjoining catchments restrict the lateral expansion of sediment and stream flows (Bull, 1977) producing long narrow fans. The fans can overlap with differing lithology and stratigraphy often able to be differentiated at sites of overlapping.

\section{The Tectonic Environment}

The tectonic environment has an influence over the location of alluvial fan sites. Alluvial fans commonly develop along mountain fronts that are tectonically controlled (Bull, 1977; Blair and McPherson, 1994; Davies and McSaveney, 2008). For example many alluvial fans have developed in the hilly and mountainous areas surrounding the Southern Alps of New Zealand's South Island (Davies and Korup, 2007). This tectonic activity influences the processes acting within the fan catchment leading to the generation of sediment. High relief, due to high uplift, and brittle shattered rock due to faulting is exposed to increased weathering processes, making a constant supply of sediment available within the catchment for transport onto the alluvial fan. Earthquakes 
can trigger landslides in tectonically active areas, thus further increasing sediment availability within the catchment (Davies and McSaveney, 2008).

The base level and gradient of streams located both on the fan and within the catchment can be altered by tectonic activity. Vertical offsets along fault lines cause stream base levels to change and the stream resets itself by eroding downwards. The sediment deposited on the fan increases the fan slope. Once the stream has adjusted the stream incises the fan leaving sections at the apex of the fan inactive (Davies and Korup, 2007; Davies and McSaveney, 2008). Bull (1977) discusses the idea that fan development and growth over time (t) is most favourable when uplift rates $(\mathrm{U})$ are greater than the rate at which channel downcutting (I) in the catchment and sediment deposition (D) onto the fan can occur (Equation 2.2) (Selby, 1982).

$$
\frac{\Delta U}{\Delta t} \geq \frac{\Delta I}{\Delta t}+\frac{\Delta D}{\Delta t}
$$

Equation 2.2

\section{The Climatic Environment}

The climatic environment is an external factor which has a great amount of control on the type of processes leading to fan development. Fans are prevalent in a range of varying climatic locations, forming as a result of similar sedimentary processes. However, the morphology of each fan is related to the sediment and water availability for each individual catchment (Brennan, 2007). Climate essentially controls the amount of water available for weathering, transport and vegetation growth (affecting stability and therefore sediment availability).

Blair and McPherson (1994) note that the climatic variables precipitation and temperature can affect weathering processes within the catchments. Precipitation increases with altitude and influences weathering rates, sediment transport and vegetation growth. The frequency and intensity of precipitation events determines how much water is soaked into the catchment or flowing as overland flow and therefore able to transport sediment. Heavy rainfall or rainfall over long durations tends to lead to overland flow due to water not being able to infiltrate into the soil. Temperature alters weathering processes. Chemical weathering is likely to increase with increases in 
temperature, while physical weathering processes, for example freeze-thaw, are likely to increase with decreasing temperature. Vegetation cover is linked to climate, as it can advance or decline with changing climates, and is an important factor in slope stability (Blair and McPherson, 1994).

Altering climatic situations can change the amount of water available, therefore altering sediment supply and stream discharge patterns. These alterations, in turn, result in changes to sediment transport, deposition and the overall morphology of the fan (Davies and McSaveney, 2008). Climate change could potentially vary precipitation by altering the mean annual precipitation or altering the intensity, duration and frequency of precipitation events (Brennan, 2007).

The Transition-to-Drier-Climate model, the Paraglacial model, the Humid-PeriodAggradation model and the Periglacial model are conceptual geomorphic models which aim to relate altering climatic situations to the development of fans. The Transition-toDrier-Climate model (Figure 2.3) is the most commonly used model in fan research. This model acknowledges the effect vegetation cover has on erosion rates (Dorn, 1994). Bull (1991) described aggradation on fans occurring due to less vegetation cover resulting from a change to a drier climate.

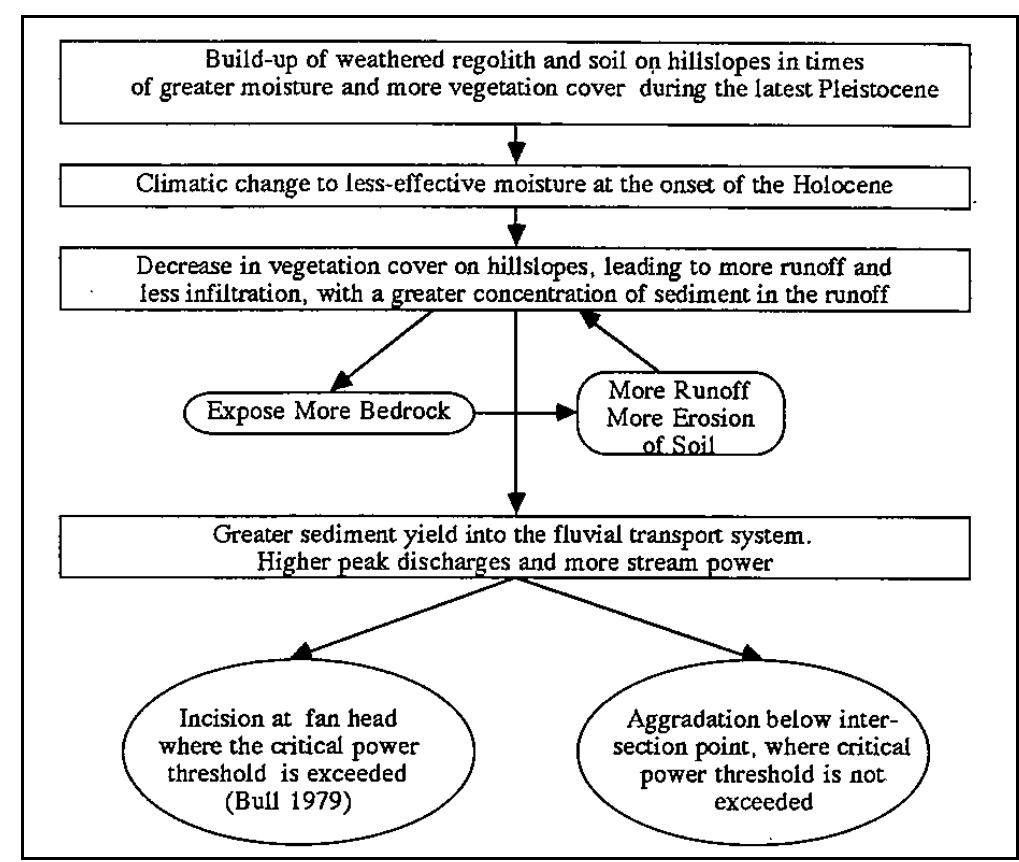

Figure 2.3: Transition-to-Drier-Climate model showing the processes leading to aggradation as the climate becomes drier (Dorn, 1994: modified from Bull, 1979, 1991). 
The Paraglacial model (Figure 2.4) links the importance of glaciation to the formation of fans. During glacial periods, sediment is produced, transported or stored by glacial processes. This sediment then becomes available to be transported for fan development over long time periods, for example thousands of years, after the glacial period has ended (Dorn, 1994).

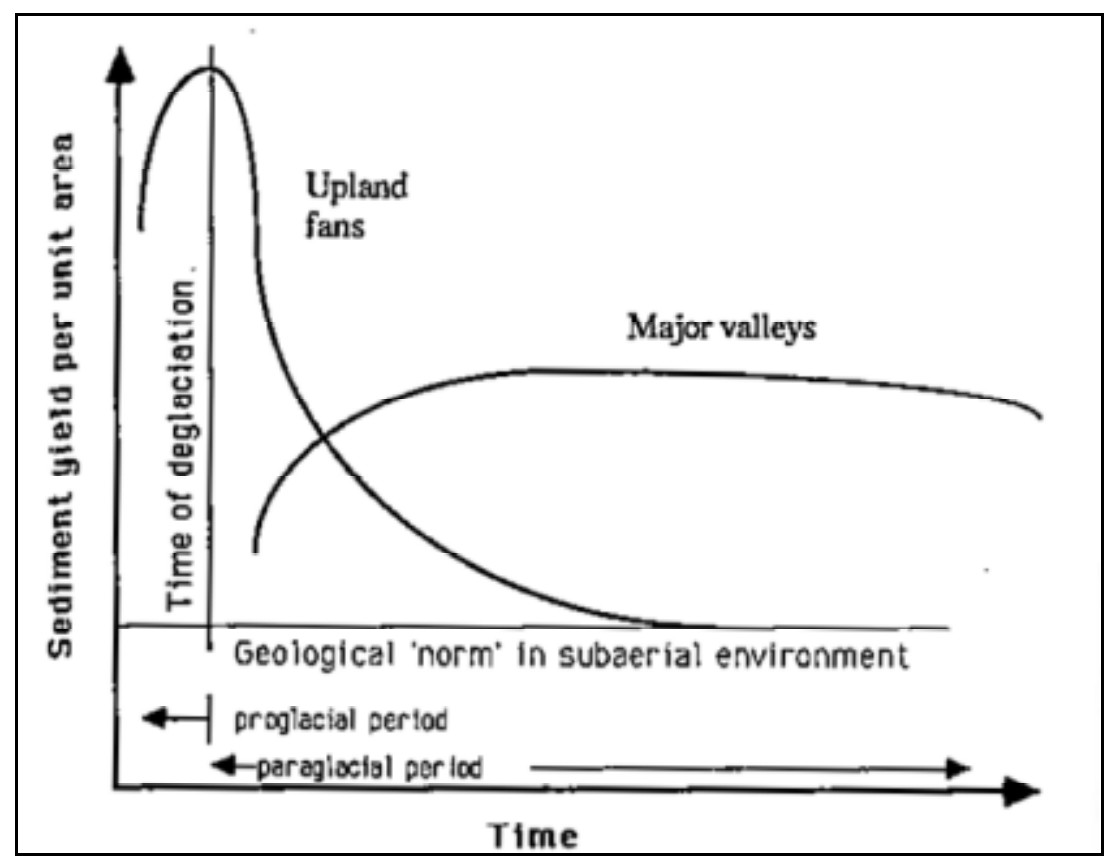

Figure 2.4: The Paraglacial sediment model (Dorn, 1994; modified from Church and Ryder, 1972; and Church and Slaymayer, 1989).

The Humid-Period-Aggradation model relates moist humid climates to fan aggradation periods. The climate is wetter and therefore is able to transport more sediment efficiently. The ability for sediment entrainment will increase due to slopes being saturated more regularly, although vegetation cover may increase, changing the frequency of events overall (Davies and McSaveney, 2008).

The Periglacial model acknowledges periglacial activity as a means of sediment production and transport. At high elevations during cooler time periods sediment is weathered by periglacial processes and transported onto the fan (Figure 2.5) (Dorn, 1994). 


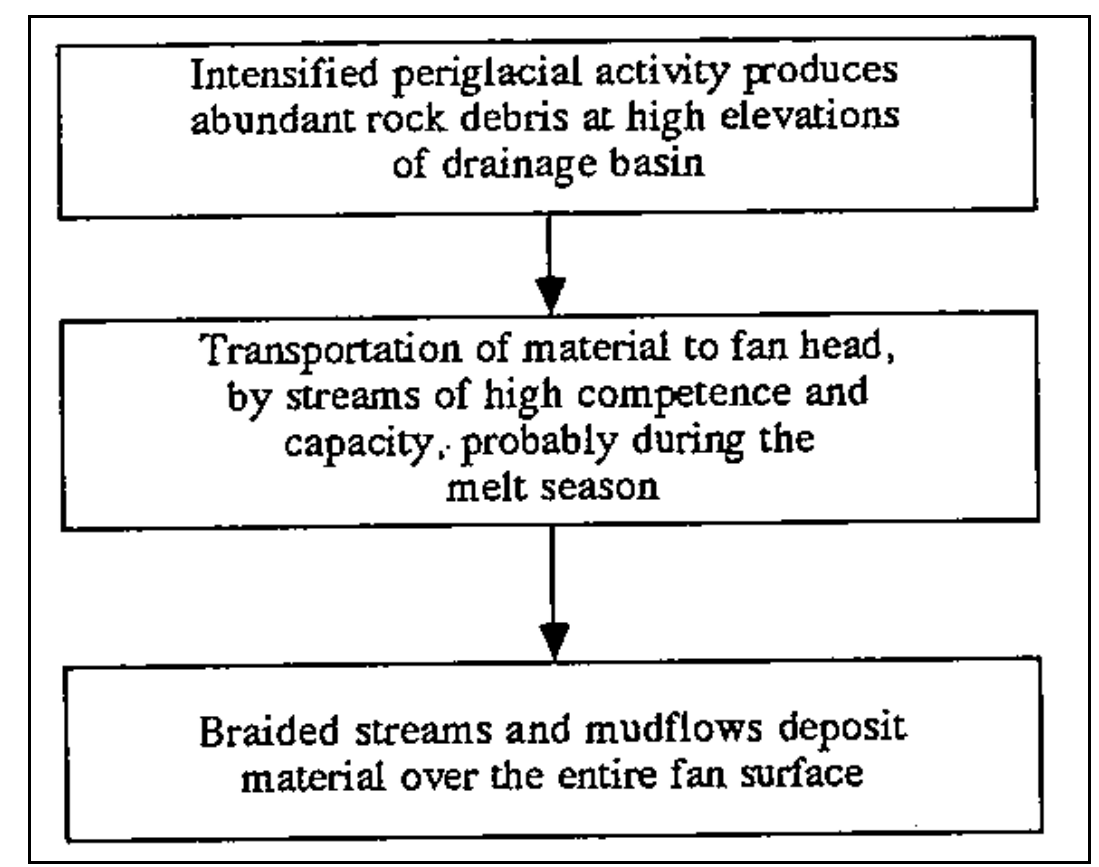

Figure 2.5: The Periglacial model (Dorn, 1994)

Problems exist with these models however. It is difficult to separate the effects and controls that the other influencing factors (the catchment characteristics, neighbouring environments and tectonics) have from climate change or even how they interact with altering climatic situations (Dorn, 1994). Further Dorn (1994) acknowledges that rainfall events able to trigger processes leading to fan development could occur in any type of climate.

It is important to note that the above four geomorphic climate models are not relevant to the formation of fans in New Zealand. Rather, recent fan formation in New Zealand can be related to a change in the climate from periglacial conditions to a warmer, vegetation covered landscape, which has locked up available sediment supplies produced during periglacial conditions. Anthropogenic alterations to the landscape, including the clearance and devegetation of land for farming and development, since the settlement of Europeans in New Zealand have since allowed this sediment to become available again for fan formation. 


\subsubsection{Fan Types and their Formation}

While the term "alluvial fan" is often used as a general term to encompass all fans (McArthur, 1987; Crosta and Frattini, 2004; Davies and McSaveney, 2008), fans can be divided into several key types. This division can be determined by many differing fan characteristics such as size, morphology, stratigraphy, sediment type, the hazard type or the landscape or the climatic environment (Davies and McSaveney, 2008). However the most common characteristic used for fan classification is based on the dominating formative processes leading to fan development. Two main fan types are commonly recognised: colluvial fans and alluvial fans. Colluvial fans are dominantly formed by colluvial sediment-gravity flow processes and consist of mainly debris flow deposits. Conversely alluvial fans are formed by fluvial fluid-gravity flow processes and consist mainly of water laid gravels. Blair and McPherson (1994) have termed these Type I and Type II fans, respectively.

There is no clear boundary between processes that lead to colluvial or alluvial fan development. The formative processes vary depending on the amount of sediment and water that is being transported. Fluvial processes consist mainly of water flows with very little sediment content within it. On the other end of the scale are mass movement processes, for example rock falls, which is mainly sediment containing very little water being transported. In between these two extremes are a range of flows that contain varying amounts of sediment and water. It is very rare that fans are formed solely from one flow type. For this reason many authors (for example Davies and McSaveney, 2008) additionally recognise mixed fans as a third type of fan, consisting of a mixture of alluvial and colluvial processes.

Davies and McSaveney (2008) further identify two additional fan types: episodicaggradation fans and dynamic equilibrium fans. However these fan types are classified by the hazards they present and not by the processes that form them.

Fluid-gravity and sediment-gravity flow processes that lead to fan formation are termed primary processes (Blair and McPherson, 1994). Primary processes are defined as the processes in which sediment is transported from the catchment out on the fan surface. 
Due to primary process events occurring relatively infrequently, secondary sediment processes are able to act on the fan surfaces in the intervening time. Secondary processes, such as surface water flows, aeolian activity, bioturbation, soil formation and tectonics, alter the fan surface (Blair and McPherson, 1994).

The two main fan types and the dominant primary processes that lead to their formation and evolution are described in the following sub-sections. The secondary processes that can affect the fan intervening primary events will then be briefly looked at.

\begin{abstract}
Alluvial Fans
Alluvial fans result from stream flow processes largely dominated by fluid-gravity flows (Blair and McPherson, 1994) and as a result their general morphology differs from colluvial fans. Fluid-gravity flows are water flows in which sediment is transported downslope due to the force of turbulent moving water on sediment. These flows exhibit a lack of shear and yield strength as the water and sediment remain separate within the flow. Rather sediment is entrained and transported by being carried in the water as suspended load or along the stream bed through rolling or saltation (Blair and McPherson, 1994).
\end{abstract}

Alluvial fans are generally large, although in size can vary from $10 \mathrm{~m}^{2}$ to approximately $60 \mathrm{~km}^{2}$ depending on the relative size of the catchment and the sediment supply. They have upwards concave longitudinal profiles (curvature decreases distally down the fan) and are convex upwards laterally. Alluvial fans exhibit a generally low gradient which is less than $11^{\circ}$ (Selby, 1982) although there is a large range of alluvial fan maximum slope angles reported in the literature (see Figure 2.6). Research carried out by De Scally and Owens (2004) on fans in the Southern Alps of New Zealand found that alluvial fan characteristics - size, concavity and slope - differed significantly from those of colluvial fans. 


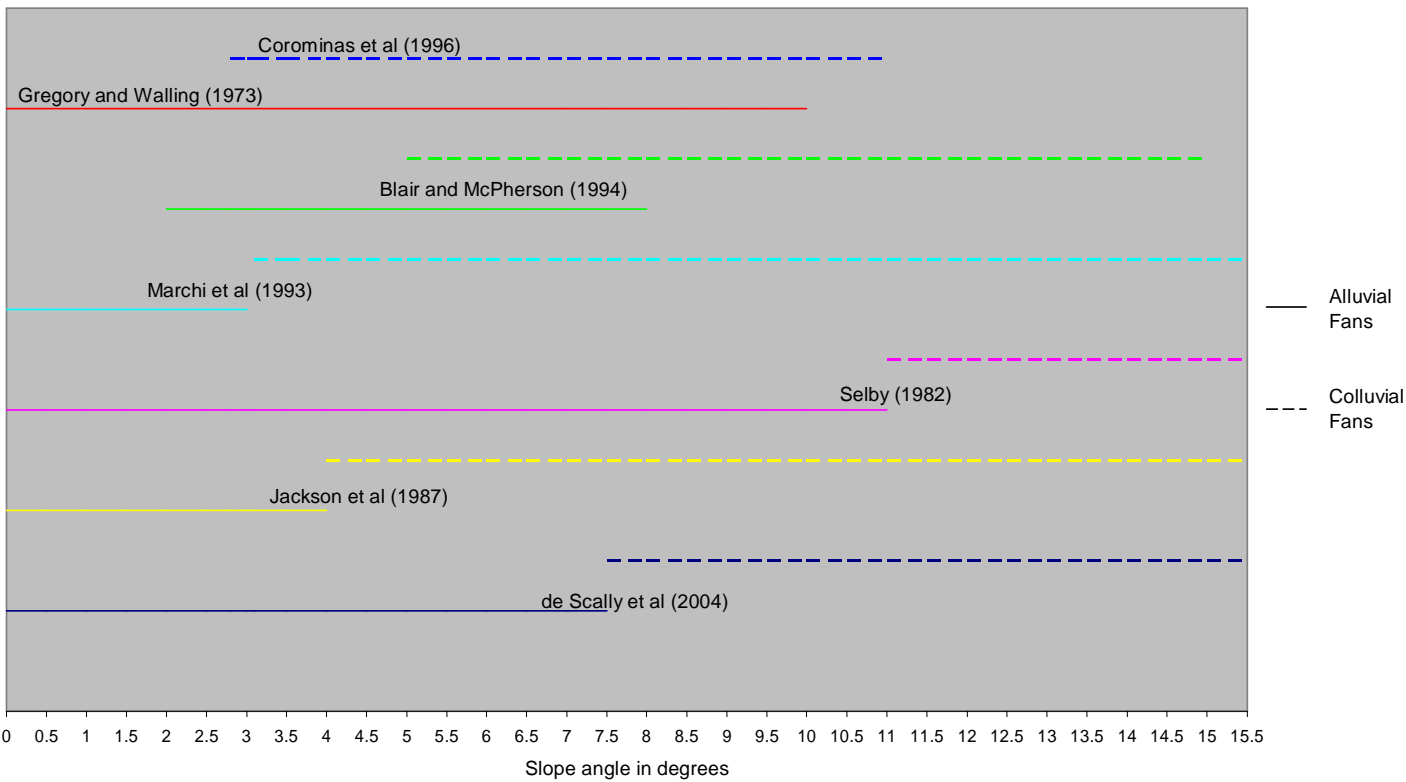

Figure 2.6: The range of alluvial fan slope angles compared to colluvial fan slope angles reported within the literature.

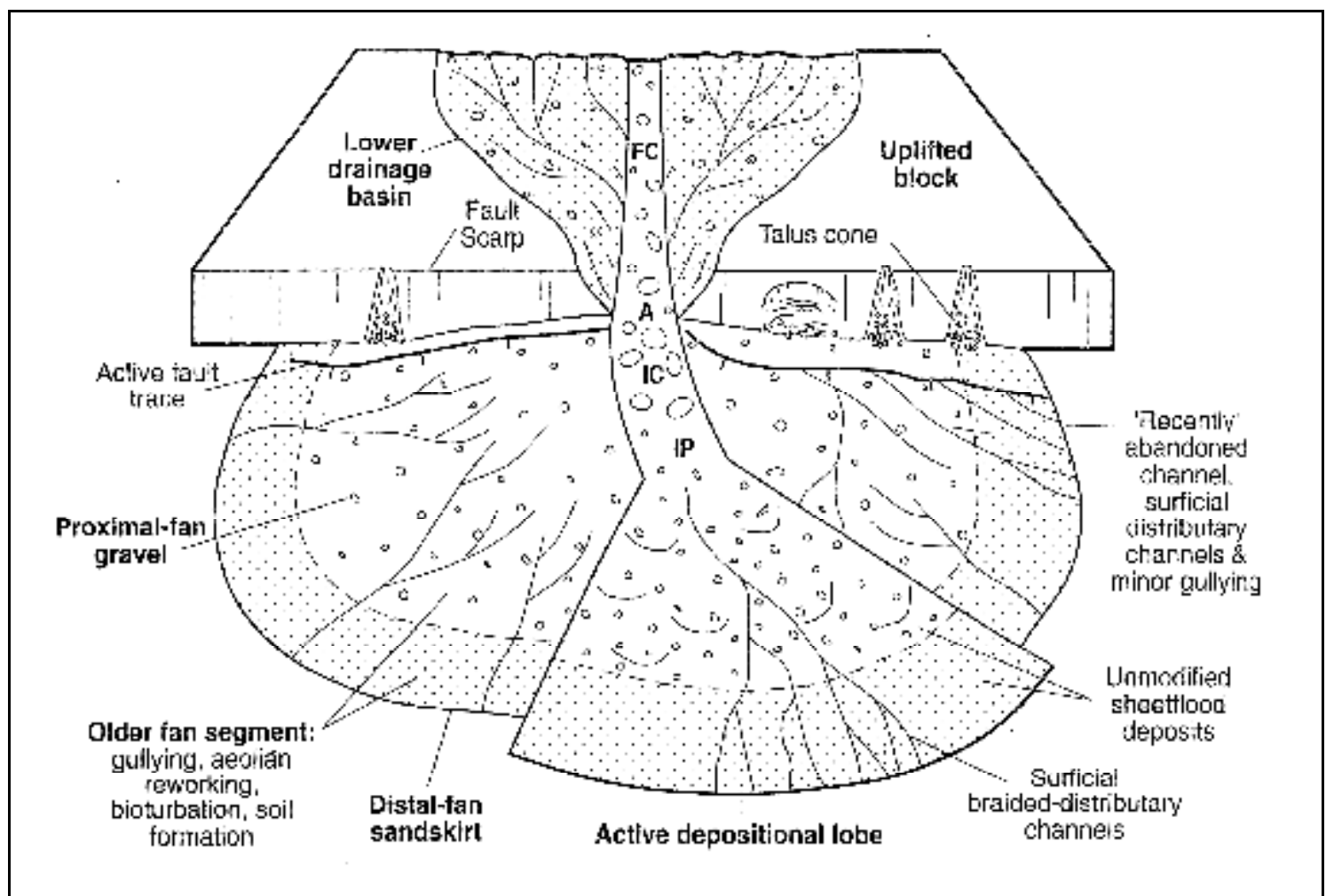

Figure 2.7: Common processes and deposits present on fluid-gravity dominated alluvial fans. A is the fan apex, FC is the main stream (feeder) channel, IC is an incised channel and IP is the intersection point of the current active fan surface with the incised channel (Blair and McPherson, 1994). 
Fluid-gravity flows and the deposition of alluvial sediments onto the fan are triggered by rapid water discharges produced from high intensity rainstorms or rapid snow or ice melt. Steep catchment characteristics further aid in the build up of rapid discharges. Sheetfloods and incised channel flows are the two main fluid-gravity flows active in alluvial fan formation and determine the types of deposits located on alluvial fans (Figure 2.7)

Sheetfloods are shallow, unconfined runoff discharges that move downslope onto the fan surface (Blair and McPherson, 1994). This rare, high magnitude flow type is relatively short lived and often has a limited distance of flow. Sheetfloods transport a range of sediment sizes ranging from silt to boulders. The coarser sediment is deposited first as the flow spreads out over the fan, with the finer portion of sediment being deposited further down the fan or during waning flows displaying an upward fining vertical depositional profile. Sheetfloods can further result in the deposition of sandskirts on the lower distal sections of alluvial fans due to the fine portion of the entrained sediment being able to be transported further downslope (Blair and McPherson, 1994). These flows are common in the middle and lower sections of the fan due to incised channels (Selby, 1982).

Incised or entrenched channels near the head of the fan act as conduits which enable stream flows, including sheetfloods and sediment-gravity flows, to move further down the fan surface. Incised channels typically range from 1 metre to greater than 4 metres in depth (Blair and McPherson; 1994) and therefore can have high flow and sediment transport competency with the coarsest fraction of sediment deposited in the channel. In a similar manner to sheetfloods, the finer portion of entrained sediment can be deposited in the channel during waning flows (Bull, 1977; Blair and McPherson, 1994). As stream flows leave the incised channel, the flow is able to spread out over the fan surface, allowing for smaller divergent distributary channels to form, where further deposition of entrained sediment occurs due to decreased flow (Selby, 1982). Anthropogenic modifications made to stream channels, for example the clearing and maintaining of a deep restricted channel, can enhance the effects of incised channels in transporting flows further downslope. The infilling of incised channels with sediment can cause the 
water flow to avulse and form a new channel. Stream avulsions are a common hazard presented by alluvial fans and will be discussed in section 2.3.

Alluvial fan deposits generally consist of well rounded silt to boulder sized clasts that are moderately to well sorted. Sediment size decreases down the fan as coarse sediment is deposited first as the stream's capability to transport large calibre sediment decreases, while the finer portion of sediment is able to be carried further down the fan. Alluvial fan deposits are generally clast supported and show evidence of imbrication in the direction of the flow. Vertical profiles cut into alluvial fan surfaces display stratified sediment layers as initial flows over the fan deposit large sediments and finer sediments are deposited on top of these by waning flows (Selby, 1982; Blair and McPherson, 1994; De Scally and Owens, 2004; Crosta and Frattini, 2004).

\section{Colluvial Fans}

Colluvial fans, also referred to as debris fans (Davies and McSaveney, 2008), result from processes dominated by sediment-gravity flows. Generally colluvial fans are small in proportion to the size of the catchments from which they exit, although both the catchment and the fan are often smaller and steeper than alluvial fans and their respective catchments (De Scally and Owens, 2004). Longitudinally they are less concave, with a more constant slope. However, similar to alluvial fans, a wide range of minimum and maximum slope angles has been reported in the literature ranging between greater than $2.8^{\circ}$ and approximately $15^{\circ}$ (Selby, 1982; Jackson et al., 1987; Blair and McPherson, 1994; Corominas et al., 1996; De Scally and Owens, 2004; Davies and McSaveney, 2008). Furthermore some overlap exists between reported slope angles for alluvial and colluvial fans (see Figure 2.6), making it difficult to distinguish between the two fan types purely based on fan slope.

Sediment-gravity flows are sediment flows in which the downslope movement of sediment is caused by the force of gravity acting directly on the sediment particles. Sediment-gravity flows are triggered by high intensity rainfall events, rapid snow melt, extended periods of wet weather or seismic shaking from earthquakes (Blair and McPherson, 1994). While water is often involved, it is not necessary, and the flow is often clast supported. Mass movement processes, for example debris flows, rockfalls, 
rock avalanches, and gravity slides are sediment-gravity processes that are active in producing a sediment supply in the catchment. These mass movement processes can be deposited straight onto the fan surface, although debris flows are the most significant sediment-gravity process active in fan deposition.

Debris flows are dense flows of saturated soil, rock and other debris, for example plant material, moving rapidly downslope under the force of gravity. A high amount of fine sediment is carried within the flow, although a varying size range of sediment clasts, including boulders, can be carried. Various amounts of water and/or air are entrained and mixed within the flow of sediment to give it a viscous flow. This has been described as being similar to wet concrete by some authors (Davies and McSaveney, 2004). Debris flows follow the catchment drainage pattern and move in a series of discrete surges as new sediment is added, or under the influence of gravity, or sudden collapses of material within the flow. Large sediment clasts are often located on top or near the front of these surges. Debris flow velocities can be high, commonly around approximately $10 \mathrm{~m} / \mathrm{s}$ (McSaveney et al., 1995) which is related to sediment size and concentrations and the geometry of the catchment's drainage pattern. Deposition of sediments occurs when the flow moves out of the confined channel onto the fan surface where the slope angle is too low for the debris flow to continue to flow. The deposits of debris flows containing a large amount of medium to large clasts often have a lobate shape. Levees of large clasts can also develop along channel margins as they laterally fall away from the main debris flow (Bull, 1977; Blair and McPherson, 1994; De Scally and Owens, 2004). Mud flows are debris flows with fine clasts such as small gravel and sands. These deposit thinner, smoother lobe deposits as a result of the finer sediment in the flow (Bull, 1977; Blair and McPherson, 1994). Blair and McPherson (1994) term debris flows that produce these different deposits "clast-rich debris flows" and "clastpoor debris flows" respectively. 


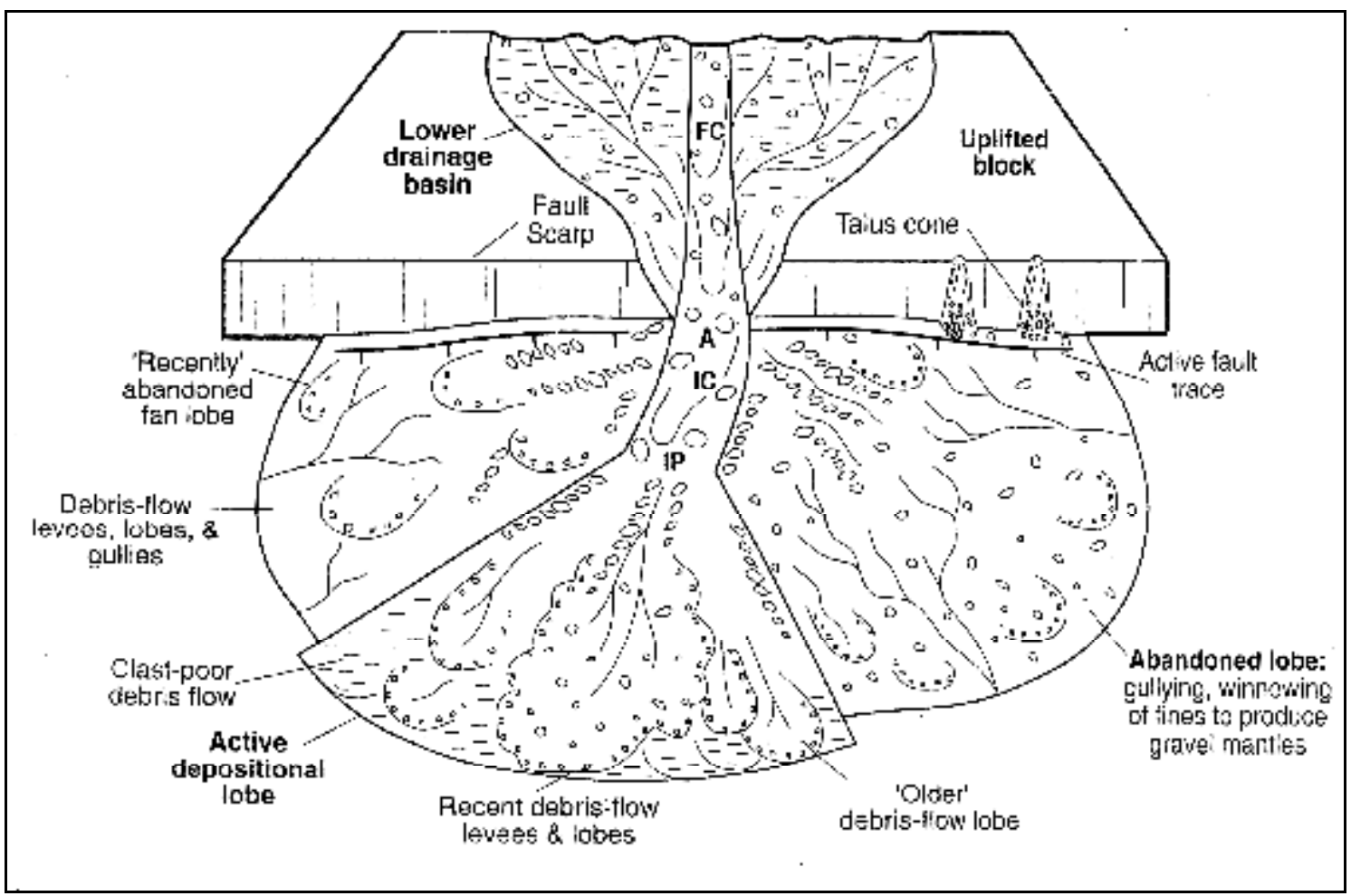

Figure 2.8: Common processes and deposits present on sediment-gravity dominated colluvial fans. A is the fan apex, FC is the main stream (feeder) channel, IC is an incised channel and IP is the intersection point of the current active fan surface with the incised channel (Blair and McPherson, 1994).

Debris flows are typically likely to be triggered on slopes between $27^{\circ}$ to $56^{\circ}$ (Blair and McPherson, 1994) which have stores of unconsolidated rock, soil and organic material. The removal or alteration of the vegetation cover can enhance the likelihood of a debris flow occurring. Nonetheless, where vegetation cover is present, Selby (1974) notes that the occurrence of a debris flow is likely to be more severe.

Debris flows can present significant hazards on colluvial fans. Debris flows require time for the build up of sediment and the occurrence of infrequent high intensity or prolonged rainfall as a triggering event. Therefore large magnitude debris flows are relatively infrequent (Blair and McPherson, 1994; Davies and McSaveney, 2008).

Colluvial fan deposits consist of angular to sub-angular, poorly sorted clasts ranging in size from clay to large boulders which can be clast- or matrix supported. The clasts are often orientated parallel to the laminar-flow boundary. 


\section{Secondary Processes}

Secondary processes are those processes that act on alluvial fans during the time between primary events, by reworking and modifying the exposed surfaces of fans. Examples of these processes are aeolian reworking, surface and groundwater flow, bioturbation, sediment weathering leading to soil formation and tectonic faulting and folding (Blair and McPherson, 1994). These processes alter or hide evidence of the primary processes. Anthropogenic modification of the fan surfaces can further alter the fan surface and can, therefore, also be described as a secondary process (Crosta and Frattini, 2004).

\section{$\underline{\text { Surface and Groundwater Flow }}$}

Most rainfall is not of the high intensity required for fan development and is therefore unable to initiate fluid-gravity or sediment-gravity flows. Overland flow can result from most general rainfall events, resulting in the erosion of fan deposits and transport of sediment to areas further down the fan surface. Water at low flow winnows the fine portion of sediment away from coarser sediment leaving an armoured surface which protects sediment layers beneath. Incised channels, rills or headward-eroding gullies may develop (Blair and McPherson, 1994).

Fans can act as groundwater aquifers as water sinks into the fan surface. Groundwater can destabilise channel walls and other slopes located on the fan resulting in slumping. Groundwater can further lead to stabilisation on parts of the distal fan through vegetation cover. Overland flow from springs or groundwater near the fan surface provides suitable conditions for vegetation growth, which protects the fan surface (Blair and McPherson, 1994).

\section{Aeolian Processes}

The fine proportion of sediment on a fan surface is exposed to erosion by wind and aeolian reworking. Fine sand and silt can be winnowed away from around coarser gravels leaving an armoured layer, sometimes called desert pavement, of coarse clasts protecting sediment layers below from aeolian erosion. Deposition of the fine particles moved by the wind can lead to dune like formations surrounding vegetation or small 
topographic forms on the fan. These can occur as isolated deposits or as sand sheet deposits (Blair and McPherson, 1994).

\section{Bioturbation}

Plants and animals can disturb the surface of the fan allowing further erosion by other secondary processes, especially from wind and water, to occur. Burrowing animals, rodents or insects and grazing animals disrupt and disperse surface sediment and armouring layers, allowing for protected sediment to become exposed. Plant roots, which extend into the fan surface, and burrowing animals can further disrupt the stratification of sediment layers laid down by primary processes (Blair and McPherson, 1994).

\section{$\underline{\text { Sediment Weathering and Soil Formation }}$}

Physical and chemical weathering of sediment on or near the fan surface can lead to the formation of soil on fan surfaces. Chemical weathering can lead to oxidation, crystal growth and the formation of precipitate coatings on rocks, for example rock varnish. Plant roots can enhance the formation of a soil layer by aiding in the movement of precipitates and water through the sediment. Soil formation occurs on areas of the fan which have been inactive for some time, signifying areas of fan stability and can be used to determine relative ages of when the area was last active (Blair and McPherson, 1994).

\section{$\underline{\text { Tectonic Faulting and Folding }}$}

Due to the fact that alluvial fans commonly form along mountain or hill fronts that have resulted from tectonic uplift, the fan surface can be disturbed or modified, showing evidence of recent tectonic activity. Lateral offsets disconnect the fan from its catchment by shifting the fan deposit sideways. Vertical offsets can produce scarps running parallel or obliquely to the mountain front. The scarps are unstable high-angled slopes and mass movement processes can lead to their failure, and they are unlikely to persist for any length of time (Blair and McPherson, 1994). 


\section{$\underline{\text { Anthropogenic Modifications }}$}

People can have a significant control over the modification of fan surfaces. Anthropogenic modification can conceal or alter topography that results from primary or secondary processes (Crosta and Frattini, 2004). Fans are often altered to avoid the hazards presented by primary processes to settlement or infrastructure located on the fan. Stream channels can be cleared or bulldozed, removing fresh sediment deposits and artificially lowering the stream channel (Davies and McSaveney, 2008). This exposes previously stable sediment to erosion processes and alters the overall topography of the fan. Cuts made in the fan to allow for roads or other infrastructure further exposes stable sediment. Stabilisation of stream channels or cut surfaces by various methods reduces erosion acting on these sections of the fan surface and acts as a control for primary processes that occur after the stabilisation.

\subsubsection{Alluvial Fan Research in New Zealand}

New Zealand has many alluvial fans, particularly in the Southern Alps of the South Island where high rates of tectonic uplift and orographic rainfall occur, leading to high rates of erosion (Davies and McSaveney, 2008). Fans in New Zealand are, however, formed in a temperate setting rather than the semi-arid or arid settings of many other fans studied around the world.

Julias von Haast and Charles Cotton were two early researchers to describe fans in New Zealand examining fans on the Canterbury plains and at the foot of the Mount Hutt Ranges respectively (Anderson, 1988; Brennan, 2007). More recent research carried out on fans within the last few decades in New Zealand has been concerned with morphodynamics and morphometric characteristics, and the sedimentation and formation processes involved with New Zealand's temperate alpine fans. For example, De Scally and Owens (2004) have looked at the relationships between catchment and fan characteristics, and the differing morphometric characteristics exhibited by alluvial, colluvial and mixed fans, discussing how these can be used to determine the main formative processes operating on the fans. Fan deposit morphology and the characteristics of the sediment clasts have also been studied (McArthur, 1987; De Scally 
and Owens, 2005). Davies and Korup (2007) investigated fan head entrenchment along the Southern Alps in relation to large, rare sediment inputs.

Recent fan research in New Zealand, as in many other parts of the world, has additionally focused on the hazards presented by the processes operating on the fans and in their evolution, and how to sustainably and effectively manage these hazards, especially where infrastructure and people are located on the fans (e.g. Davies and McSaveney (2008)). Many alluvial fans in New Zealand have transport routes, such as state highways or rail lines, located on or near them, while others present more potential hazards to buildings and people living on or using the fans. Due to this there is a growing recognition for the need for fan hazards to be understood and in some cases mitigation procedures to be carried out (Crosta and Frattini, 2004; De Scally and Owens, 2004; Garfi et al., 2007; Davies and McSaveney, 2008). A large amount of attention has been paid to the fans at Aoraki/ Mt Cook due to their location within the Southern Alps and the potential hazard of debris flows and floods to the village located on them (McSaveney and Whitehouse, 1989; McSaveney et al., 1995; Skermer et al., 2002; Davies and McSaveney, 2008). Mitigation structures and land use zoning have been put in place to protect the village and its tourism industry from potential hazard.

Other fans within New Zealand that have been studied include the Cass fans (McArthur, 1987), Matata in the Bay of Plenty, the Waiho River fans (Davies, 1997; Davies and McSaveney, 2008), largely due to their potential hazards to infrastructure and people or morphometric and development characteristics. Little geomorphic study has been undertaken on the set of alluvial fans between the Clarence River mouth and Kekerengu other than the consulting reports for the alterations to the State Highway.

\subsection{Hazard}

\subsubsection{An Introduction to Hazard}

Hazard exists where there is potential risk of death, injury, loss or damage to people, infrastructure or resources from events or processes (Smith, 1996). Generally, Crozier 
and Glade (2005, pp 1) define hazard as "those processes and situations, actions or nonactions that have the potential to bring about damage, loss or other adverse effects to those attributes valued by mankind". This can include social losses, for example injury or death to ourselves or family, or economic losses, for example damage to property and infrastructure or loss of income.

Hazard in this sense can have two meanings. The first meaning is used to describe the actual physical hazard or process as a phenomenon that can cause damage (Smith, 1996; Crozier and Glade, 2005), for example when discussing the hazards present on fans. The second meaning of hazard is a technical one used when making a statement to describe the probability of occurrence of a certain size hazardous event (Smith, 1996; Crozier and Glade, 2005). It describes hazard as a condition that could occur and is indicated by a return period or likelihood of occurrence (Crozier and Glade, 2005).

Hazard can only exist where people or our belongings (including buildings, infrastructure and natural resources) are present. Naturally occurring geophysical or atmospheric events, phenomena or landforms, for example floods, earthquakes, landslides, debris flows and sediment aggradation or degradation, are natural phenomena (Chapman, 1994). Natural phenomena can occur in unpopulated areas where no infrastructure or resources are located and not be a hazard as no risk or danger exists to people or our belongings. However when populated areas and infrastructure or resources are located near the location of natural phenomena, a potential hazard exists and these natural phenomena can be termed natural hazards (Smith, 1996). Natural hazards are defined as the interaction between extreme rare natural phenomenon and people and our build environment or resources, which can be harmful to man through injury or possible loss of life or by causing damage to infrastructure (Figure 2.9; Burton and Kates, 1964; Chapman, 1994). Thus the processes active on fans can be termed natural hazards and pose a potential risk to people, our property and infrastructure located on or near the fans. 


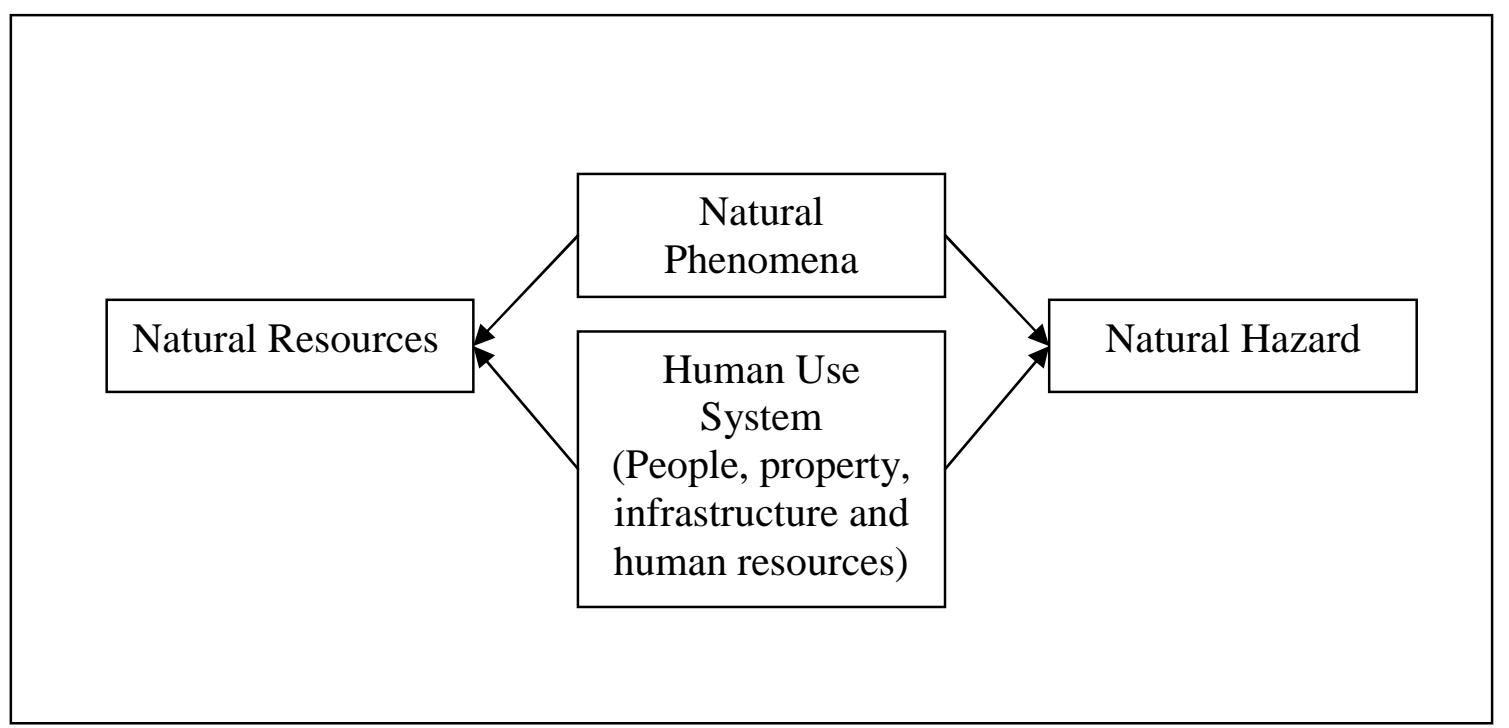

Figure 2.9: Natural phenomena can be natural resources which are useful to people but natural hazards can also result from the interaction of natural phenomena and the use of an area by humans (modified from Smith, 1996).

\section{Frequency and Magnitude}

The notion of frequency and magnitude and the relationship between them is an important concept in the study of geomorphology and hazards. Wolman and Miller (1960) discussed frequency and magnitude in relation to events that are dominant in shaping the landscape and which do the most geomorphic work. Using examples prominently from sediment transport in fluvial geomorphology but also sand transport by aeolian processes and changes to beach morphology, Wolman and Miller concluded that the most geomorphic work and therefore the dominant event shaping the landscape, termed a formative event, was carried out by events that were of a moderate frequency and magnitude (Wolman and Miller, 1960; Selby, 1974).

While Wolman and Miller (1960) acknowledge the importance of extreme rare events and their ability to carry out large amounts of work, for example to transport sediment that requires a high threshold to be passed (Selby, 1974) such as for alluvial fan development, many authors, for example Selby (1974), Crozier (1996, 1999), Richards (1999), Bovis and Jakob (1999), Crozier and Glade (1999) and many others, have since further discussed, refined or challenged Wolman and Miller's conclusions. The main discussion has been around the difficulty in applying their conclusions to processes located on hillslopes and floodplains. 
However, while Wolman and Miller and others are concerned with the medium events that shape the landscape; studies within natural hazards are concerned with the extreme or catastrophic events. Natural hazards are events that are of a high magnitude and a low frequency. Magnitude is a measure of the size or intensity of an event (Abbott, 2008) and represents the energy released in an event. It can be measured using the size, an amount, volume or mass, speed or intensity or duration of the event or a measure of the scale of danger presented by the event. The parameter used as a measure of magnitude should be relevant to the specific hazard event which is being measured (Crozier and Glade, 1999). For example a rainfall event can be measure in millimetres per hour and a sediment transport event can be measured by the volume of sediment moved.

Frequency refers to how often an event occurs and is commonly expressed in terms of a return period, recurrence interval or an annual probability of occurrence. These are statistical measures of the average time between events of a similar size magnitude (Smith, 1996; Abbott, 2008) and can be expressed as a proportion, for example, a 1 in 20 year event or as a probability, for example a 0.05 chance of it occurring in any year. However an event with a return period of 1 in 20 years may occur several times in a 20 year period or it may not occur at all for 40 years. As the record of events grows with time, the frequency of an event of a specific event magnitude will alter and become more refined and accurate.

The frequency and magnitude of hazards has a negative relationship (Figure 2.10). Hazardous events of a small magnitude generally occur regularly in time and space. These events release little energy and cause little or no damage. Hazardous events of a larger magnitude occur less frequently in time and space and a large amount of energy is released from them. They are the extreme, rare events. These high magnitude, low frequency events are more hazardous than the low magnitude, high frequency events and have the potential to result in a large amount of damage (Smith, 1996; Abbott, 2008) as they can be unexpected. 


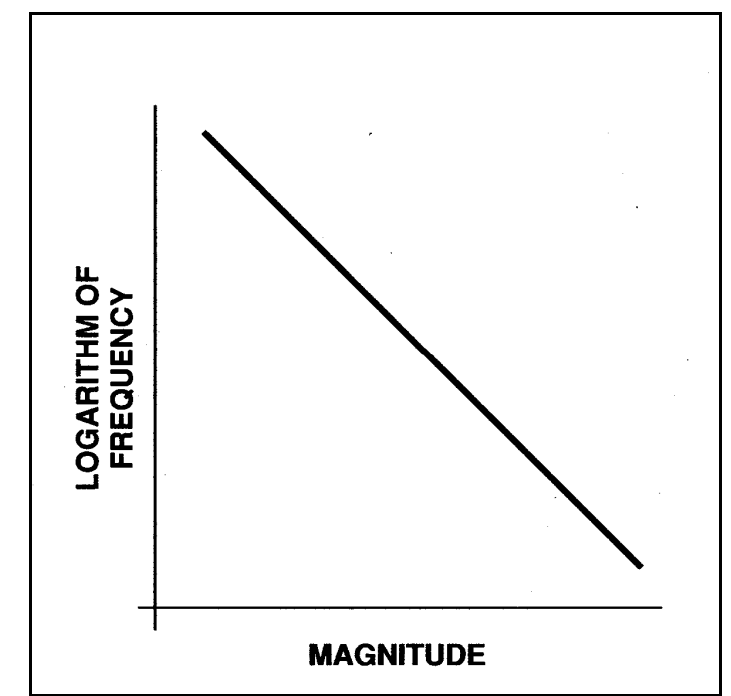

Figure 2.10: The relationship between the frequency and magnitude of hazard events (Smith, 1996). The logarithm of frequency produces an approximate straight line relationship with the magnitude of the events.

Generally fans are viewed as stable landforms with limited non-hazardous fluvial processes occurring within the stream channel of the fan. Occasionally hazardous high magnitude events such as flooding, aggradation, avulsion, scouring and debris flows can occur on the fan. These events can be rare and are therefore often difficult to predict. The magnitude of the hazard depends on the type of event which is occurring. Floods and scouring of sediment present a small amount of hazard and only a small amount of damage can occur, although they can occur on any part of the fan surface. Alternatively debris flows and stream or debris flow avulsions are often of a higher magnitude and present a larger amount of hazard to development on fans as they can have a large sediment load. The magnitude and frequency of each individual event that can occur on fans can vary and is dependant on the conditions and characteristics of the catchments from which the fans form and the magnitude and the frequency of the triggering event (Crozier, 1996, 1999; Crozier and Glade, 1999). This can complicate the frequencymagnitude relationship for fans, as has been discussed for other mass movement and hillslope processes. For example the amount of sediment available within a catchment to be transported onto the fan in stream or debris flows will determine how large the debris flow is and whether the stream or debris flow will avulse. A triggering event must also be of a large enough magnitude to overcome the thresholds to initiate the event. Hazardous events on fans are usually triggered by high intensity and/or long duration rainfall events. Further, if two closely spaced rainfall events of a similar 
magnitude occur, the second may not generate a hazardous event of the same magnitude due to the sediment supply being depleted by the first rainfall event (Crozier, 1996, 1999; Crozier and Glade, 1999).

An understanding of frequency and magnitude of hazardous events for specific sites is a key component for managing and mitigating the hazard (Smith, 1996; Bovis and Jakob, 1999), particularly for areas where important infrastructure is located or development has or is to take place. Records of hazardous events at many sites are either limited or do not exist (McSaveney and Whitehouse, 1989; Smith, 1996) and this can make it difficult to estimate the frequency and magnitude relationships of the hazard for the site, especially if a high magnitude, low frequency event has not occurred in the time of the record. Consequently estimating a return period may be difficult also.

The relationship between frequency and magnitude can alter through time (Smith, 1996; Crozier, 1999; Crozier and Glade, 1999), adding further difficulty to understanding, managing and mitigating hazards. The mean magnitude of a hazardous event could shift as the whole frequency distribution curve shifts sideways. This could result in an increase or decrease of the number of high magnitude, low frequency hazardous events (Figure 2.11; Smith, 1996). For example, as climate change takes effect the mean temperature and rainfall may be expected to increase, in turn increasing expected extreme temperatures and rainfall events leading to potentially more floods and droughts (MfE, 2008).

The relationship between frequency and magnitude can also alter if events occur over a more variable range of magnitudes. The mean would stay the same, although both hazardous events of a lower magnitude and higher frequency and hazardous events of a higher magnitude and lower frequency could occur (Figure 2.12; Smith, 1996). Further a combination of a change in both the mean and a greater variability could also result. 


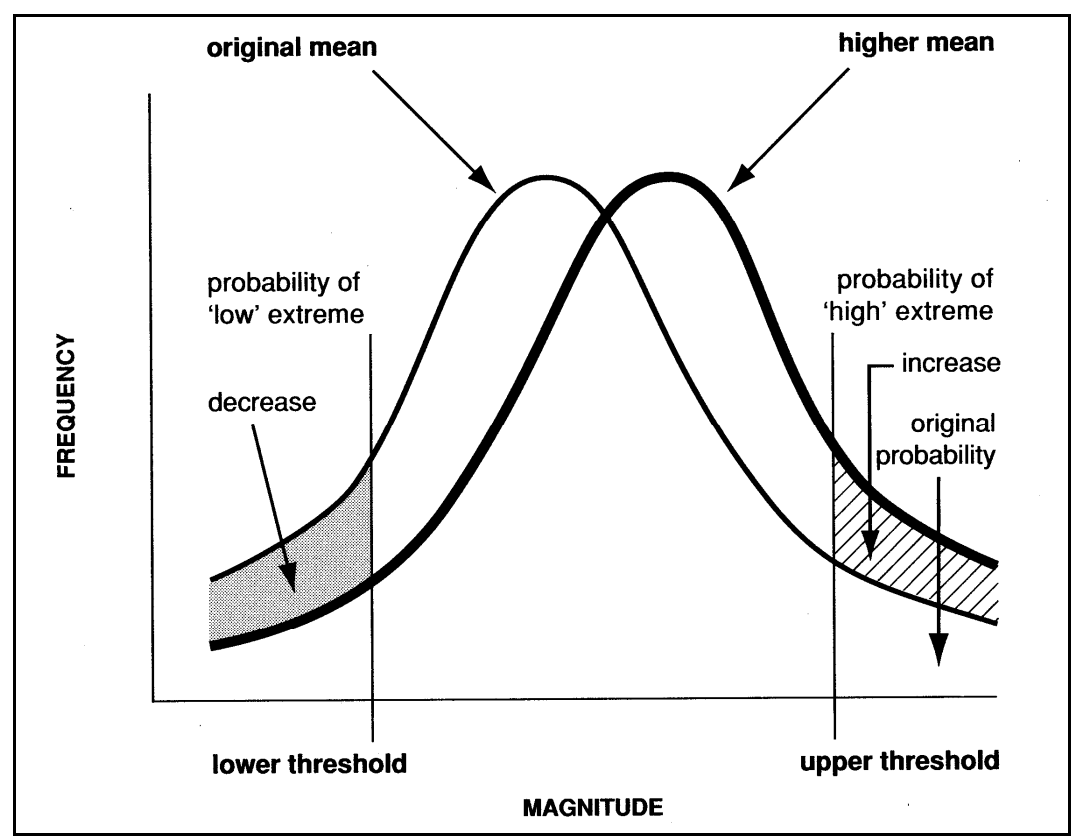

Figure 2.11: A shift right of the whole distribution curve of possible magnitudes increase the magnitude of the mean hazardous event that can be experienced resulting in potentially more, higher extreme hazardous events occurring (Smith, 1996).

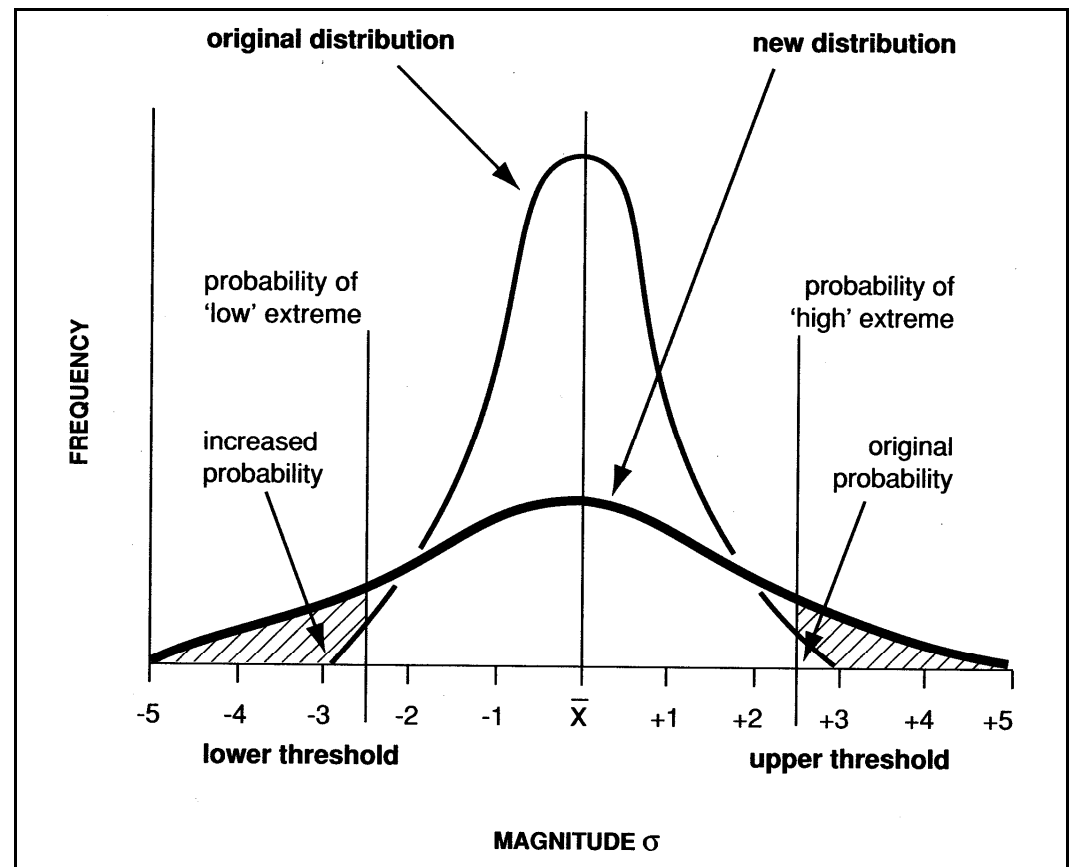

Figure 2.12: Greater variability of possible magnitudes could result in more extreme hazardous events (Smith, 1996).

Crozier (1999) points out that these changes in the relationship between the frequency and magnitude of hazardous events may highlight environmental changes. These changes could be to the characteristics of the catchment, for example the amount of sediment available for transport by debris flows or floods or the amount of vegetation 
cover, or changes to the triggering events, for example the more frequent occurrence of intense rainfall events which trigger debris flows. These changes can be induced both naturally, for example as a sediment supply becomes exhausted (Crozier, 1996), or through anthropogenic interference with the natural system (Smith, 1996; Crozier, 1999; Crozier and Glade, 1999). Land use changes or engineering can alter the characteristics of the catchment while climatic changes, partly induced by humans, can alter triggering event such as the intensity or frequency of rainfall events.

\subsubsection{The Natural Hazards Associated with Fans}

Fans are naturally occurring phenomena that result from naturally occurring processes. As outlined above, it is only due to the presence of people, our property and infrastructure on or near the fans that fans become a natural hazard.

Fans are increasingly being populated and used for development, including the construction of buildings, transport routes and other key infrastructure located on them. Development, both worldwide and within New Zealand, is commonly carried out on fans without first having a prior knowledge and complete understanding of the processes that have actively led to the formation of the fan, which may, in fact, still be occurring (Davies and McSaveney, 2008). Fan activity and the stability of the fans is therefore becoming an important issue due to the significant natural hazards presented to people and the development.

Fans provide land that can be relatively flat and gentle sloping which is well elevated above floodplains and coastal areas, away from the possible hazards of these areas. Aesthetically, this also allows for good views of the surrounding landscape. In mountainous areas, for example New Zealand's Southern Alps, fans may provide the best land appropriate for building on. Fans are assumed to be stable, with only small non-hazardous processes occurring, and hence they are assumed to be good sites for development. They additionally generally have well drained soils and can provide sources of water (Bull, 1977; Selby, 1982; McSaveney and Whitehouse, 1989; Davies and McSaveney, 2008). Key infrastructure, for example camp grounds, hotels, sewage ponds, State Highways and roads, rail lines and houses are often located on fans. 
The processes involved in fan formation result in a number of hazards which occur during sedimentation events. Davies and McSaveney (2008, p 46) recognise that "all (active) parts of a fan are exposed to hazards". Even areas that are protected by mitigating measures or structures can be exposed to hazard and/or damage if the magnitude of an event exceeds the event magnitude for which the measures and structures were designed for. Flooding, aggradation, stream avulsion and scouring can occur on alluvial fans and, in addition to these, debris flows can occur on debris fans (McSaveney and Whitehouse, 1989; McSaveney et al., 1995; Garfi et al., 2007).

Flooding on the fan surface can result from rising water flows in the stream channel. McSaveney and Whitehouse (1989) note that any area of the fan is generally lower than areas of the fan above it and so flooding is a potential risk for development on any area of the fan, even though floodwater inundation may be short lived. While flooding is a hazard in its own right, it is important to recognise that the processes of sediment movement rather than the flow of water that can result in the most hazard on fans and cause the most damage (Davies and McSaveney, 2008). Floods carrying very little or no sediment can occur on fans without causing any damage (Davies and McSaveney, 2008). Flooded streams can scour areas along the stream banks, leading to instability in these areas. Flooded streams also lead to the aggradation of sediment within the stream channel. Sediment build up can occur quickly near the apex of the fan (McSaveney and Whitehouse, 1989) during sedimentation events and can result in the stream avulsing to other parts of the fan. Stream avulsion occurs when the sediment is built up within the stream channel so that the stream may suddenly switch its flow path to a lower part of the fan or reoccupy an old stream channel (Bull, 1977, McSaveney and Whitehouse, 1989). Stream avulsion can occur very abruptly and with no warning, presenting a high hazard to development on the fan which may be in the path of the new stream location. Sediment transport and deposition will now occur along this new path.

Debris flows can also result in sediment aggradation and avulsion events. They are recognised as being more hazardous to development on fans than other fan processes (McSaveney et al., 1995; Garfi et al., 2007) due to the volume of sediment transported within them, some of which can be large clasts, and the speed at which they can travel. This can lead to debris flows causing a large amount of damage (Skermer et al., 2002) 
to buildings and other infrastructure on the fan. Further, debris flows are relatively rare and unexpected (Blair and McPherson; 1994), requiring sediment build up and a storm event large enough to trigger a debris flow. As a result debris flows can be difficult to predict.

Many authors have noted that the hazards produced by fans are inadequately recognised and acknowledged (McSaveney and Whitehouse, 1989; Crosta and Frattini, 2004; De Scally and Owens, 2004; De Scally and Owens, 2005; Davies and McSaveney, 2008). Many fan sites lack recorded historical data for both stream flows and hazardous event occurrences, thus making it difficult to determine the frequency and magnitude of past events and predict the size of potential future events (McSaveney and Whitehouse, 1989). There is a clear need for protective or mitigating measures to be put in place on fans where development or infrastructure exist or are proposed. The lack of recorded historical data, however, can make it difficult to determine the size and extent to which these measures are required.

Mitigation options can be either an active or passive response to try to control fan processes and reduce the effects of the hazard events when they occur (EBA, 1997). Active mitigation measures aim to restrict the location of where the hazard can occur and subsequently the path of sediment aggradation and stream or debris flow avulsion or where the hazard can originate from. It involves the placement of physical structures and geotechnical engineering (Brennan, 2007), for example placing stopbanks or dykes along the stream channels as has been carried out on the Blackbirch and Glencoe fans at Aoraki/ Mt Cook (McSaveney and Whitehouse, 1989; Skermer et al., 2002; Davies and McSaveney, 2008), clearing of the stream channel to reduce sediment accumulation or the positioning of sediment dams across the stream channel to trap sediment and reduce the power of the stream. Planting along the stream channels, the fan surface and within the catchment can also stabilise areas of erosion. Active mitigation measures can be uneconomic and may only exacerbate or change the hazard or move the hazard to another location on the fan (Davies and McSaveney, 2008). Further, active mitigation can make the extreme events worse (EBA, 1997). 
Passive responses to mitigating fan hazards include the use of land use zoning, management policies, warning systems and raising public awareness. An example of land use zoning has been carried out on the Blackbirch and Glencoe fans at Aoraki/ Mt Cook (McSaveney and Whitehouse, 1989; Skermer et al., 2002; Davies and McSaveney, 2008). However, this can be difficult to implement if development has already occurred on the fan. Warning systems and evacuation measures may be of little use given the suddenness and unpredictability of some of the hazards on fans (EBA, 1997).

Given the fans concerned in this study are alluvial fans, controlled by dominantly alluvial processes, this study will focus on the processes and hazards of alluvial fans.

\subsection{The Entrainment and Transport of Clasts in Stream Flows}

The fluvial entrainment and transport of coarse sediment onto the surface of fans can potentially present a hazard to people, buildings and/or the key infrastructure which is situated on these landforms. Sediment entrainment, and the resulting transport, is only possible under certain flow conditions; therefore, the actual hazard is only recognised when these conditions are met. This section will overview the forces active in initiating sediment entrainment and reviews the point at which sediment entrainment can occur.

Potential and kinetic energy is present within stream flow. This energy is used to do work within the stream channel. Some of the energy within a stream is lost from the system when work is carried out by flow turbulence and friction created along the stream bed or within the flow itself. The remaining available energy can be used to do mechanical work such as eroding, entraining and transporting sediment (Summerfield, 1991; Knighton, 1998; Fryirs and Brierley, 2001), and is commonly determined by the power of the stream.

A number of external forces act on individual sediment clasts on the stream bed. The degree to which these forces act on the clast determine whether it can be entrained or not. Forces acting on clasts in a stream channel can be separated into two categories. 
Driving forces work against the clasts to move them or make the clasts unstable on the channel bed, while resisting forces are those forces which work to keep clasts stable on the stream bed, resisting entrainment. Lift, gravity and drag are the three main forces acting on individual clasts present on the stream bed (Figure 2.13; Leopold et al., 1964; Statham, 1977; Summerfield, 1991; Knighton, 1998; Charlton, 2008). Further, cohesion between smaller clasts, and neighbouring clasts can have a minor effect.

Hydraulic lift works to lift clasts vertically upwards (Figure 2.13). It is a driving force. Lift is generated from uneven pressure gradients from the water flow velocity of the stream above and below the clast. Water flowing above a clast, a small distance away from the stream bed has a faster velocity than the water flowing under the clast, very close to the bed of the stream channel. The faster flowing water exerts less pressure on the clast, as it moves over it, than the slower moving water below the clast. This flow beneath the clast exerts more pressure on the clast. This greater pressure below the clast results in a force working to lift the clast away from the stream bed (Summerfield, 1991; Charlton, 2008).

Gravity applies stresses on individual clasts resting on the stream channel bed. The force of gravity has two key components: normal stress and shear stress. Normal stress acts vertically to a slope and works to hold material on a slope, whether in a stream channel or on a hillslope. Shear stress is the force of gravity which pulls material downslope and can result in the transport or movement of material.

Due to this, gravity can act both as a driving force and a resisting force. Alone the driving force of the downslope shear stress of gravity acting on a clast is minimal as stream beds often have very low slope angles (Statham, 1977), as opposed to slope angles common on hillslopes and is therefore not shown on Figure 2.13. Drag (Figure 2.13), a driving force, is the force of water flowing downslope over the clast. It is generated by uneven stream flow pressure gradients on either side of the clast, where the flow immediately upstream of the clast is greater than the flow immediately downstream of the clast. The shear stress component of gravity generates the downslope movement of water which in turn acts as a tractive stress on individual clasts. Drag is therefore seen as the main shear stress working to move particles downslope (Leopold 
et al., 1964; Summerfield, 1991; Charlton, 2008). Fluid force, and thus the direction of the fluid force, is a combination of both lift and drag.

The normal stress exerted on individual clasts from gravity is a resisting force and is the immersed weight of the particle under the water (gravity in Figure 2.13). This acts vertically (perpendicular to the stream bed) on clasts, working to hold them to the stream bed. Normal shear stress vertically opposes the driving force of hydraulic lift (Leopold et al., 1964; Summerfield, 1991). If the normal stress of gravity is greater than the hydraulic lift, the clast will remain on the stream bed. Conversely if the hydraulic lift is greater than the normal stress of gravity then the clast can be lifted off the stream bed.

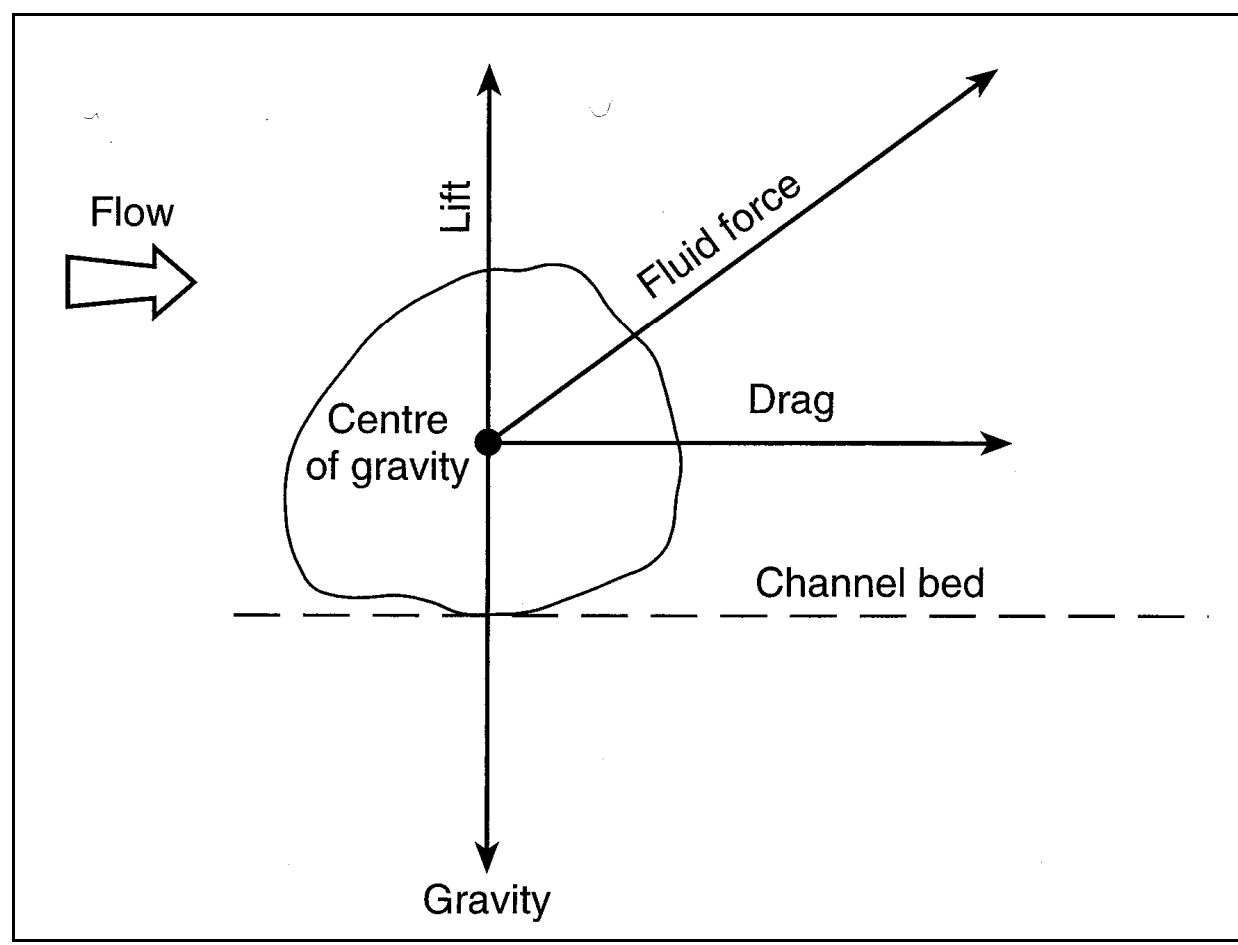

Figure 2.13: The main driving and resisting forces acting on individual clasts on the stream bed (Charlton, 2008). 
Charlton (2008, p 94) defines stream competence as the "ability of a given flow to entrain sediment of a certain size". Entrainment of a clast occurs when a threshold is met between the driving and resisting forces acting on the individual clast. This is known as the threshold of motion or erosion (Knighton, 1998) or the time of incipient motion (Leopold et al., 1964) and can be expresses as:

$$
\tau_{0}=\tau_{c r}
$$

Equation 2.3

where $\tau_{0}$ is the average boundary shear stress in $\mathrm{N} / \mathrm{m}^{2}$ and $\tau_{c r}$ is critical shear stress in $\mathrm{N} / \mathrm{m}^{2}$ (Knighton, 1998). Boundary shear stress is the point at which the flow of water on a non-cohesive stream bed is capable of initiating clast or particle movement from the stream bed (Fryirs and Brierley, 2001). Critical shear stress is the shear stress of the flow of water needed by specific sized individual clasts for entrainment to occur (Knighton, 1998). Boundary shear stress must thus be equal or greater than the critical shear stress of an individual clast for it to be entrained. The equations for calculating boundary shear stress and critical shear stress and the assumptions and limitations of these equations will be discussed further in Chapter 5.

Knighton (1998) notes that the entrainment of clasts depends on the physical characteristics of the stream channel and the individual clasts. The size, shape and density of the clasts are all important factors and can affect the packing and arrangement of the clasts on the stream bed. Tightly packed or imbricated clasts are more difficult to entrain. Additionally the range of clast sizes present is important. Larger clasts protect smaller clasts, as they are sheltered or armoured from the flow of water and the flow velocity over the smaller clast is reduced (Pye, 1994).

Many authors have carried out work on the threshold conditions of sediment entrainment but the most well known is that carried out by Hjulstrom (1935) and Shields (1936). Hjulstrom collated empirical data from 30 studies to relate the mean or critical flow velocity with grain size to determine when grains of a certain size could be entrained, transport and deposited (Figure 2.14; Summerfield, 1998; Fryirs and Brierley, 2001). The curve shows that clasts between $0.2 \mathrm{~mm}$ and $0.7 \mathrm{~mm}$ (small to coarse sand) 
are easily entrained in lower velocities, while clasts smaller or larger than this size require higher flow velocities to be entrained. Large clasts are deposited quickly if the velocity falls only slightly, while smaller clasts can still be transported even if flow velocities fall greatly (Statham, 1977; Fryirs and Brierley, 2001; Charlton, 2008).

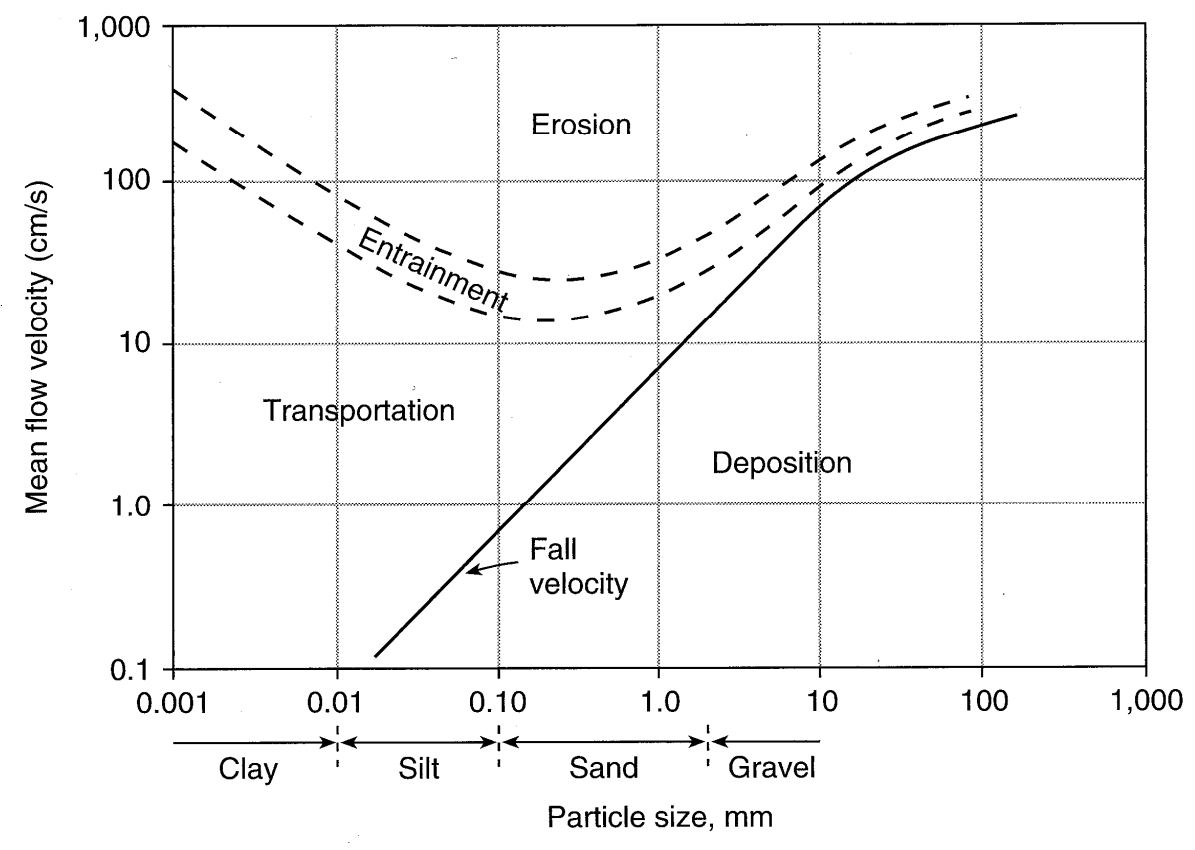

Figure 2.14: The Hjulstrom Curve, outlining the flow velocity at certain size grain particles can be entrained, transported and deposited (Charlton, 2008; modified from Hjulstrom, 1935).

The Hjulstrom Curve has a number of underlying assumptions. Stream channels are assumed to be smooth, with uniform, well sorted, loose clasts. Further the stream flow is assumed to be steady, both with depth, across the stream and through time, by using the mean stream velocity to determine conditions of entrainment, transport or deposition of clasts (Summerfield, 1991). These assumptions lead to the recognition that the Hjlustrom Curve is difficult to apply to most natural streams. It is difficult to determine what the mean flow velocity of a natural stream is as the flow velocity is often variable both in time and space, varying between high and low flows and deep and shallow sections across a section of the stream channel. Additionally sediment entrainment occurs on the stream bed. In natural streams flow velocities are lower on the stream bed than the mean flow velocity as clasts and other debris can slow the stream flow. Hjulstrom used data from samples taken from well sorted sand and gravel stream 
studies and so the curves may not be representative of the poorly sorted samples generally found in most natural streams, as larger clasts can protect smaller clasts from entrainment. It is also recognised that the characteristics of the stream channel and the individual clasts can make it difficult to apply these curves to natural streams (Summerfield, 1991). Channel roughness and particle packing, size, shape and density can all have an effect the smoothness of the stream channel, with natural streams generally being irregular, thus having an effect on entrainment (Knighton, 1998; Fryirs and Brierley, 2001).

Shields presented a similar sediment entrainment curve which relates a dimensionless critical shear stress to the entrainment of particles (Figure 2.15; Knighton, 1998; Charlton, 2008). The size of the particles is represented by a grain Reynolds number which is related to the roughness of the channel. The dimensionless critical shear stress required to move a particle can be calculated from the Shield equation:

$$
\theta=\frac{\tau_{c r}}{g\left(\rho_{s}-\rho\right) D}
$$

where $\theta$ is the dimensional critical shear stress, $\tau_{c r}$ is critical shear stress, $g$ is the acceleration of gravity, $\rho_{s}$ is the density of sediment, $\rho$ is the density of water and D is the grain size (Knighton, 1998). The Shields curve is basically similar to the Hjulstrom curve, showing that small to coarse sand grains are the easiest clast size to entrain and that clasts both smaller and larger than this need a higher shear stress to initiate entrainment.

Many of the same assumptions held for the Hjulstrom curve are also recognised for the Shield curve (Summerfield, 1998). It is also recognised that the Shield curve is a more indirect method of determining an entrainment threshold (Knighton, 1998). This is due to the curve using a Reynolds number of the particles which is related to channel roughness rather than the actual size of the clasts present in a stream channel. The roughness of natural stream channels can vary greatly depending on the vegetation, the type of stream channel and the characteristics of the clasts within the channel. This 
along with the variables discussed above for the Hjulstrom curve lead to difficulties in applying the Shield curve to natural streams.

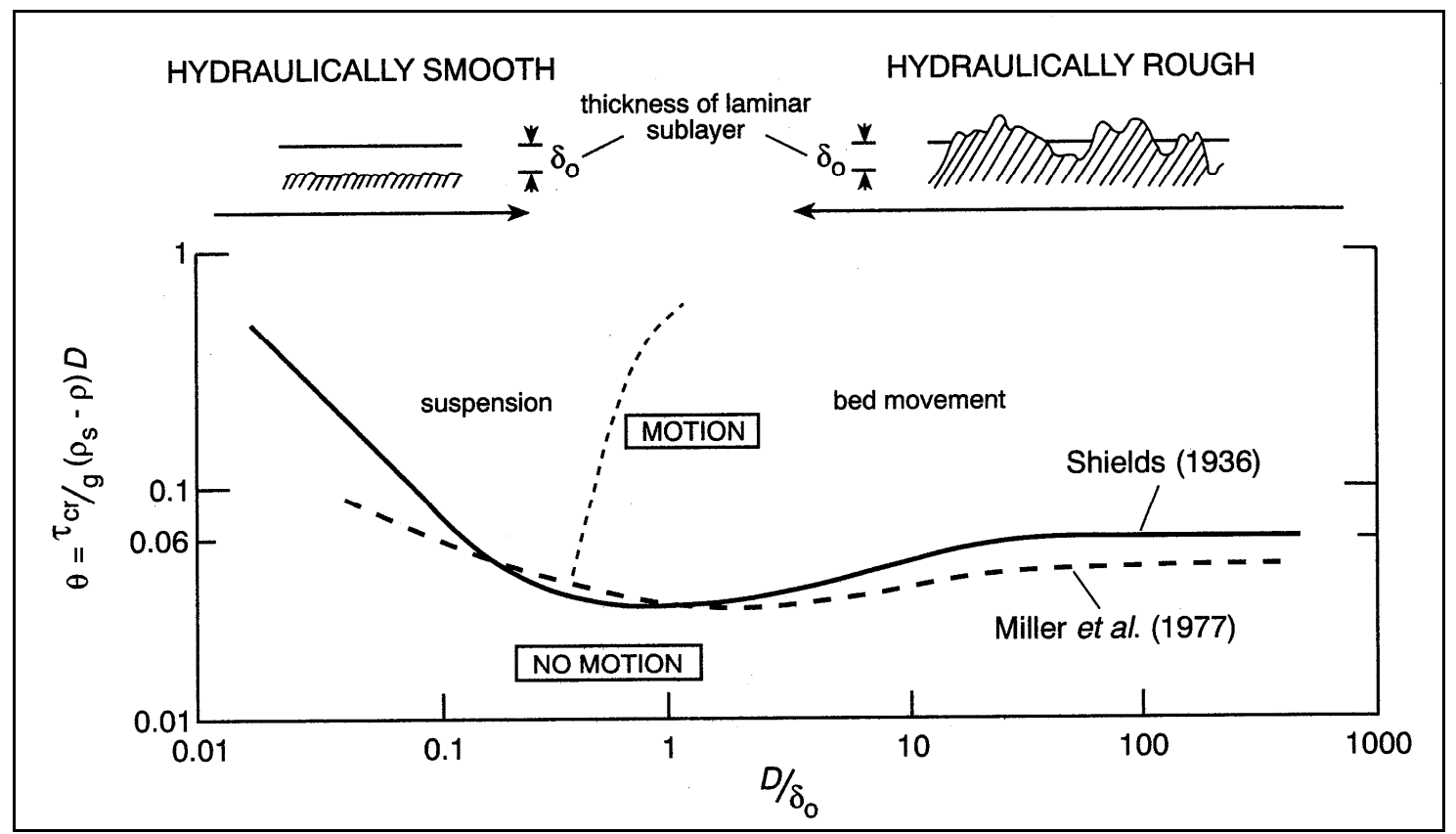

Figure 2.15: The Shields Entrainment Diagram which shows the relationship between a dimensionless critical shear stress and the Reynolds number for a clast. The dashed lined shows the Shields curve modified by Miller et al. (1977) (Knighton, 1998.) 


\section{Chapter 3 \\ $\underline{\text { Regional Setting }}$}

\subsection{Introduction}

This study is based on three catchments and the corresponding alluvial fans that flow from them, situated along the northeast coast of the South Island, New Zealand between the settlement of Kekerengu and the mouth of the Clarence River (between $173^{\circ} 56^{\prime \prime} \mathrm{E}$ and $173^{\circ} 56^{\prime \prime} \mathrm{E}$ and $42^{\circ} 06^{\prime \prime} \mathrm{S}$ and $42^{\circ} 08^{\prime \prime} \mathrm{S}$ ) (Figure 3.1). The catchments, in the foothills of the Seaward Kaikoura Ranges, are steep, with large areas of bare rock and sediment exposed, and are highly erodible. As a result three moderately sized alluvial fans have formed at the outlet of these catchments on the narrow coastal plain. The fans are vegetated to varying degrees and are heavily engineered and maintained to control water and sediment flows which present a potential hazard to State Highway 1 and the Main Rail Trunk Line between Picton and Christchurch. Both of these main access routes cross over the alluvial fans, although there has been very little geomorphic enquiry into these specific alluvial fans and their catchments. Further, few records exist of water and sedimentation events onto the fans.

This chapter will introduce the regional setting of the field site describing the geology, geomorphology, the climate and weather and the land use and vegetation history of the area. The human modification to the fans and past triggering events will further be discussed. 


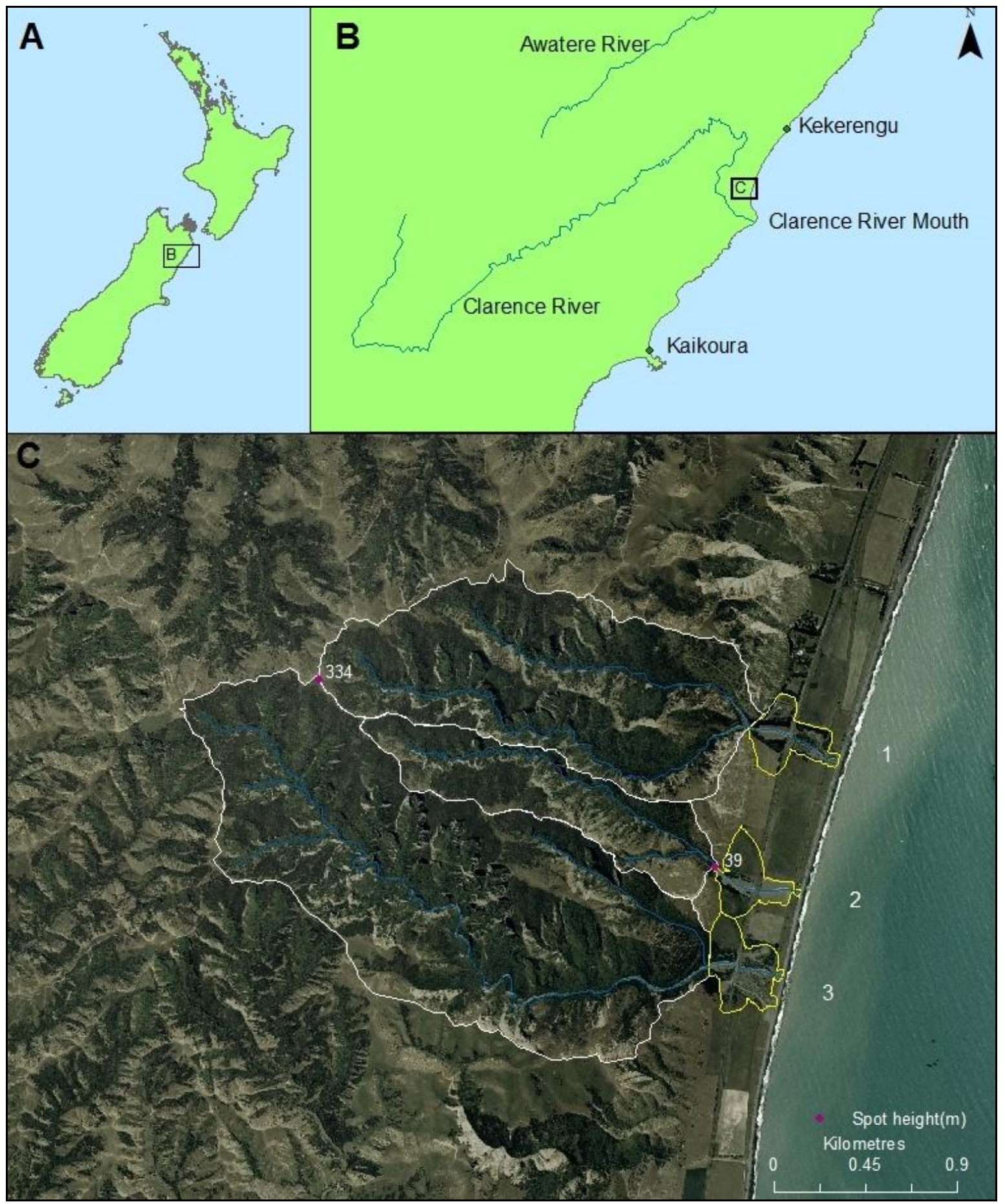

Figure 3.1: A: Location of the field site in the South Island, New Zealand. B: Position of the field site between the Clarence River mouth and Kekerengu. C: Location of the three alluvial fans and the respective catchments. Aerial photograph source: LINZ, 2004. 


\subsection{Geology}

\subsubsection{Tectonic Setting}

New Zealand is sitting on the boundary of the Pacific plate and the Australian plate. In the central and upper part of the South Island these tectonic plates are converging at a rate of up to $46 \mathrm{~mm}$ per year (Van Dissen and Yeats, 1991). As a result, this area has a very active tectonic setting. The main fault line in the South Island, the Alpine Fault, runs northeast trending along the Southern Alps. Located at the northern end of this fault is a group of faults called the Marlborough Fault System. The Marlborough Fault System consists of five major faults, the Wairau (an extension of the Alpine Fault), the Awatere, the Clarence, the Kekerengu and the Hope faults. Additionally there are many smaller splinter faults within the system including the Elliott, Fidget, Fowlers, Fyffe, Heavers Creek, Jordan Thrust, Kakapo, Kowhai and Waihopai faults (Figure 3.2).

Movement along these faults during the Quaternary has been recorded, for example by Van Dissen and Yeats (1991) and Browne (1992), with large amounts of faulting and folding. The five main faults are oblique dextral strike slip faults, all trending in a northeast direction. The Hope Fault is the most active fault, moving at a current slip rate of approximately 20 to $25 \mathrm{~mm}$ per year (Van Dissen and Yeats, 1991) with the other four faults moving at a lesser rate; for example, the Clarence Fault has a slip rate of 4 to $8 \mathrm{~mm}$ per year (Browne, 1992).

The Kekerengu Fault runs northeast to meet the coast just to the north of Kekerengu. The study site is located between this fault and the coast to the south of where the fault meets the coast. There are many small unnamed splinter faults running throughout this enclosed section, with at least four small splinters running through the three catchments concerned here. The Hope Fault runs east-northeast to meet the coast to the south of the Clarence River mouth. 


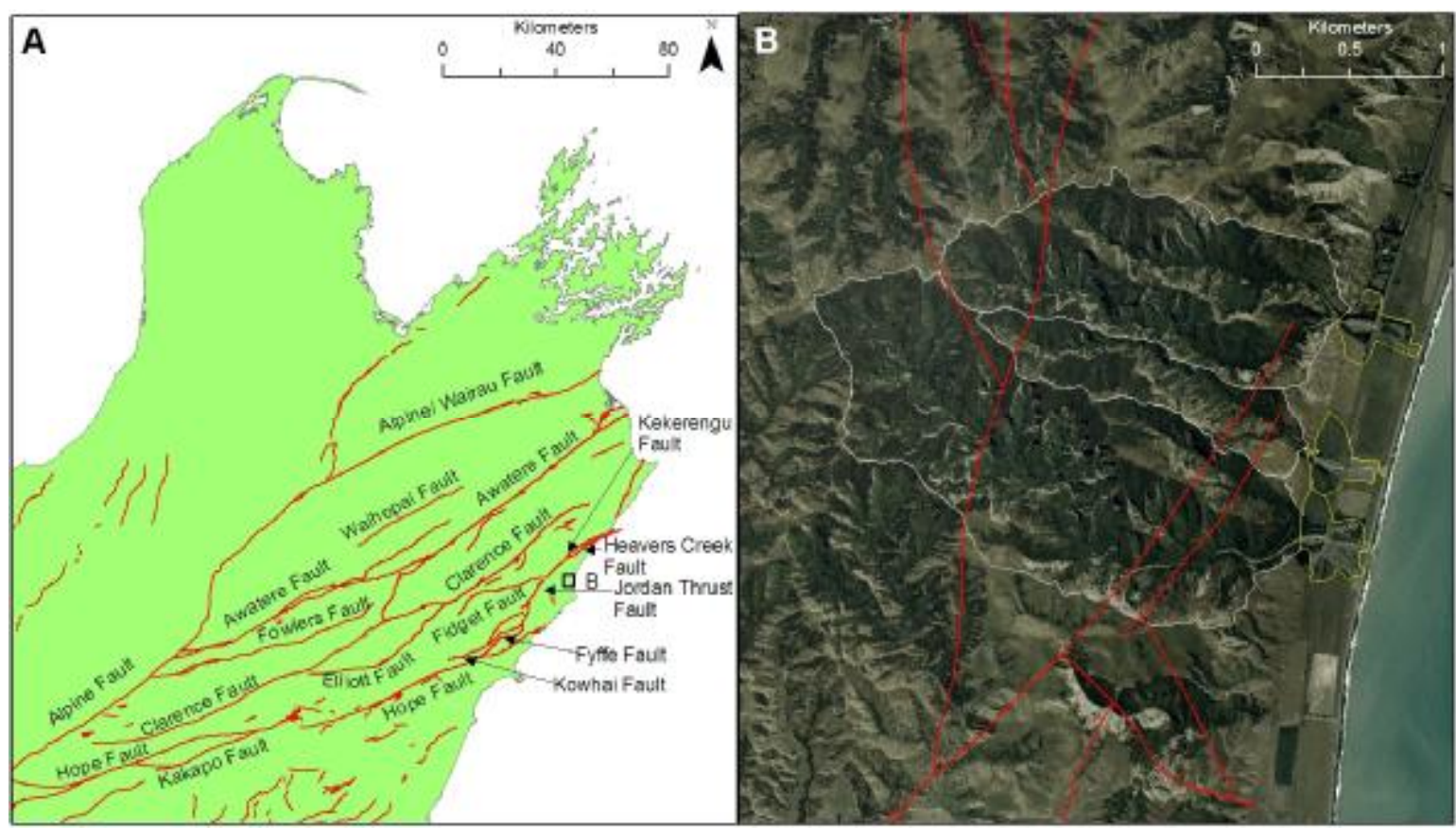

Figure 3.2: The Marlborough Fault System. A: Map of the upper South Island detailing the five main faults and main smaller splinter faults within the Marlborough Fault System. B: An enlargement of box B on map A showing the unnamed splinter faults that pass through the field site. Aerial photograph source: LINZ, 2004.

Vickery and Lamb (1995) have recorded a clockwise rotation in the Marlborough region that started during the Miocene, aligning the faults in the northeast direction. The region is thought to have been rotated by approximately $20^{\circ}$ during the last four million years, with the area southeast of the Kekerengu Fault forming a hinge between the rotating areas to the north and non-rotating areas to the south of this fault (Lamb and Bibby, 1988; Vickery and Lamb, 1995).

The tectonic setting of the region leads to a large number of large, shallow earthquakes. Rattenbury et al. (2006) note that eight earthquakes of magnitude 6 (on the Richter scale) or larger have been recorded in this region. The 1848 Marlborough and the 1888 North Canterbury are two large earthquakes of note that occurred along the Awatere and Hope faults respectively (Rattenbury et al., 2006). Earthquakes can lead to cracks and surface ruptures in the areas surrounding the faults and the triggering of landslides. 


\subsubsection{Rock Type}

The field site and the surrounding area are made up of three main rock types. The primary rock type for the area north of the Clarence River mouth is called the Waima Formation. It is a calcareous silty mudstone that was deposited during the early middle Miocene (Browne, 1995; Rattenbury et al., 2006). This sedimentary rock is greenish to a pale blue-grey colour and the massive to poorly bedded formation has been described as being up to 360 metres thick in some areas of the formation (Browne, 1995). The Waima Formation sits conformably on a basement of limestone that was formed during the Oligocene with a gradational contact (Rattenbury et al., 2006).

Within the Waima formation are deposited lenses of the Great Marlborough Conglomerate (GMC) from the early Miocene (Figure 3.3). This conglomerate is very poorly sorted ranging from fine pebbles to very large boulders that are angular to well rounded within a fine supporting matrix (Lewis et al., 1980; Browne, 1995). The clasts are derived from the Torlesse Supergroup and consist of greywacke from the Pahau terrane, limestone from the Mead Hill and Amuri formations, as well as those formed from Oligocene and Late Cretaceous volcanic rocks (Lewis et al., 1980; Browne, 1995). The GMC was deposited by a range of debris flow processes and can be up to 300 metres thick in parts of the Clarence Valley (Browne, 1995; Rattenbury et al., 2006).

Cutting through the Waima mudstone near the bottom of the three catchments is an Early Pliocene blue-grey calcareous siltstone and sandstone. This unit has Torlessederived debris flow conglomerate deposited within it (Rattenbury et al., 2006). It is similar to the Waima Formation and the GMC with poorly sorted subangular to well rounded clasts consisting of greywacke and limestone (Browne, 1995). However, this unit is younger than the Waima Formation and the GMC and only found to the north of the Clarence River mouth.

The three catchments concerned in this study primarily consist of GMC conglomerate and the Torlesse-derived debris flow conglomerate. As a result of the nature of this conglomerate, the catchments are highly erodible. 


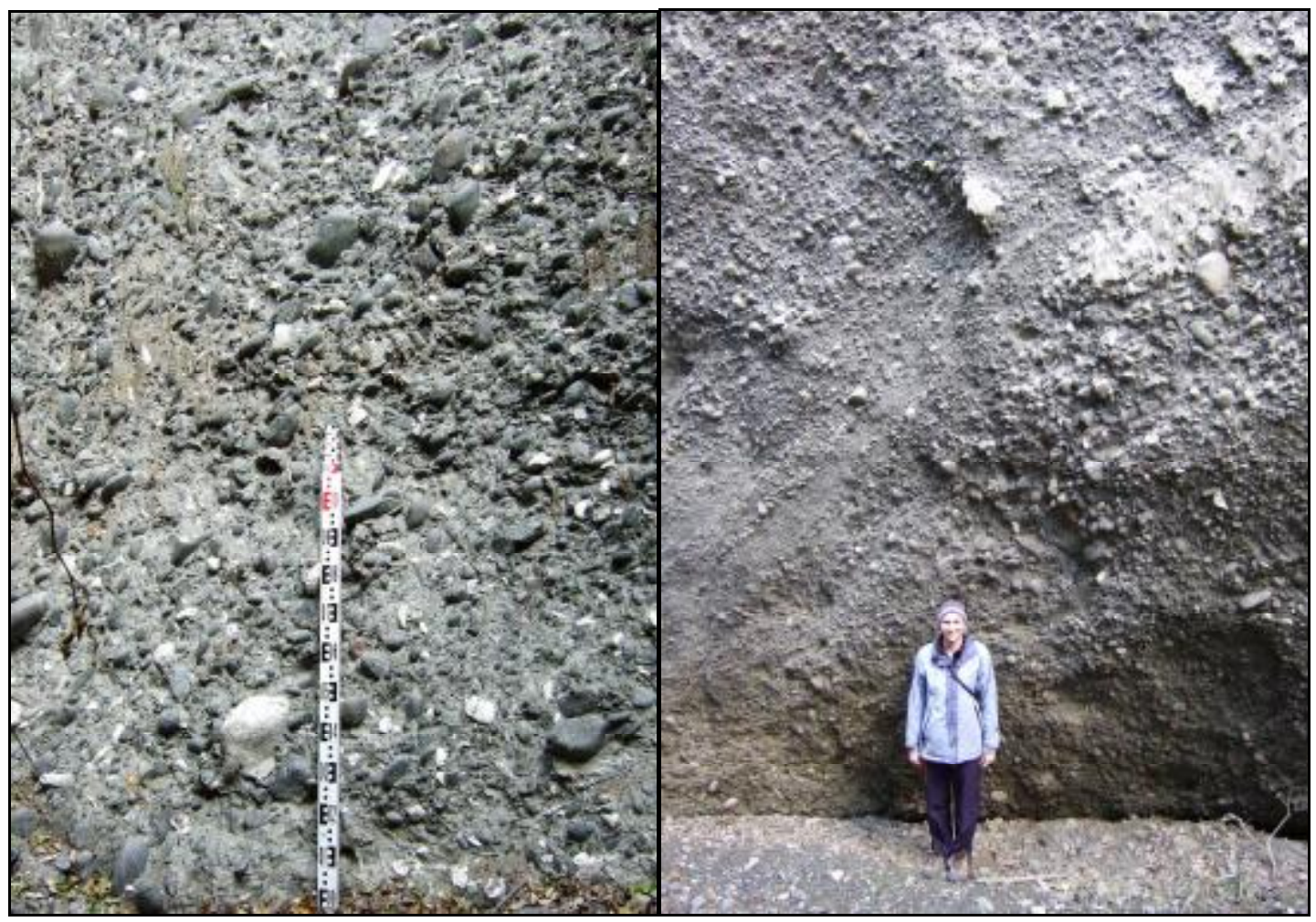

Figure 3.3: Examples of the Great Marlborough Conglomerate rock type in the three catchments with measurement staff and person for scale.

The coastal plain is made up of alluvial and marine gravel deposits, deposited during the Quaternary (Rattenbury et al., 2006). Much of this sediment has been transported to the coastal areas by rivers and streams or from glacial outwash. Many alluvial fans are located on the coastal plain as small streams flow out of steep valleys in the Seaward Kaikoura Ranges. Loess is common on the top of terraces near rivers (Rattenbury et al., 2006) and thick layers can be seen on the hills to the south of the field site, by the Clarence River.

\subsection{Climate and Weather}

\subsubsection{Regional Climate and Weather}

Broadly, New Zealand's climate is influenced by mid-latitude westerly weather patterns and the topography of the land. In general the southeastern Marlborough and northern Canterbury regions have a warm, dry, temperate, maritime climate. The area, located on the northeastern side of the South Island, is one of the driest regions in New Zealand 
due to sheltering by the Southern Alps and the North Island (Pascoe, 1983). Temperatures in Kaikoura, approximately $43 \mathrm{~km}$ south of the field site, are higher in the summer months than in the winter months (Figure 3.4). The mean annual temperature recorded at the Kaikoura AWS gauging station between 1971 and 2000 was $12.4^{\circ} \mathrm{C}$ with a mean summer temperature of $16.6^{\circ} \mathrm{C}$ in January and a mean winter temperature of $8.1^{\circ} \mathrm{C}$ in July (NIWA, 2009). The region receives a high number of sunshine hours (Pascoe, 1983), with 2082.3 sunshine hours recorded in Kaikoura for the same time period (NIWA, 2009).

The mean annual rainfall recorded at the Kaikoura AWS gauging station between 1971 and 2000 is $823.4 \mathrm{~mm}$ (NIWA, 2009). Rainfall amounts vary between the seasons, with winter receiving the most rainfall and the summer being the driest (Figure 3.4). March, however also receives a high amount of rainfall. The mean annual rainfall recorded at the Ngaio Downs gauging station, located to the north of the field site, closely matches the seasonal rainfall pattern of Kaikoura but indicates slightly less rainfall (NIWA, 2009). Droughts can often occur during the summer, with the summer of 2007/2008 being very dry.

Snow and frost commonly occur during the winter. Snow falls on the ranges, including the Seaward and Inland Kaikoura ranges and the Richmond Ranges (Pascoe, 1983), but is rare at sea level. Frosts are common in the valleys. 


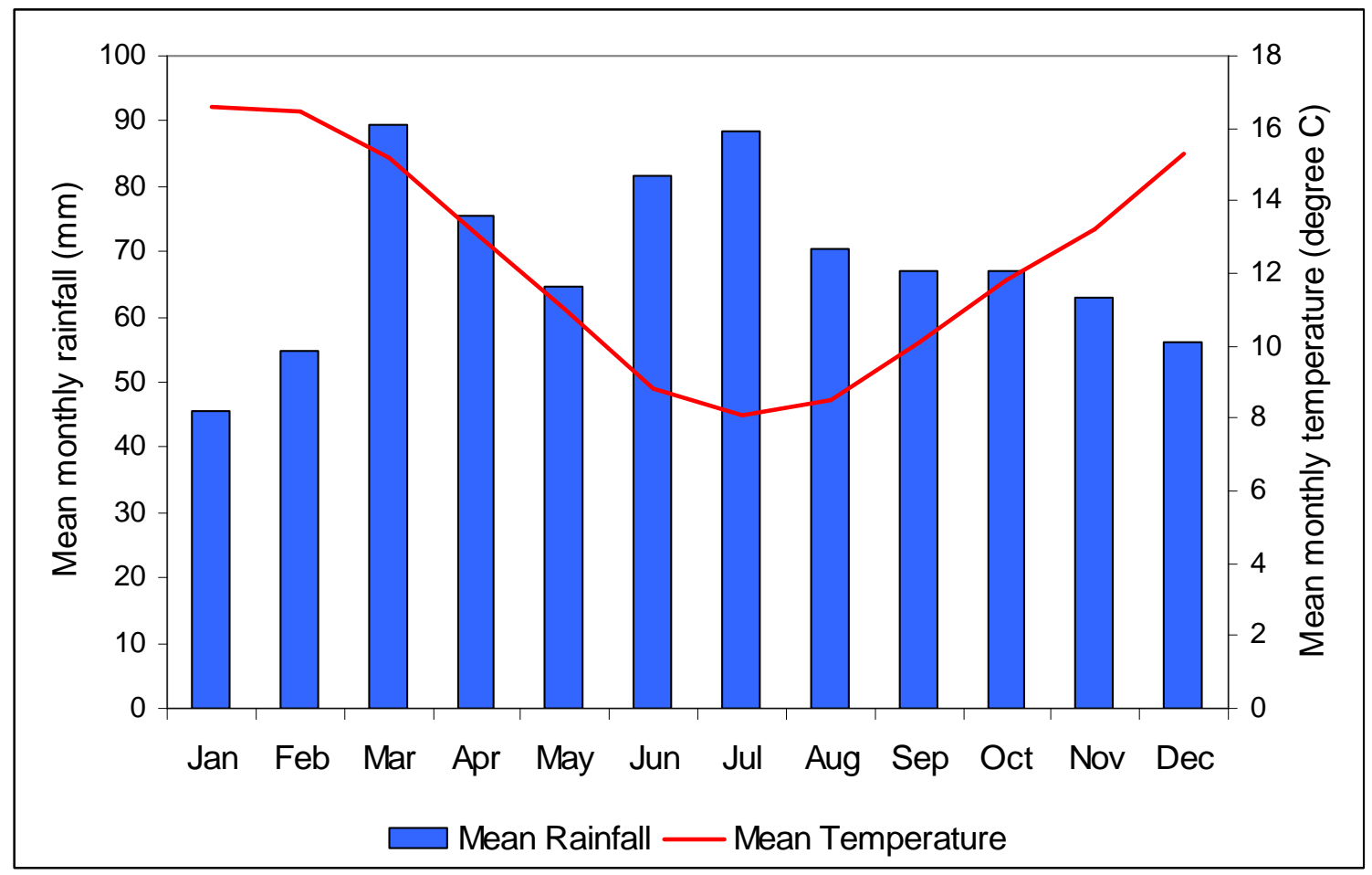

Figure 3.4: Average monthly rainfall and temperatures of southeastern Marlborough and northern Canterbury. Data source: NIWA Cliflo database.

Easterlies and southerlies are the two main moisture laden air flows that can affect this area. Southerlies bring cold winds and rain to coastal areas as low pressure systems move away from the east coast of the South Island (Pascoe, 1983). Easterlies can bring rainfall to this area; sometimes this can be heavy and intense (Pascoe, 1983). This rainfall is due to the uplifting of air coming off the Pacific Ocean over the coastal ranges. Cyclone Alison in 1975 and the rainstorm events of July and August 2008 were produced from this type of weather system and brought heavy rainfall to this area. The southeast Marlborough and northern Canterbury area is sheltered from westerly, northwesterly and southwesterly weather by the Southern Alps and the hills to the southwest of the area (Pascoe, 1983). These weather patterns often cause warm, dry weather over the rest of the area. Further, the area is sheltered from the north and northeast by the North Island (Pascoe, 1983).

\subsubsection{Climate Change}

Climate change is likely to have an effect on much of New Zealand (MfE, 2002; 2008). It is difficult to reliably downscale the predicted alterations of the climate to smaller 
areas or regions of New Zealand (MfE, 2008). The National Institute of Water and Atmospheric Research (NIWA) and the Ministry for the Environment (MfE) have attempted to downscale some predictions of climate changes for New Zealand, producing the Climate Change Effects and Impacts Assessment (MfE, 2008). These predictions are relative to a 20 year period between 1980 and 1999 (referred to as 1990) and are predicted changes for 50 years on (2030 to 2049, referred to as 2040) and 100 years on (2080 to 2099, referred to as 2090). A set of six emission scenarios (B1, A1T, $\mathrm{B} 2, \mathrm{~A} 1 \mathrm{~B}, \mathrm{~A} 2$ and $\mathrm{A} 1 \mathrm{FI})$ reflecting a range of future emissions, each with 12 general circulation models were used and a process of statistical downscaling was then applied. A Regional Climate Model (RCM) using two emission scenarios (B2 and A1) was also used for this report (MfE, 2008).

In the report, based on data generated by NIWA, the Ministry for the Environment reported a projected mean annual temperature change of $+0.9^{\circ} \mathrm{C}$ for the Marlborough and Canterbury regions by 2040, while a mean annual temperature change of $+2{ }^{\circ} \mathrm{C}$ was projected for both regions by 2090. This is the mean for all 12 models under all six of the emission scenarios. These gave a projected increased temperature range for Marlborough of between $+0.2^{\circ} \mathrm{C}$ and $+2.1^{\circ} \mathrm{C}$ and $+0.6^{\circ} \mathrm{C}$ and $+5.1^{\circ} \mathrm{C}$ for 2040 and 2090 respectively. The predicted temperature range for Canterbury in 2040 is between $+0.2^{\circ} \mathrm{C}$ and $+1.9^{\circ} \mathrm{C}$, and $+0.7^{\circ} \mathrm{C}$ and $+5.0^{\circ}$. The changes to temperatures may vary depending on the season and the location. Canterbury is expected to have a slightly higher increase in temperature during the winter months than during the rest of the year (MfE, 2008). Projected temperature changes for the 12 models under the A1B emission scenario are shown in Figure 3.5. 

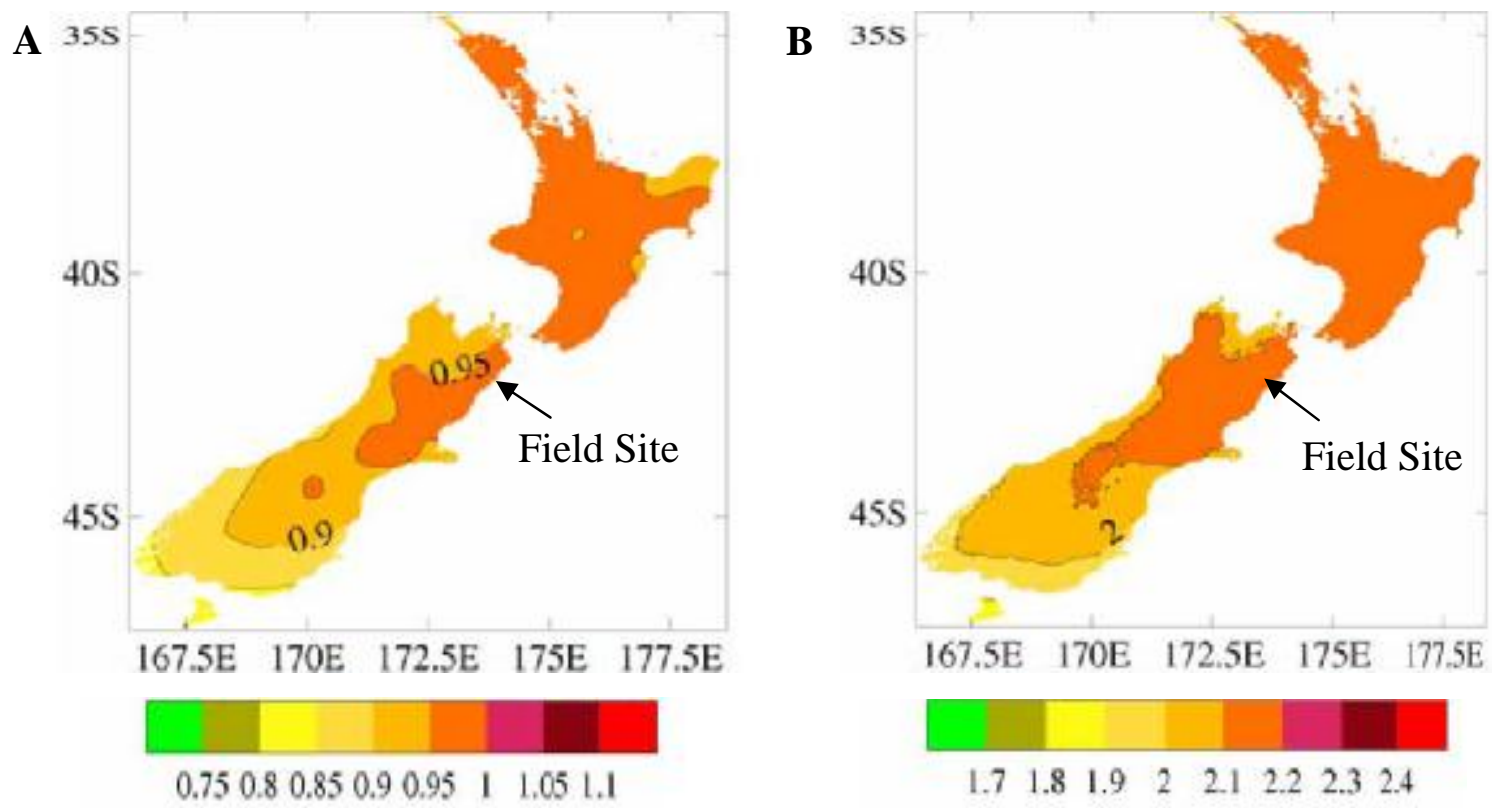

Figure 3.5: Projected mean annual temperature changes in ${ }^{\circ} \mathrm{C}$ for A: 2040 and B: 2090 for the 12 models under the A1B emission scenario. Note the scales are different (Figure modified from MfE, 2008)

The Ministry for the Environment report (2008) also projected a range of varying rainfall changes for the Marlborough and Canterbury regions. Maps of the projected mean annual rainfall changes, in percentages, for 2040 and 2090 from the 12 models under the A1B scenario are shown in Figure 3.6. Nationally, these maps show that generally the mean annual rainfall received will decrease in the east of both the North and the South Islands and in the north of the North Island. The west of both islands is expected to have an increase in the mean annual rainfall. Specifically, for the area of the field site, these maps suggest a decrease in the mean annual rainfall by 2.5 to 5 percent and a decrease of 5 to 7.5 percent by the 2040 and 2090 time periods respectively (MfE, 2008). When comparing the seasons it is likely that there will be a greater variation in the amount of rainfall received at the field site. For both 2040 and 2090 the summer and autumn months are likely to receive an increase in rainfall, with 2040 projected to increase 2.5 to 5 percent in summer and 5 to 7.5 percent in autumn. 2090 is projected to increase 5 to 7.5 percent in summer and greater than 10 percent in autumn. Conversely rainfall during the winter and spring months are likely to receive less rainfall. Winter is projected to receive 7.5 percent less rainfall for both 2040 and 2090, while spring is projected to receive a decrease of 5 to 7.5 percent by 2040 and a decrease of greater than 7.5 percent by 2090 (MfE, 2008). 

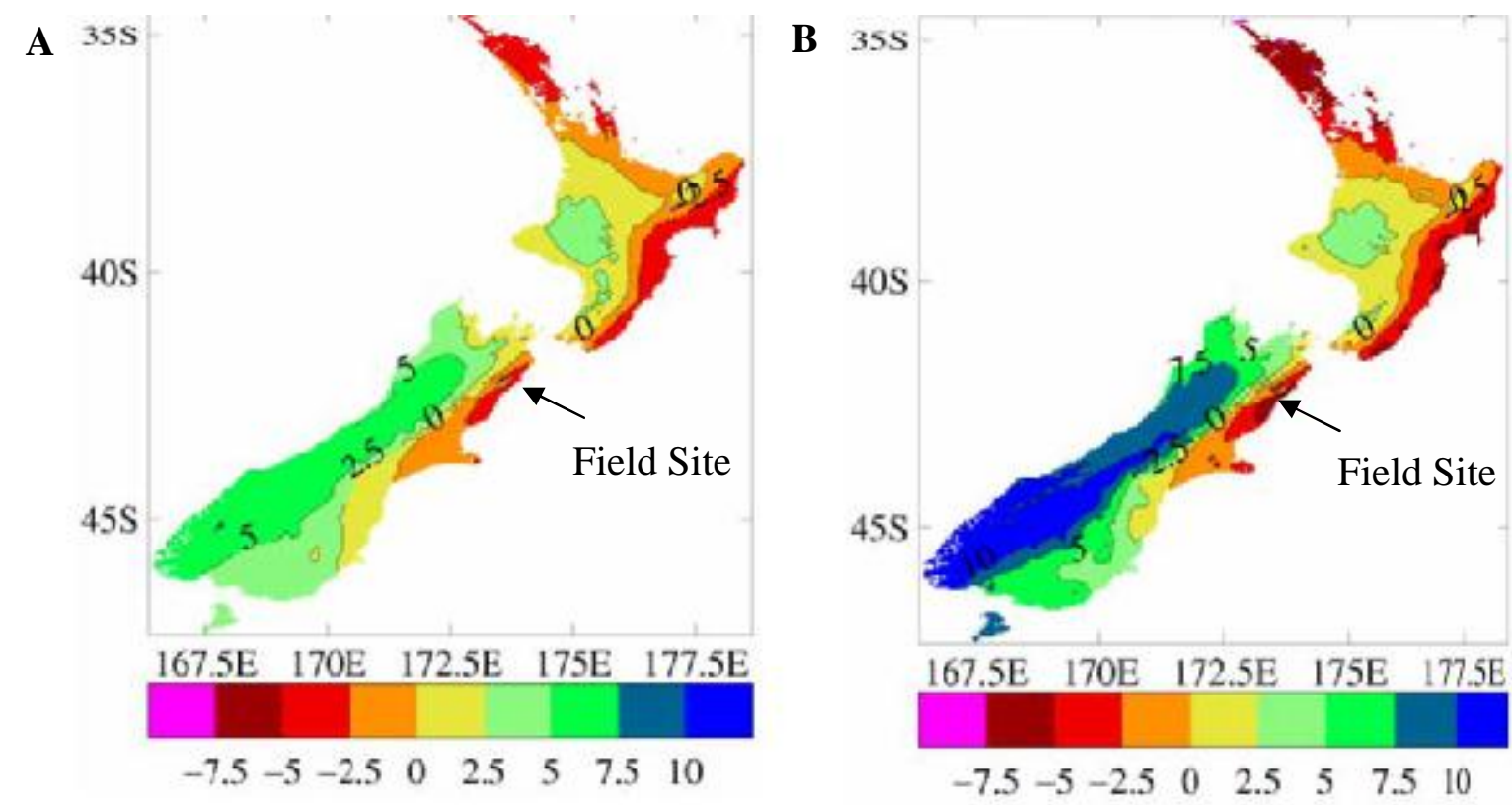

Figure 3.6: Projected mean annual rainfall changes in percentages for A: 2040 and B: 2090 for the 12 models under the A1B emission scenario. (Figure modified from MfE, 2008)

The projected changes to temperatures and rainfall for these areas will contribute to the amount of weathering and erosion of the land surface and thus the amount of raw sediment available on the slopes of the catchment. It is, however, the changes in extreme rainfall and storms that will allow this material to be carried off the slopes, out of the catchments and onto the fans. Large changes to the frequency or intensity of extreme conditions could result from the small changes to the averages discussed above. For example a small increase in the average rainfall may be associated with intense rainfall events occurring more often and droughts occurring more often due to the whole rainfall distribution shifting as the average amount changes (MfE, 2002; MfE, 2008).

Whetton et al. (1996) estimated that extreme rainfall events in New Zealand could range from "no change through to a fourfold reduction in the return period" by 2030 , implying that these events could occur more often. While the MfE report (2008) recognises that there is potential for rainfalls to become heavier and more extreme both globally and over New Zealand and reports a general increase in extreme rainfall, it remains somewhat inconclusive as to how this will change for specific regions of New Zealand as only preliminary analyses have been carried out by NIWA. 


\subsection{Vegetation and Land Use}

\subsubsection{Vegetation}

There are three distinct types of vegetation in the area of the three alluvial fans and their catchments. The land on the coastal plain between the sea and the foot of the Seaward Kaikoura Ranges is vegetated with pasture. The land surrounding the catchments is also farming pasture. Prior to settlement this land would have been covered in native forest and scrub and was cleared during the late 1800 s to early 1900 s as migrants began to farm in the area (Sherrard, 1966). The fans themselves are vegetated with weeds, grasses, shrubs and scrub to varying amounts. Fan 2 has very little vegetation growing on it, with only a few sparse mosses, shrubs and grasses. Fans 1 and 3 are well vegetated with young scrub, shrubs and a few pine trees (Pinus spp.). The channels of all three alluvial fans are kept clear of vegetation by bulldozing and the lower slopes are vegetated with pasture.

The catchment valleys are vegetated with regenerating native trees and scrub. At the apex of the fans the catchment vegetation is small and open with mainly Kanuka (Kunzea spp.), which is possible evidence of recent natural re-vegetation occurring, and well established poplar tress growing. Further up the catchments, the catchments are densely vegetated with young native forest and scrub, with some well established trees.

Large areas within the catchments, as well as some areas surrounding the catchments, are bare rock and sediment with very little vegetation present. These areas are generally very steep and easily eroded. In places mosses, ferns, grasses and small shrubs, e.g. the Marlborough Rock Daisy (Pachystegia spp.), grow on the bare slopes.

\subsubsection{Land Use}

The area between Kekerengu and the Clarence River mouth is rural land, with only a small farming population. The closest main town centres are Blenheim to the north and Kaikoura to the south. Both of these towns are based around supporting and providing 
services to the rural community and agricultural industry. Kaikoura additionally has a large tourism industry. The field site location is part of the Kaikoura District and is under the jurisdiction of the Canterbury Regional Council.

The land surrounding the alluvial fans and their catchments is rural farming land. Sheep and cattle have been farmed here since the late 1800s when the land was settled by farmers (Sherrard, 1966; pers. comm. James Murray, 23 January 2008). The lower slopes of the alluvial fans are used for pasture with only the area around the main stream channels fenced off.

State Highway 1 and the South Island Main Trunk Rail Line are situated on the coastal plain and cross all three of the alluvial fans as shown is Figure 3.7. These provide the main access routes between Picton and Christchurch. A fibre optic cable and 400 volt power lines also cross the alluvial fans at various locations (Ballard, 2008).

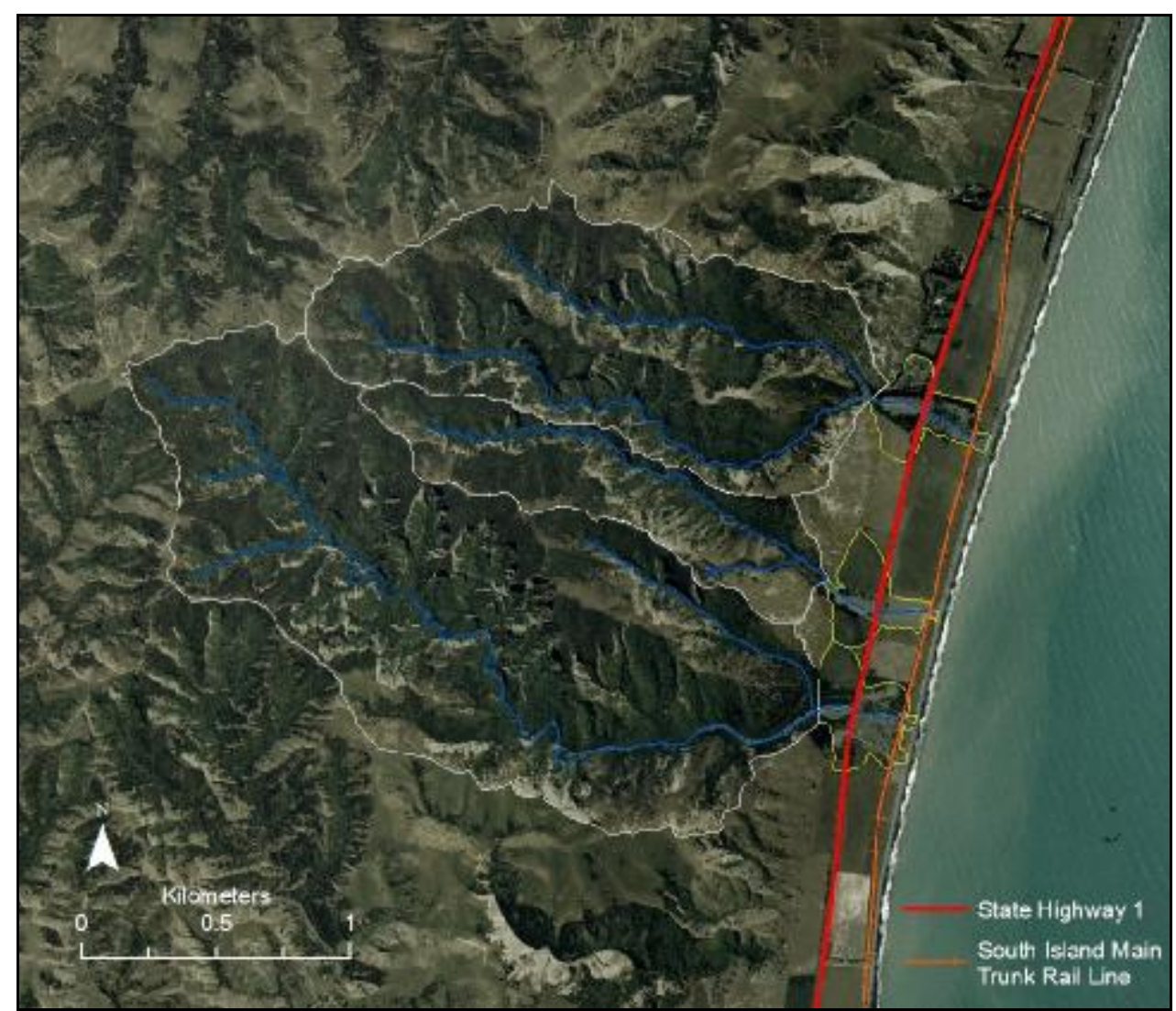

Figure 3.7: The location of State Highway 1 and South Island Main Trunk Rail Line crossing the three alluvial fans. Aerial photograph source: LINZ, 2004. 


\subsection{Geomorphology}

The three alluvial fans are located on the northeast of the South Island, New Zealand between Kekerengu and the Clarence River mouth, approximately $43 \mathrm{~km}$ north of Kaikoura and radiate from the foothills of the Seaward Kaikoura Ranges onto the coastal plain. A number of fans have formed along this coastal stretch, although these three fans are the largest. The individual areas of the three fans are $0.09 \mathrm{~km}^{2}, 0.08 \mathrm{~km}^{2}$ and $0.11 \mathrm{~km}^{2}$ respectively; each fan being comparable in area relative to the area of its catchment, even though engineering has limited the size of the fans. These fans are alluvial fans (Blair and McPherson's type II fans; see chapter two); the current dominant flow processes onto the fans are fluid-gravity flows from the streams exiting the catchments. Debris flows onto the fans may have occurred in the past and there is a possibility that debris flows may still occur. Large areas of both the left and the right sides of all three fans are inactive due to the stream channels being restricted to the centre of the fan by engineering. The stream channel is artificially entrenched, allowing water and sediment to flow further down the fan.

The catchments are relatively small in area. Catchment 3 is the largest of the three catchments, being approximately $2.46 \mathrm{~km}^{2}$ in area, while at approximately $0.56 \mathrm{~km}^{2}$, Catchment 2 is the smallest. Catchment 1 is approximately $1.46 \mathrm{~km}^{2}$ in area. The maximum elevation of the three catchments ranges between approximately $300 \mathrm{~m}$ to $350 \mathrm{~m}$. All three catchments are elongated in shape and are narrow with moderately steep to very steep relief. In many places the catchment and gully walls are canyon like, very high and almost vertical (Figure 3.8). The catchment walls are easily eroded by water flowing down the walls (Figure 3.9) due to the conglomerate rock type.

The three catchments consist of either second or third order stream networks, according to Strahler's stream order hierarchy. Both Catchments 1 and 3 consist of two small valleys. The Kawauiti Stream and an unnamed stream flow through Catchment 1 and join at the apex of Fan 1. The Kawaunui Stream is the main stream draining Catchment 3. A large unnamed tributary flows out of the smaller valley in the north east of this catchment and joins the Kawaunui Stream at the base of the catchment before flowing 
onto Fan 3. Catchment 2 consists of only one valley with an unnamed stream draining it. The streams are ephemeral, only containing surface water flow during intense or prolonged rainfall events. A recent report suggests that there may be a small amount of groundwater flow below the gravel stream beds (Opus, 2008).

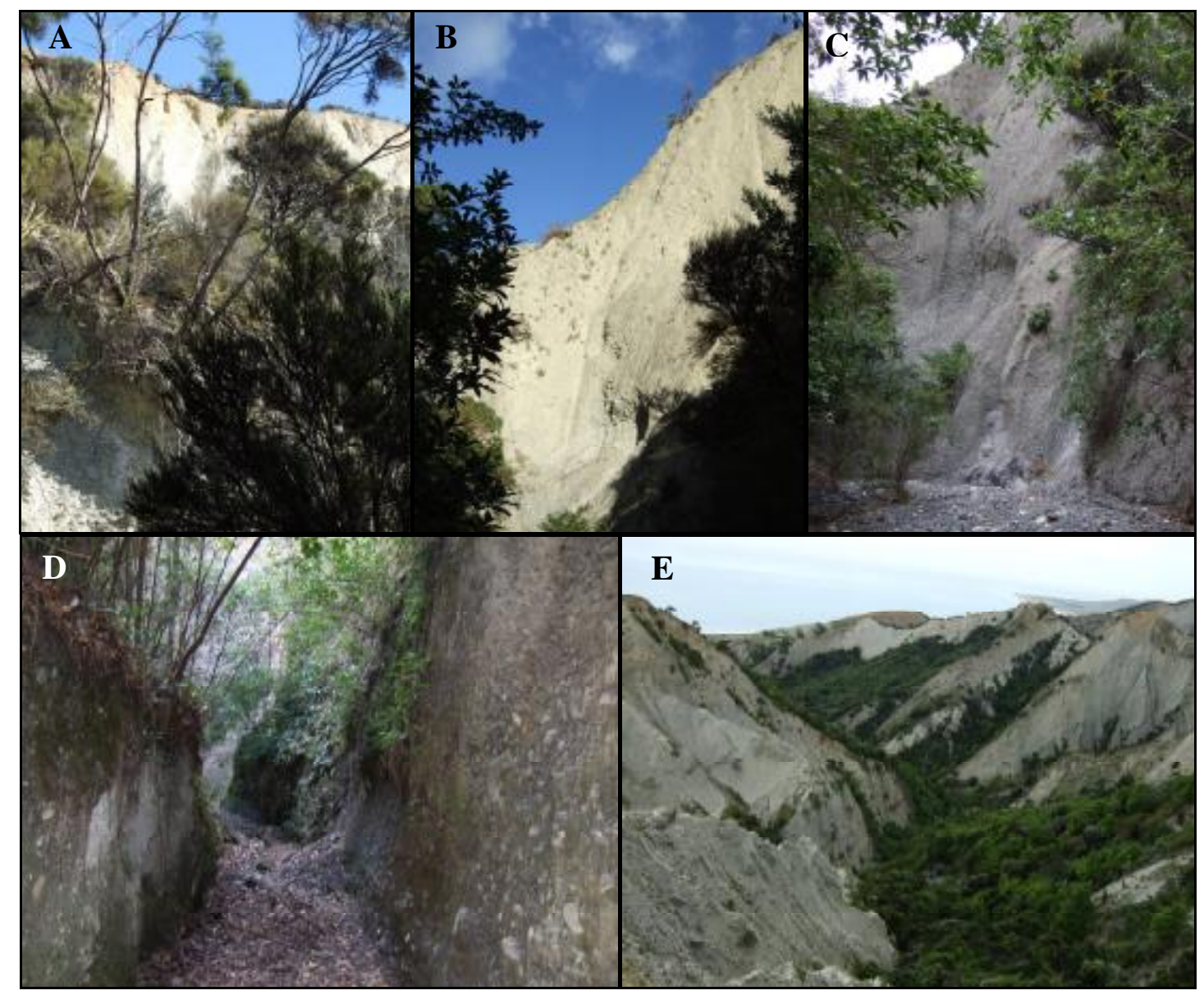

Figure 3.8: Photographs showing the terrain of Catchments 1 and 2 . The terrain of Catchment 3 is similar. A, B and C: The steep, almost vertical conglomerate slopes with very little vegetation cover. D: A section of the narrow stream channel near the back of Catchment 2, which is well connected to the catchment and gully walls. E: View from the back of Catchment 1. 


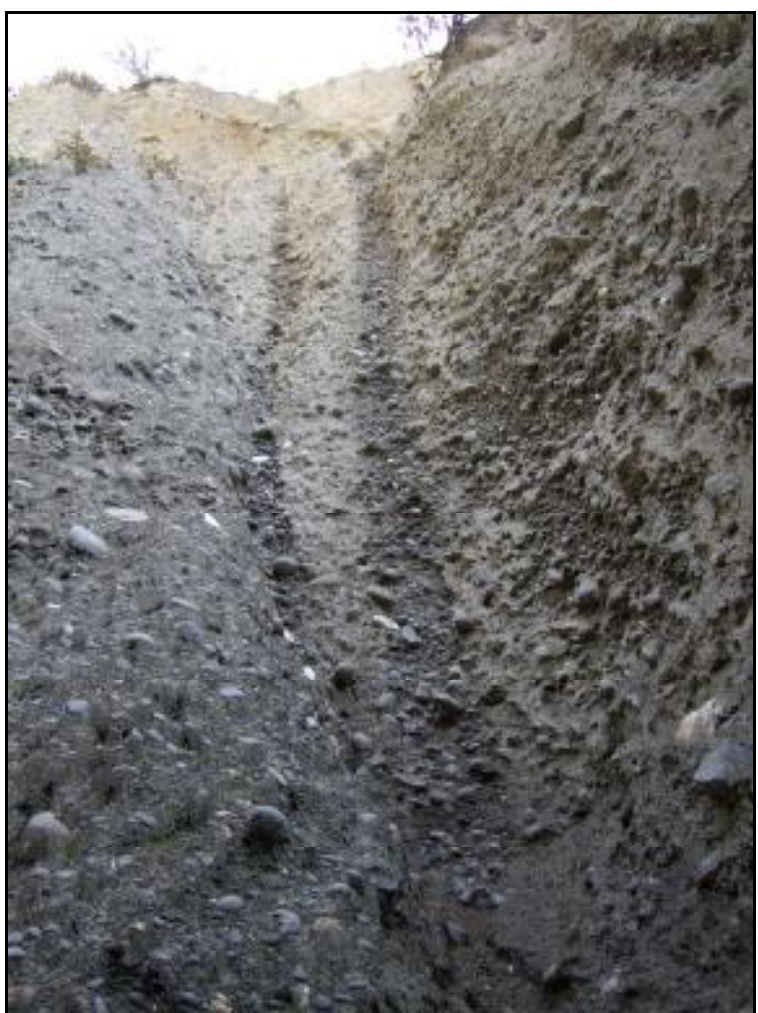

Figure 3.9: An example of erosion paths from water running down the catchment and gully walls.

\subsection{Engineering of the Fans}

As a result of State Highway 1 and the South Island Main Trunk Rail Line crossing over the alluvial fans, much engineering and maintenance work has been undertaken on the alluvial fans to try to control sediment movement onto the road and rail line.

The original highway between Blenheim and Kaikoura was a gravel road (Sherrard, 1966). When it was concreted over, the section of the road where the fan channels flowed was kept as a gravel road and smoothed out after each rain event that produced a sediment movement onto the road (Ballard, 2008). Concrete fords and culverts were placed in the road across the fan channels in 1956 and road lighting was put in place in 1962. According to more recent reports (Ballard, 2008), up until around this time, the Ministry of Works was towing vehicles across the fans during sedimentation and flood events. During 1971 three bypass bridges were placed lower down the fans away from the road. These bridges were of a similar height to the road and were often overtopped by water and sediment during flood events prior to being raised. Additionally, up until 
this time the three streams were allowed to freely avulse across the fans and the road. A report from 1969 states that before road and rail culverts and fords were established, the fans had a wide, flat appearance (Thomson, 1969). However, the streams began to be held in one place in the 1970s and the 1980s and this has continued through to the present. Stop banks were formed from bulldozing the fan sediment on either side of the channels. The channels were also cleared by bulldozing.

Much sediment control work has been carried out. During the 1970s the head of each catchment was partly re-vegetated and various sediment control projects were established by the Marlborough Catchment Board, the Railways and Roads Board and the local landowners. For example sediment retention dams were placed in the channel of the lower parts of the catchments to control channel degradation. This trapped sediment and lowered the gradient of the stream, reducing the amount of sediment that would be transported over the fords. Rock work and vegetation planting were undertaken on the lower fan to help protect the State Highway, the bypass bridges and the rail line (Thomson, 1969). In 1980, the sediment control projects were extended with more planting and additional debris dams put in place. Some land surrounding the fans was purchased from the local landowners to be used to stockpile sediment.

In 1981 the three bypass bridges were replaced by old trusses from the Buller River Bridge and relocated on the fans to be near the road (Ballard, 2008). The bypass bridges were also raised 1.5 metres at this time to allow the water flow and sediment to pass under the bridges without being overtopped (Figure 3.10). The bypass bridges are currently used an average of 28 days per year (Opus, 2008). 


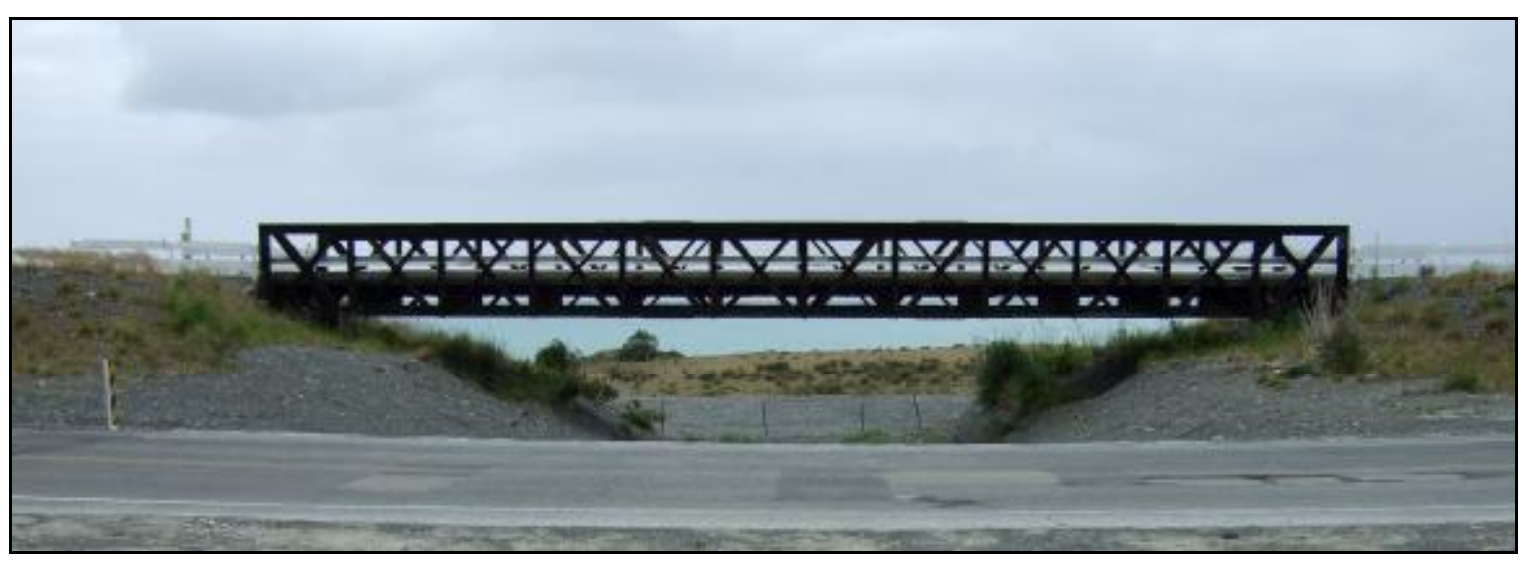

Figure 3.10: The bypass bridge that currently allows access across Fan 2 during sediment and flood events. The bypass bridges over Fans 1 and 3 are the same.

The fans have been used as a local source of gravel to be used as fill for road works and other infrastructure work around the area. Unknown amounts of sediment have been removed from the lower fans for this purpose over the last few decades.

At present there are currently plans by Transit New Zealand to upgrade this area of State Highway 1 by potentially removing the fords and placing large culverts under the road to allow the streams to flow through. The design flood for these culverts would be for approximately a 1 in 100 year return period event (Ballard, 2008).

\subsection{Past Triggering Events}

\subsubsection{Cyclone Alison}

Cyclone Alison passed close to New Zealand between the $10^{\text {th }}$ and the $14^{\text {th }}$ of March 1975, bringing heavy rainfall and high winds to areas of New Zealand. It formed off the coast of the New Hebrides Islands on the $4^{\text {th }}$ of March, moving towards the west and then changing direction to move rapidly in a south to southeast direction towards New Zealand. By the $12^{\text {th }}$ of March, Cyclone Alison was located in the Tasman Sea to the west of New Zealand and by the $15^{\text {th }}$ it had developed into a weak depression and moved past the bottom of the South Island (Tomlinson, 1975; Bell, 1976). 
However, it was the combination of the other prevailing weather patterns with Cyclone Alison that caused the extreme weather that affected large areas of New Zealand during this time (Figure 3.11). A high pressure anticyclone was located in the south of the Tasman Sea and as Cyclone Alison approached this system, strong east to northeast winds and heavy rainfall were produced (Tomlinson, 1975).

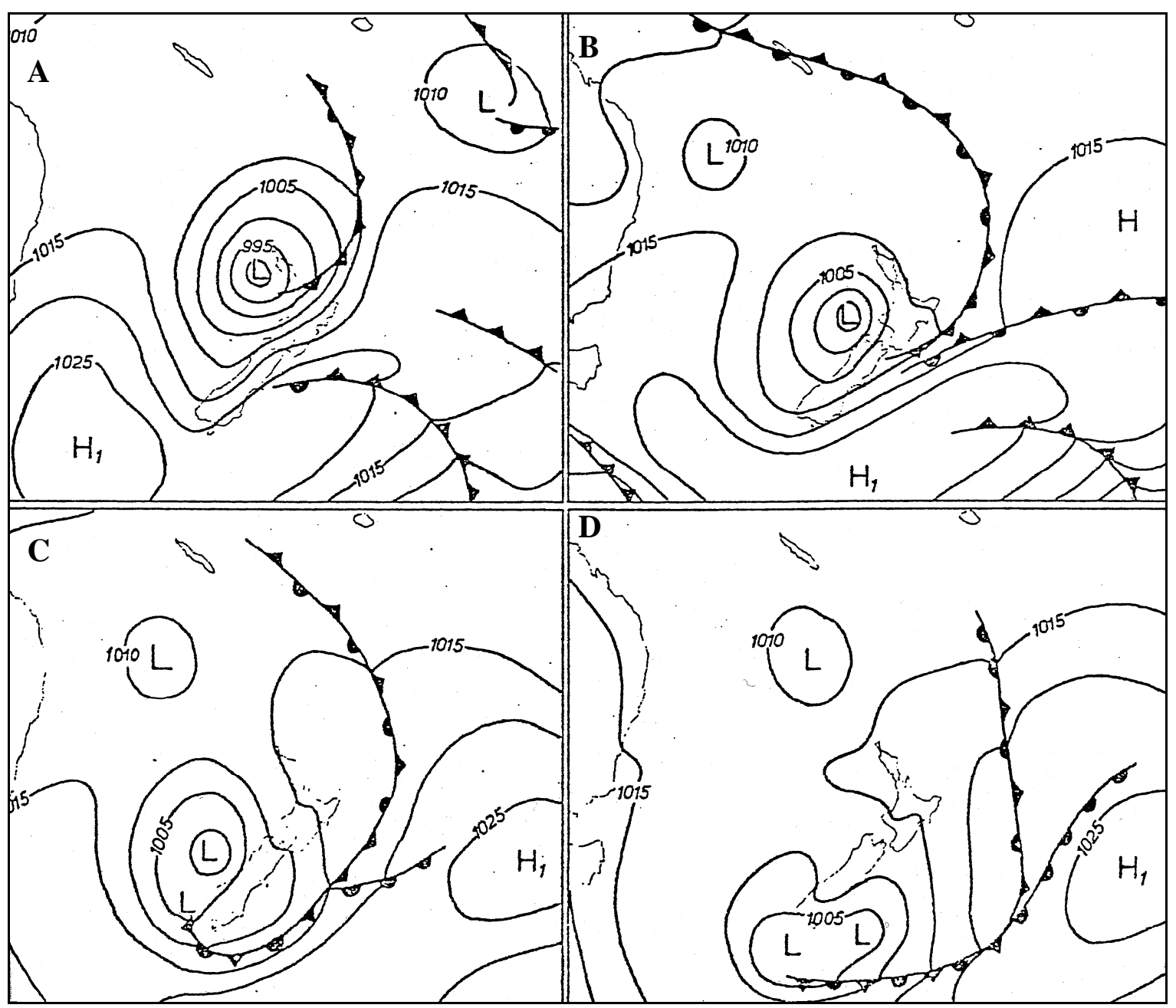

Figure 3.11: Synoptic weather maps, at midnight (NZST) of Cyclone Alison's path over New Zealand from the $11^{\text {th }}$ of March to the $14^{\text {th }}$ of March 1975. A: $11^{\text {th }}$ of March. B: $12^{\text {th }}$ of March. C: $13^{\text {th }}$ of March. D: $14^{\text {th }}$ of March (Tomlinson, 1975).

While many areas of New Zealand were affected, those on the north and east coasts of New Zealand were affected the most. The coastline between Blenheim and Christchurch received severe weather, with Kaikoura being declared a disaster zone on the $17^{\text {th }}$ of March (Bell, 1976). The Kaikoura Peninsula received intense rainfall; $205 \mathrm{~mm}$ was recorded at the Kaikoura Peninsula meteorological station in 24 hours, greater than a 1 in 100 year return period, while the six and 12 hour rainfalls were greater than a 1 in 
200 year return period (Tomlinson, 1975; Bell, 1976). Parts of the Seaward Kaikoura Ranges received greater then $500 \mathrm{~mm}$ in 24 hours on the $12^{\text {th }}$ of March (Pascoe, 1983). This rainfall caused flooding around Kaikoura and both State Highway 1 and the South Island Main Trunk Rail Line were closed for many days by landslides and washouts (Tomlinson, 1975; Bell, 1976). Wind and wave damage also occurred.

These intense rainfall events were centred near the coast where small, steep catchments were located with easily eroded lithologies, triggering mass movements (Bell, 1976). Bell (1976) noted sediment failures and aggradation of streams further down the catchments. He further states that sediment had accumulated to a thickness of approximately five metres where streams from the small, steep catchments flowed out onto the coastal plain (Bell, 1976). It is unclear, however, whether Bell is referring to the alluvial fans that are the subject of this study. Rainfall recorded at Ngaio Downs rainfall station, just to the north of the field site, was $30.5 \mathrm{~mm}$ and $195 \mathrm{~mm}$ on the $12^{\text {th }}$ and $13^{\text {th }}$ of March respectively (NIWA, 2009), which could have easily triggered sediment movement.

\subsubsection{The July and August 2008 Rainstorms}

During July and August 2008 two large heavy rainfall events occurred, triggering the most recent large movement of sediment from the catchments onto the fans. The first heavy rainfall event occurred on the $31^{\text {st }}$ of July when $143.8 \mathrm{~mm}$ of rain was recorded at the Kaikoura AWS gauging station. $175.9 \mathrm{~mm}$ of rain was recorded at the Ngaio Downs gauging station (NIWA, 2009), located to the north of the field site. Light rainfall had been recorded in the days preceding at both gauging stations. The second heavy rainfall event occurred over the period of the $25^{\text {th }}$ of August to the $27^{\text {th }}$ of August, with a total of $206.4 \mathrm{~mm}$ recorded at the Kaikoura AWS gauging station over the three day period, with the $26^{\text {th }}$ of August recording $125.8 \mathrm{~mm}$. $181.6 \mathrm{~mm}$ of rain was recorded at the Ngaio Downs gauging station over the period of the three days (NIWA, 2009). The two rainfall events were produced by depressions located over New Zealand, with easterly air flows moving off the Pacific Ocean onto the upper east coast of the South Island, as shown in Figure 3.12. 

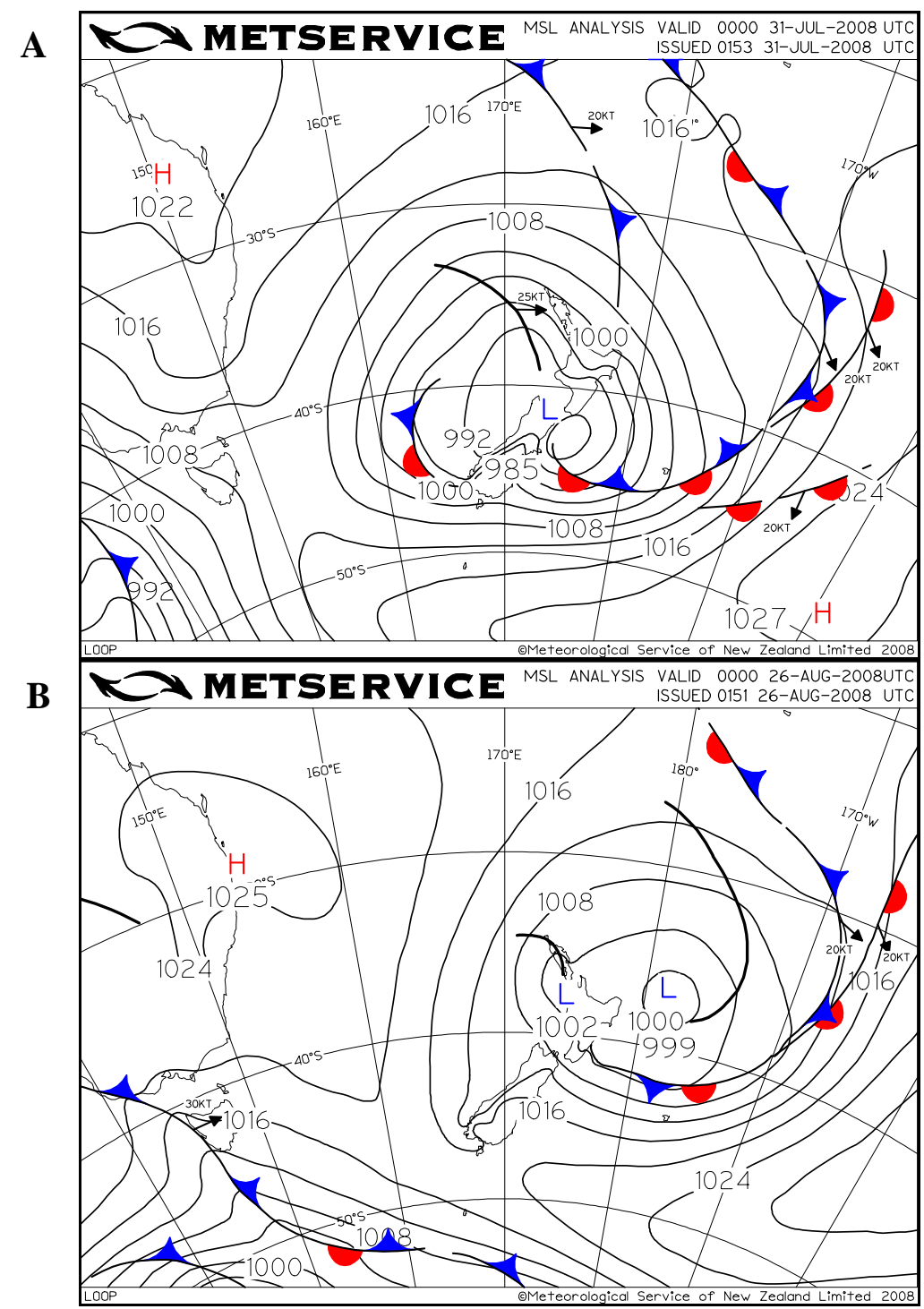

Figure 3.12: Synoptic weather maps of the weather systems that produced the rainfall events during July and August 2008. A: The weather system over New Zealand at midnight on the $31^{\text {st }}$ of July. B: The weather system over New Zealand at midnight on the $26^{\text {th }}$ of August, the day with the most rainfall during this event.

Parts of Marlborough and northern Canterbury were flooded and many landslides occurred throughout the affected area. Fresh landslides and areas of erosion were evident within the three catchments of the alluvial fans. In places the stream channels were obstructed by the landslides. A large amount of sediment was transported out of the catchments and deposited onto the three alluvial fans involved in the study. Flowing water carrying a large sediment load flowed over the three State Highway 1 fords, causing their closure for several days and the bypass bridges to be used (pers. comm. Albert Su, 10 $0^{\text {th }}$ October 2008). Figure 3.13 shows the three alluvial fans under normal conditions (A, C and E) and during the event that occurred on the $31^{\text {st }}$ of July (B, D and 
F). Records of the amount of sediment deposited onto the alluvial fans were not made. Smaller fans along the coastal plain between Kekerengu and the Clarence River mouth, many of which appeared to not have been active for a long time period, also showed evidence of sediment deposition onto them.

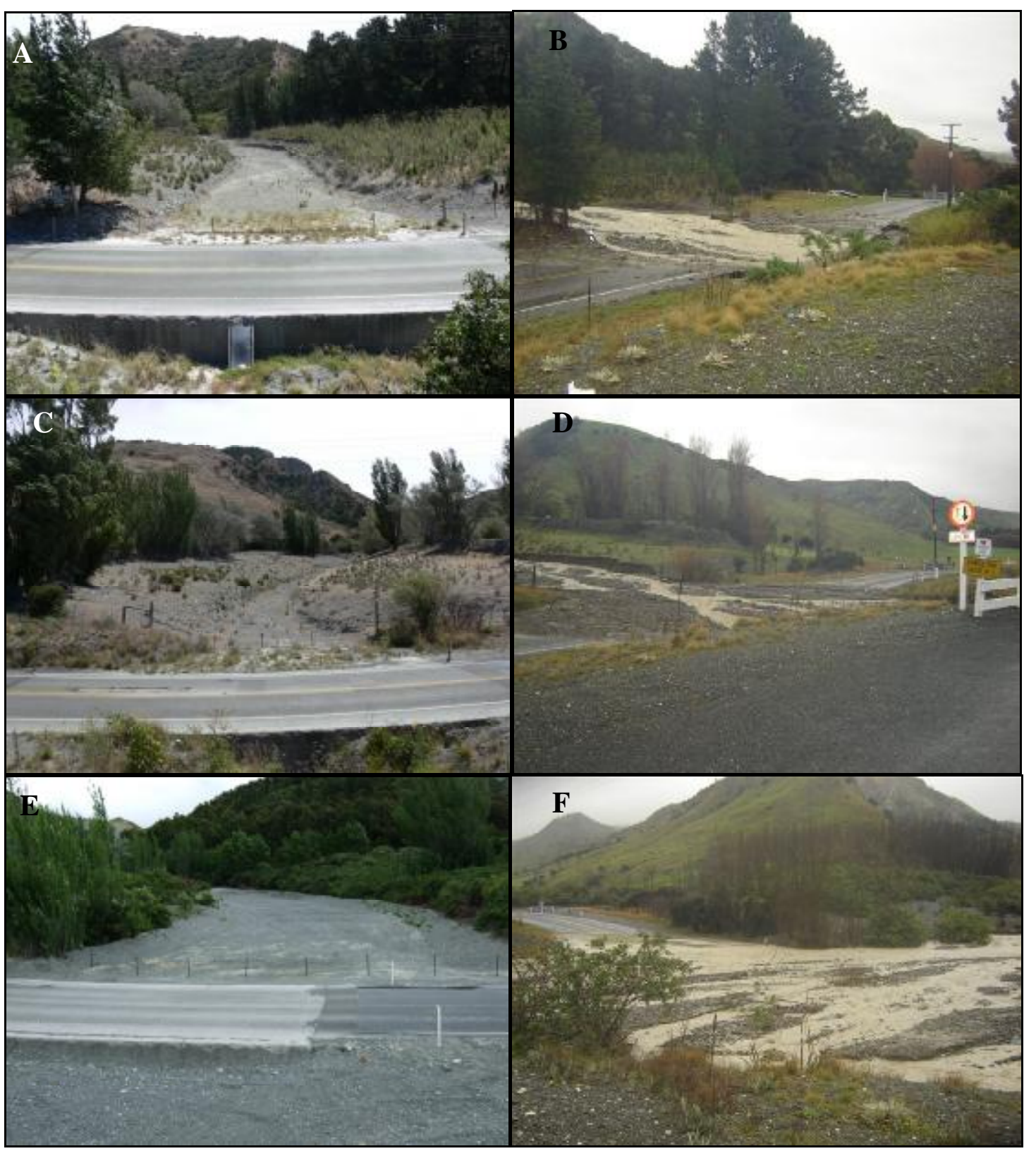

Figure 3.13: Photographs of the three State Highway 1 fords passing over the alluvial fans under normal conditions and flood conditions during the $31^{\text {st }}$ July 2008 rainfall event. Note the large amounts of sediment deposited on the road at all three fans. A: Fan 1 under normal conditions and B: during the rainfall event. C: The ford crossing Fan 2 during normal conditions and D: during the rainfall event. E: Fan 3 under normal conditions and F: during the rainfall event. (Photos B, D and F supplied by Transit New Zealand, taken on $31^{\text {st }}$ July 2008) 


\section{Chapter 4 \\ Methods Overview}

\subsection{Overview of Methods}

To understand the hazard posed by sediment events on the three alluvial fans and in doing so, determine how the potential hazard of these events could alter, it is important to understand how the temporal and spatial occurrence of erosion and entrainment events could alter. This chapter aims to provide a brief introduction and overview to the methods applied in this study. The methods are to be more comprehensively discussed in chapters five and six.

A range of methods, both in the field and the laboratory, and within a Geographic Information System (GIS) and a computer modelling environment, were applied. These methods can be separated into three key sections:

A. The longitudinal profile of the stream and sediment entrainment properties

B. Sedimentation rates

C. Modelling projections carried out with the CAESAR sediment redistribution model

Each of these key sections are displayed in Figure 4.1, presenting each of the methods undertaken to evaluate each of the key sections and how these go towards investigating the aims of this study.

The first key section involves identifying spatially "where" current and likely sediment erosion and entrainment can occur within the catchment. Erosion can be concentrated at the location of a knickpoint, leading to channel degradation. The identification of knickpoints within the longitudinal profiles of the stream channels can be used to determine where sediment inputs into the stream are originating. A report on the alluvial fans north of Clarence, by the Marlborough Catchment Board (Thomson, 1969), refers to the main source of sediment being transported onto the fans as originating from the degrading of the stream channel due to the modification of the fan surface by the State 
Highway and the regular reshaping of the alluvial fans by bulldozers. A knickpoint, initiated from these artificial changes to the base level of the catchment stream may be noticeable within the channel profile. If so this would indicate that a large proportion of the sediment input into the streams is originating from the stream channels eroding downwards. If a knickpoint could not be detected within the stream profile, then it is likely that a large proportion of the sediment deposited onto the alluvial fans would be originating from the catchment or gully walls.

Variables which evaluate the potential for sediment entrainment and transport along the stream further enable areas of likely erosion to be identified. Some areas along the stream channel may be more exposed to flows capable of initiating sediment entrainment. Sediment sizes may vary along the stream channel, with areas containing smaller clasts being more susceptible to entrainment than areas containing larger clasts. Areas within the stream channel which consist of dominantly smaller sized sediment are more likely to be eroded more often. An analysis of sediment sampled along the stream channel identified the range of sediment available. Employing the longitudinal profiles and the rational method for discharge estimation, the potential power of the stream flow and the shear stress caused by the flow of water over the stream bed were determined. Additionally, the critical shear stress required for the entrainment of selected sediment sizes from the sediment samples was estimated. A comparison between these variables can identify areas were sediment could be entrained. This would further indicate the flow conditions required within the stream for hazardous sediment events to be initiated.

The second key section involves determining rates of sediment accumulation onto the fans since their formation, through a morphological interpretation of the field site. Construction of a Digital Elevation Model (DEM) of the fans allows an estimation of the volume of material stored within them. This, along with an estimation of the age of the fans allows an annual sedimentation rate to be estimated. Additionally, rates of sediment movement during the recent rainfall events in July and August 2008 have been estimated through observation of sediment deposition depth and use of the DEM.

The final key section involves determining how the temporal frequency of potential hazardous events and the amount of sediment delivery involved in these events will 
alter in relation to climatic changes. The landscape evolution model CAESAR is employed to simulate current and future projections of sedimentation events onto the fans. Two differing rainfall runoff regimes were used; one reflecting the current climate and the other reflecting a possible altered climate in 2071. From the model output, differences in the frequency of erosion events and annual sedimentation rates can be evaluated.

This, when combined with the results of the sedimentation rate estimates, enables a comparison of previous, current and projected future rates of sediment delivery to the alluvial fans and an indication of whether the rates have altered or are likely to alter in response to climate change. 


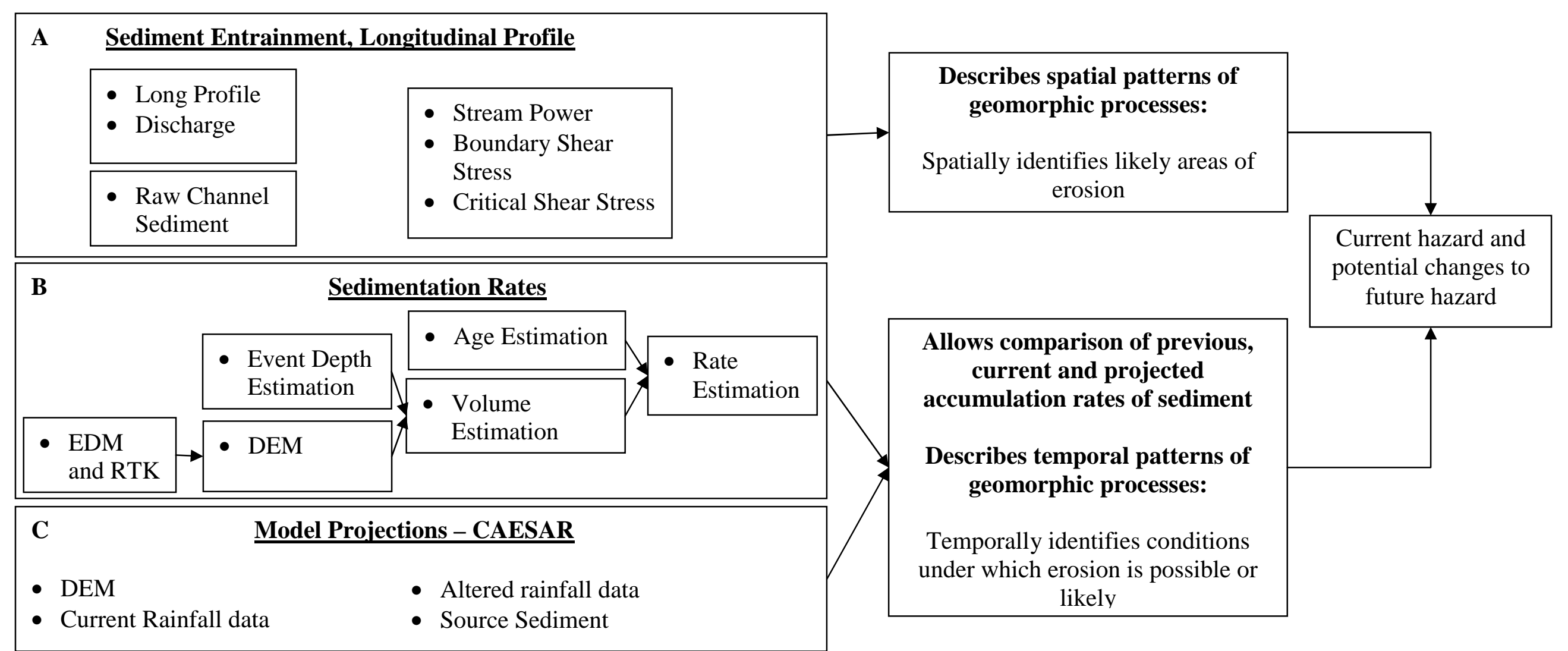

Figure 4.1: Flow chart showing an overview of the methods employed in this study, and their interrelations. Box A shows the methods used to determine sediment entrainment through collecting a longitudinal profile, a raw sediment analysis and the use of the rational method to estimate discharge. From these, stream power, boundary shear stress and critical shear stress were determined. This allows for likely areas of erosion to be identified at times of flow discharge. Box B shows the methods used to determine sedimentation rates. Field work allowed a DEM to be made and from this an estimation of sediment volume made. This together with a determination of the maximum age of the fans sedimentation rates are estimated. Box $\mathrm{C}$ identifies the data needed to enable the CAESAR sediment redistribution model to be run. When boxes B and C are combined a comparison of sediment accumulation rates and the frequency of sediment transport can be carried out. This, when combined with the spatial patterns of erosion will help describe current and future potential hazards. 


\subsection{Site Selection for Field Work}

The fans north of the Clarence River Mouth are shown in Figure 4.2. Fan 2 and its corresponding catchment were chosen as the main site for field work for this study. This was due to this catchment having a greater ratio of bare sediment to vegetated land when compared to that of Catchments 1 and 3 . The catchment is the smallest of the three, meaning there is less distance for the sediment to travel to get into the main stream channel and out onto the fan. This also makes the entire catchment much more accessible by foot. Additionally there is an absence of large inaccessible vegetated areas located on the fan, and both the fan and its catchment are easily accessible from the road. Due to the three fans and catchments having similar geology, climate, vegetation and land use, the results from Fan 2 and its catchment will be broadly relevant for the Fans 1 and 3 and their respective catchments.

Catchment 2 was divided into ten sub-catchments (A to J) for the determination of sediment entrainment within the stream (Figure 4.3). The ten sub-catchments were selected using a 2004 coloured aerial photograph and a topographic map on ArcMap (version 9.2). The sub-catchments are located where major topographic features are located, for example below the confluence of a tributary with the main stream channel or where spurs meet the narrow catchment floor. Additionally, changes in the vegetation cover were looked at. Each sub-catchment extends to the back of Catchment 2.

Catchment 1 was used to carry out a second longitudinal profile of the stream channel. A fourth fan (Figure 4.2), where a recently active fan is superimposed on a truncated relict fan, was used to estimate geological sedimentation rates. 


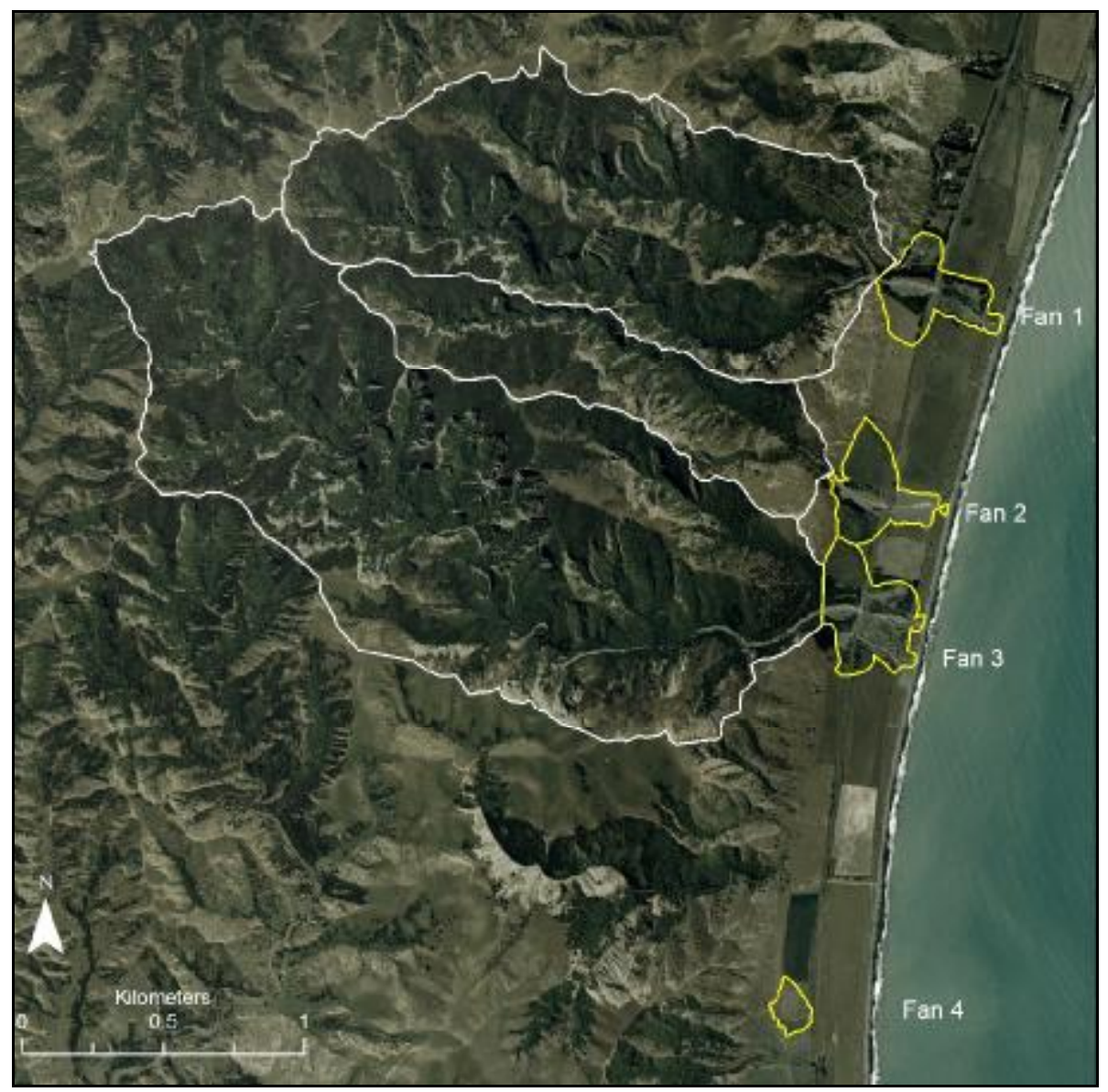

Figure 4.2: The fans north of the Clarence River mouth. Fan 2 and the corresponding catchment is the main site for field work to be carried out. Fan 4 is located to the south of the main three fans. Aerial photograph source: LINZ, 2004.

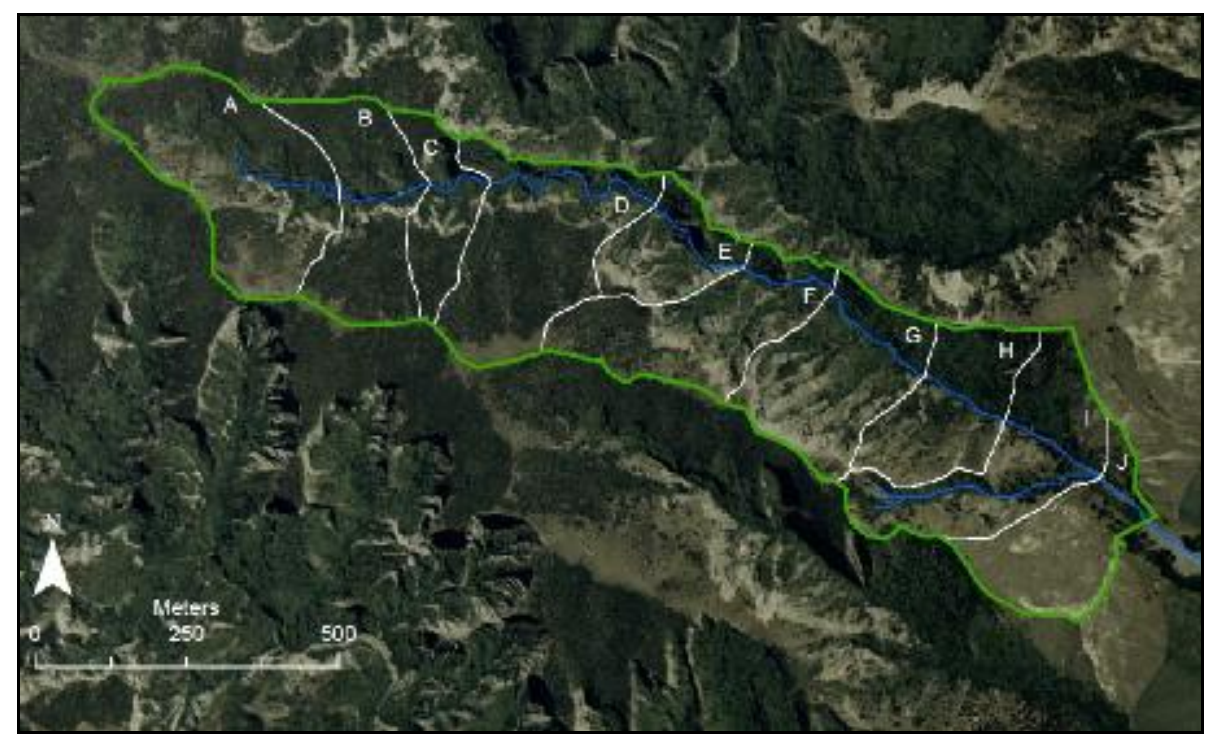

Figure 4.3: Catchment 2 divided into sub-catchments A to J. Each sub-catchment extends from the white line to the back of Catchment 2. Aerial photograph source: LINZ, 2004. 


\subsection{Methods Structure}

Due to the wide range of methods undertaken to investigate the aims of this study, the description of methods will be separated into two chapters, and results will be presented alongside. Chapter five will explain the methods carried out to determine where sediment is originating from. It will include a discussion of how longitudinal profiles were taken, and provides information on the calculation of stream power, boundary shear stress and critical shear stress. Chapter six outlines the methods carried out to describe the temporal patterns of sedimentation events on Fan 2. The methods undertaken to determine sedimentation accumulation rates onto the fan are described. Chapter six additionally introduces a spatially distributed sediment transport model called CAESAR (Box C, Figure 4.1). It will describe and outline what the model does, how the model works, which data are required to operate CAESAR and the preparation of these data and the running of the model.

While, for convenience, the results from each method are presented in Chapter five and Chapter six respectively, their interpretation will be presented in Chapter seven. 


\section{Chapter 5}

\section{Likely Areas of Erosion:}

\section{Longitudinal Profiles and Sediment Transport}

\subsection{Introduction}

Chapter 4 provided an overview of the range of methods to be applied, discussing how the results of each of the methods will go towards answering the main aims of this study. The current chapter presents the methods carried out to determine where sediment is originating from. The presence or absence of a knickpoint moving through the channel longitudinal profiles of Catchments 1 and 2 may indicate whether sediment is originating from the down cutting of the stream channel or from the catchment or canyon walls. Stream power values are used to evaluate which areas of the stream channel have the required amount of energy available to carry out sediment erosion and transport. An analysis of the sediment within the stream channel determined what sediment is available for transport at times when there is water flow within the stream channels, while boundary shear stress and critical shear stress variables are calculated to evaluate the potential for the entrainment of varying calibre sediment at selected locations along the stream channel.

This chapter consists of eight main sections. Section 5.2 discusses the methods carried out to construct the longitudinal profiles. The profile results are displayed in section 5.3. Section 5.4 provides information on the calculation of stream power while the results are presented in section 5.5. Section 5.6 discusses how an analysis of the channel sediment was carried out. The results of the sediment analysis are then presented in section 5.7. The methods undertaken in the calculation of boundary shear stress and critical shear stress are outlined in section 5.8 and the results of both of these calculations are presented in the final section, section 5.9. 


\subsection{Longitudinal Profiles}

Knickpoints within the longitudinal profile of a stream channel are short sections of the stream channel where the gradient is much steeper than the neighbouring stream sections. Knickpoints can be initiated by the lowering of base levels, in which the stream channel attempts to readjust its slope back to a graded profile by incising the stream channel at the location of the knickpoint (Charlton, 2008; Davies and McSaveney, 2008). This erosion, concentrated at the knickpoint, causes the knickpoint to migrate upstream towards the back of the catchment, becoming less evident in the longitudinal profile. Base level lowering on fans can be caused by tectonic uplift, changes to sea or lake levels or anthropogenic alterations to the fan or within the catchment. An apparent uplift of the upper part of the fan or the catchment, through the down cutting of the fan surface for construction purposes artificially lowers the base level. A knickpoint may be formed and start to migrate along the stream channel. The cutting of the fan surface for the construction of the State Highway 1 concrete fords across the fans in 1956 and the continual clearing and reshaping of the stream channels, which extends to a point near the apex of the fans, would have lead to the initiation of a knickpoint migrating through the catchments the fans in this study, as is suggested by the degradation of the stream channels reported in 1969 (Thomson, 1969). The presence or absence of a knickpoint within the stream channel can be used as an indication of where sediment inputs are originating from.

\subsubsection{Surveying with the Engineering Level}

A wide range of field equipment could have been used to carry out the development of the longitudinal profiles. However, there were problems associated with the use of many of these within the selected catchments. The amount of vegetation and the close proximity of the steep canyon walls prevented an Electronic Distance Meter (EDM) from easily being used and would have required the frequent and time consuming moving and resetting up of the EDM. Further an EDM would have been difficult to carry through the catchment. Similarly the vegetation and the close proximity of the steep canyon walls restricted the Real-Time Kinematic (RTK) Global Positioning 
System (GPS) unit from gaining satellite signal. Both pieces of equipment would have produced an accurate, detailed longitudinal profile, but unfortunately were not able to be used. Small hand held GPS units were also unable to gain a strong satellite signal, and in any case could provide elevation estimates only to within 10 to 20 metres, which is not to the level of accuracy required. An alternative approach to developing longitudinal profiles of the stream channels was the use of an engineering level. The engineering level allowed large areas to be easily and relatively quickly surveyed. Vegetation and sharp turning corners blocking the line of sight of the engineering level through to the staff potentially required the moving of vegetation and careful positioning of the engineering level and staff. While this is largely a reliable instrument, there is a limit to the distance that the staff can be read away from the engineering level. The staff can be extended a maximum of five metres high and if the engineering level can not locate the top or bottom of the staff, then either the staff or engineering level needs to be moved close to the other piece of equipment. Shifting of the engineering level is needed to survey past corners or vegetation but this is more easily achieved than would be the case with an EDM. Small inaccuracies may result from this movement of the level and staff.

\subsubsection{Profile Collection}

The longitudinal profiles of the main stream channels were surveyed for Catchments 1 and 2. The profiles were measured using an engineering level and staff (Figure 5.1). Each long profile was surveyed along the centre of the stream channel and began on the western side of the rail bridge, moving up the fan, crossing the road and into the catchment. The channel was divided into relatively straight sections to allow a visual sight between the engineering level and the staff for readings to be taken. In areas where vegetation obstructed the line of sight, branches were cut away. 


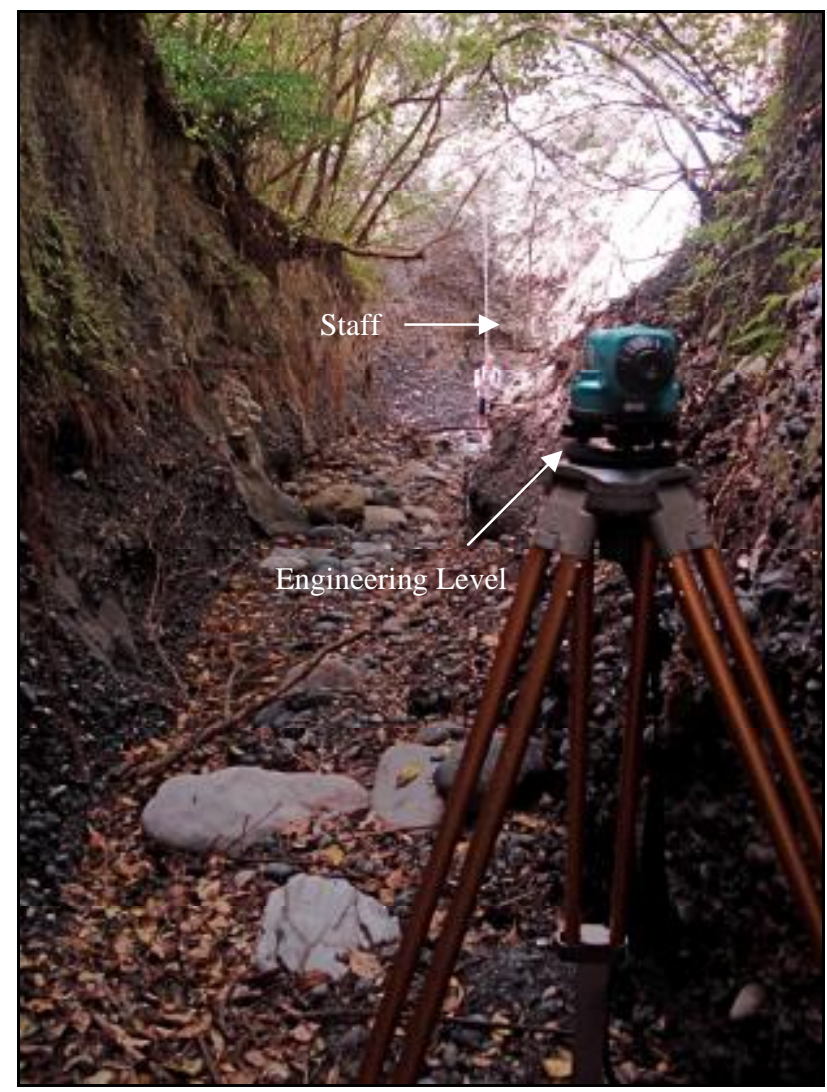

Figure 5.1: The engineering level in the foreground surveying the longitudinal profile of the stream channel in Catchment 1 to the measuring staff in the distance.

The distance and change in elevation to the staff were recorded at each staff point along the transect (Figure 5.2). The data were processed and the profiles drawn up using Microsoft Excel (version 2003). For the equations used to process the data see Appendix I.

Ideally the tributaries to the main stream channels would have been surveyed to determine if a knick point was moving up them as it moved up the main stream channel. These were not completed due to the amount of vegetation growing in the channels and their steepness. Additionally the rainstorms of July and August 2008 generated a large amount of loose material that is sitting in and around these tributaries making it difficult to get back into the tributaries. 


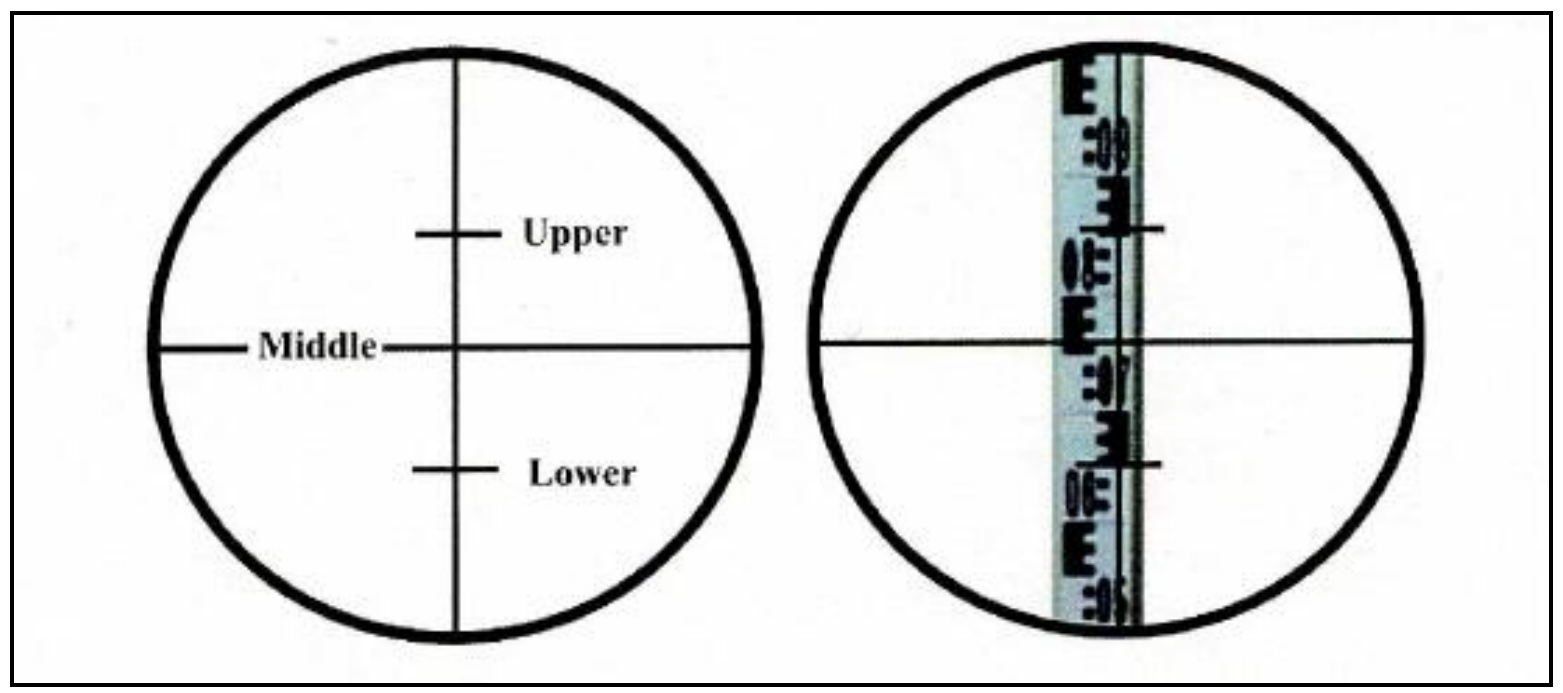

Figure 5.2: Three cross-hairs are visible when sighting through the engineering level. Values can be read off the staff for each of these. The middle cross-hair is the height of the staff compared to the engineering level. If the cross-hair is low on the staff compared to the height of the level, the level is on higher ground than the staff. Conversely if the cross-hair is higher on the staff than the height of the level, the level is on lower ground than the staff. The upper and lower cross-hairs are used to determine the distance of the staff away from the level. This is calculated as the upper cross hair minus the lower cross hair multiplied by 100 .

\subsection{Longitudinal Profile Results}

\subsubsection{Unnamed Stream, Catchment 2}

The longitudinal profile of the unnamed stream that drains Catchment 2 was surveyed from the western side of the rail bridge and into the catchment, ending near the back of the catchment where the main channel divided into two small tributary channels (Figure 5.3). A GPS reading was unable to be taken at the end of the profile due to limited satellite signal and so the location of the end of the profile was estimated with reference to the last GPS reading and the total distance of the profile. The total length of the recorded stream profile is $2.076 \mathrm{~km}$ and rises $179.9 \mathrm{~m}$ from the start point to the end point of the profile (Figure 5.4). 


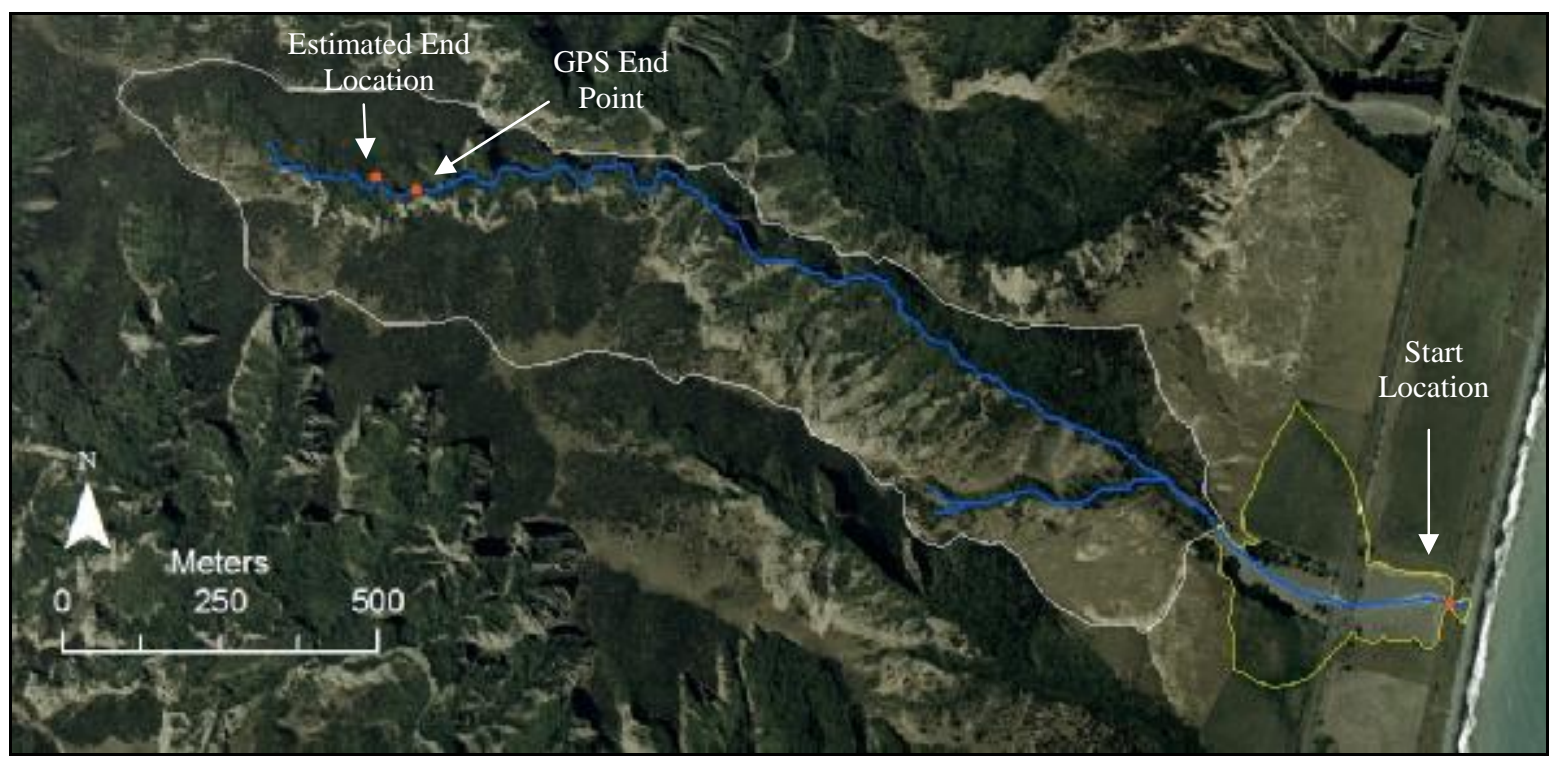

Figure 5.3: The location of the longitudinal profile through Catchment 2. The profile followed the main channel of the unnamed stream. The tributary near the base of the catchment was not included in the profile. Aerial photograph source: LINZ, 2004.

The profile appears to be very regular. It is important to note that the profile is for the entire length of the stream system and not just the stream channel on the fan or the stream channel within the catchment. The average gradient of the whole profile is 0.09 metres per metre. The profile initially rises evenly for a distance, flattens out at approximately $1.3 \mathrm{~km}$ along the profile (distances are from the start of the profile) and continues to rise evenly after this point. There is no evidence of a knickpoint moving back along the stream channel, although several small artificial and natural steps were evident. Two artificial steps in the profile are located on the fan: a 0.87 metre vertical step below where State Highway 1 passes over the fan, located at $0.189 \mathrm{~km}$ along the profile, and a bulldozed ramp 5 metres wide by 1.35 metres high near the apex of the fan, $0.350 \mathrm{~km}$ along the profile, where the stream channel had been cleared of sediment. A number of small natural steps occur along the length of the profile where boulders, vegetation debris or small landslides have blocked the stream channel and sediment has built up behind these blockages. These natural steps are not enough to affect the overall profile or gradient of the stream channel and are therefore not considered as knickpoints.

On the fan the active stream channel is approximately 21.5 to 22.7 metres wide, and is relatively straight due to the channel being artificially controlled. Past the limit of the maintained channel, on the upper part of the fan and extending a short way back into the 
catchment, the stream channel becomes slightly narrower and an incised thalweg is evident within the active channel. From $0.591 \mathrm{~km}$ along the stream profile the entire width of channel becomes active with the canyon's walls becoming the stream banks. Travelling along the profile the stream channel becomes narrower with a width of 3.1 metres at the end of the profile; although in places the channel width is narrower. Fourteen small tributaries flow into the main stream channel from both sides of the catchment. 


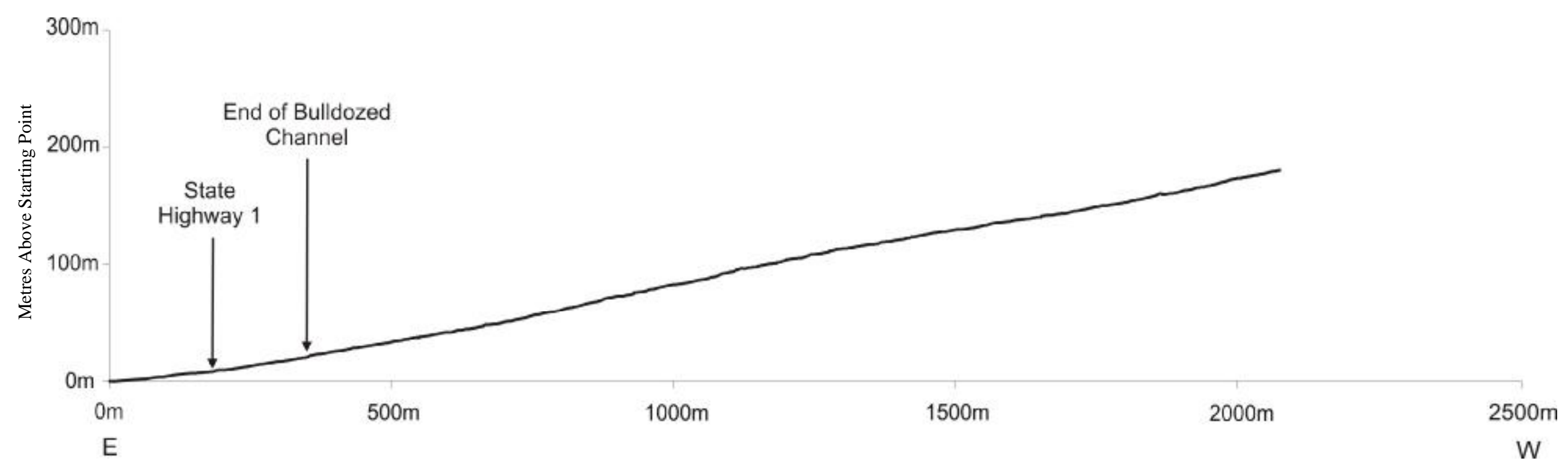

Figure 5.4: The longitudinal profile of the unnamed stream located in Catchment 2 starting in the east on the western side of the rail bridge on the alluvial fan and moving west over State Highway 1 and into the catchment. Vertical exaggeration factor: 2.x 


\subsubsection{Southern Branch of Kawauiti Stream, Catchment 1}

A longitudinal profile along the south channel of the Kawauiti Stream in Catchment 1 was also undertaken. A knickpoint may, in fact, have moved through to the back of the Catchment 2, indicating that the stream profile had already adjusted itself to the artificial change in base level from State Highway 1. The Kawauiti Stream in Catchment 1 is longer, thus a knickpoint may not have reached the back of the catchment.

The profile was surveyed from the western side of the rail bridge and into the catchment's southern branch, ending near the back of the catchment (Figure 5.5). At the apex of the fan, the Kawauiti Stream divides into two main stream channels. The southern channel is the wider at this point and is the longer of the two channels so, for the purpose of constructing a long profile, was considered to be the main stream channel. A large landslide and dense vegetation blocked the channel at the end of the longitudinal profile, making it difficult to proceed past this point. A GPS reading was unable to be taken at this point and so the location of the end of the profile was estimated with reference to the last GPS reading and the total distance of the profile. The total length of the recorded stream profile is $2.785 \mathrm{~km}$ and the profile rises 202.15 $\mathrm{m}$ from the start point to the end point of the profile. Similar to the profile of the unnamed stream in Catchment 2, this profile also appears to be very regular as it is for the entire length of the stream system. 


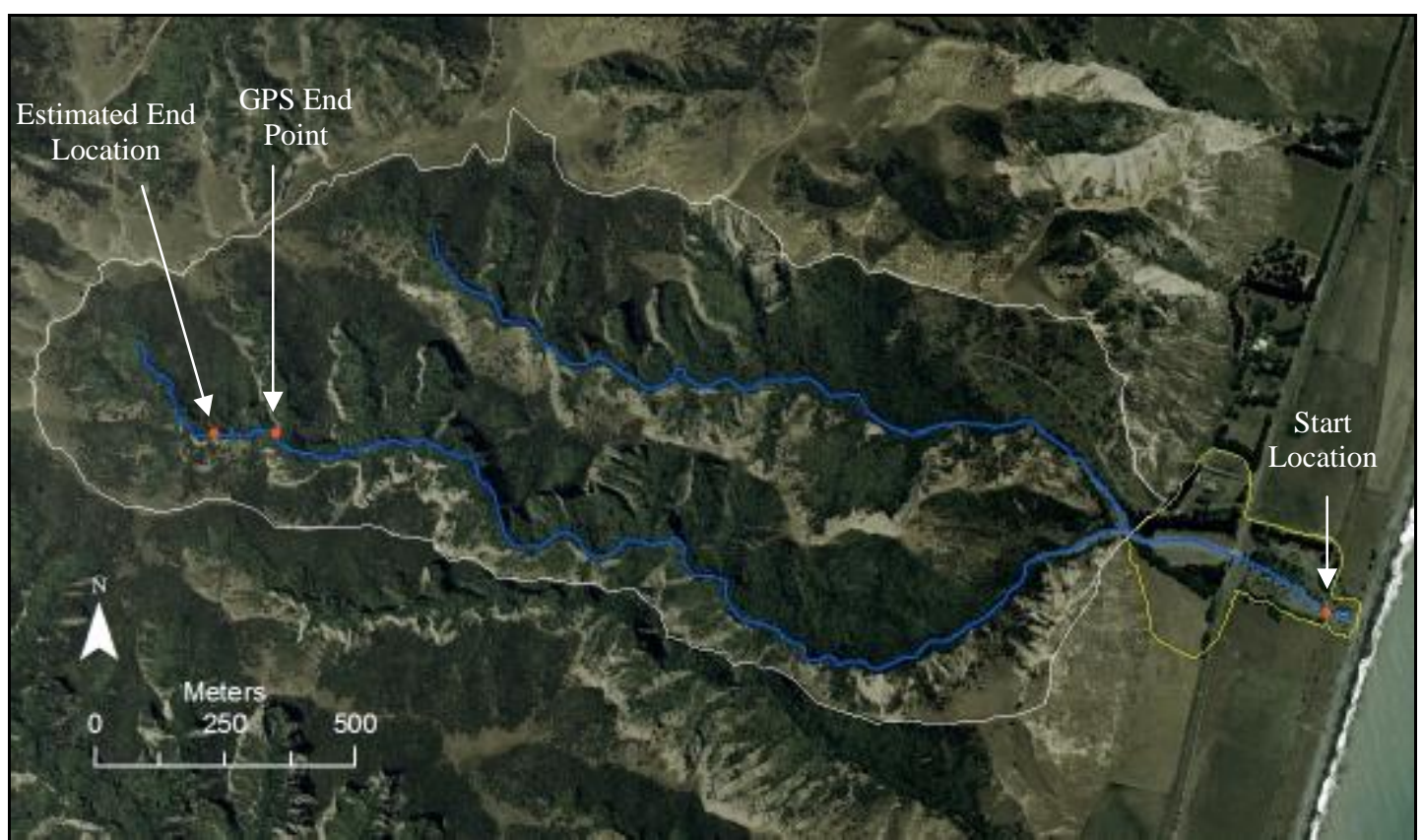

Figure 5.5: The location of the longitudinal profile through Catchment 1. The profile followed the southern branch of the Kawauiti Stream. A longitudinal profile the northern channel of the Kawauiti Stream was not taken. Aerial photograph source: LINZ, 2004.

There is no evidence of a knickpoint moving back along the Kawauiti Stream channel (Figure 5.6). The profile rises with a steady gradient, with a gradient of 0.07 metres per metre. Similar to the profile of the unnamed stream in Catchment 2, the Kawauiti Stream profile has two small artificial steps evident from where State High 1 passes over the fan and at the end of where the fan channel has been bulldozed. These are located at $0.213 \mathrm{~km}$ and $0.387 \mathrm{~km}$ along the profile respectively. A number of natural steps occur in the profile due to boulders, vegetation debris and small landslides blocking the channel. All but one of these steps are not considered a knickpoint. A 2.6 metre natural step is evident at $0.930 \mathrm{~km}$ along the profile. This has resulted from a blockage of vegetation and logs, behind which sediment has become trapped and is therefore not considered to be evidence of a knickpoint eroding back up the stream channel.

The active stream channel on the fan is artificially wide, similar to that on the fan of Catchment 2. Upstream of the confluence with the northern channel, the Kawauiti Stream's the southern channel gradually narrows and the stream channel fills the narrow valley floor. Nine small to moderate tributaries flow into the southern stream channel, a majority from the northern side. 


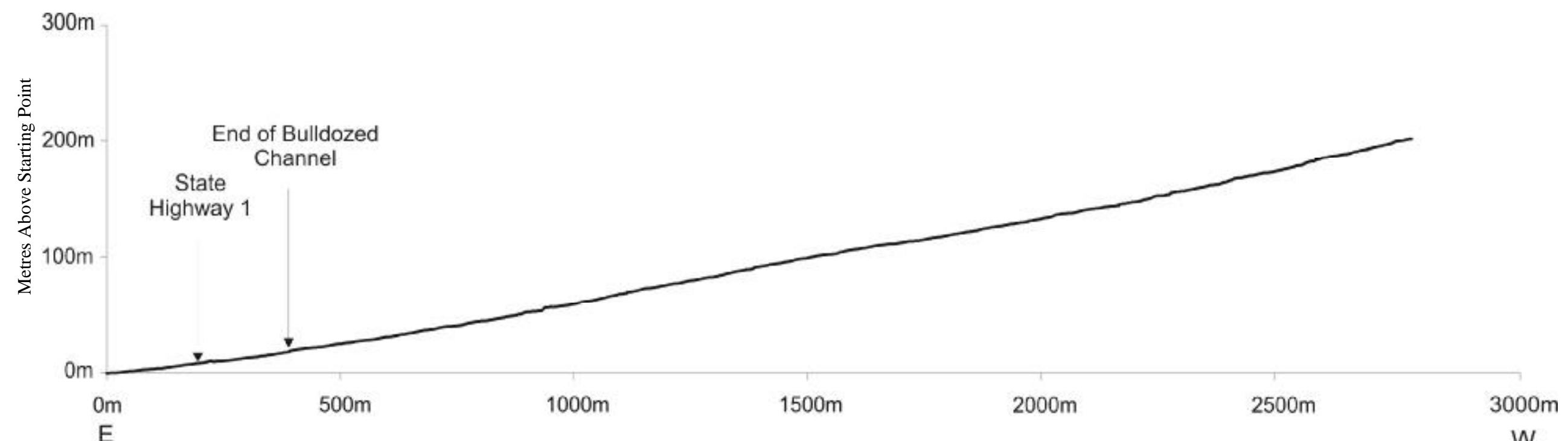

Figure 5.6: The longitudinal profile of the southern channel of the Kawauiti Stream located in Catchment 1 starting in the east on the west side of the rail bridge on the alluvial fan and moving west over State Highway 1 and into the catchment. Vertical exaggeration factor: 2.4x. 


\subsection{Stream Power}

The current section discusses the methods undertaken to determine likely areas of sediment erosion within the stream channel. Stream power is a variable which can indicate whether there is enough energy within the stream flow for work to be performed for sediment entrainment and transport within the stream channel. Stream power values will be calculated for Catchment 2 and used to evaluate where areas along the stream channel are which have energy available for sediment entrainment and transport. Stream power values were calculated for the outlets of each of the ten subcatchments, A to J, along Catchment 2 (see Figure 4.3). All the data in this section were processed and analysed using the Geographical Information System (GIS) ArcMap (version 9.2) or Microsoft Excel (version 2003).

Stream power is the rate of potential energy available in a stream to carry out work to transport sediment (Summerfield, 1991; Knighton, 1998; Worthy, 2005; Charlton, 2008). The equation for stream power is:

$$
\Omega=\rho g Q s
$$

Equation 5.1

where $\Omega$ is stream power per unit stream length, $\rho$ is the density of water, $g$ is the acceleration of gravity, $\mathrm{Q}$ is the discharge of the stream and $\mathrm{s}$ is slope of the channel. Variations in the density of water $\left(1000 \mathrm{~kg} / \mathrm{m}^{3}\right)$ and the acceleration of gravity $(9.8$ $\mathrm{m} / \mathrm{s}^{2}$ ) are both negligible and therefore these variables can be treated as constants in the equation.

Stream power can vary under differing flow conditions, for example a stream will have higher stream power when it is in flood than when it is not in flood. A greater stream channel gradient will also cause stream power to be higher (Summerfield, 1991). Therefore, stream power varies from the head of the catchment to the stream outlet due to the increase in discharge entering into the stream system as tributaries join up with the main water course and the characteristics of the catchment change. 
Unit stream power is a measure of the energy a stream has available to carry out work per unit area of the stream channel bed (Leopold et al., 1964; Summerfield, 1991; Charlton, 2008). Unit stream power is calculated by:

$$
\omega=\Omega / w
$$

Equation 5.2

where $\Omega$ is the total stream power of the stream and $\omega$ is the channel width. Unit stream power removes the effect of scale when comparing the amount of available stream power between or within streams, as it is measured for a unit area of the channel bed (Charlton, 2008). This means that the potential energy available for sediment transport can easily be compared between a sample site at the catchment headwaters and a sample site at the catchment outlet. For a given stream power, a narrow section of a stream channel will exhibit high unit stream power while, for the same given stream power, a wider section of channel will exhibit lower unit stream power values.

Stream power is used to give an indication of the potential energy available within the unnamed stream channel under differing flow conditions. Variables necessary for the calculation of stream power are stream discharge, the slope of the stream channel, the density of water and the acceleration of gravity. Due to the density of water and the acceleration of gravity being constants, only the stream discharge and the slope of the stream channel are required to be determined for the calculation of stream power. Channel width is further required for the calculation of unit stream power.

\subsubsection{Channel Slope}

The slope of the channel for a short distance upstream of the outlet of each subcatchment was determined from the longitudinal profile collected of the main stream channel, using the 'horizontal slice' approach described by Jain et al. (2006). In the 'horizontal slice' approach the value representing the horizontal length of each section of the stream channel, used for the calculation of the channel slope, is kept constant, while the value representing the vertical rise of the stream channel over this set horizontal distance can be variable. For example if stream power was to be determined 
at three locations along a stream profile, the horizontal length used for each stream section could be kept constant at 20 metres but the change in the vertical height of the stream profile at each of these three locations may vary over this 20 metre length. For example the three locations may have a change in vertical height of 5 metres, 0.5 metres and 1 metre. Jain et al. (2006) note that this approach is appropriate for determining the channel slope as stream power is a calculation of the available power for a unit length of the stream channel.

The point of the profile recorded closest to between 20 to 25 metres horizontally from the outlet upstream of each sub-catchment from the longitudinal profile was used. The horizontal value was not set to be exactly constant due to the points recorded for the construction of the longitudinal profile not being a constant distance apart. The small horizontal length of 20 to 25 metres upstream of the point being considered was used rather than a longer distance upstream of the point being considered, such as 200 metres, as it would average out important slope changes (Jain et al., 2006). A longer horizontal length would also cause an overlap between sub-catchment outlets as the distance between some of the sub-catchments outlets is only small (less than 200 metres).

Table 5.1: Channel slope at the outlets of sub-catchments A to J

\begin{tabular}{|c|c|}
\hline Sub-Catchment & Channel Slope $(\mathbf{m} / \mathbf{m})$ \\
\hline A & 0.09 \\
\hline B & 0.13 \\
\hline C & 0.12 \\
\hline D & 0.09 \\
\hline E & 0.11 \\
\hline F & 0.09 \\
\hline G & 0.18 \\
\hline H & 0.14 \\
\hline I & 0.08 \\
\hline J & 0.08 \\
\hline
\end{tabular}

\subsubsection{Discharge}

A variety of methods could have been used to determine the discharge. Determination of the discharge using the velocity-area method, which requires gauging with a current meter or float, is a possible method. Dilution gauging is another possible method which 
is a more appropriate technique for use in these streams. A high degree of mixing occurs in these streams and the method is suitable to a small rocky channel with low flows. Dilution gauging produces accurate results compared to other methods as it is direct method (Herschy, 2008).

Both of the above methods, however, require a surface flow to be present in the stream channel at the time of measurement. The Kawauiti Stream, the Kawaunui Stream and Catchment 2's unnamed stream are ephemeral; they only have a discharge during and after intense or prolonged rainfall. Thus these streams can only be gauged at these times when the stream is in flood. The characteristics of the catchments are problematic to gauging the streams when they contain surface flow. The narrow catchment with steep, easily eroded gully walls and stream channel banks make it dangerous to be in the catchments during rainfall and discharge events due to potential sediment movement off the gully walls or along the channel. This sediment movement could additionally damage or disrupt the gauging equipment and produce errors in the results. For these reasons field work in the catchments was carried out at times when there was no flow in the streams.

Thus, an indirect method of determining discharge was required. The slope-area method using either the Manning's or Chezy's equations can be used to calculate flood discharges indirectly for past or current floods. The method is simple to carry out and can give somewhat reliable results (Herschy, 2008) but is dependant on the accurate estimation of three variables. The slope of the water surface can be easily approximated from the longitudinal profile. However, there is no indication of how high stream flows reach on the stream banks or gully walls leading to difficulty in estimating cross sectional areas of the channel. Determination of Manning's ' $n$ ' or Chezy's 'C' values would have also introduced inaccurate variables.

The rational method is a rainfall-runoff formula that is thought to be designed by Mulvary in 1851 (Chow, 1964). The rational method enables discharge of peak flows to be determined, without the need to gauge the stream. It is a simplistic method that is suitable for small (approximately 3 to $10 \mathrm{~km}^{2}$; Martel, 2005) natural or rural catchments which have little or no data available, although it can also be applied to urban 
catchments. The rational method allows for discharge to be remotely obtained using past rainfall data. This method, through the runoff coefficient, takes into consideration the specific characteristics of the catchment concerned, and unlike the slope-area method does not require the calculation of the stream cross sectional area. The rational method is therefore suitable to determine discharge for this study.

A number of assumptions are associated with the rational method however. The key assumption of the method is that rainfall will occur at a constant intensity over the whole catchment area and that the rate of runoff (and therefore discharge) is at its maximum when the rainfall intensity is equal to the concentration time (Frevert et al., 1955; Chow, 1964).

\section{The Rational Method}

In order to determine the discharge of the unnamed stream the rational method was used. The rational method formula is:

$$
Q p=0.278 C I A
$$

where $Q p$ is the maximum rate of runoff, $C$ is a dimensionless runoff coefficient, $I$ is the rainfall intensity in $\mathrm{mm} / \mathrm{hr}$ and $A$ is the catchment area in $\mathrm{km}^{2}$. The constant 0.278 is used when the data are in metric units, for example when the catchment area is in $\mathrm{km}^{2}$ and the rainfall intensity is in $\mathrm{mm} / \mathrm{hr}$. The methods carried out to determine each of these parameters are described below.

\section{$\underline{\text { Runoff Coefficient ' } \mathrm{C} \text { ' }}$}

Frevert et al. (1955) defines the runoff coefficient as a ratio between rainfall intensity and the peak runoff rate. To determine the ' $\mathrm{C}$ ' parameter for use in the rational method equation, catchment characteristics (soil type, land cover and the slopes within the catchment) must be considered. These contribute to and greatly affect the time taken for water to reach a stream channel. Vegetation intercepts rain and slows its passage to the ground. Bare or impermeable soils and steep slopes allow water to flow quickly towards streams. 
There are many tables giving values for runoff ' $\mathrm{C}$ ' coefficients in the literature. However, many of these present general values only and give no method for the calculation of a runoff coefficient value for a specific catchment (Martel, 2005). Tables produced by Turner (1960) and Frevert et al. (1955) are two approaches which allow runoff coefficient values to be calculated for specific catchments. Both tables are for small catchments and use slope (relief), soil type, which is representative of water infiltration, and land use and vegetation cover to determine a runoff coefficient. Turner's table also includes rainfall intensity.

The approach using the table produced by Turner (1960) is designed for rural areas in Victoria, Australia. Rainfall intensities and vegetation cover (mainly referring to pasture) used in the table therefore reflect these catchment characteristics of the Australian landscape which may have little resemblance to the landscape of the concerned field site. As Turner's runoff coefficient table is for rural pastoral areas it has been suggested by Davidson Ayson (1996) that it may be of only limited use to catchments which are urbanised or vegetated with natural bush and forest cover (Martel, 2005).

For these reasons runoff coefficients for the sub-catchments $\mathrm{A}$ to $\mathrm{J}$ are determined using Frevert's approach (the Frevert's runoff coefficient table and equation are presented further on in this section). While the Frevert's table is also not specifically designed for catchment characteristics within New Zealand, compared to Turner's table it is more applicable to the catchment concerned as it presents runoff coefficient values for natural forest/woodland, pasture and cultivated (for which bare soil can be substituted) vegetation covers. Values for urban areas are also presented. Further, the soil types are more representative of possible soil types within New Zealand. Frevert's approach requires an analysis of soil type, vegetation cover and mean slope angles within the catchment to calculate a runoff coefficient value.

Soil Type

Soil type was determined in ArcMap using the South Island Fundamental Soil Layer from the New Zealand Land Resource Inventory and National Soils Database produced 
by Landcare Research NZ Ltd. A soil map of the Awatere, Kaikoura and Marlborough areas (Gibbs and Beggs, 1953) was also consulted to determine the soil type of the site.

Catchment 2 consists of a mixture of two soil types. The Medway Soil is a silt and clay loam, while the Woodbank Soil is a stony silt loam and silt loam which is situated on conglomerate.

\section{Percent Vegetation Cover}

In ArcMap vegetation cover types were identified and digitised from a 2004 coloured aerial photograph using multipart polygons to create a vegetation cover map (Figure 5.7). Three vegetation cover types were identified and are described in Table 5.2. Areas of uncertainty, for example from shadows on the aerial photograph which made it difficult to determine the vegetation cover type, were verified by ground truthing while in the field.

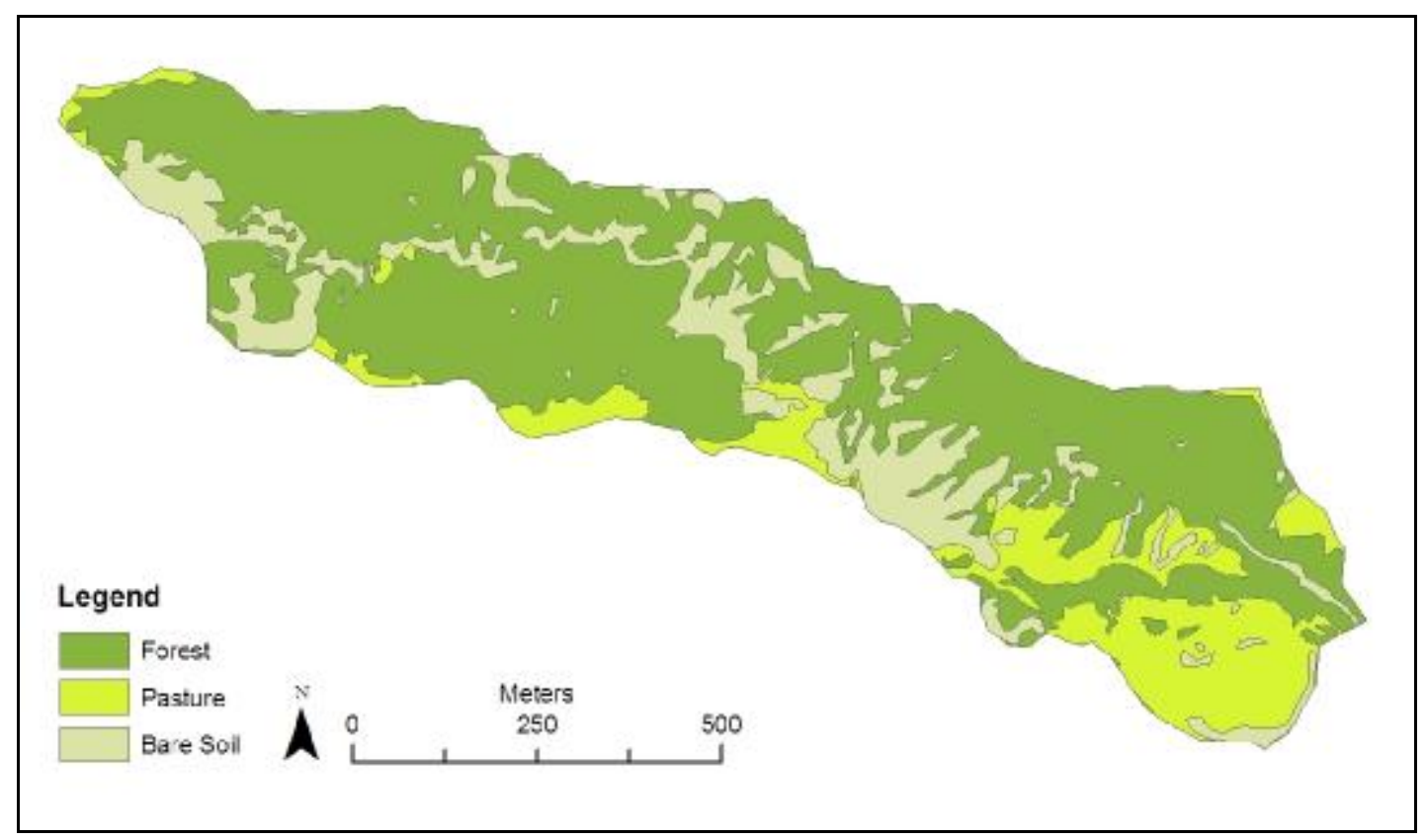

Figure 5.7: Vegetation cover types in Catchment 2. 
Table 5.2: Table describing the vegetation cover types and how they were identified on the 2004 aerial photograph

\begin{tabular}{|c|c|c|}
\hline $\begin{array}{c}\text { Land } \\
\text { Cover Type }\end{array}$ & Vegetation Cover Description & Land Cover Type Identified By \\
\hline Bare Soil & $\begin{array}{l}\text { Exposed soil and sediment where } \\
\text { erosion has occurred. Stream channel } \\
\text { where clearly identifiable. }\end{array}$ & $\begin{array}{l}\text { Light areas (almost a cream brown } \\
\text { colour) }\end{array}$ \\
\hline Pasture & Pastured farm land and areas of grass & Light green to light brown areas \\
\hline Forested & Areas of scrub or forest & $\begin{array}{l}\text { Dark green, appears in a } \\
\text { hummocky texture }\end{array}$ \\
\hline
\end{tabular}

The vegetation cover map was clipped to each of the sub-catchment polygons and dissolved to aggregate each of the vegetation cover types within each sub-catchment. The area of each vegetation cover type for each sub-catchment was calculated in the attribute table using the 'Calculate Geometry' tool. The percentage for each vegetation cover type within each sub-catchment was then calculated.

Table 5.3: Percentages of the bare soil, pasture and forest vegetation cover types within each of the sub-catchments A to $\mathrm{J}$

\begin{tabular}{|c|c|c|c|}
\hline Sub-Catchment & \% Bare Soil & \% Pasture Cover & \% Forest Cover \\
\hline A & 27.65 & 4.10 & 68.25 \\
\hline B & 18.51 & 4.94 & 76.55 \\
\hline C & 18.81 & 4.13 & 77.06 \\
\hline D & 16.70 & 5.03 & 78.27 \\
\hline E & 19.39 & 4.46 & 76.15 \\
\hline F & 19.40 & 6.59 & 74.01 \\
\hline G & 22.33 & 6.19 & 71.48 \\
\hline H & 20.83 & 8.31 & 70.86 \\
\hline I & 19.23 & 11.10 & 69.67 \\
\hline J & 18.55 & 16.05 & 65.40 \\
\hline
\end{tabular}

\section{Mean Catchment Slope Angle}

In ArcMap, a 25 metre Digital Elevation Model (DEM), produced by GeographX with data from LINZ, was converted into a slope layer using the Spatial Analyst tool 'Slope'. Each of the sub-catchment layers was applied as a mask to the slope layer and clipped. The slope layer for Catchment 2 is shown in Figure 5.8. The mean slope angle was read from the 'Classification Statistics' box of the 'Symbology' tab in the 'Layer Properties' box and was converted to a percentage slope angle (Table 5.4). 
The 25 metre DEM was used to determine mean slope angle although a higher resolution DEM $(20 \mathrm{~m})$ was available. The 20 metre DEM has a New Zealand Transverse Mercator coordinate system and required converting to New Zealand Map Grid to be consistent with the rest of the GIS layers. Converting this layer to New Zealand Map Grid produced small errors which were larger than the approximate 1 degree difference in the mean slope angle between the 20 metre slope layer and the 25 metre slope layer.

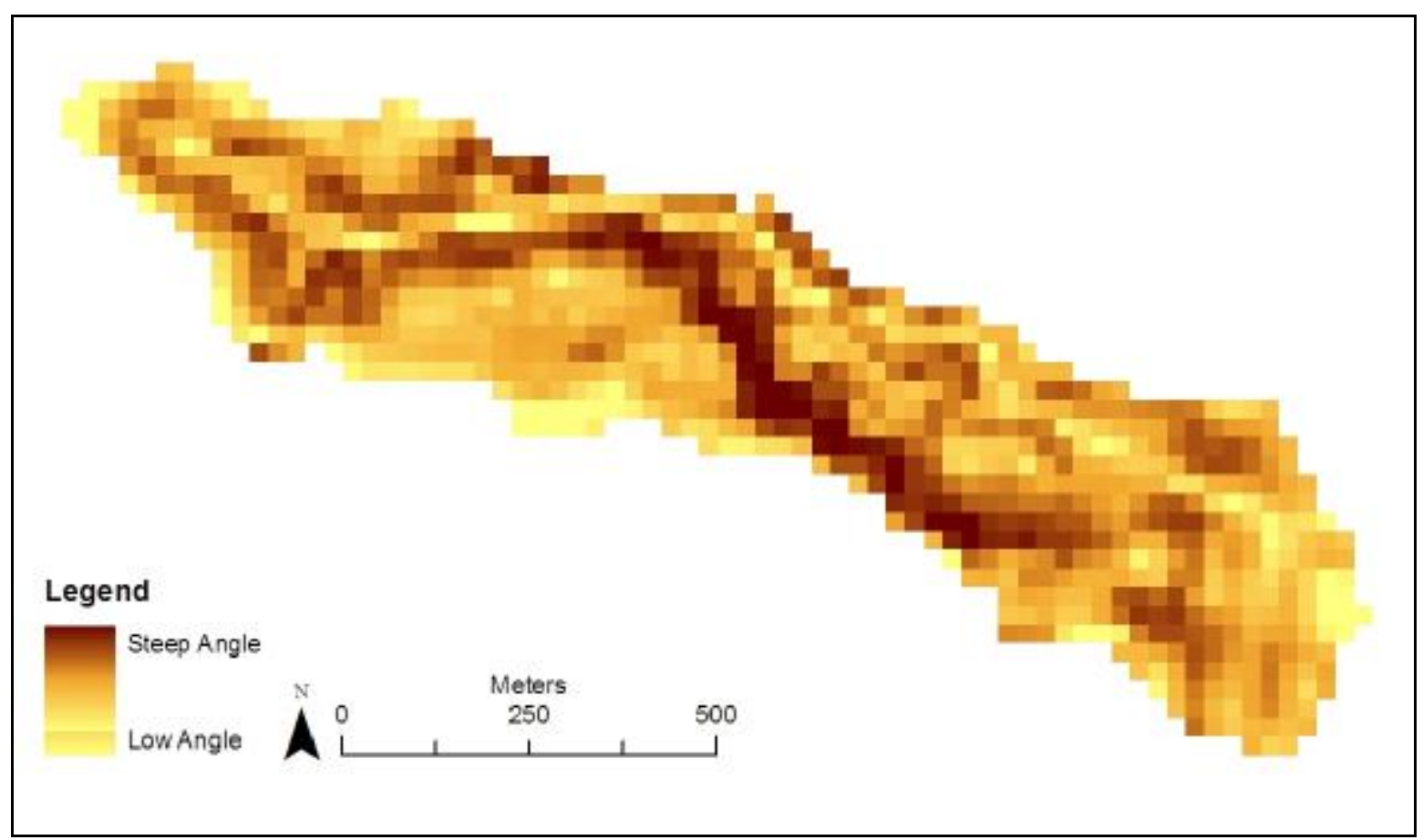

Figure 5.8: The slope layer determined from the 20 metre DEM of Catchment 2 (subcatchment J)

Table 5.4: Mean slope angles of each of the sub-catchments A to J.

\begin{tabular}{|c|c|c|}
\hline Sub-Catchment & Mean Slope Angle & Percent Slope Angle (\%) \\
\hline A & $23.27^{\circ}$ & 43.02 \\
\hline B & $23.00^{\circ}$ & 42.46 \\
\hline C & $23.30^{\circ}$ & 43.07 \\
\hline D & $23.60^{\circ}$ & 43.70 \\
\hline E & $24.43^{\circ}$ & 45.42 \\
\hline F & $25.01^{\circ}$ & 46.65 \\
\hline G & $25.42^{\circ}$ & 47.52 \\
\hline H & $25.50^{\circ}$ & 47.69 \\
\hline I & $25.20^{\circ}$ & 47.05 \\
\hline J & $24.73^{\circ}$ & 46.05 \\
\hline
\end{tabular}


Determining the runoff coefficient ' $C$ '

For use in this study the vegetation cover types 'Forest' and 'Bare Soil' will refer to Frevert's 'Woodland' and 'Cultivated' land cover types respectively. However, some of the values required altering to represent the data calculated for the catchment. The mean slope angles calculated are higher than the maximum mean slope angle considered in Frevert's approach. Further, the Medway and Woodbank soil types at the field site are assumed to have properties that are similar to both Frevert's 'Open Sandy Loam' and 'Clay and Silt Loam'. Appropriate values were determined by calculating the middle value between the soil types and then adjusting this value with the difference between the mean slope types. This adjustment produced a value that was more representative of the catchment characteristics. Frevert's runoff coefficient table with the adjusted values is shown in Table 5.5.

The equation to determine ' $\mathrm{C}$ ' from the table is presented in Equation 5.4. For each of the sub-catchments, a ' $\mathrm{C}$ ' value was calculated by reading a value off the table which corresponds to the mean slope and the soil type for each vegetation cover type, and multiplying this value by the percentage of the vegetation cover type. This was repeated for the three vegetation cover types within the sub-catchment and these were summed together (Table 5.6). 
Table 5.5: Frevert's runoff coefficient table, displaying adjusted values representative of the catchment concerned (italicised values) (Adjusted from Frevert et al., 1955)

\begin{tabular}{|c|c|c|c|c|c|}
\hline Vegetation & Topography & $\begin{array}{c}\text { Open } \\
\text { Sandy } \\
\text { Loam } \\
\end{array}$ & $\begin{array}{l}\text { Altered Value } \\
\text { Representative } \\
\text { of Catchment }\end{array}$ & $\begin{array}{l}\text { Clay and } \\
\text { Silt Loam }\end{array}$ & $\begin{array}{l}\text { Tight } \\
\text { Clay }\end{array}$ \\
\hline \multirow{4}{*}{$\begin{array}{c}\text { Forest } \\
\text { (Frevert's } \\
\text { Woodland) }\end{array}$} & $\begin{array}{c}\text { Flat }(0-5 \% \\
\text { slope) }\end{array}$ & 0.10 & - & 0.30 & 0.40 \\
\hline & $\begin{array}{c}\text { Rolling (5- } \\
10 \%)\end{array}$ & 0.25 & - & 0.35 & 0.50 \\
\hline & $\begin{array}{c}\text { Hilly (10- } \\
\text { 30\%) }\end{array}$ & 0.30 & - & 0.50 & 0.60 \\
\hline & $\begin{array}{l}\text { Altered Value } \\
\text { Representative } \\
\text { of Catchment } \\
\text { (Steep >30\%) }\end{array}$ & & 0.45 & 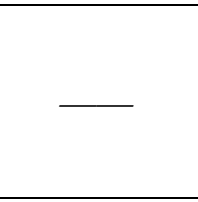 & - \\
\hline \multirow{4}{*}{ Pasture } & $\begin{array}{c}\text { Flat }(0-5 \% \\
\text { slope) }\end{array}$ & 0.10 & - & 0.30 & 0.40 \\
\hline & $\begin{array}{c}\text { Rolling (5- } \\
10 \%)\end{array}$ & 0.16 & - & 0.36 & 0.55 \\
\hline & $\begin{array}{c}\text { Hilly (10- } \\
\text { 30\%) }\end{array}$ & 0.22 & - & 0.42 & 0.60 \\
\hline & $\begin{array}{l}\text { Altered Value } \\
\text { Representative } \\
\text { of Catchment } \\
\text { (Steep >30\%) }\end{array}$ & & 0.40 & - & - \\
\hline \multirow{4}{*}{$\begin{array}{c}\text { Bare Soil } \\
\text { (Frevert's } \\
\text { Cultivated) }\end{array}$} & $\begin{array}{c}\text { Flat }(0-5 \% \\
\text { slope) }\end{array}$ & 0.30 & - & 0.50 & 0.60 \\
\hline & $\begin{array}{c}\text { Rolling (5- } \\
10 \%)\end{array}$ & 0.40 & - & 0.60 & 0.70 \\
\hline & $\begin{array}{c}\text { Hilly (10- } \\
\text { 30\%) }\end{array}$ & 0.52 & - & 0.72 & 0.82 \\
\hline & $\begin{array}{l}\text { Altered Value } \\
\text { Representative } \\
\text { of Catchment } \\
\text { (Steep >30\%) }\end{array}$ & - & 0.72 & 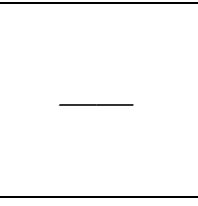 & - \\
\hline
\end{tabular}

Equation 5.4

$C=($ Forest $\% \times$ TableValue $)+($ Pasture $\% \times$ TableValue $)+($ BareSoil $\% \times$ TableValue $)$ 
Table 5.6: Runoff coefficients calculated for sub-catchments A to $J$ using Frevert's runoff coefficient table.

\begin{tabular}{|c|c|}
\hline Sub-catchment & Runoff Coefficient ' $^{\mathbf{C}}$ ' \\
\hline A & 0.523 \\
\hline B & 0.498 \\
\hline C & 0.499 \\
\hline D & 0.493 \\
\hline E & 0.500 \\
\hline F & 0.499 \\
\hline G & 0.507 \\
\hline H & 0.502 \\
\hline I & 0.496 \\
\hline J & 0.492 \\
\hline
\end{tabular}

\section{$\underline{\text { Rainfall Intensity 'I' }}$}

The rational method requires the calculation of the rainfall intensity (in $\mathrm{mm} / \mathrm{hr}$ ) which corresponds to the time required for the rate of stream discharge to equal the rate of rainfall input into the catchment, known as the time of concentration. A data set from the Kaikoura Weather Station was used for the calculation of rainfall intensity. The Kaikoura Weather Station is the closest rain gauge located near the field site which records maximum total rainfall. This is the highest annual rainfall value which occurred for specified durations over the period of a year. It is assumed that the maximum rainfall intensity values for Kaikoura are the same as those which were experienced at the location of the field site. It is additionally assumed that the rainfall intensity is equal over the entirety of Catchment 2.

The data set represents 23 years, from 1968 to 1990, of the maximum total rainfall for five differing rainfall durations. Data from 1985 were omitted from the calculations due to the data record being incomplete for these years. The five rainfall durations used were:

- 10 minutes

- 20 minutes

- 30 minutes

- 60 minutes

- 120 minutes 
For each duration the maximum rainfall total was converted into an hourly rainfall intensity and return periods were then calculated for each value. A frequency magnitude graph was then constructed. Rainfall intensity values for 10- and 23- year return periods were calculated from the frequency magnitude graph and used to construct intensity duration graphs for each return period. Tables showing the rainfall intensity and return period calculations and the frequency magnitude and intensity duration graphs are provided in Appendix II.

The concentration time for the catchment is needed before the ' $\mathrm{I}$ ' value can be read from the intensity graph.

\section{Concentration Time}

The concentration time for a catchment is the time required for surface water runoff from the most distant part of the catchment to flow to the point along the stream channel being considered, which is often the catchment outlet (Chow, 1964; Frevert et al., 1955). When storms occur over the catchment with a rainfall duration equal to the catchment's concentration time, all parts of the catchment are assumed to be contributing discharge to the point of the stream of interest and the runoff rate would therefore be at its greatest. Storms with rainfall durations longer than the concentration time are assumed to have a lower runoff rate due to lower rainfall intensities; storms with shorter rainfall durations are assumed to also have a lower runoff rate due to storm ending before the surface water runoff can be contributed from the whole catchment (Frevert et al., 1955).

The concentration time is calculated using the Bransby-Williams formula:

$$
T=\frac{L}{1.5 D} \times \sqrt[5]{\frac{M^{2}}{F}}
$$

where $\mathrm{T}$ is the concentration time in hours, $\mathrm{L}$ is the length of the catchment from the catchment mouth to the farthest point on the catchment boundary in kilometres, $\mathrm{M}$ is the area of the catchment in kilometres squared, D is the diameter in kilometres of a circle equal to the area of catchment and $\mathrm{F}$ is the average fall of the stream. The methods 
carried out to determine each of these variables, in order to calculate the concentration time, are described below.

Length of the Catchment, ' $\mathrm{L}$ '

The 'Measure' tool in ArcMap was used to measure to distance from the mouth of each sub-catchment to its farthest point (Table 5.7).

Table 5.7: The length (in kilometres) of each of the sub-catchments A to J.

\begin{tabular}{|c|c|}
\hline Sub-Catchment & Catchment Length ' $\mathbf{L}$ ' $(\mathbf{k m})$ \\
\hline A & 0.431 \\
\hline B & 0.572 \\
\hline C & 0.671 \\
\hline D & 0.944 \\
\hline E & 1.110 \\
\hline F & 1.262 \\
\hline G & 1.446 \\
\hline H & 1.596 \\
\hline I & 1.777 \\
\hline J & 1.871 \\
\hline
\end{tabular}

Area of the Catchment, 'M'

In ArcMap, the area of each sub-catchment was calculated using the 'Calculate Geometry' tool in the attribute table (Table 5.8).

The Diameter of a Circle Equal to the Catchment Area 'D'

The diameter of the circle which is equal to the area of each sub-catchment was calculated using Microsoft Excel by rearranging the formula for the area of a circle equal to ' $M$ ' for each sub-catchment to determine the circle's radius and then multiplying by two (Table 5.8). 
Table 5.8: The area of each sub-catchment $A$ to $J$ and diameter of a circle equal to the area of each sub-catchment

\begin{tabular}{|c|c|c|}
\hline Sub-Catchment & Area 'M' $\mathbf{( k m}^{\mathbf{2}} \mathbf{)}$ & Diameter of Circle Equal to 'M', 'D' $(\mathbf{k m})$ \\
\hline A & 0.087 & 0.332 \\
\hline B & 0.143 & 0.427 \\
\hline C & 0.171 & 0.467 \\
\hline D & 0.249 & 0.563 \\
\hline E & 0.281 & 0.598 \\
\hline F & 0.342 & 0.660 \\
\hline G & 0.404 & 0.717 \\
\hline H & 0.452 & 0.758 \\
\hline I & 0.517 & 0.811 \\
\hline J & 0.564 & 0.847 \\
\hline
\end{tabular}

Average Fall of the Stream Channel

The average fall of the stream of each sub-catchment was determined using the longitudinal profile of Catchment 2, determining the change in the length and the height of the stream of each sub-catchment. This was then converted into the rise in metres per 100 metres (Table 5.9).

Table 5.9: Average fall of the stream channel for each of the sub-catchments A to $J$

\begin{tabular}{|c|c|}
\hline Sub-Catchment & $\begin{array}{c}\text { Average Fall of the Stream } \\
\text { Channel ' } \mathbf{F} \text { ' }(\mathbf{m} / \mathbf{1 0 0 m})\end{array}$ \\
\hline A & 9.620 \\
\hline B & 10.068 \\
\hline C & 9.721 \\
\hline D & 8.661 \\
\hline E & 8.689 \\
\hline F & 8.897 \\
\hline G & 9.277 \\
\hline H & 9.430 \\
\hline I & 9.306 \\
\hline J & 9.227 \\
\hline
\end{tabular}

\section{Concentration Time Values}

The calculated concentration time, converted from hours to minutes, for each subcatchment is shown in Table 5.10. 
Table 5.10: Concentration times for sub-catchments A to J.

\begin{tabular}{|c|c|}
\hline Sub-Catchment & Concentration Time ' $\mathbf{T}$ ' (min) \\
\hline A & 12.41 \\
\hline B & 15.52 \\
\hline C & 18.00 \\
\hline D & 26.72 \\
\hline E & 29.00 \\
\hline F & 32.16 \\
\hline G & 35.96 \\
\hline H & 39.10 \\
\hline I & 43.08 \\
\hline J & 45.03 \\
\hline
\end{tabular}

Determining the Rainfall Intensity ' $I$ '

Using the concentration times presented above, the rainfall intensity for the 10 - and $23-$ year return periods were read off the intensity duration graphs.

Table 5.11: The calculated rainfall intensity values 'I' required for the calculation of the stream discharge using the Rational Method.

\begin{tabular}{|c|c|c|}
\hline \multirow{2}{*}{ Sub-Catchment } & \multicolumn{2}{|c|}{ Rainfall Intensity 'I' (mm/hr) } \\
\cline { 2 - 3 } & 10 Year Return Period & 23 Year Return Period \\
\hline A & 56.303 & 71.085 \\
\hline B & 52.815 & 66.928 \\
\hline C & 50.621 & 64.306 \\
\hline D & 45.223 & 57.823 \\
\hline E & 44.178 & 56.564 \\
\hline F & 42.889 & 55.006 \\
\hline G & 41.544 & 53.380 \\
\hline H & 40.561 & 52.188 \\
\hline I & 39.452 & 50.843 \\
\hline J & 38.955 & 50.240 \\
\hline
\end{tabular}

Catchment Area 'A'

In ArcMap, the area of each sub-catchment was calculated using the 'Calculate Geometry' tool in the attribute table. See Table 5.8 above.

\section{Discharge Values Calculated Using the Rational Method}

Once the values for the runoff coefficient, the rainfall intensity and the catchment area for each of the sub-catchments A to $\mathrm{J}$ were determined, the peak stream discharges for each sub-catchment were calculated using the rational method. Table 5.12 presents the discharges for each sub-catchment for the two different return periods. 
Table 5.12: Stream discharges $\left(\mathrm{m}^{3} / \mathrm{s}\right)$ for sub-catchments A to $\mathrm{J}$ over the $10-$ and $23-$ year return periods.

\begin{tabular}{|c|c|c|}
\hline \multirow{2}{*}{ Sub-Catchment } & \multicolumn{2}{|c|}{ Stream Discharge $\left.\mathbf{~ m}^{\mathbf{3}} / \mathbf{s}\right)$} \\
\cline { 2 - 3 } & 10 Year return Period & 23 Year Return Period \\
\hline A & 0.709 & 0.895 \\
\hline B & 1.045 & 1.324 \\
\hline C & 1.201 & 1.525 \\
\hline D & 1.543 & 1.972 \\
\hline E & 1.725 & 2.208 \\
\hline F & 2.034 & 2.608 \\
\hline G & 2.368 & 3.042 \\
\hline H & 2.556 & 3.289 \\
\hline I & 2.815 & 3.627 \\
\hline J & 3.006 & 3.876 \\
\hline
\end{tabular}

\subsubsection{Channel Width}

At each of the sediment sample sites the width of the stream channel was measured using a tape measure (Table 5.13). Only five of the eight sediment sample sites were located near the outlets of the sub-catchments. Therefore channel width was only available for sub-catchments A, E, G, I and J.

Table 5.13: Channel width near the outlets of sub-catchments A, E, G, I and J

\begin{tabular}{|c|c|}
\hline Sub-Catchment & Channel Width (m) \\
\hline A & 3.1 \\
\hline E & 9.12 \\
\hline G & 5.3 \\
\hline I & 11.8 \\
\hline J & 21.5 \\
\hline
\end{tabular}

\subsection{Stream Power Results}

Stream power was calculated for the outlets of sub-catchments A to $\mathrm{J}$ to determine the energy available within the stream flow which can carry out work to entrain and transport sediment. Stream power was calculated for flows with a 10- and 23- year return period. The stream power values for each return period are displayed in Table 5.14 and Figure 5.9. 
The stream power for the 23 year return period is higher than the stream power for the 10 year return period for all ten sites. The 23 year return period flow results from a rarer storm event which can produce higher flood flows with more energy to transport sediment. For both return periods, stream power is lowest at the back of Catchment 2 (at the outlet of sub-catchment A) and increases with distance downstream. Sub-catchment A has stream power values of $625.5 \mathrm{~W} / \mathrm{m} / \mathrm{s}$ and $789.7 \mathrm{~W} / \mathrm{m} / \mathrm{s}$ for the 10 year return period and the 23 year return period respectively. Catchment $\mathrm{J}$, at the outlet of Catchment 2 has stream power values of $2356.5 \mathrm{~W} / \mathrm{m} / \mathrm{s}$ and $3039.1 \mathrm{~W} / \mathrm{m} / \mathrm{s}$ for the 10 year return period and the 23 year return period respectively. Maximum stream power occurs at the outlet of sub-catchment $\mathrm{G}$, with values of $4176.4 \mathrm{~W} / \mathrm{m} / \mathrm{s}$ and $5366.2 \mathrm{~W} / \mathrm{m} / \mathrm{s}$ for the 10 and 23 year return periods respectively. Further downstream stream power decreases but is still relatively high.

Table 5.14: Stream power values calculated for sub-catchments A to J.

\begin{tabular}{|c|c|c|}
\hline \multirow{2}{*}{ Sub-Catchment } & \multicolumn{2}{|c|}{ Stream Power $(\mathbf{W} / \mathbf{m} / \mathbf{s})$} \\
\cline { 2 - 3 } & 10 Year Return Period & 23 Year Return Period \\
\hline A & 625.505 & 789.730 \\
\hline B & 1330.754 & 1686.354 \\
\hline C & 1412.210 & 1793.965 \\
\hline D & 1360.632 & 1739.734 \\
\hline E & 1859.134 & 2380.339 \\
\hline F & 1793.652 & 2300.430 \\
\hline G & 4176.372 & 5366.223 \\
\hline H & 3507.478 & 4512.999 \\
\hline I & 2206.603 & 2843.737 \\
\hline J & 2356.464 & 3039.090 \\
\hline
\end{tabular}




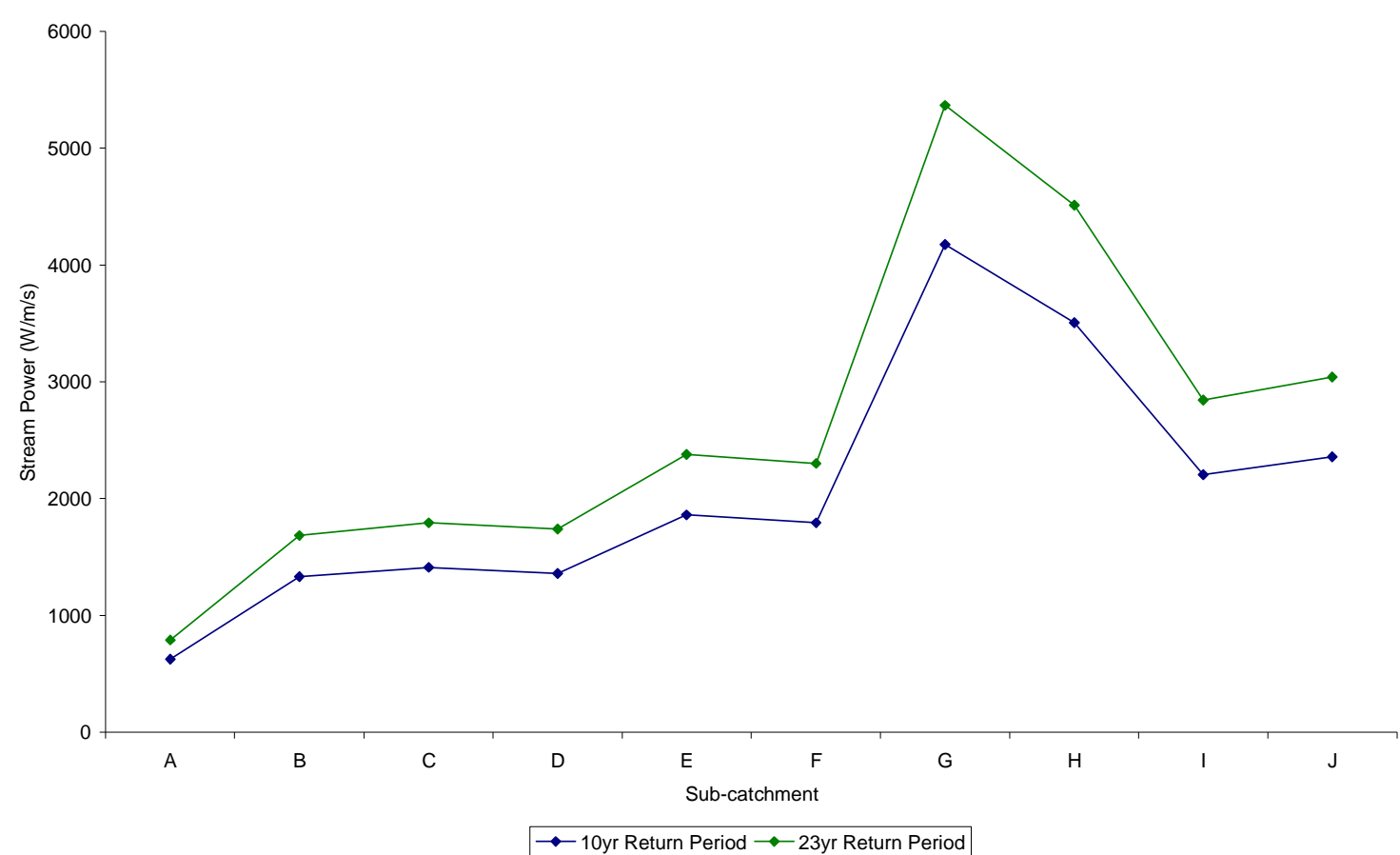

Figure 5.9: Graph displaying how stream power varies along the stream of Catchment 2 with distance from the headwaters to the catchment outlet. Sub-catchment A is at the back of the catchment near the headwaters. Sub-catchment $J$ is at the outlet of Catchment 2

Unit stream power is a more effective measure of the energy available within a stream to carry out work. It removes the effect of scale and enables stream power values between different locations along the stream channel to be easily compared. It is calculated by dividing the sites stream power by the width of the stream channel at the site. Channel width measurements were available for sub-catchments A, E, G, I and J and unit stream power has been determined for these sites.

Unit stream power values for each return period at sub-catchments A, E, G, I and J and are displayed in Table 5.15 and Figure 5.10. As with stream power, the 23 year return period unit stream power values are higher than the 10 year return period unit stream power values. However for both return periods, with the exception of sub-catchment G, unit stream power across all the sub-catchments is relatively similar. Unit stream power at the outlet of sub-catchments A, E and I ranges between $187.0 \mathrm{~W} / \mathrm{m}^{2}$ and $203.9 \mathrm{~W} / \mathrm{m}^{2}$ for a 10 year return period flow and $241.0 \mathrm{~W} / \mathrm{m}^{2}$ to $254.8 \mathrm{~W} / \mathrm{m}^{2}$ for a 23 year return period flow. Unit stream power at sub-catchment $\mathbf{J}$ (the outlet of Catchment 2) is significantly lower than the rest of the sites with unit stream power values of 109.6 
$\mathrm{W} / \mathrm{m}^{2}$ and $141.4 \mathrm{~W} / \mathrm{m}^{2}$ for the $10-$ and $23-$ year return periods respectively. Similar to stream power, sub-catchment $\mathrm{G}$ has a high unit stream power.

Table 5.15: Unit stream power values calculated for sub-catchments A, E, G, I and J.

\begin{tabular}{|c|c|c|}
\hline \multirow{2}{*}{ Sub-Catchment } & \multicolumn{2}{|c|}{ Unit Stream Power $\left(\mathbf{W} / \mathbf{m}^{\mathbf{2}}\right)$} \\
\cline { 2 - 3 } & 10 Year Return Period & 23 Year Return Period \\
\hline A & 201.776 & 254.752 \\
\hline E & 203.852 & 261.002 \\
\hline G & 787.995 & 1012.495 \\
\hline I & 187.000 & 240.995 \\
\hline J & 109.603 & 141.353 \\
\hline
\end{tabular}

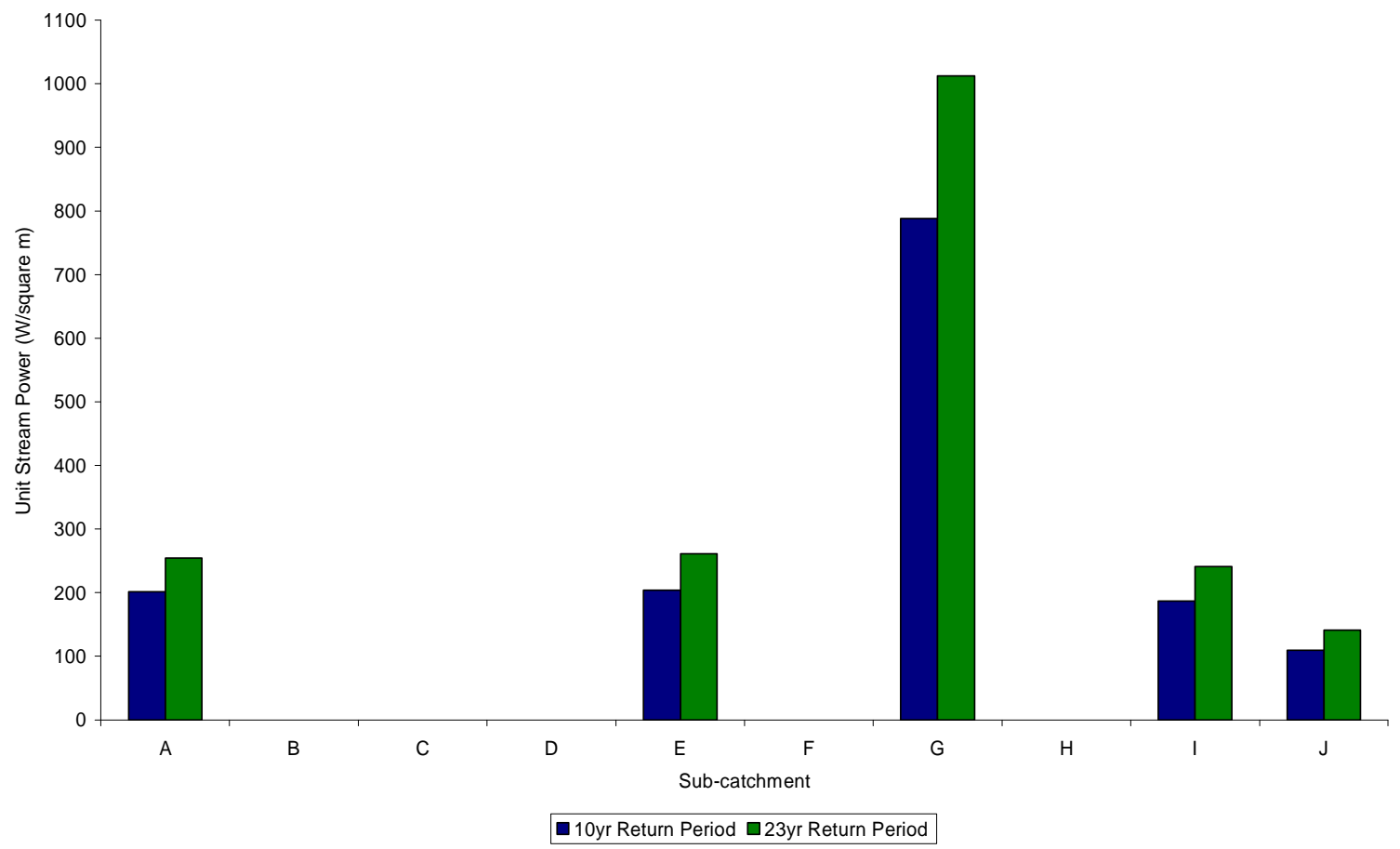

Figure 5.10: Unit stream power for a 10 - and $23-$ year return period stream flow at the outlets of sub-catchments A, E, G, I and J.

\subsection{Grain Size}

In order for boundary shear stress and critical shear stress to be compared to identify areas of potential sediment entrainment and transport, an analysis of the sediment clasts present within the stream channel is important. Sediment entrainment is largely dependant on a number of clast characteristics; however, the individual size of each clast is the dominant characteristic determining sediment entrainment. An analysis of 
the sediment size available within the stream channel for entrainment was carried out at eight locations along to the stream channel of the unnamed stream in Catchment 2.

\subsubsection{Collection of Sediment Samples}

Nine sediment samples were collected from eight locations within the stream channel of Catchment 2. A fine (Sample 8A) and a coarse (Sample 8B) sample were taken from two adjacent deposits within the channel on the lower part of the fan. The location of each sample was determined in the field by observation of a noticeable change in the sediment size and/or type and the area surrounding the channel. The location of the nine sediment samples is shown in Figure 5.11. At each location a quadrat (250 mm by 250 $\mathrm{mm}$ ) was randomly laid down to outline the area that was to be sampled. A large surface sample was taken from within the quadrat using a spade and placed into a bag to be brought back to the laboratory to be analysed. Large coarse clasts were measured in the field with either callipers or a tape measure if they were too big to bring back to the laboratory.

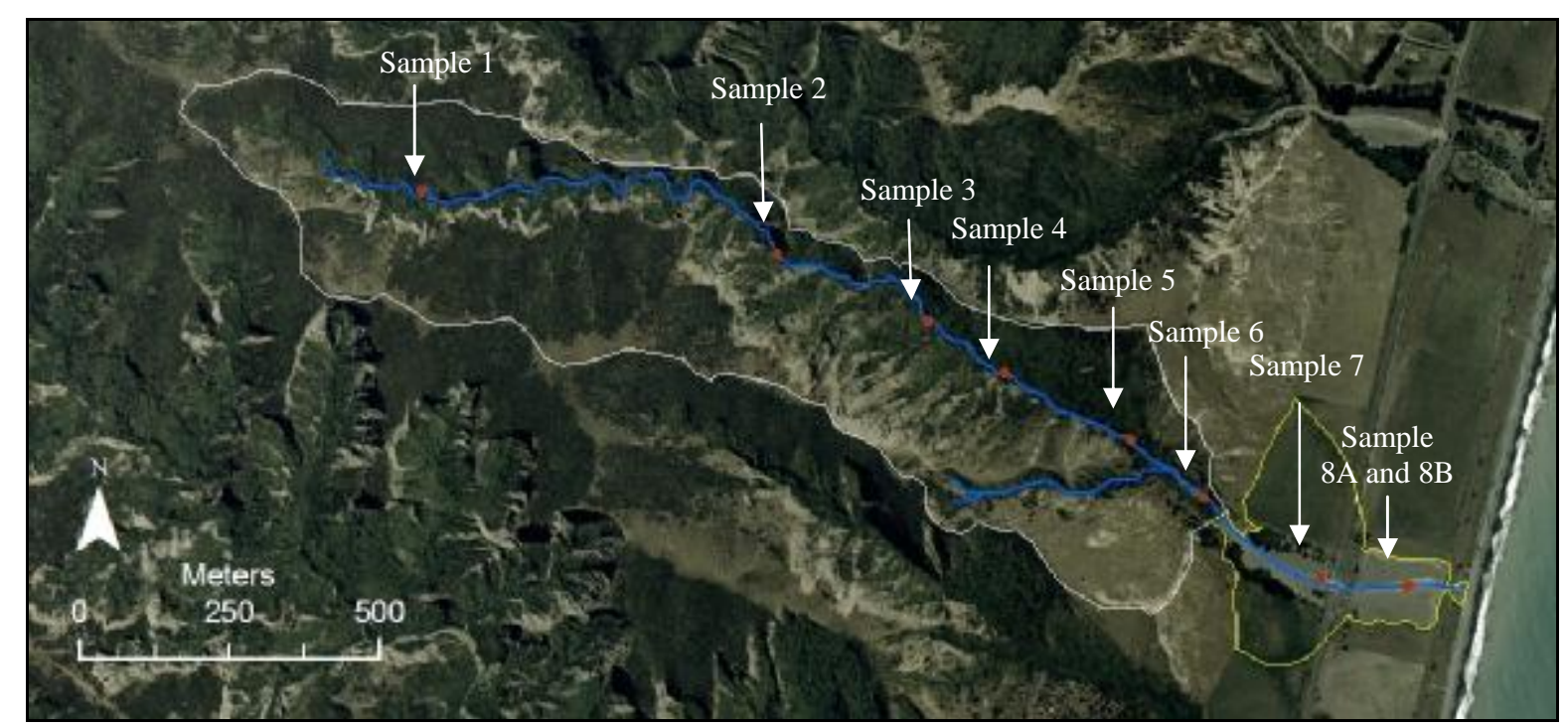

Fig 5.11: Map detailing the location of the nine sediment samples collected from the channel of Catchment 2. Aerial photograph source: LINZ, 2004. 


\subsubsection{Justification of Laboratory Procedures}

A range of possible methods was available for processing the sediment samples from the stream channel. Settling tube analysis (Rapid Sediment Analyser), laser diffractometry analysis (laser particle sizer) and microscope analysis are suitable for processing sands, silts and clays. For example sediments up to $1.5 \mathrm{~mm}$ may be processed with the laser particle sizer. The rapid sediment analyser can also analyse small gravels. All three methods were, therefore, not appropriate for analysis of stream sediments due to the high proportion of gravel clasts and very little amounts of silts and clays within the sediment samples. The individual measurement of clasts is suitable for stream channel sediment samples, particularly for the larger gravel clasts. With large samples, a large number of samples or samples with a high proportion of gravels this method can be time consuming. Further, depending on the apparatus used for measurement, for example a ruler, tape measure or callipers, precise readings may not be possible. Dry sediment sieving is suitable for the processing of moderate sized clasts and sediment, ranging from large cobbles to silts. This method is relatively time efficient, although it only gives a range of sizes between which clasts can be located. This is the most appropriate method for processing the sediment samples collected for this study due to the calibre of the samples collected. Unfortunately, Victoria University of Wellington only has sieves ranging in size from $-4 \Phi$ to $5 \Phi$. As a result of this, clasts larger than $-4 \Phi$ required individual measuring.

\subsubsection{Laboratory Procedures}

In the laboratory, depending on the sediment calibre, two procedures were carried out. For the coarse portion of the sediment samples, the A, B and C axes were measured to the nearest millimetre for each individual clast using callipers, with a phi size determined from the B axis. Each individual clast was also weighed and the total weight of the individual clasts within each $\Phi$ class was calculated. A coarse clast was any clast that had a B axis larger than approximately $20 \mathrm{~mm}$. 
The portion of the sediment samples finer than approximately $20 \mathrm{~mm}$ (e.g. the smaller coarse clasts, sand, and silt) were sieved using sediment sieves (Figure 5.12). The size of the sieves ranged from $-4 \Phi$ to $4.5 \Phi$. The sample was weighed before being placed into the top of the stacked sieves and shaken. The sediment collected on each sieve was then weighed. The two sets of clast measurements were combined by summing together the total weights for each $\Phi$ class and a percentage of the original weight of the total sample calculated to determine the percentage in each $\Phi$ class. Folk and Ward's (1957) graphical methods were used to determine mean grain size, sorting and skewness.

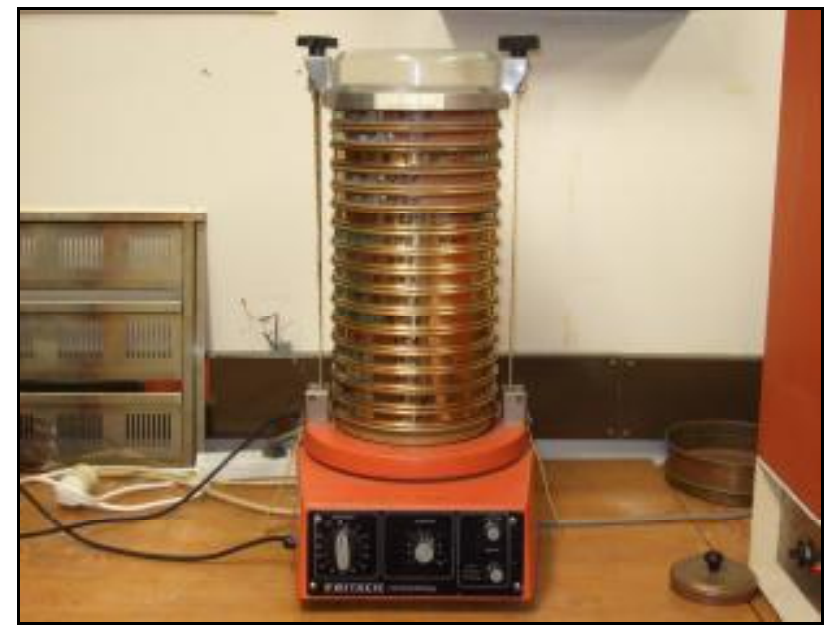

Figure 5.12: The sediment sieves used to sieve the fine portion of each sediment sample.

\subsection{Grain Size Results}

Generally the sediment located in the stream channel of Catchment 2 has a range of sediment sizes ranging between cobbles to silts. Cobbles and pebbles contribute greatly to all nine samples taken and are the dominant sediments in those samples located along the stream channel within the catchment (Samples 1 to 4). Moving downstream the percentages of smaller pebbles and sands increase, with the greatest amounts present in the samples taken on the fan (Samples 6, 7 and 8A), except Sample 8B which is made up of mostly coarse clasts. Silts are also only evident in the samples taken on the fan. The mean grain sizes for the nine samples range between $-5.73 \Phi$ and $-1.92 \Phi$ while the median grain size ranges between $-6.1 \Phi$ and $-1.85 \Phi$. 
The nine samples are moderately to poorly sorted. The more poorly sorted samples are located in the stream channel near or on the fan surface (Samples 5, 6, 7 and 8A), while the moderately sorted sediment samples are located near the back of the catchment (Samples 1, 2 and 4). Sample 8B is also moderately sorted. All samples except Sample 6 are positively skewed, indicating a tail of fine sediments. Skewness values for the nine samples range between 0.0 and 0.9. An individual analysis of each of the samples is presented in Appendix III.

It is worth noting that it has been recognised, through the analysis of the results that larger sample sizes should have been taken at each site to accommodate for the larger clasts within the samples. In examining the sediment samples, and the area of the stream channel from where the sample was taken, it is obvious that clasts approximately ranging between small to large pebbles $(-1 \Phi$ to $-4.5 \Phi)$ were the most common clasts present. Due to weight being used as a measure for the amount of clasts in each size range, the larger clasts, for example very large pebbles and cobbles, have tended to obscure the results as a small amount of these larger clasts weigh more than more of the smaller clasts. The results are therefore slightly skewed towards the larger sediments being more dominant within the samples. A larger sediment sample would have reduced this effect.

\subsection{Calculation of Shear Stresses}

This section describes the methods undertaken to determine likely or potential areas of sediment entrainment within the stream channel, through a comparison of boundary shear stress and critical shear stress. Boundary shear stress is the stress caused by the flow of water on the stream bed which is capable of entraining sediment, while critical shear stress is the stress required by a specific clast size for entrainment to occur. If boundary shear stress is equal to or greater than critical shear stress, a threshold of motion is reached where entrainment of individual clasts can be initiated and transported within the stream flow. Boundary shear stress variables are calculated for the outlets of sub-catchments A, E, G, I and J, while critical shear stress variables are calculated for the outlets of sub-catchments A to J (see Figure 4.3). 
This section is divided into two sub-sections. The first sub-section, section 5.8.1 describes the calculation of boundary shear stress, while sub-section 5.8 .2 will describe the calculation of critical shear stress for selected size clasts within the stream channel. All the data in this section were processed and analysed using Microsoft Excel (version 2003).

\subsubsection{Boundary Shear Stress}

Boundary shear stress is the point at which stress from the flow of water over the stream bed is available and capable of initiating sediment movement from the stream channel bed (Statham, 1977; Knighton, 1998; Fryirs and Brierley, 2001). The equation to calculate boundary shear stress is:

$$
\tau_{0}=\gamma R s
$$

Equation 5.6

where $\tau_{0}$ is the (boundary) shear stress exerted by the flow of water in the stream on the stream bed in $\mathrm{N} / \mathrm{m}^{2}, \gamma$ is the specific weight of water, $\mathrm{R}$ is the hydraulic radius of the stream cross section and $\mathrm{s}$ is the slope of the channel.

The main assumption behind the calculation of boundary shear stress is that the stream flow is uniform (Statham, 1977; Robert, 1990; Knighton, 1998). In many natural streams the flow of the water is not uniform in time or space. The velocity of water can vary at different locations across the stream channel as sections of the channel are shallower or deeper and with depth at the same location in the stream channel. In deeper sections of the stream channel, the stress caused by the water flowing over the stream bed will be greater. The stress caused by the stream flow on the stream bed also varies depending if the stream is in flood or not. As a result of this Robert (1990) notes that boundary shear stress is often an overestimate.

Boundary shear stress was only able to be calculated for sub-catchments A, E, G, I and J for the same reasons as discussed for unit stream power in Section 5.4.3. Variations in the specific weight of water $\left(9800 \mathrm{~kg} / \mathrm{m}^{3}\right)$ are negligible and therefore this variable will 
be treated as a constant in the equation. Due to this, only the hydraulic radius of the stream cross section and the slope of the stream channel are required to be determined for the calculation of boundary shear stress.

\section{Hydraulic Radius}

Stream depth can be used as an approximation of hydraulic radius. To determine the hydraulic radius of the point at the outlet of each sub-catchment, the equation for stream discharge is used (Equation 5.6):

$$
Q=A \times V
$$

where $\mathrm{Q}$ is the stream discharge $\left(\mathrm{m}^{3} / \mathrm{s}\right)$ at the outlet of the sub-catchment and $\mathrm{A}$ is the cross sectional area of the stream channel, which is equal to the width $(\mathrm{w})$ of the stream channel multiplied by the flow depth (d) of the stream. V is the velocity of the stream flow. The equation for stream discharge was then rearranged to determine the flow depth (Equations 5.7 and 5.8).

$$
\begin{aligned}
& A=Q / V \\
& d=A / w
\end{aligned}
$$

Equation 5.8

Equation 5.9

The values for discharge at each of the sub-catchment outlets were calculated using the Rational Method and are displayed in Table 5.12. The same stream channel width values used for the calculation of unit stream power, displayed in Table 5.13, were used. A stream velocity of 2 metres per second was assumed at all of the sub-catchment outlets as this value is representative of a reasonably rapid stream velocity which can be expected under high flow conditions within this stream channel. It is recognised that although velocity within the stream flow may be higher than this, the velocity of the stream flow over the channel bed is likely to be lower and therefore 2 metres per second is a good middle point. 
The values calculated for the hydraulic radius at the outlet of each sub-catchment are presented in Table 5.16.

Table 5.16: Values of hydraulic radius for sub-catchments A to $\mathrm{J}$ for $10-$ and $23-$ year return periods.

\begin{tabular}{|c|c|c|}
\hline \multirow{2}{*}{ Sub-Catchment } & \multicolumn{2}{|c|}{ Hydraulic Radius } \\
\cline { 2 - 3 } & 10 Year Return Period & 23 Year Return Period \\
\hline A & 0.114 & 0.144 \\
\hline E & 0.095 & 0.121 \\
\hline G & 0.223 & 0.287 \\
\hline I & 0.119 & 0.154 \\
\hline J & 0.070 & 0.090 \\
\hline
\end{tabular}

\section{Channel Slope}

The channel slope values calculated for each of the sub-catchments in the calculation of stream power (see Section 5.4.1, Table 5.1) were used as the channel slope values for the calculation of shear stress.

\subsubsection{Critical Shear Stress}

Critical shear stress is the shear stress from the flow of water required by a specific sized clast to begin to be entrained (Statham, 1977; Knighton, 1998). The equation for the calculation of critical shear stress is:

$$
\tau_{c}=K(\sigma-\rho) g D s
$$

Equation 5.10

where $\tau_{c}$ is the critical shear stress of a certain grain size in $\mathrm{N} / \mathrm{m}^{2}, \mathrm{~K}$ is a constant representing the packing of the clasts, $\sigma$ is the density of particles, $\rho$ is the density of water, $\mathrm{g}$ is the acceleration of gravity, $\mathrm{D}$ is the grain size diameter and $\mathrm{s}$ is the slope of the channel.

Critical shear stress is largely reliant on the characteristics of the sediment and the individual clasts within the stream channel and so assumptions are required to be made when calculating critical shear stress for natural streams. Critical shear stress is dependant on the size of the clasts within the stream channel and it is assumed that all of 
the clasts are of a similar size, which is rare in a natural stream channel. It is further assumed that the clasts are spherical. Packing and the orientation of the grains also affects how easily a clast can be entrained and values for this are also assumed to be constant. These assumptions can result in inaccurate predictions because the actual critical shear stress for clasts of different sizes will vary (Leopold et al, 1964; Statham, 1977; Knighton, 1998).

Variations in the density of the particles $\left(2600 \mathrm{~kg} / \mathrm{m}^{3}\right)$, the density of water $(1000$ $\left.\mathrm{kg} / \mathrm{m}^{3}\right)$ and the acceleration of gravity $(9.8 \mathrm{~m} / \mathrm{s} / \mathrm{s})$ are all negligible and therefore these variables can be treated as constants in the equation, with the values in parentheses used. For this reason, only the grain size diameter, the slope of the stream channel and the constant $\mathrm{K}$ are required to be determined for the calculation of critical shear stress.

\section{Grain Size}

Sediment samples 1, 2, 4, 5 and 6 were used as representative samples of subcatchments A, E, G, I and J respectively. Critical shear stress values were determined for eight grain sizes from each sediment sample site. These grain sizes were $-6 \Phi$ (64 $\mathrm{mm}),-5 \Phi(32 \mathrm{~mm}),-4 \Phi(16 \mathrm{~mm}),-3 \Phi(8 \mathrm{~mm}),-2 \Phi(4 \mathrm{~mm}),-1 \Phi(2 \mathrm{~mm}), 1 \Phi(0.5 \mathrm{~mm})$ and $3 \Phi(0.125 \mathrm{~mm})$. These grain sizes were selected as they represent a good spread of the range of the grain sizes within the sediment samples. Critical shear stress values could have been determined for certain percentiles of the sediment samples, for example the $75^{\text {th }}$ percentile grain size of the sample. However due to a high proportion of the sediment within the samples being of a coarse size, this method would not determine critical shear stress values representative of the range of grain sizes within the samples.

\section{Channel Slope}

The channel slope values calculated for each of the sub-catchments in the calculation of stream power (see Section 5.4.1, Table 5.1) were used as the channel slope values for the calculation of critical shear stress. 


\section{The Constant K}

$\mathrm{K}$ is a constant value used to describe the characteristics of the sediment within the stream bed. K can be calculated by:

$$
K=\eta(\pi / 6)
$$

Equation 5.11

where $\eta$ is the packing coefficient of the sediment sample (Leopold et al., 1964). Packing of stream bed clasts is the degree of spacing between the individual clasts. The packing of clasts present in the stream bed can affect how easily individual clasts can be entrained and is controlled by the characteristics of the individual clasts, particularly the size and shape of each clast. Packing of the clasts in a stream bed also has an influence on porosity. Assuming the clasts are spherical, the loosest available packing occurs when clasts are arranged in a cubic formation, which exhibits a packing concentration of 0.524 and a porosity of 0.476 , while the tightest available packing occurs when clasts are arranged in a rhombic formation. Clasts in a rhombic formation have a packing concentration of 0.74 and a porosity of 0.26 (Allen, 1985; Selby, 1993). In natural streams clasts are rarely spherical and in areas with poorly sorted clasts voids between large clasts can be in filled by smaller clasts, leading to a tighter packing concentration and less porosity between individual clasts. However, it is more difficult to determine these values (Allen, 1985; Selby, 1993).

The packing coefficient of the sediment clasts at the locations of the sediment samples was empirically determined from photographs taken at each of the sites. At all of the sediment sample sites the clasts in the stream channel were poorly sorted which resulted in a low porosity and a tight packing of the clasts in the stream channel due to the large range of grain sizes present. For this reason it was assumed that the clasts were packed in a rhombic form which has a packing concentration of 0.74 . This additionally required the assumption that the clasts were spherical and of equal size, although it is recognised that the clasts were not likely to be spherical and were poorly sorted. A theoretical maximum for the packing coefficient $(\eta=0.74)$ has therefore been assumed for all of the sediment samples and sediment sizes. Using this value for the packing coefficient, Equation 5.10 produces a value of 0.387 for the constant $\mathrm{K}$. 


\subsection{Shear Stress Results}

\subsubsection{Boundary Shear Stress Results}

The boundary shear stress values for a 10- and 23- year return period at the outlet of sub-catchments A, E, G, I and J are displayed in Table 5.17 and Figure 5.13. Similar to the values calculated for stream power and unit stream power, the 23 year return period boundary shear stress is higher than the 10 year return period boundary shear stress. Boundary shear stress for the calculated locations ranges between $54.8 \mathrm{~N} / \mathrm{m}^{2}$ and 394.0 $\mathrm{N} / \mathrm{m}^{2}$ and $70.7 \mathrm{~N} / \mathrm{m}^{2}$ and $506.2 \mathrm{~N} / \mathrm{m}^{2}$ for the 10 year return period and the 23 year return period respectively. Sub-catchment J, located at the outlet of Catchment 2, has the lowest boundary shear stress values for both return periods. There is a large increase in the calculated boundary shear stress for the outlet of sun-catchment G, as was seen with the values of stream power and unit stream power for the location, and is the highest value of boundary shear stress along the stream profile. Values for the other three locations along the stream profile are all within a small range of each other for both return periods.

Table 5.17: Boundary shear stress values calculated for sub-catchments A, E, G, I and J.

\begin{tabular}{|c|c|c|}
\hline \multirow{2}{*}{ Sub-Catchment } & \multicolumn{2}{|c|}{ Boundary Shear Stress $\left(\mathbf{N} / \mathbf{m}^{\mathbf{2}}\right)$} \\
\cline { 2 - 3 } & 10 Year Return Period & 23 Year Return Period \\
\hline A & 100.888 & 127.376 \\
\hline E & 101.926 & 130.501 \\
\hline G & 393.997 & 506.247 \\
\hline I & 93.500 & 120.497 \\
\hline J & 54.801 & 70.678 \\
\hline
\end{tabular}




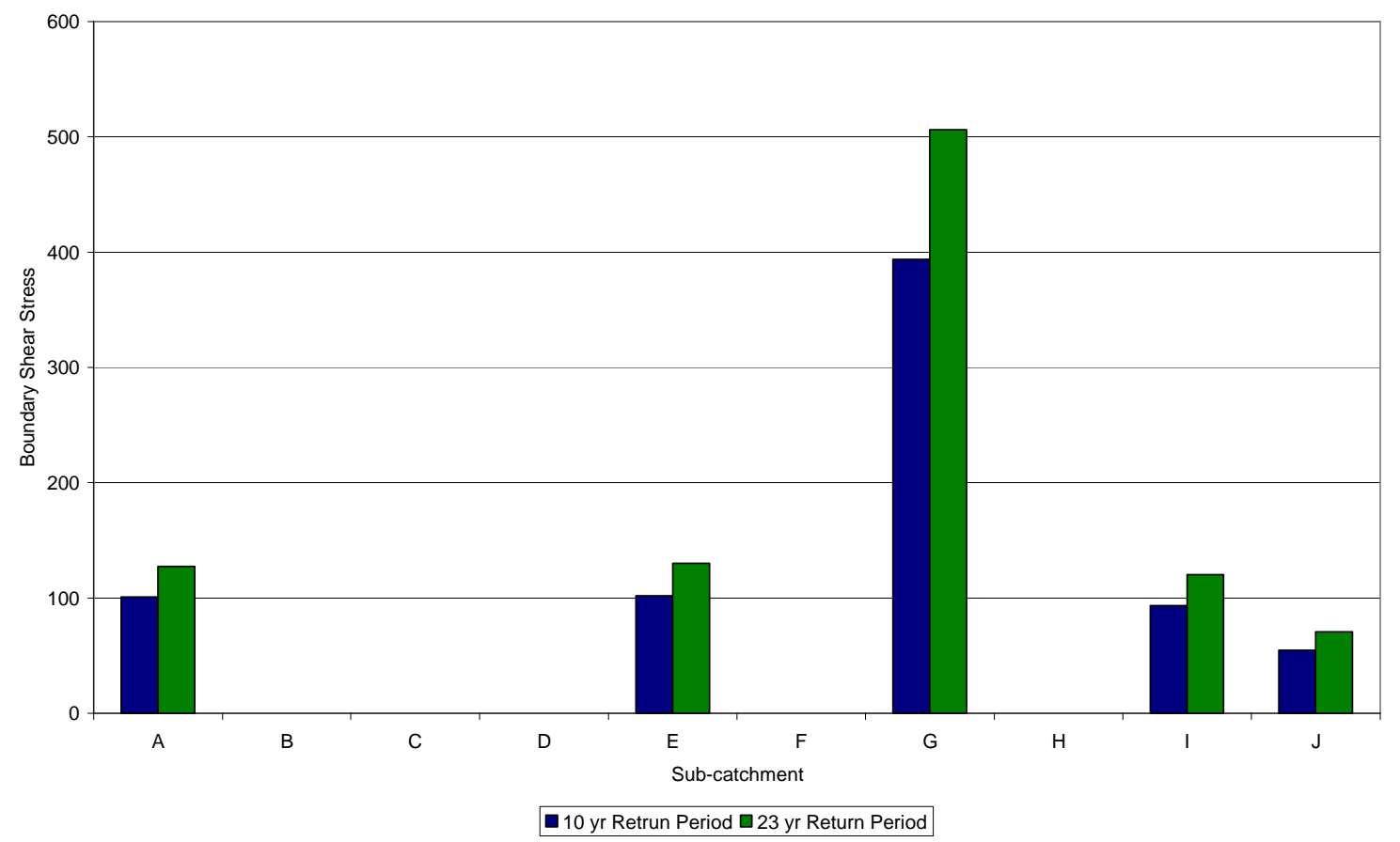

Figure 5.13: Boundary shear stress $\left(\mathrm{N} / \mathrm{m}^{2}\right)$ for a $10-$ and 23 - year return period stream flow discharge at the outlets of sub-catchments A, E, G, I and J.

\subsubsection{Critical Shear Stress Results}

The critical shear stress values for eight grain sizes at the outlets of the ten subcatchments, A to J, are displayed in Table 5.18 and Figure 5.14. As expected larger sized clasts have a higher critical shear stress than the smaller sized clasts, needing a higher shear stress to initiate entrainment. $-2 \Phi,-1 \Phi, 1 \Phi$, and $3 \Phi$ size clasts in all subcatchments have very low critical shear stress values. The range between each of the sub-catchments for each of these clast sizes is very small, with little difference in the critical shear stress values required for entrainment of the same size clast across each of the locations. As the clast size gets larger, the range of critical shear stress values of each clast size gets larger with critical shear stress values for $-6 \Phi$ clasts ranging between $31.1 \mathrm{~N} / \mathrm{m}^{2}$ and $70.0 \mathrm{~N} / \mathrm{m}^{2}$. Additionally the range of critical shear stress values between the different clasts sizes within each sub-catchment location gets larger. 
Table 5.18: Critical shear stress values calculated for sub-catchments A to J.

\begin{tabular}{|c|c|c|c|c|c|c|c|c|}
\hline \multirow[b]{2}{*}{$\begin{array}{c}\text { Sub- } \\
\text { Catchment }\end{array}$} & \multicolumn{8}{|c|}{ Critical Shear Stress $\left(\mathbf{N} / \mathbf{m}^{2}\right)$} \\
\hline & $\begin{array}{c}-6 \Phi \\
(64 \mathrm{~mm}) \\
\end{array}$ & $\begin{array}{c}-5 \Phi \\
(32 \mathrm{~mm})\end{array}$ & $\begin{array}{c}-4 \Phi \\
(16 \mathrm{~mm})\end{array}$ & $\begin{array}{c}-3 \Phi \\
(8 \mathrm{~mm})\end{array}$ & $\begin{array}{c}-2 \Phi \\
(4 \mathrm{~mm})\end{array}$ & $\begin{array}{c}-1 \Phi \\
(2 \mathrm{~mm})\end{array}$ & $\begin{array}{c}1 \Phi \\
(0.5 \mathrm{~mm})\end{array}$ & $\begin{array}{c}3 \Phi \\
(0.125 \mathrm{~mm}) \\
\end{array}$ \\
\hline A & 34.994 & 17.497 & 8.749 & 4.374 & 2.187 & 1.094 & 0.273 & 0.068 \\
\hline $\mathrm{B}$ & 50.548 & 25.274 & 12.637 & 6.318 & 3.159 & 1.580 & 0.395 & 0.099 \\
\hline $\mathrm{C}$ & 46.659 & 23.330 & 11.665 & 5.832 & 2.916 & 1.458 & 0.365 & 0.091 \\
\hline $\mathrm{D}$ & 34.994 & 17.497 & 8.749 & 4.374 & 2.187 & 1.094 & 0.273 & 0.068 \\
\hline $\mathrm{E}$ & 42.771 & 21.385 & 10.693 & 5.346 & 2.673 & 1.337 & 0.334 & 0.084 \\
\hline $\mathrm{F}$ & 34.994 & 17.497 & 8.749 & 4.374 & 2.187 & 1.094 & 0.273 & 0.068 \\
\hline G & 69.989 & 34.994 & 17.497 & 8.749 & 4.374 & 2.187 & 0.547 & 0.137 \\
\hline $\mathrm{H}$ & 54.436 & 27.218 & 13.609 & 6.804 & 3.402 & 1.701 & 0.425 & 0.106 \\
\hline I & 31.106 & 15.553 & 7.777 & 3.888 & 1.944 & 0.972 & 0.243 & 0.061 \\
\hline $\mathbf{J}$ & 31.106 & 15.553 & 7.777 & 3.888 & 1.944 & 0.972 & 0.243 & 0.061 \\
\hline
\end{tabular}

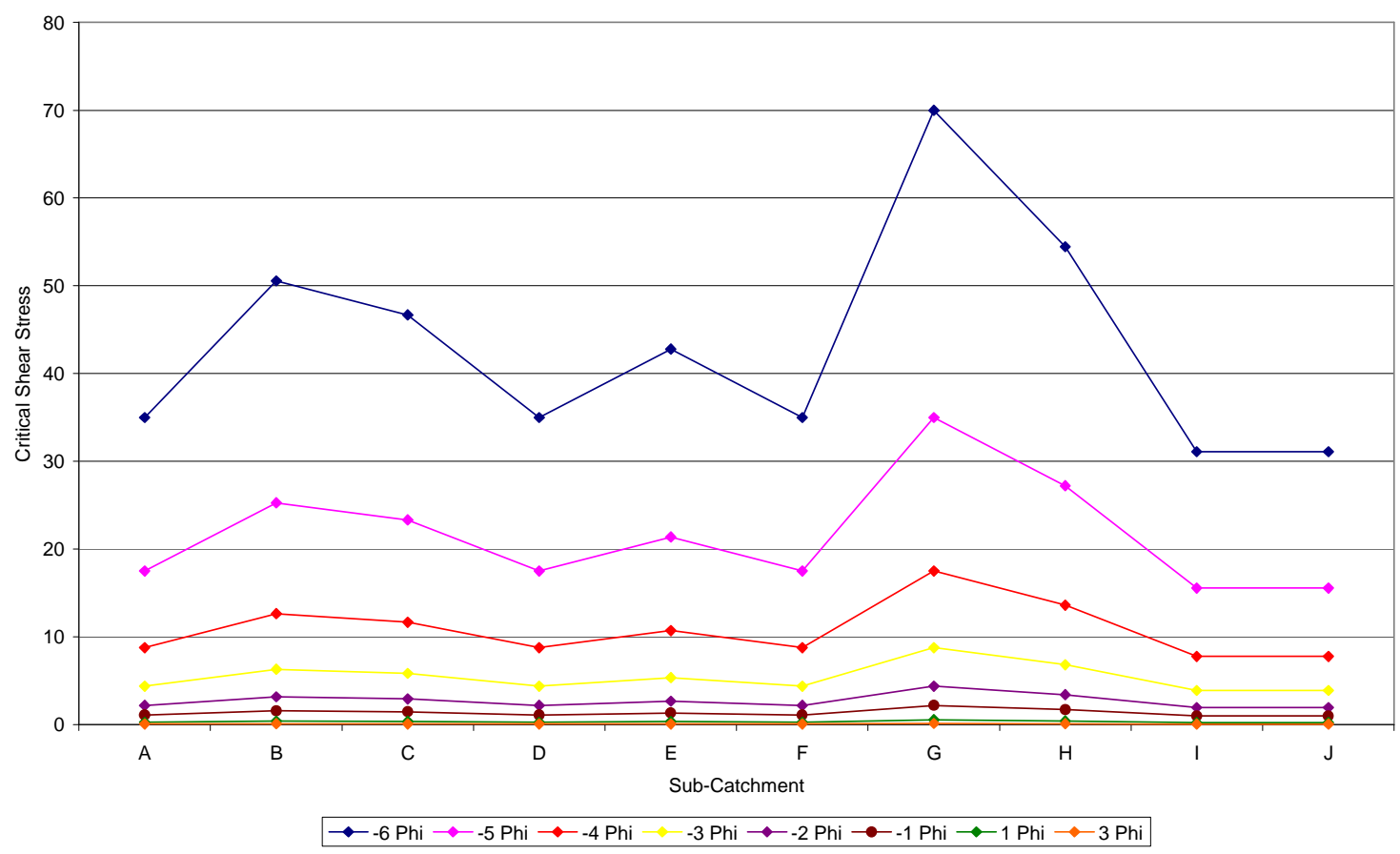

Figure 5.14: Critical shear stress $\left(\mathrm{N} / \mathrm{m}^{2}\right)$ values required for the initiation of entrainment for eight different clast sizes in the sub-catchments, A to J.

Clasts can be entrained when boundary shear stress is equal to or greater than the critical shear stress exhibited by specific sized clasts. The calculated boundary shear stress values for the outlets of sub-catchments A, E, G, I and J, under both 10- and 23year return period flood events, are all greater than calculated critical shear stress values determined for each clast size. This comparison of the shear stresses within the unnamed stream channel will be discussed further in Chapter 7. 


\section{Chapter 6 \\ Sediment Event Temporal Patterns: \\ Sedimentation Rates and Model Projections}

\subsection{Introduction}

This chapter deals with the investigation of temporal patterns of sediment deposition on Fan 2, as introduced in Chapter 4. Through morphological interpretation of the field site, annual rates of sediment accumulation onto the fan are determined, as is an estimate of the sedimentation rate of two events which occurred during 2008. These provide an indication of how much sediment has been deposited onto Fan 2 and allows for a comparison with recent sediment events. Potential changes to the frequency of sedimentation events and the annual rates of sediment accumulation onto Fan 2 due to altered rainfall runoff regimes are determined through the use of the spatially distributed sediment transport model, CAESAR.

This chapter consists of four main sections. Section 6.2 describes the methods used to estimate sedimentation rates onto Fan 2, while section 6.3 presents the results of this. A description of CAESAR and its use to project potential changes to the frequency of hazardous events on Fan 2 is provided in section 6.4. The final section (section 6.5) displays the results generated from CASEAR.

\subsection{Sedimentation Rates}

Sediment accumulation rates on alluvial fans is highly specific to each individual fan and is related to the characteristics of the catchment (such as lithology, catchment area, vegetation and relief), and the tectonic and climatic environment specific to the area. In addition, sediment accumulation rates are also dependant on the occurrence of the triggering events over the area of the individual catchment and fan (Blair and McPherson, 1994; Crosta and Frattini, 2004; Garfi et al., 2006). A morphological 
interpretation of the fans and their surrounding landscape was carried out to determine an estimate of yearly potential sediment deposition and a contemporary event sediment accumulation rate on the fans.

\subsubsection{Field Surveying Using the EDM and RTK}

A field survey of alluvial Fan 2 and a fourth fan, located to the south of the field site, was undertaken. The fourth fan consists of a recently active fan superimposed on an older truncated relict fan (Figure 6.1). The truncated fan is possibly evidence of an old shore line, which has been uplifted and the recently active fan has been deposited in front of this since the time of uplift. Location and elevation coordinates were collected with a Trimble S6 servo-driven total-station Electronic Distance Meter (EDM) and a Trimble R8 Real-Time Kinematic (RTK) Global Positioning System (GPS) unit.

The EDM was used to map location and elevation coordinate points only on Fan 2. This was due to the fan surface being larger than that of Fan 4. It was, therefore, more time efficient to gather the points in this way. The EDM contains reflectorless terrain scanning capability. This was set to automatically scan the surface of the fan and record the location and elevation coordinates at a set interval of two metres between each point. Thirteen base station locations were required to ensure the entire fan surface was covered by the scans, with five located on the upper fan and eight on the lower fan. This method was relatively time efficient, although it allowed for important points to be missed if they fell between readings taken by the EDM, for example small rises or falls in the land such as a terrace that would need to be included in the survey. The EDM could also record vegetation, for example trees. These were edited out in the processing of the data points.

The RTK unit was used to gather location and elevation coordinates on Fan 4 and to gather additional finer detailed coordinates, which were needed to avoid important areas of interest not being recorded by the EDM as may have occurred on some sections of Fan 2. The RTK base station was set up near the centre of each fan to receive GPS signals from satellites. This information was then sent to the rover unit which receives a GPS signal from satellites also. The rover unit makes a comparison between the two 
signals to give accurate location and elevation coordinates for each recorded point relative to the base unit. On Fan 2, finer detailed data points were gathered for the location of the stream channel, mature trees, fences, the rail line and the State Highway. The ridges of the stopbanks were also traced. Points were recorded continuously every 0.5 to 1 metre depending on the detail required for the feature.

Location and elevation coordinates were continuously recorded every 1 metre as the rover unit was carried over the surface of Fan 4 . The edges of the fan terrace and the main stream channel were additionally surveyed to ensure that these features were recorded.

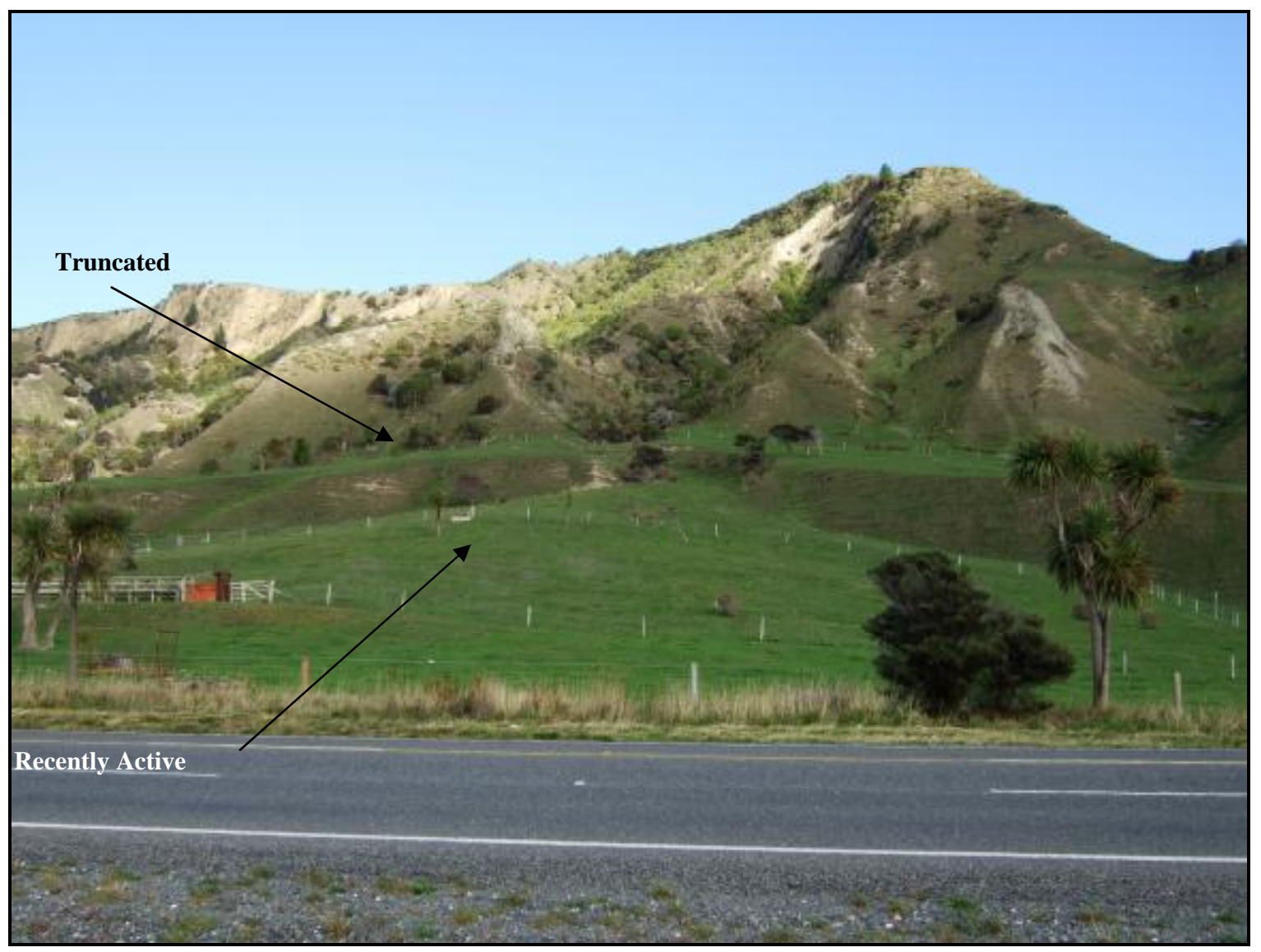

Figure 6.1: Fan 4 showing a recently active fan superimposed upon a truncated relict fan. 


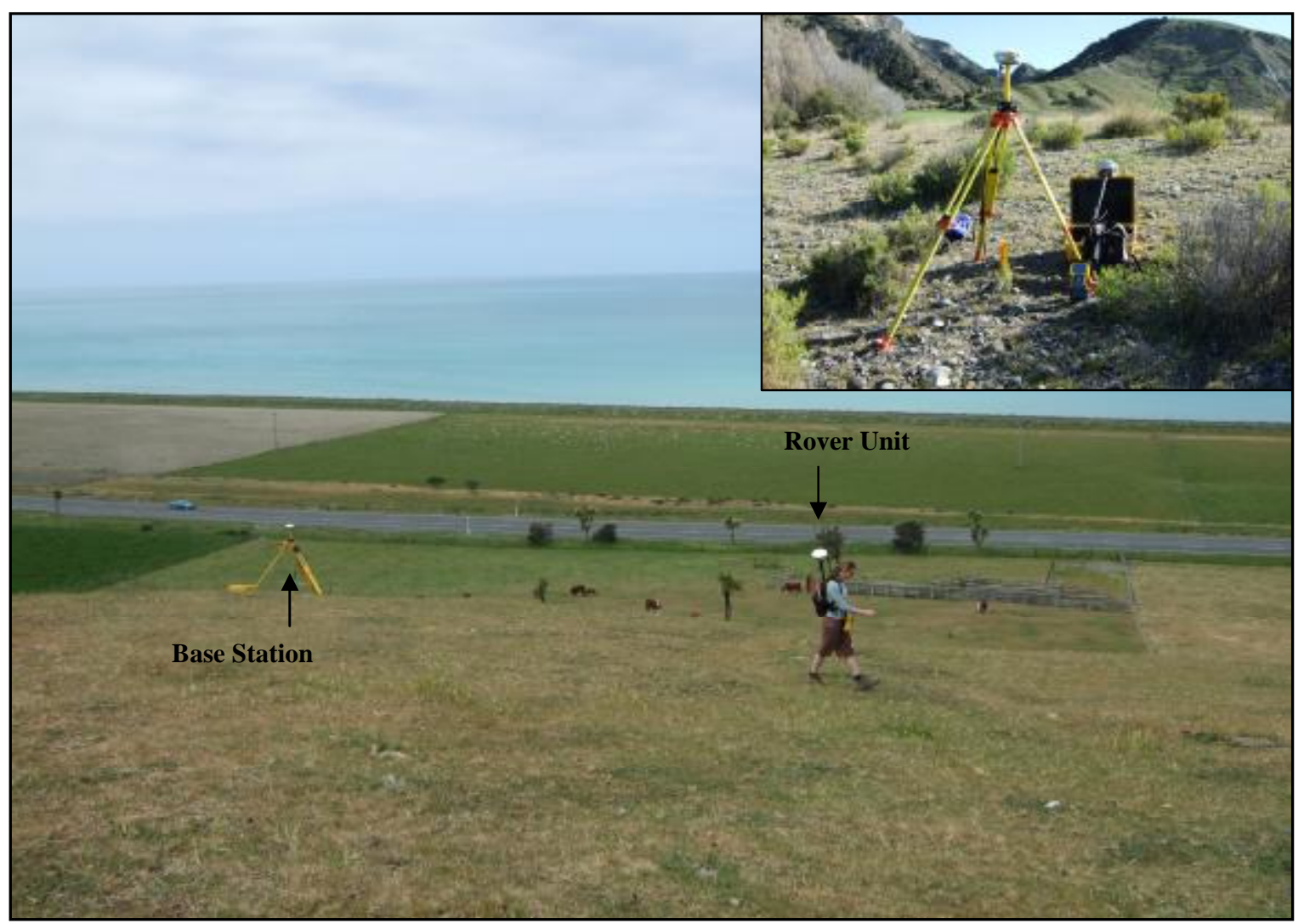

Figure 6.2: Use of the RTK GPS unit to collect elevation and location coordinates on Fan 4 . The inset shows the base station and the rover unit.

\subsubsection{Stored Sediment Volume Calculation}

The data coordinates collected during field work were downloaded into Microsoft Excel (version 2003) and then loaded into ArcMap (version 9.2). In ArcMap, a Digital Elevation Model (DEM) was created from these data coordinates using the Spatial Analyst Tool 'Natural Neighbour Interpolation'. The DEM was clipped to the area of the fan. From this clipped DEM of the fan, an estimation of the volume of the sediment underneath the fan surface was calculated using the 'Area and Volume' tool. It uses a simplifying assumption that the base of the fan is a flat smooth surface with a horizontal elevation. In reality the base of the fan may not be flat and smooth. There may be rises, sinks or other geomorphic features on the coastal plain that underlies the fans. Additionally the slope of the coastal plain is not horizontal and may rise slightly towards the hills. It is therefore likely that the estimated volume will be a slight overestimate of the actual sediment stored within the fans for this reason. Conversely, sediment has been removed from Fan 2 for use in local road works and infilling and 
sediment has been cleared from the channel after heavy rainfall events. This could lead to a slight under-estimate of the volume of sediment within this fan. The volume of sediment in the fans is therefore only an approximate estimation.

\subsubsection{Estimation of Geological Sedimentation Rates}

The truncated fan, which is part of the fourth fan, is possibly evidence of an old shore line, which has been uplifted and the recently active fan has been deposited in front of this since the time of uplift, hence the recently active fan is younger than the time of uplift. Evidence of this old shore line can be traced both north and south along the coastline, where further recently active fans are superimposed upon truncated relict fans. It is difficult to locate evidence of this truncation on the three main fans concerned in this study due to vegetation cover, erosion and the ongoing engineering of the currently active fans. However, it can be inferred to be continuing across the back of these fans. This would imply that the current active fans have also formed since the truncation of the sea cliff and Fans 1,2, and 3 are, therefore, younger than the time of uplift of the sea cliff.

The age of the sea cliff was determined from a Quaternary geological map. The volume of sediment in the fan is divided by the age of the sea cliff to give an average annual amount of sediment deposition since the relict fan was truncated.

\subsubsection{Event Sedimentation Rates}

The two large rainfall events which occurred during July and August 2008 resulted in large amounts of sediment being transported through the catchments and out onto the alluvial fans. Records of the amount of sediment movement were not made, but it can be inferred from features near the apex of the alluvial fans, located beyond the bulldozed section of the stream channel, that a large amount of sediment was deposited onto the fans. Kanuka (Kunzea spp.) and other small shrubs near the apex of Fan 2, which were not buried prior to these rainfall events, were partially buried (Figure 6.3A). 
Stream bank escarpments were also partly buried by sediment deposited during these two rainfall events (Figure 6.3B).

Additionally, fencing posts put in place to stabilise the sides of the stream channels near the apex of Fan 2 and the bottom of its catchment were either partially or completely buried. Most of the posts photographed during field work in May 2008 were completely buried by sediment during the two rainfall events, with only two partially buried posts being easily located (Figure 6.3C and D). The fence posts photographed during May ranged in height from approximately $12.5 \mathrm{~cm}$ to $28 \mathrm{~cm}$ (excluding the two posts which were partially buried). For the tallest post to be buried by sediment at least $28 \mathrm{~cm}$ of sediment must have been deposited in the stream channel of Fan 2. Assuming sediment was deposited evenly along the stream channel, a volume of sediment deposited in the stream channel of Fan 2 has been estimated.

In ArcMap the location of the stream channel on Fan 2 was digitised onto the DEM of Fan 2 and the area of the stream channel was calculated using the 'Calculate Geometry' tool. The area of the stream channel was then multiplied by the estimated minimum depth of sediment that was deposited to bury the fence posts. 


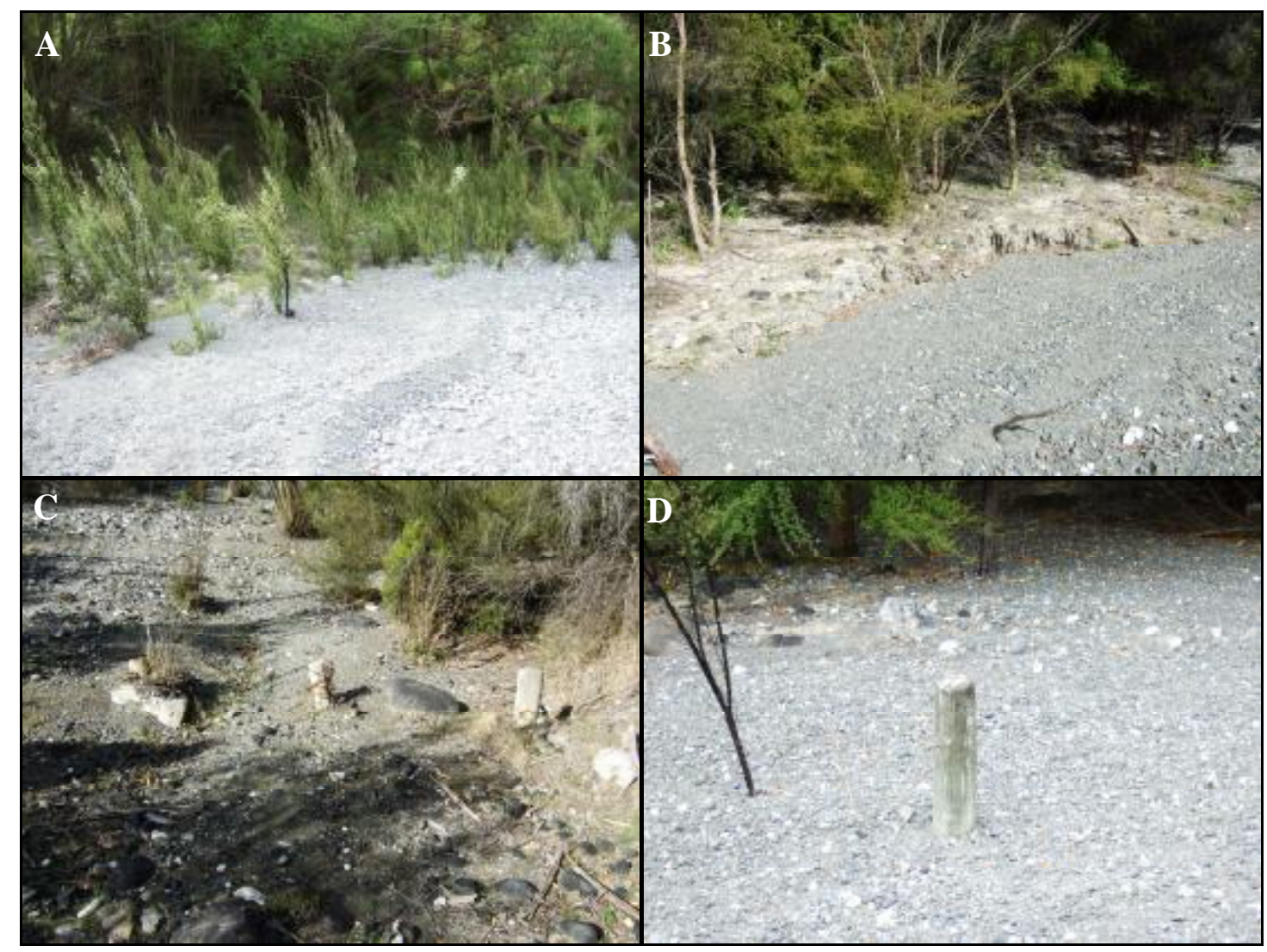

Figure 6.3: Features near the apex of Fan 2 which were partially or completely buried during the two heavy rainfall events in July and August 2008. A: Partially buried Kanuka at the apex of the fan. B: A partially buried stream bank escarpment. C: Three of the fence posts photographed in May 2008 which were completely buried by the two rainfall events. D: The top portion of a partially buried fence post located near the apex of the fan.

\subsection{Sedimentation Rates Results}

\subsubsection{Stored Sediment Volume}

The volume of sediment stored within Fan 2 and Fan 4 was calculated from a DEM of each fan using GIS (Figure 6.4).

The estimated volume of sediment stored in each of the fans is presented in Table 6.1 below. Fan 2 has developed at the outlet of a much larger catchment than Fan 4. The area of Fan 2 and therefore the volume of sediment stored within it are much larger than for Fan 4 as a result of this. 


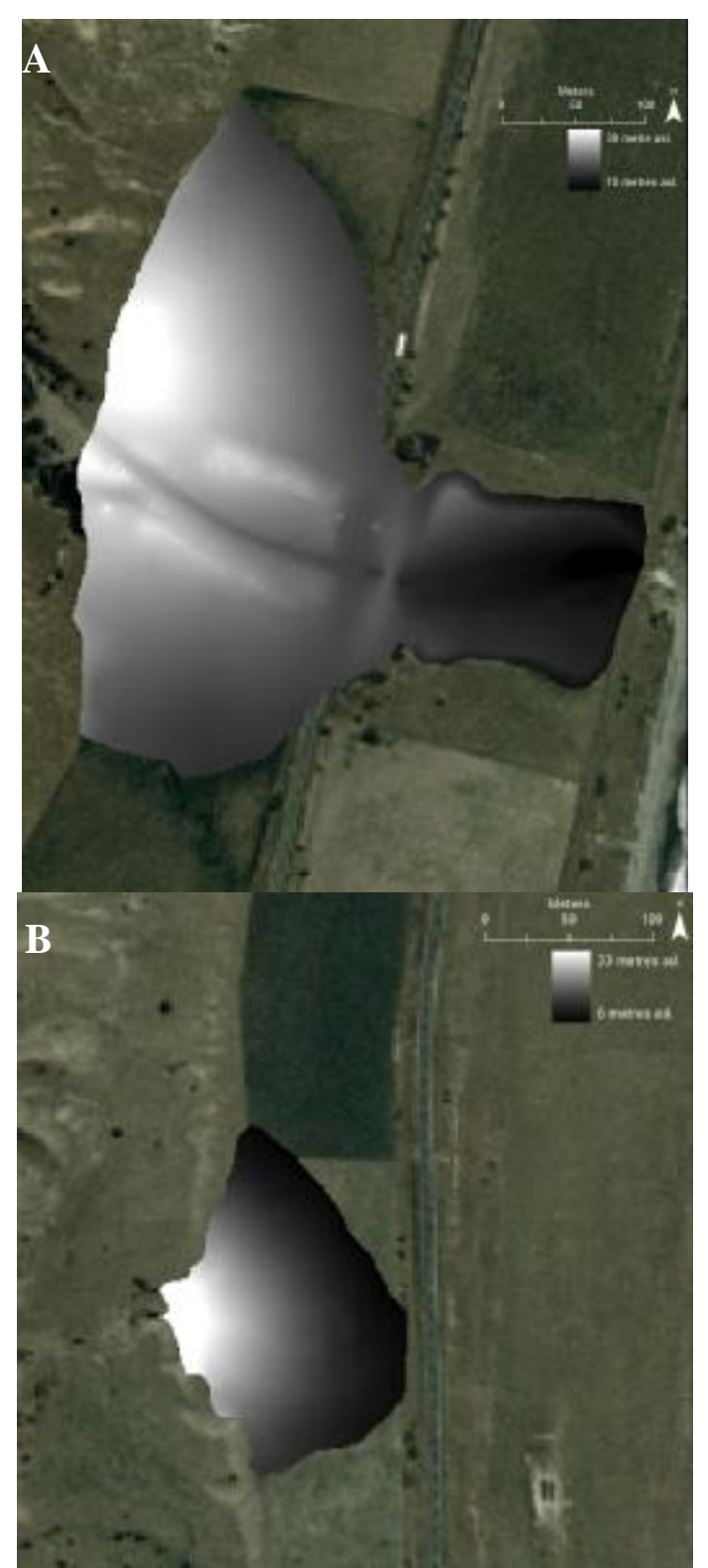

Figure 6.4: The clipped DEMs of A: Fan 2 and B: Fan 4 constructed in ArcMap from data collected in the field.

\subsubsection{Geological Sedimentation Rates}

The age of the uplifted sea cliff was determined from a Quaternary geological map which showed the sea cliff to be approximately 6000 years old. The terraces were formed after the Holocene maximum sea level high stand. This implies that the fan deposits located in front of this sea cliff have been deposited in the last 6000 years.

An approximate average annual rate of sediment accumulation onto the fans has been calculated (Table 6.1). Over the last 6000 years an annual average of $181.07 \mathrm{~m}^{3}$ of 
sediment has been deposited onto Fan 2. An annual average of $23.41 \mathrm{~m}^{3}$ of sediment was deposited onto Fan 4 over this time.

Table 6.1: Estimated volume of stored sediment and the geological sedimentation rates for Fan 2 and Fan 4

\begin{tabular}{|c|c|c|}
\hline Fan & Volume of Stored Sediment in Fan & Geological Sedimentation Rate \\
\hline Fan 2 & $1,086,430.36 \mathrm{~m}^{3}$ & $181.07 \mathrm{~m}^{3} /$ year \\
\hline Fan 4 & $140,442.06 \mathrm{~m}^{3}$ & $23.41 \mathrm{~m}^{3} /$ year \\
\hline
\end{tabular}

\subsubsection{Event Sedimentation Rates}

The area of the stream channel on Fan 2 is $4137.49 \mathrm{~m}^{2}$. Assuming sediment was deposited evenly along the stream channel, it can be inferred from the height of the buried fence posts that at least $1158.50 \mathrm{~m}^{3}$ of sediment was deposited into the stream channel of Fan 2 during the two heavy rainfall events which occurred in July and August 2008.

An assessment report on possible improvements to the State Highway crossing the alluvial fans (Ballard, 2008), completed for Transit New Zealand, states that the by-pass bridges are used on average 28 days per year due to streams carrying sediment flowing over the road. From this information, and using the annual geological sedimentation rates (Table 6.1), it can be inferred that approximately $6.47 \mathrm{~m}^{3}$ of sediment is deposited onto Fan 2 per day of sedimentation. The clear differences between the annual sediment accumulation rates and the 2008 event sediment accumulation rates will be discussed in Chapter 7.

\subsection{Model Projections}

A spatially distributed cellular sediment transport model was employed to determine how the temporal frequency of potential hazardous events, and the amount of sediment delivered by streams onto the fans during these events, could alter in relation to climatic changes. Rainfall/runoff regimes representing the current climate and a possible altered climate in 2070 are used for two separate model runs which simulate sediment discharge events through the catchment and out onto the fan. A comparison of the 
frequency of differing magnitudes of sedimentation events enables an indication of how the frequency and likelihood of hazardous events may change in the future.

A selection of cellular models are able to do this, including the CAESAR, CASCADE, CHILD, GOLEM and SIBERIA cellular models. These models operate over a variety of time and space scales and focus a variety of geomorphic processes such as tectonics, hillslope processes and fluvial erosion and deposition (Coulthard, 2001). The use of the spatially distributed cellular sediment transport model CASEAR (Cellular Automation Evolutionary Slope and River model; Coulthard and Van De Wiel, Date unknown; Coulthard et al., 2002; Coulthard et al., 2005) is most suitable for this study as it is capable of modelling landscapes over smaller spatial (1 metre to 50 metre cells representing the landscape) and temporal (10 to 10000 years) scales with good detail (Coulthard, 2001). It therefore does not include processes that operate over longer spatial and temporal scales, for example tectonic uplift, which other cellular models are able to model but rather focuses on the fluvial processes within the catchment. CAESAR further allows catchment processes to be modelled for the catchment. For these reasons CAESAR (version 5.9c) has been used in this study.

This section describes CAESAR and its use to project potential changes to the frequency of hazard on the alluvial fan of Catchment 2. A brief description of how CAESAR works is first given. The methods undertaken to process and collate the data required for the running of CAESAR are then discussed and resultant data presented. Finally a brief outline of the two model runs using this data is given. In section 6.5 the results generated from CAESAR under both current and climatically altered future rainfall runoff regimes are presented.

\subsubsection{CAESAR}

The use of cellular models in simulating the geomorphic processes occurring in river catchments is increasing and becoming well accepted in fluvial geomorphology (Coulthard and Van De Wiel, Date unknown; Coulthard et al., 2007). These models are starting to allow the potential geomorphic reactions of catchments and rivers to land use changes or altered climatic situations to be studied (Coulthard and Van De Wiel, Date 
unknown; Coulthard, 1999; Coulthard et al., 2000; Coulthard et al., 2002; Coulthard et $a l ., 2005)$. The spatially distributed sediment transport model CAESAR is one of these models developed within the last decade. CAESAR has been developed to simulate the morphological changes that occur in river catchments (Coulthard and Van De Wiel, Date unknown). It models the flow of water and sediment transport within a catchment in a two dimensional view by using a grid of cells which represent the landscape, that are altered by a set of rules controlling the morphological processes (Coulthard and Van De Wiel, Date unknown; Coulthard et al., 2003).

CAESAR was initially developed to determine possible changes to river catchments, especially through sediment erosion and deposition, as a result of climatic or land use changes in temperate areas (Coulthard and Van De Wiel, Date unknown). For this reason the model was designed to model short to intermediate temporal scales (within the Holocene) and small to moderate spatial scales (Coulthard, 2001; Coulthard et al., 2007). It has been used to investigate river meandering (Coulthard and Van De Wiel, 2006) and braiding (Coulthard, 2001) and alluvial fan development (Coulthard et al., 2002). CAESAR can additionally model smaller scale landscape features such as river terraces, channel migration and pointbars.

\subsubsection{How CAESAR Works}

The CAESAR model has two modes in which simulations can be run: reach mode and catchment mode. The catchment mode allows the whole catchment to be modeled, and requires the inputs of a DEM and a rainfall data set (Coulthard and Van De Wiel, Date unknown; Coulthard et al., 2003). The reach mode allows only a section of the stream channel to be modeled. The reach mode requires a DEM and the input of stream discharges and sediment fluxes at one or more points where they enter the section of the stream concerned (Coulthard and Van De Wiel, Date Unknown; Coulthard et al., 2003). CAESAR is used in catchment mode for this study and the rest of this section will focus on how this mode works. 


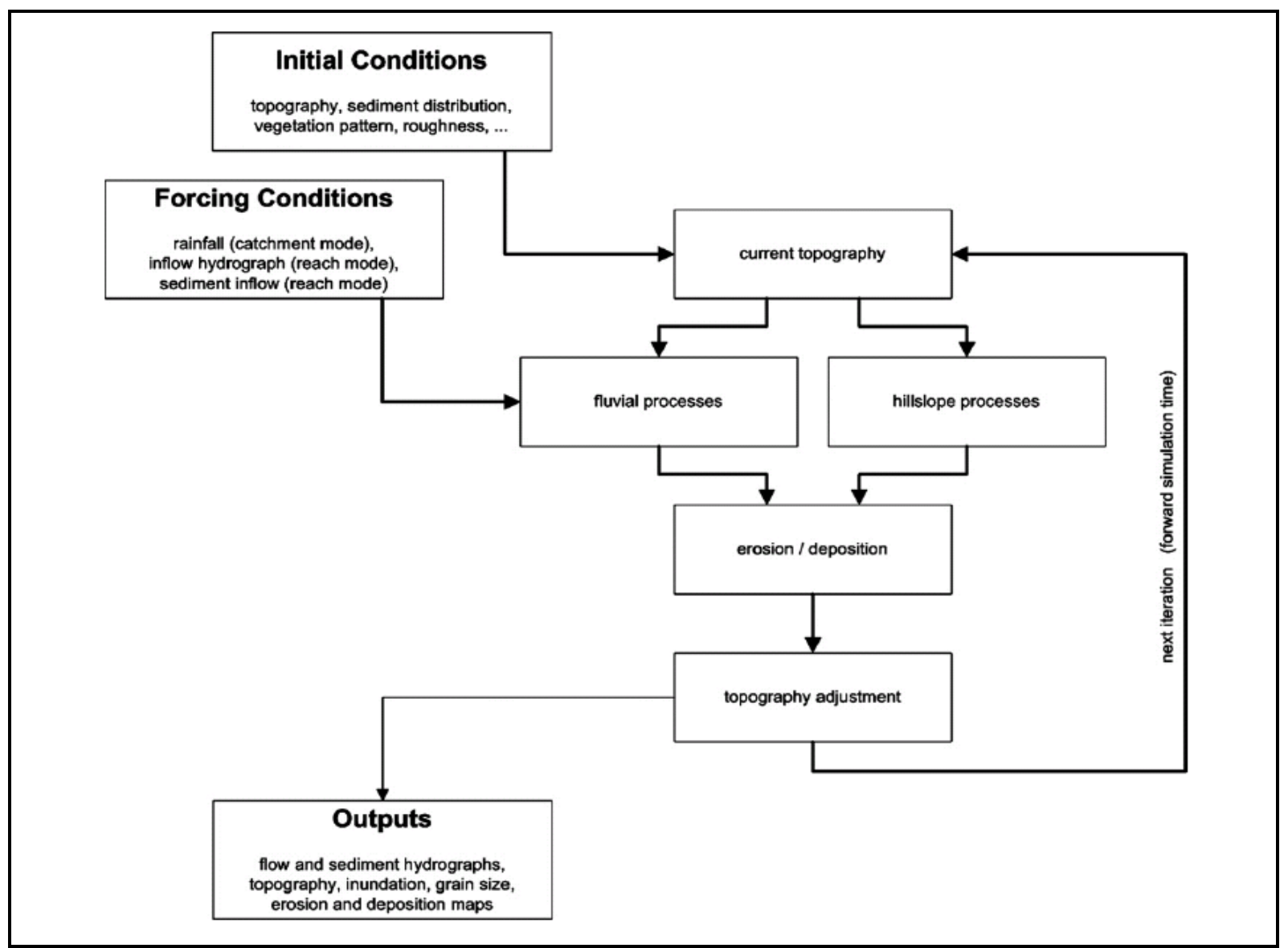

Figure 6.5: Flow chart showing the operation processes carried out during the running of CAESAR (Van De Wiel et al., 2007)

Figure 6.5 shows the operation processes carried out by the CAESAR model during each iteration of the model run. The characteristics of the catchment, for example elevation and topography (from the DEM) and the grain size ranges of the source sediment, are entered into the model, where this information is assigned to each cell within the DEM grid (Coulthard and Van De Wiel, Date unknown; Coulthard, 1999). This represents the initial conditions of the catchment. Hourly rainfall data is also entered into the model to provide climatic information for the entire catchment.

Once the location of the stream channel has been calculated by the model during the first model iterations (normally set at 20 iterations), a discharge of water is determined from the rainfall data and calculated for each cell, and then run through the catchment, where it flows into the stream and out the outlet of the catchment. This is carried out by a "flow-sweeping" or "scanning" (Coulthard, 1999) algorithm, which is illustrated in Figure 6.6. 


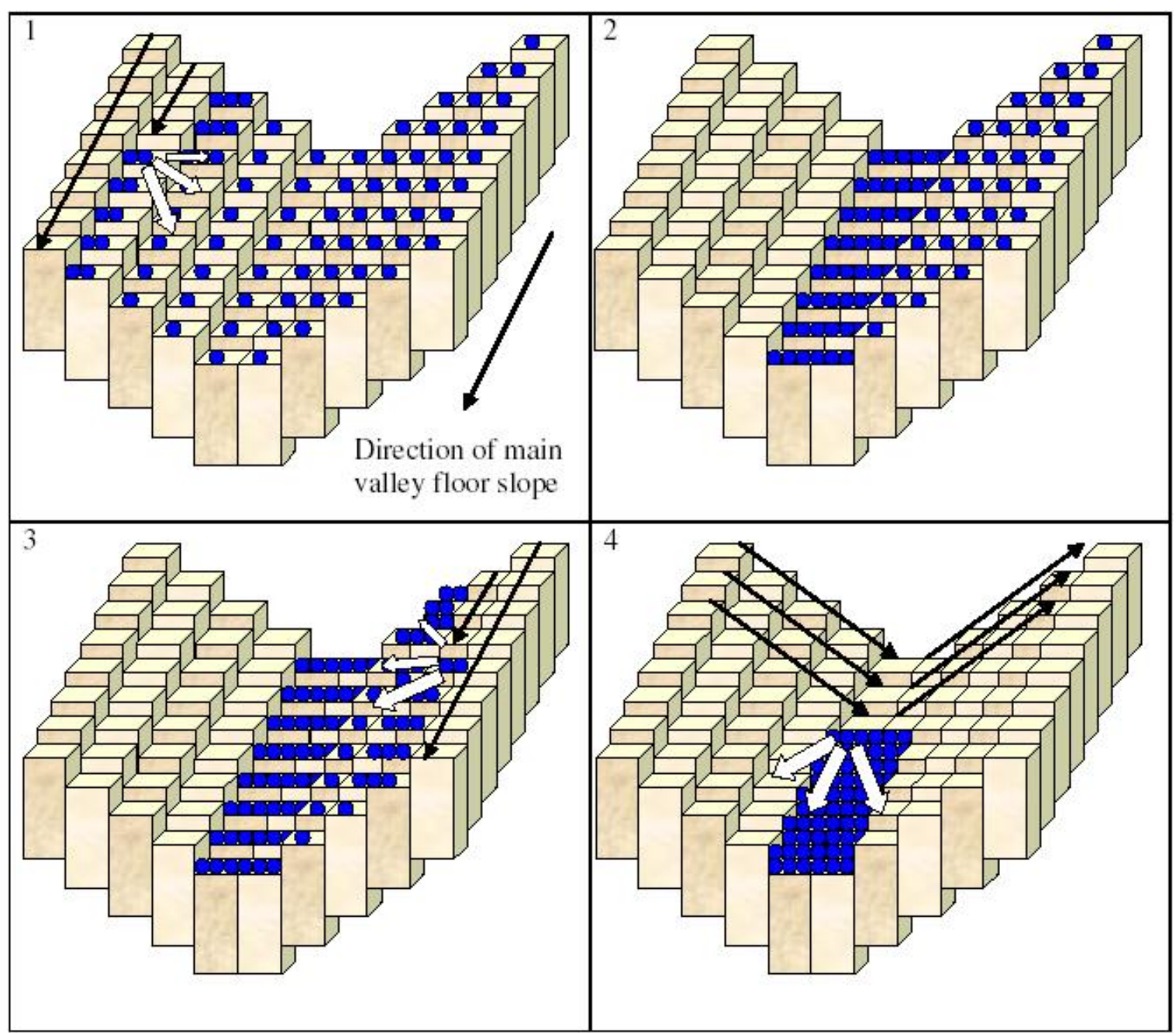

Figure 6.6: Schematic diagram of the scanning algorithm used to pass water through a catchment by the CAESAR model. Box 1 shows the left to right scan moving down the catchment pushing water to cells on the right. Box 2 shows the result after the left to right scan is completed. Box 3 shows the right to left scan, pushing water to cells on the left leaving water in the channel cells. Box 4 shows the top to bottom scan moving water down the channel. (Coulthard et al., 2002)

The flow-sweeping algorithm moves over the catchment in four directions, allowing water to potentially flow in all directions so the modelled river can braid or meander. The first scan moves from the left side of the catchment, over the valley bottom (or channel), and up the right side, moving the water from each cell to any lower cells occurring to the right. No water can be moved from the right side of the catchment, as the cells to the right are all higher than the passing cell (Box 1 in Figure 6.6). This water is moved in the next scan, where the same process is repeated, moving water to lower cells as the scan moves from the right side of the catchment, over the valley bottom, and up the left side (Box 3 in Figure 6.6; Coulthard and Van De Wiel, Date unknown; Coulthard et al., 2002). 
After the first two scans are complete, water is located only in the stream channel. The last two scans work to move the water through the channel and out of the catchment by moving from the top of the catchment to the bottom (Box 4, Figure 6.6) and then from the bottom of the catchment to the top (Coulthard and Van De Wiel, Date unknown; Coulthard et al., 2002). The "scanning" algorithm allows water to be trapped within the catchment if all surrounding cells are higher than the passing cell. This trapped water remains in the passing cell until the next model iteration, where water may be able to be passed to the next cell if the additional flow is able to overtop the surrounding cells (Coulthard and Van De Wiel, Date unknown; Coulthard et al., 2002; Van De Wiel et al., 2007).

Hillslope processes are also calculated, while the process of moving water through the catchment is carried out. CAESAR is a fluvial geomorphologic model, so most of the model run time is spent determining the channel processes, while the rest of the catchment is ignored. This allows the model to run faster (Coulthard, 1999; Coulthard, 2001; Coulthard et al., 2003). At set iteration intervals the rest of the catchment is scanned for mass movements, for example locations where landslides or soil creep could occur. Mass movements occur where the slope between two cells is greater than a set threshold, normally set at $45^{\circ}$ to $50^{\circ}$. Sediment is moved to the cell below until the slope between cells is below the set threshold. This movement can additionally trigger cells located above to transfer sediment as the supporting material has been removed from underneath the cell (Coulthard, 1999). Mass movements are calculated every 100 iterations. Soil creep is calculated once a month of the model run time and can result in minor cell elevation changes (Coulthard, 1999).

Once the water has been run through the catchment and the hillslope processes (if necessary) have been calculated, the fluvial erosion, transport and deposition of sediments in and around the channel are determined using either the Wilcock and Crowe or Einstein-Brown equations (Coulthard and Van De Wiel, Date unknown; Coulthard, 1999). This calculates the amount of sediment moved from one cell to another cell or transported out of the catchment. Sediment can be transported as bedload or suspended load (Van De Wiel et al., 2007). The elevations of the cells that make up the catchment are then altered in the final step of each individual model iteration 
(Coulthard and Van De Wiel, Date unknown; Coulthard, 1999). This process is then repeated until all of the model iterations have been run.

CAESAR makes a number of assumptions about the catchment and the processes which operate within the catchment. It is assumed that the stream flowing through the catchment is a perennial stream. Up to nine grain sizes can be input into CAESAR. Another key assumption made by the model is that these nine grain sizes are representative of the sediment which is present both in the catchment and in the stream channel. CAESAR further assumes that the rainfall intensity is equal over the entirety of the catchment. CAESAR further, recognises that vegetation cover acts to protect sediment from being eroded by water flows and so incorporates a function which enables a grass cover to grow over the cells where water flow is not occurring. The length of time this grass cover takes to mature can be set.

\subsubsection{Data Collection}

For CAESAR to be run in "catchment" mode several site specific types of data are required:

- DEM of the catchment

- Hourly rainfall record

- Sediment grain size

The methods used to collect and prepare these data are discussed and the resultant data are presented in the following subsections.

\section{Digital Elevation Model}

A relatively high resolution DEM is needed to produce a good result from CAESAR. Given that Catchment 2 is narrow with steep slopes and a narrow stream channel, a moderate resolution DEM, for example a 20 or 25 metre DEM, would not display the catchment and its stream channel accurately. A 10 metre DEM of Catchment 2 was constructed using the DEM Extraction Wizard tool, within the DEM Extraction Module of the ENVI software (version 4.6.1). This software uses stereo pair aerial photographs with Rational Polynomial Coefficients (RPC). These RPC points are calculated by the software using ground control points and camera information in a digital 
photogrammetry technique which determines the position, angle and orientation of the aerial photographs in relation to the camera used to take the photographs and the ground control points representing the actual landscape.

Stereo pair aerial photographs (photos D23 and D24, flight run SN3839) of the field site taken in 1975 were scanned at high resolution. RPCs were generated for each photograph using GPS points gathered in the field and camera information supplied with the aerial photographs. Six GPS points were referenced for photo D23 with a RMS error of 3.2 metres, while four GPS points were referenced for photo D24 with a RMS error of 0.0 metres. Tie points were selected to define the relationship between each of the stereo images by locating identical points on each of the images. 20 tie points which were present on both photographs were located. The tie points had a Maximum Y Parallax error of 1.0349 pixels between the two aerial photographs. The Maximum Y Parallax error is the maximum error in which the selected tie points on the second aerial photograph are located away from the $\mathrm{Y}$ parallax which has been estimated for this aerial photograph by the placement of the tie points on the first aerial photograph. The Maximum Y Parallax should be as close to 0 as possible but values of 1 are acceptable and a minimum of nine tie points are required for it to be calculated.

The tie points and the RPC information were then used to generate an epipolar image (Figure 6.7). An epipolar image allows stereo pair photographs to be viewed in 3D or stereo when the left and right aerial photographs are orientated so that the same features on each photograph have the same Y coordinate. The aerial photographs are viewed in a 'Red, Blue, Green' colour mode which allows the photographs to be viewed in 3D with anaglyph glasses. For these aerial photographs the left photograph (D24) was viewed in red and the right photograph (D23) was viewed in blue and green. From the epipolar image a 10 metre DEM was extracted. The DEM was edited within ENVI and tidied further in ArcMap (version 9.2) using the Spatial Analyst 'Hydrology' tools and clipped to the area of Catchment 2 (Figure 6.8). 


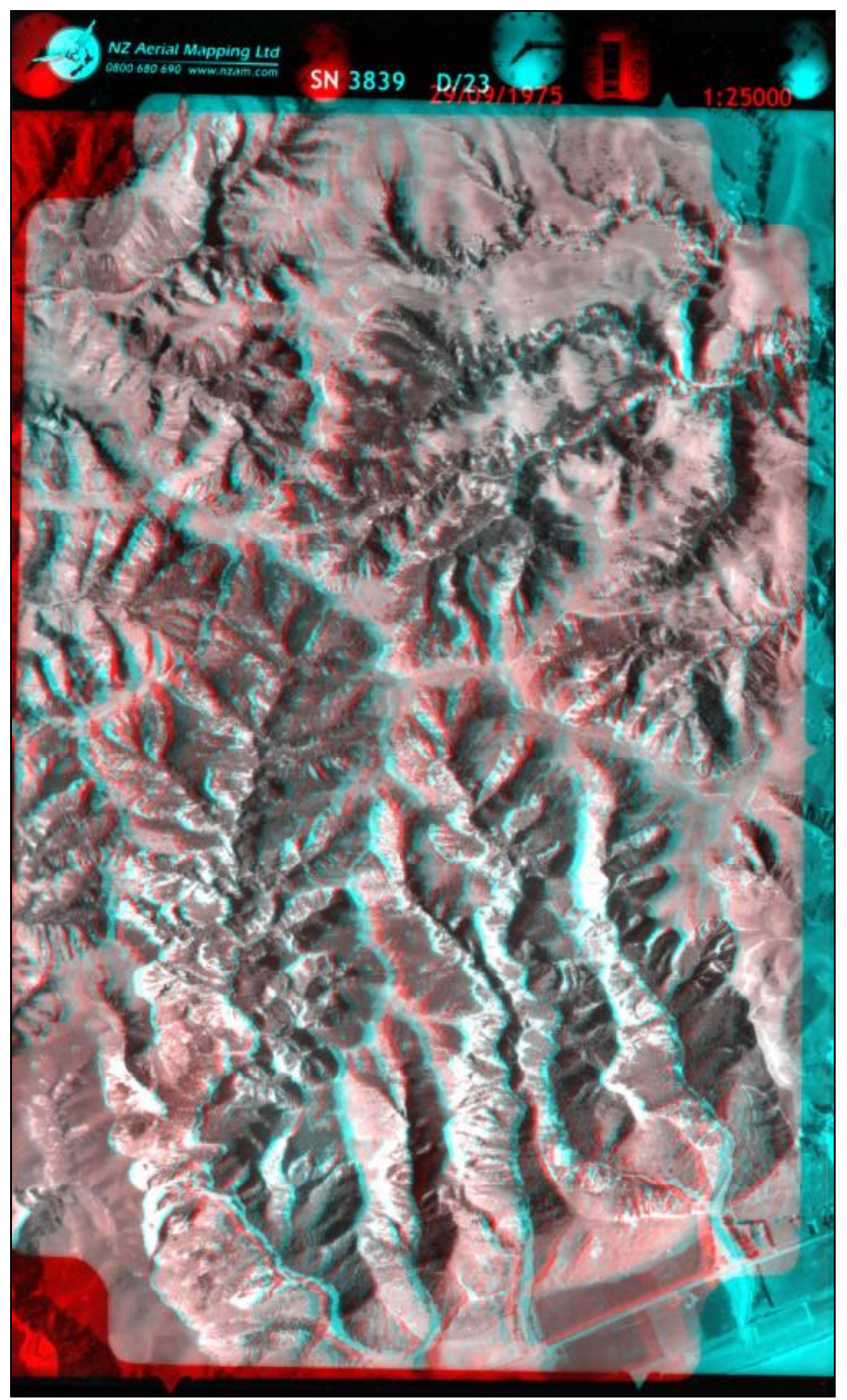

Figure 6.7: The epipolar image of the stereo pair images D23 and D24 generated in ENVI using tie points and the RPC information of the aerial photographs. 


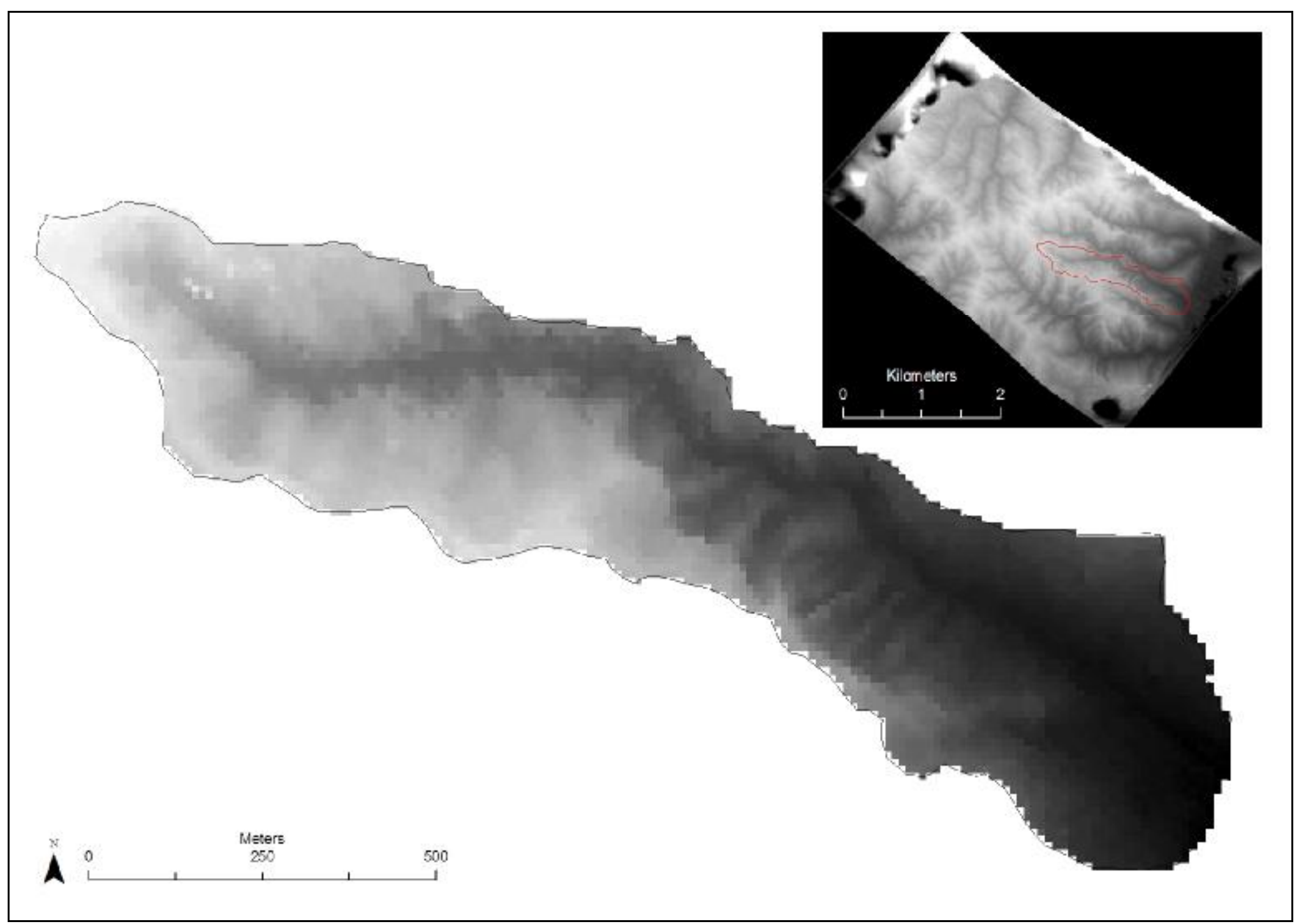

Figure 6.8: The clipped DEM of Catchment 2 to be used in the CAESAR model. Low elevations are dark coloured and high elevations are light coloured. The insert shows the DEM generated using ENVI from which the DEM of Catchment 2 was clipped. 


\section{Rainfall}

CAESAR requires an hourly rainfall data set for the model to be run. For use in this study two data sets were required: one representing the current climate and therefore the current amount of rainfall and one representing an altered climatic situation representing the possible climate changes projected for the region. An hourly rainfall data set recorded near the location of the field site was not available, with the closest gauging sites capable of providing hourly rainfall records located in Kaikoura, the Awatere Valley and Cape Campbell.

As an alternative, hourly rainfall data for the field site were produced by NIWA's Regional Climate Model (RCM). The RCM model produced rainfall data for two 30 year periods: 1971 to 2000 and 2071 to 2100 . The 1971 to 2000 rainfall data set is a control data set which represents the current climatic situation.

The 2071 to 2100 data represent a climatically altered future rainfall regime. The RCM was run based around the Intergovernmental Panel on Climate Change's "Special Report on Emission Scenarios (SRES)" A2 emissions scenario and was run using a 360 day calendar, with each month consisting of 30 days. The A2 emission scenario assumes a high carbon world, producing large changes in the climate. Countries become self-reliant with the gap between developed and less developed countries growing. Population growth is expected to continue to increase in the A2 scenario and greenhouse gas emissions are projected to continue to increase unchecked (IPCC, 2000; Mullan et al., 2009). The rainfall data provided by NIWA are generated from their RCM using output from a Global Climate Model (GCM) assessed as being "middle of the range" under the A2 emission scenario (pers. comm. Sam Dean, 8 June 2009). Therefore the climatically altered rainfall data produced from the RCM that are used here are only an indication of possible rainfall from one model within one emission scenario. The actual changes to rainfall may actually be higher or lower than the data used for this study.

Data for a grid point located roughly over the centre of Catchment 2 were extracted from within the $30 \mathrm{~km} \mathrm{RCM} \mathrm{grid} \mathrm{box} \mathrm{data} \mathrm{which} \mathrm{covers} \mathrm{the} \mathrm{area.} \mathrm{The} \mathrm{grid} \mathrm{box} \mathrm{has} \mathrm{an}$ elevation of 500 metres. This is high because it is an average of the elevations within 
the whole $30 \mathrm{~km}$ grid box which includes part of both the Inland and Seaward Kaikoura Ranges. These areas with higher elevation are likely to receive more rainfall. For this reason the extracted rainfall data for this grid point may be higher than the actual rainfall received at the area.

Both the extracted current rainfall data and the climatically altered rainfall data were prepared separately in Microsoft Excel (version 2007) and converted into ASCII text files for use in CAESAR. The first ten years from each data set were used. There are a large amount of rainfall data from both the current control data and the projected climatically altered data. These data are presented in Appendix V.

The 2071 rainfall data set illustrates a drier climate than the 1971 rainfall data set. There is a mean annual decrease of $189.78 \mathrm{~mm}$ between the 1971 and 2071 rainfall data set for a ten year period, with a total of $9808.3 \mathrm{~mm}$ and $7910.5 \mathrm{~mm}$ of rainfall occurring in the first ten years of the 1971 and 2071 rainfall data sets respectively. For the 2071 data set all months except February and December show a decrease in the mean monthly rainfall over a ten year period, with large decreases occurring in March, May, August and September (Figure 6.9). As a result autumn, winter and spring appear to be slightly drier and summer appears to be getting wetter. The first ten years of the 2071 rainfall data set had 2.49 percent less rainfall hours than the first ten years of the 1971 data set. However the rainfall occurring in the 2071 data set is more intense. The highest hourly rainfall values for the 1971 and 2071 data sets were $14.1 \mathrm{~mm}$ and $18.3 \mathrm{~mm}$ respectively. There is a 100 percent increase, from 13 hours to 26 hours, in the number of hours which recorded a rainfall of between 10 to $15 \mathrm{~mm}$. The 2071 data set also recorded 6 hours where rainfall was greater than $15 \mathrm{~mm}$. In the 2071 data set, a total of 8 hours recorded higher values than the highest 1971 data set hourly value. Figures 6.10 and 6.11 show the hourly rainfall values of the ten years input into CAESAR for both data sets. 


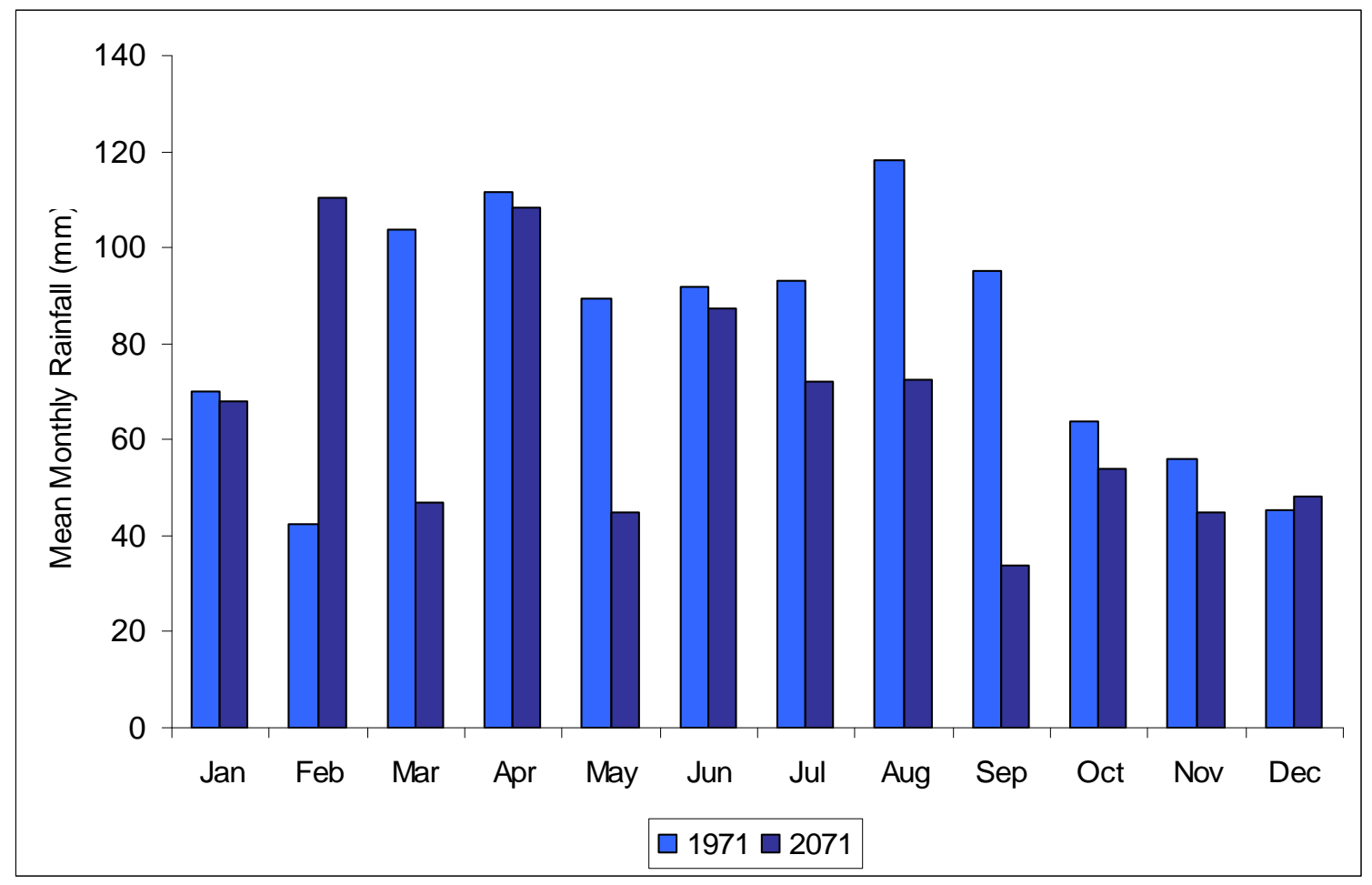

Figure 6.9: Mean monthly rainfall of the first ten years of the 1971 and 2071 rainfall data sets.

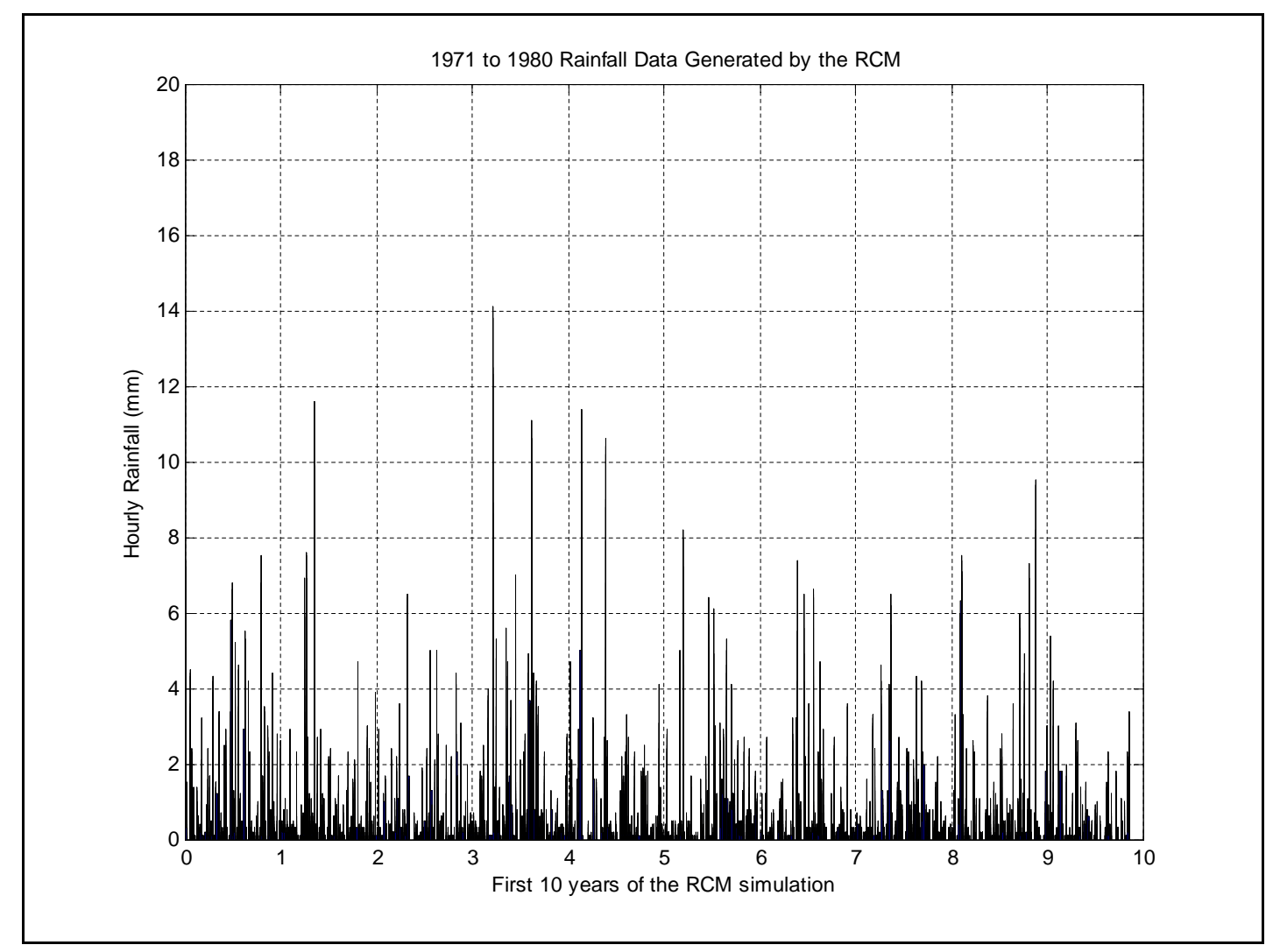

Figure 6.10: Time series of the hourly rainfall values used in the current conditions model run generated by the RCM for 1971 to 1980 . 


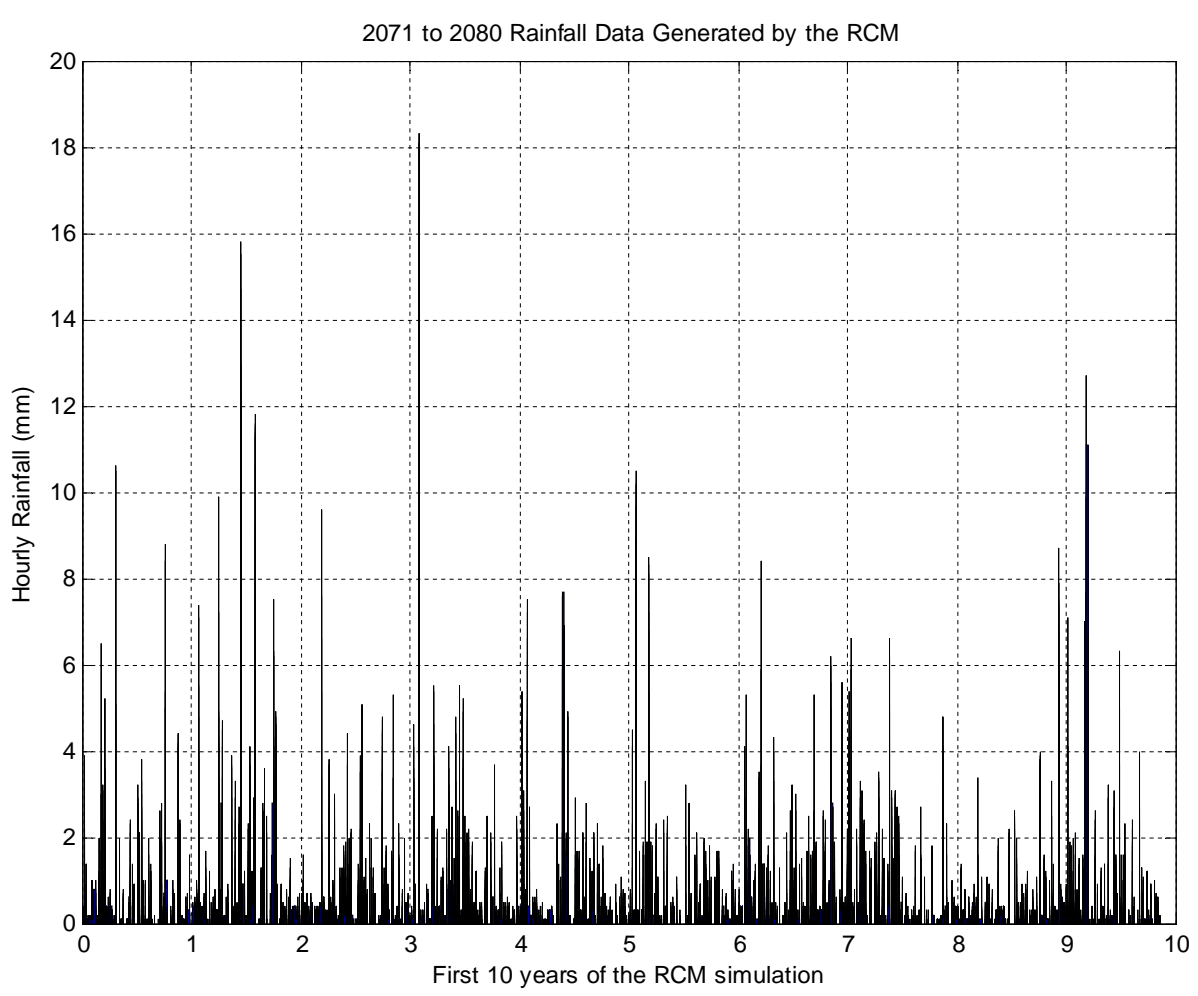

Figure 6.11: Time series of the hourly rainfall values used in and the altered climatic conditions model run generated the RCM for 2071 to 2080.

\section{Grain Size}

In order for CAESAR to be able to model sediment erosion, entrainment, and transport within the catchment and along the stream channel, grain size characteristics representative of the catchment bedrock and sediment sources need to be entered. A large sample (approximately $6 \mathrm{~kg}$ ) of the source sediment was taken from a canyon wall of Catchment 2 (Figure 6.12). A sample of the source sediment was taken as this sediment is easily eroded off the canyon walls, collecting in the stream channel, and is representative of the sediment which is transported through the catchment. This sample was taken from an area that is representative of the GMC and which appeared to be stable so as not to cause the collapse of the canyon wall. The same laboratory procedures were undertaken as were carried out on the sediment samples taken from the stream channel (see Chapter 5 Section 5.6.3). A maximum of nine grain sizes can be entered into CAESAR. Due to the range of grain sizes within the source sediment sample, some phi sizes were combined to get nine grain size ranges. The proportion of each grain size range was determined by its percentage of weight of the total sample. 


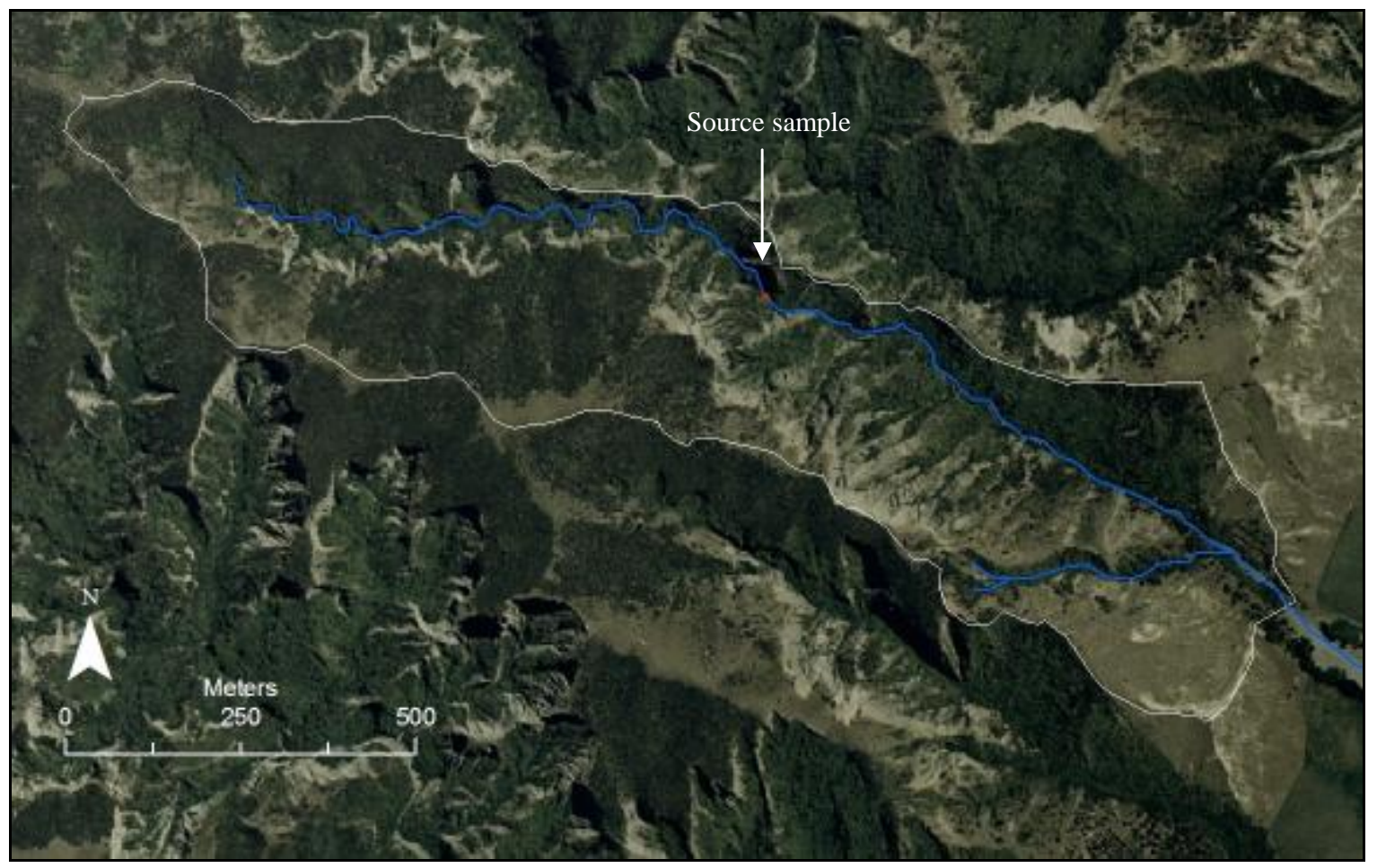

Figure 6.12: The approximate location from which the source sediment sample off a canyon wall was taken from. The location was estimated from the longitudinal profile as no GPS signal could be gained at this location. Aerial photograph source: LINZ, 2004

\section{Source Sediment Grain Size Results}

The source sediment sample was taken from a canyon wall just upstream from where the channel sediment sample 2 was taken. The near vertical canyon wall was well exposed with no vegetation growing on it and formed the stream bank. It was composed of GMC. Areas of the canyon wall appeared well compacted and cemented together, although when the surface was touched fine grains came away and clasts could easily be chipped out. It was evident that water running down the canyon wall could easily erode the finer sediment away and scour out the clasts.

The sample of source sediment was composed of a range of sediment sizes from small cobbles to coarse silt, with pebbles $(-2 \Phi$ to $-5.5 \Phi)$ making up 47 percent of the total sample. Small cobbles made up 24.2 percent of the sample. It is possible that there are larger clasts within the GMC, for example large cobbles or boulders, as noted by Browne (1995) and Lewis et al. (1980); however, no larger clasts were exposed in the canyon wall at the location of the sample. The cobble and pebble clasts were supported by a matrix of granules and sand, with a very small amount of silt also evident in the 
sample. The mean grain size for the source sediment sample was $-3.88 \Phi$ with a median grain size of $-4.45 \Phi$. The sample was very poorly sorted with a sorting value of $2.68 \Phi$ and a positive skewness value of 0.74 . The graphed data is presented in Appendix III.

The nine grain sizes and the proportions of each that are to be used for the running of CAESAR are displayed in Table 6.2. Due to the large spread of phi sizes present in the source sediment sample, the grain sizes entered into CAESAR represent the middle value of a small range of phi sizes.

Table 6.2: Grain size ranges and proportions of a sample of the source sediment from a canyon wall of Catchment 2 to be used in CAESAR

\begin{tabular}{|l|l|l|l|l|}
\hline & Grain Size Range $(\boldsymbol{\Phi})$ & $\begin{array}{l}\text { Grain Size Entered Into } \\
\text { CAESAR (metres) }\end{array}$ & Proportion & $\begin{array}{l}\text { Suspended } \\
\text { Sediment }\end{array}$ \\
\hline Size 1 & $3.5 \Phi$ to $2.51 \Phi$ and Pan & 0.000125 & 0.029 & Yes \\
\hline Size 2 & $2.5 \Phi$ to $1.01 \Phi$ & 0.00025 & 0.042 & Yes \\
\hline Size 3 & $1 \Phi$ to $-0.49 \Phi$ & 0.0007 & 0.075 & Yes \\
\hline Size 4 & $-0.5 \Phi$ to $-1.99 \Phi$ & 0.002 & 0.143 & Yes \\
\hline Size 5 & $-2 \Phi$ to $-2.99 \Phi$ & 0.0057 & 0.098 & - \\
\hline Size 6 & $-3 \Phi$ to $-3.99 \Phi$ & 0.011 & 0.088 & - \\
\hline Size 7 & $-4 \Phi$ to $-4.99 \Phi$ & 0.023 & 0.063 & - \\
\hline Size 8 & $-5 \Phi$ to $-5.99 \Phi$ & 0.045 & 0.220 & - \\
\hline Size 9 & $-6 \Phi$ to $-6.99 \Phi$ & 0.091 & 0.242 & - \\
\hline Total & & 1 & \\
\hline
\end{tabular}

\subsubsection{CAESAR Model Runs}

The CAESAR model was run for two differing climatic situations: the current situation and a possible future climate affected by climate change. The current climatic situation is represented by the first ten years of the 1971 to 2000 control rainfall data set, while the future climatic situation is represented by the first ten years of the 2071 to 2100 rainfall data set. The same DEM and grain size data were used for both model runs.

A time series containing the water discharge and the total sediment discharge recorded every 60 minutes was output from CAESAR and the data were processed using Matlab (version 7.1) and Microsoft Excel (version 2007). Frequencies for a range of varying sediment discharge event magnitudes were estimated from the time series output for both climatic situations. A sediment discharge event was identified as an hourly 
sediment discharge, or a group of hourly sediment discharges, with no sediment discharges occurring for 12 hours both before and after the hourly sediment discharge. If a spacing of less than 12 hours occurred between two hourly sediment discharges then it was considered to be one event. A spacing of 12 hours was chosen due to the intense rainfall events leading to sediment discharge onto alluvial fans rarely lasting more than 12 hours and the event can therefore be considered ended if no sediment discharges have been triggered within the 12 hour period. To determine the size of the sediment discharge events, the hourly sediment discharges were summed together. An estimation of the annual sedimentation rates for each climatic situation was calculated by dividing the total volume of discharged sediment by 10 , the number of years CAESAR was run for.

\subsection{CAESAR Results}

\subsubsection{Current Conditions Model Run}

\section{Sediment Discharge Frequency}

CAESAR output hourly time series data of the water and the sediment discharges from Catchment 2, produced from the current conditions model run. Figure 6.13 displays the hourly time series of the water flow and sediment discharged during the ten year period of the model run. The cumulative amount of sediment discharged over the ten year period is also displayed. 

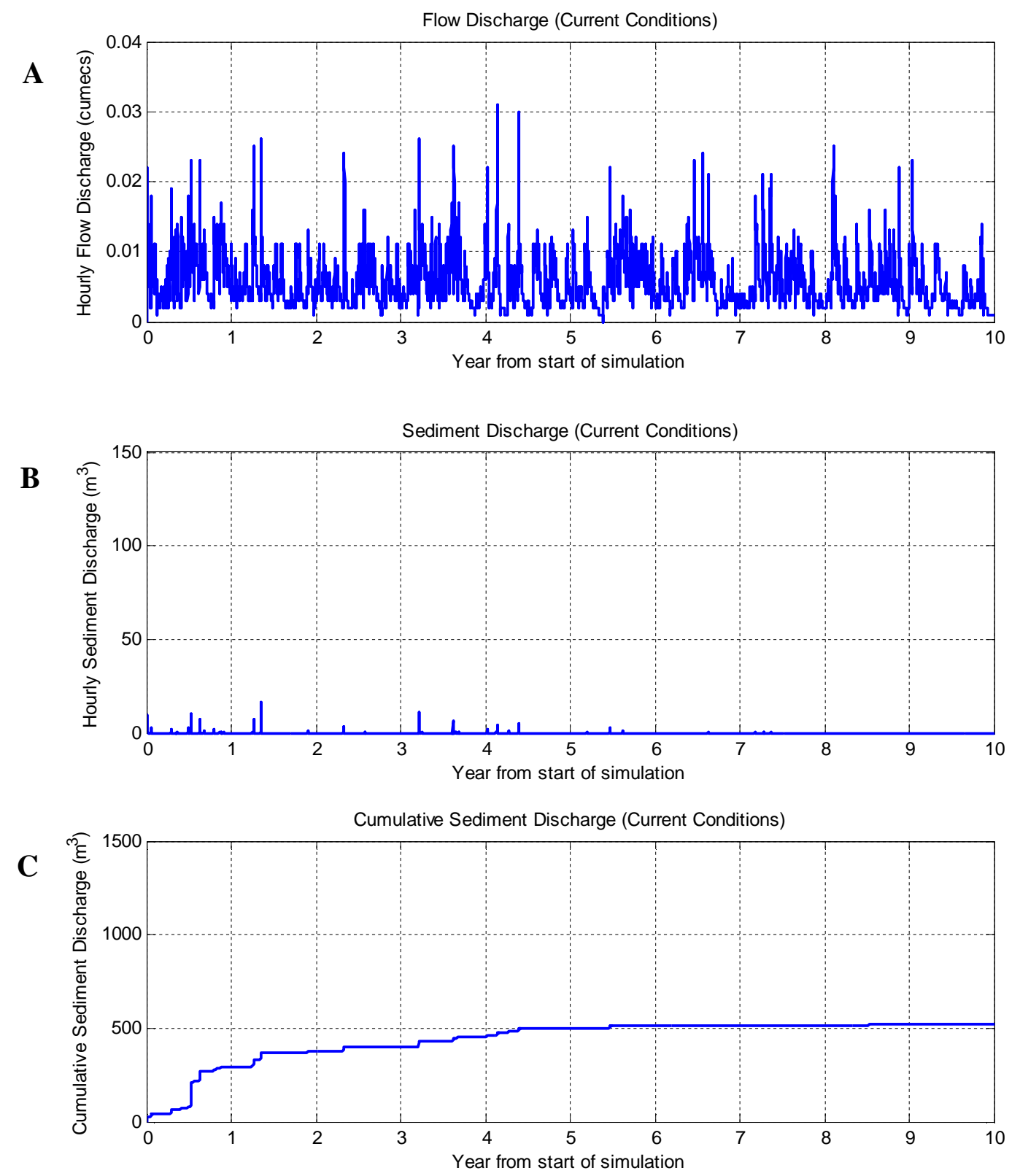

Figure 6.13: Hourly water flow and sediment discharges produced for ten years under the current conditions model run. A: Hourly time series of the water flow discharge in cumecs, over the ten year period. B: Hourly time series of the sediment discharge and $\mathrm{C}$ : the cumulative sediment discharge, in cubic metres, over the ten year period of the model run.

Hourly sediment discharges occurred 885 times (1.01 percent of the total model run time) over the ten year period. The highest recorded hourly discharge was $16.621 \mathrm{~m}^{3}$ and the lowest was $0.001 \mathrm{~m}^{3}$. A majority, 87.68 percent, of the hourly sediment discharges that were recorded were less than $1 \mathrm{~m}^{3}$ and a further 5.31 percent and 4.07 percent of the hourly sediment discharges were between 1 to $2 \mathrm{~m}^{3}$ and 2 to $5 \mathrm{~m}^{3}$ 
respectively. Hourly sedimentation events equal to or greater than $5 \mathrm{~m}^{3}$ made up 2.93 percent of the recorded hourly events. Of these hourly events greater than $5 \mathrm{~m}^{3}$ only two were greater than $10 \mathrm{~m}^{3}$ (0.23 percent). This can be seen in Figure 6.14 , which displays the relationship between the frequency of hourly water flow discharges and the distribution of hourly sediment discharges against the hourly water flow discharge with which they are associated. A high amount of these hourly sediment events occurred as a result of water flow discharges of between 0.02 and 0.025 cumecs. A large proportion of the hourly flow discharge is less than 0.005 cumecs, with a second smaller peak in flow discharges of just over 0.01 cumecs occurring.

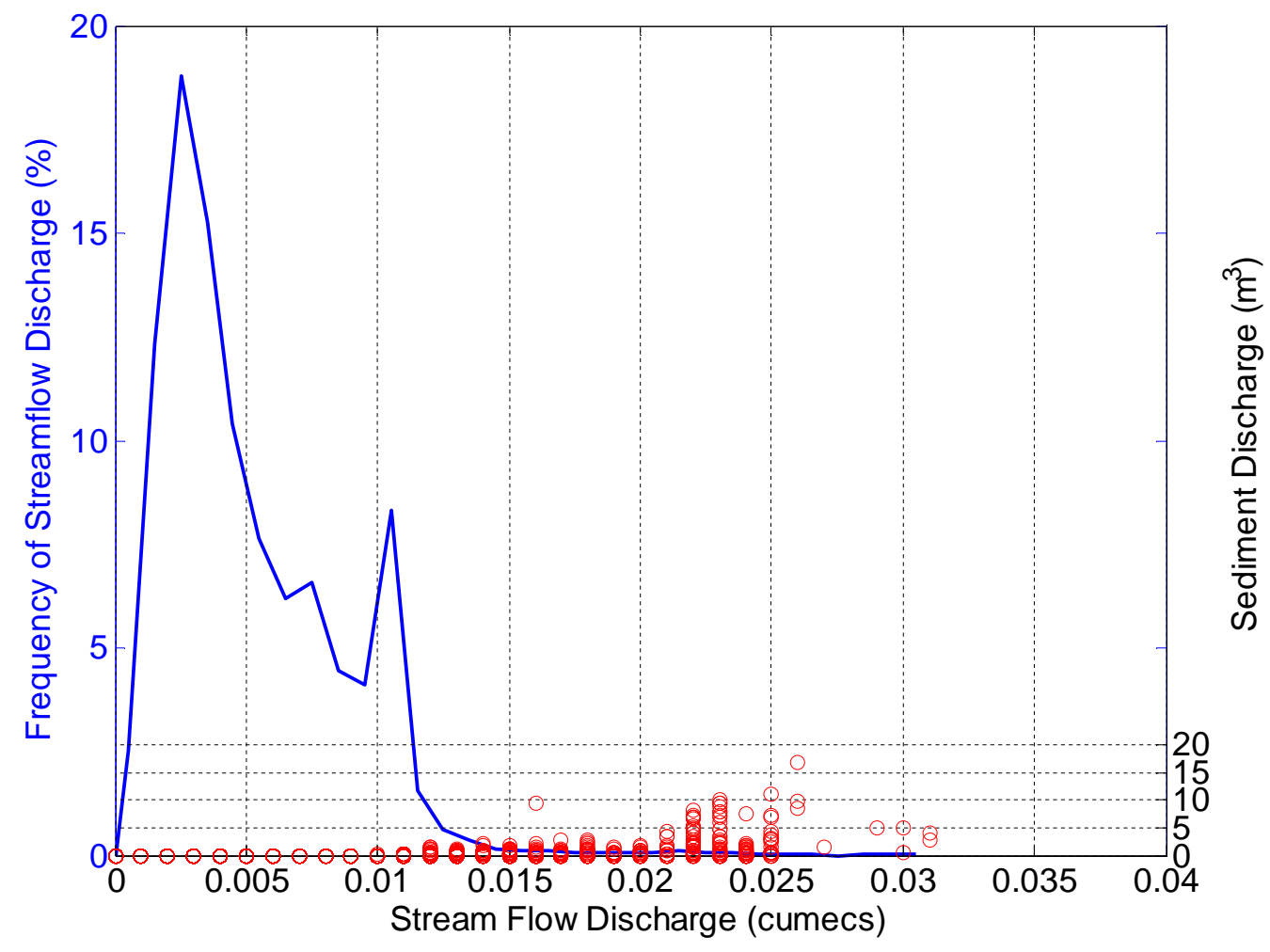

Figure 6.14: The relationship between the frequency of water hourly flow discharges and the size of hourly sediment discharges generated by each hourly water flow discharge under the current conditions model run.

While hourly water and sediment discharges are important, it is the frequency and magnitude of the entire sedimentation event which is of the main concern. 69 sedimentation events were produced by the current conditions model run using the 1971 rainfall data set. Figure 6.15 shows the total amount of sediment discharged in each of the separate events, while Table 6.3 shows the percentage of events in varying sediment discharge size ranges. The smallest sediment discharge event was $0.001 \mathrm{~m}^{3}$, while the 
largest event was $136.539 \mathrm{~m}^{3}$. This was the only event which contained over $100 \mathrm{~m}^{3}$ of discharged sediment. Figure 6.16 and Table 6.4 show the cumulative frequency of sediment events equal to or greater than events of various differing magnitudes. 50.72 percent of the events produced over the ten year period were of a magnitude of less than $1 \mathrm{~m}^{3}$. Sediment discharge events of between 1 to $2 \mathrm{~m}^{3}$ of sediment made up 14.50 percent of the events. 34.78 percent of the sediment events produced by the current conditions model run contained greater than or equal to $2 \mathrm{~m}^{3}$ of sediment. Of this, 20.29 percent of the events contained greater than or equal to $10 \mathrm{~m}^{3}$ of sediment.

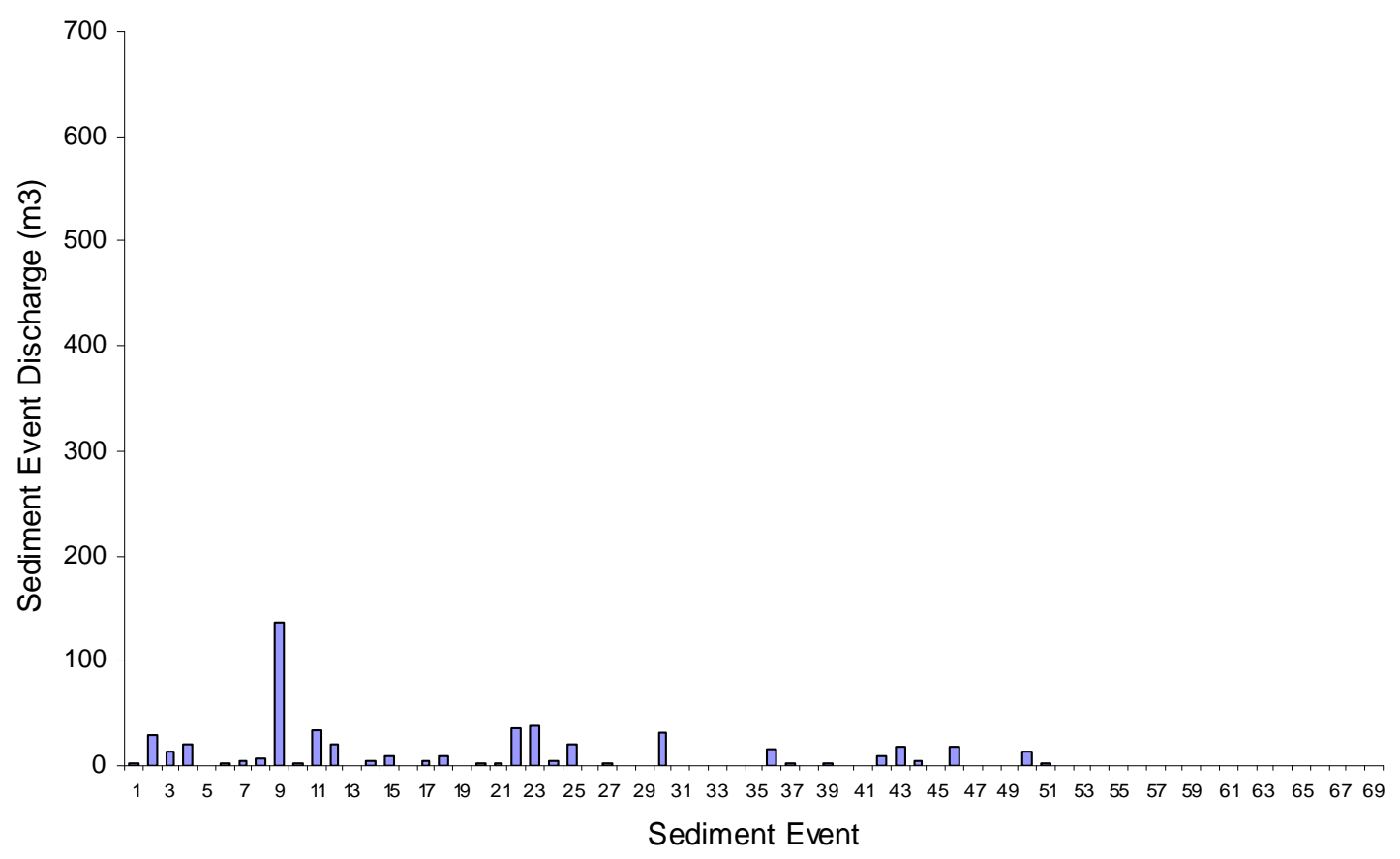

Figure 6.15: The size of the sediment discharge events produced for ten years in the current conditions model run using the 1971 rainfall data.

Table 6.3: The percentage of events of varying size ranges produced by the current conditions model run.

\begin{tabular}{|c|c|c|}
\hline Sedimentation Event Size & Number of Events & Percentage of Events \\
\hline$<1 \mathrm{~m}^{3}$ & 35 & 50.72 \\
\hline 1 to $2 \mathrm{~m}^{3}$ & 10 & 14.49 \\
\hline 2 to $5 \mathrm{~m}^{3}$ & 4 & 5.80 \\
\hline 5 to $10 \mathrm{~m}^{3}$ & 6 & 8.70 \\
\hline 10 to $100 \mathrm{~m}^{3}$ & 13 & 18.84 \\
\hline$>100 \mathrm{~m}^{3}$ & 1 & 1.45 \\
\hline Total & 69 & 100 \\
\hline
\end{tabular}




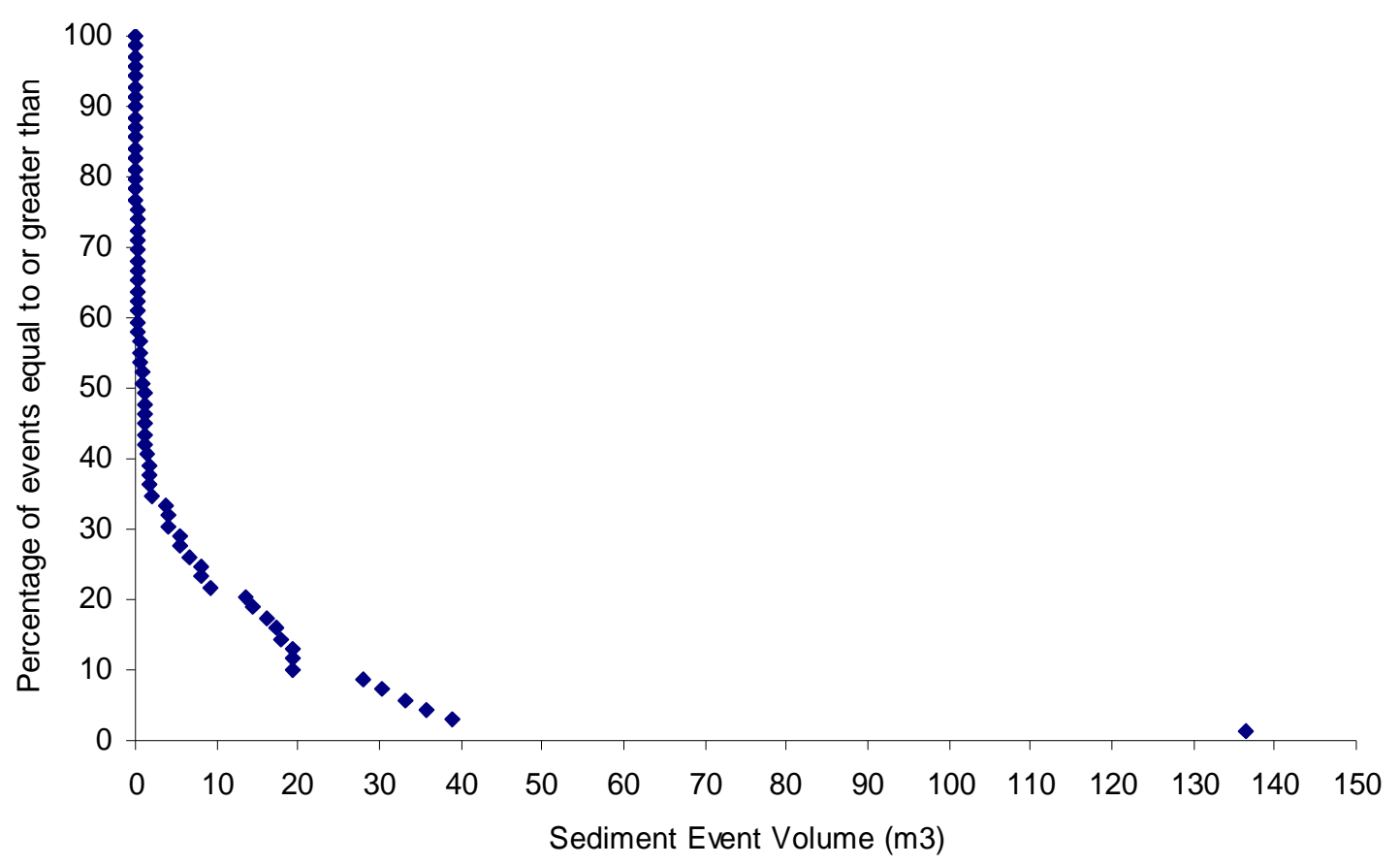

Figure 6.16: Cumulative frequency of sediment events equal to or greater than a selected sediment event volume.

Table 6.4: Cumulative frequency of sediment discharge events greater than or equal to varying event magnitudes.

\begin{tabular}{|c|c|c|}
\hline $\begin{array}{c}\text { Sedimentation } \\
\text { Event Size }\end{array}$ & Cumulative Number of Events & $\begin{array}{c}\text { Cumulative Percentage of } \\
\text { Events }\end{array}$ \\
\hline$>0 \mathrm{~m}^{3}$ & 69 & 100 \\
\hline$\geq 1 \mathrm{~m}^{3}$ & 34 & 49.28 \\
\hline$\geq 2 \mathrm{~m}^{3}$ & 24 & 34.78 \\
\hline$\geq 5 \mathrm{~m}^{3}$ & 20 & 28.99 \\
\hline$\geq 10 \mathrm{~m}^{3}$ & 14 & 20.29 \\
\hline$\geq 100 \mathrm{~m}^{3}$ & 1 & 1.45 \\
\hline
\end{tabular}

\section{Sedimentation Rates}

The total volume of sediment discharged from the Catchment 2 under the Current Conditions model run was $518.058 \mathrm{~m}^{3}$. This total volume included both the suspended sediment and bed load sediment that was discharged from the catchment.

The average annual sedimentation rate of the total volume of sediment discharged for the ten years of the Current Conditions model run was calculated. An average annual sedimentation rate of $51.805 \mathrm{~m}^{3}$ per year was discharge from Catchment 2. 


\subsubsection{Altered Climatic Conditions Model Run}

\section{Sediment Discharge Frequency}

Hourly sediment discharges from the ten years under the altered climatic conditions model run occurred 887 times (1.01 percent of the model run time). While sediment discharges occurred for the same percentage of the run time as the current conditions model run, there were large differences in the frequency and magnitude of the hourly and event sediment discharges.

The hourly water and sediment discharges over the ten year period are shown in Figure 6.17 and 6.18. The cumulative amount of sediment discharged over the ten year period is also displayed. The highest recorded hourly sediment discharge was $121.266 \mathrm{~m}^{3}$ and the lowest was $0.001 \mathrm{~m}^{3} .89 .85$ percent of the hourly sediment discharges were less than $1 \mathrm{~m}^{3}$. A further 2.82 percent of the hourly sediment discharges were between $1 \mathrm{~m}^{3}$ and 2 $\mathrm{m}^{3}$. Hourly sedimentation events equal to or greater than $5 \mathrm{~m}^{3}$ made up 4.28 percent of the recorded hourly events. The number of hourly sediment events greater than $10 \mathrm{~m}^{3}$ recorded using the climatically altered rainfall was higher with 27 events greater than 10 $\mathrm{m}^{3}$ (3.04 percent). Figure 6.18 displays the relationship between the frequency of hourly water flow discharges and the distribution of hourly sediment discharges against the hourly water flow discharges with which they are associated. It can be seen that a larger spread of hourly water flow discharge events triggered the hourly sediment events generated by this model. The range of flow magnitudes producing the hourly sediment events is additionally much greater, although a high amount of these events occurred as a result if water flow discharges between 0.015 and 0.025 cumecs. Hourly water flow discharges of less than 0.005 cumecs occur less frequently than under the current conditions model run, although it is still the discharge which occurs the most frequently. Further, the frequency of water flow discharges of approximately 0.007 cumecs and of approximately 0.01 cumecs occur a greater amount of the time than in the current conditions model run. 

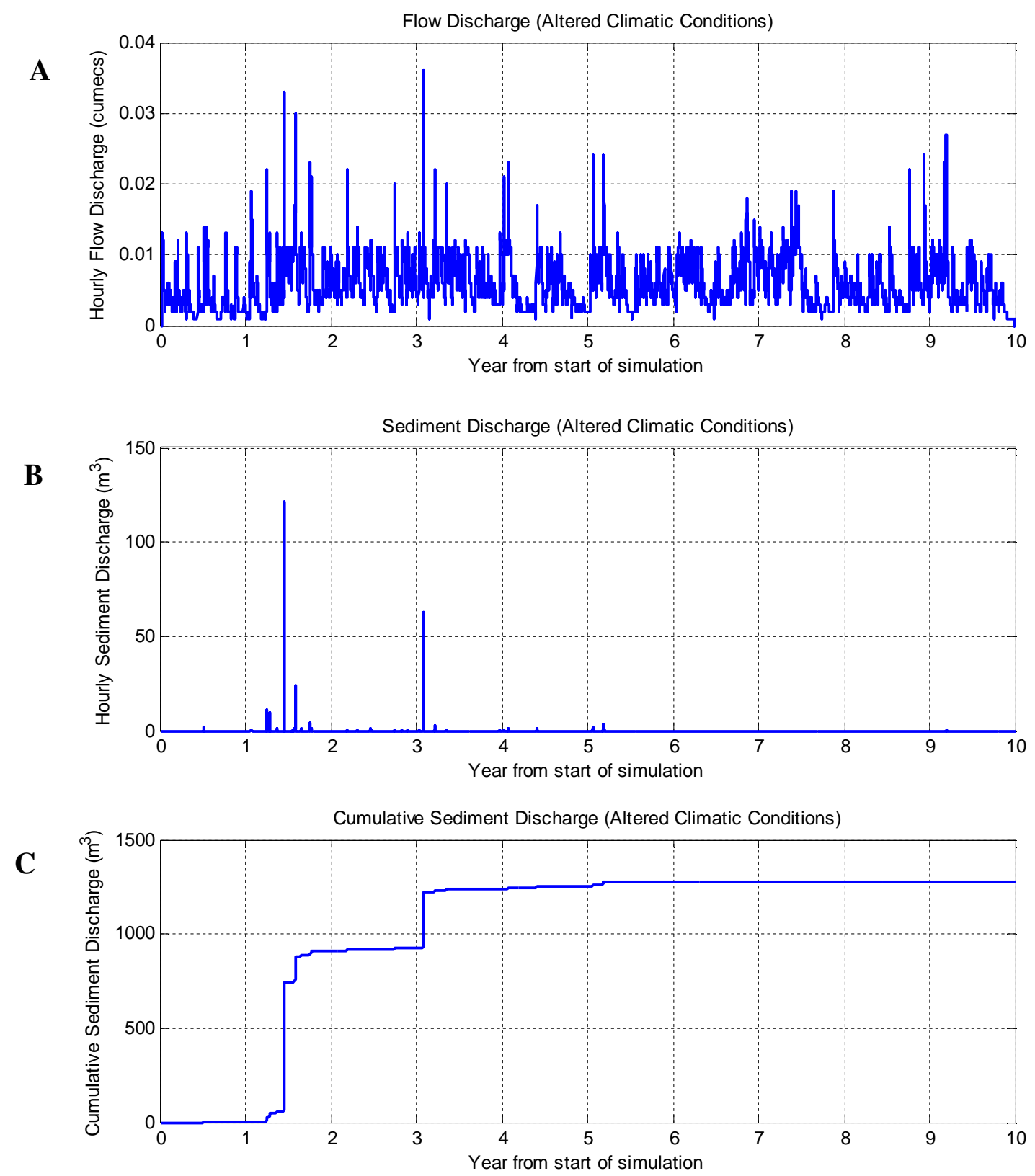

Figure 6.17: Hourly water flow and sediment discharges produced for ten years under the altered climatic conditions model run. A: Hourly time series of the water flow discharge, in cumecs, over the ten year period. B: Hourly time series of the sediment discharge and $\mathrm{C}$ : the cumulative sediment discharge, in cubic metres, over the ten year period of the model run. 


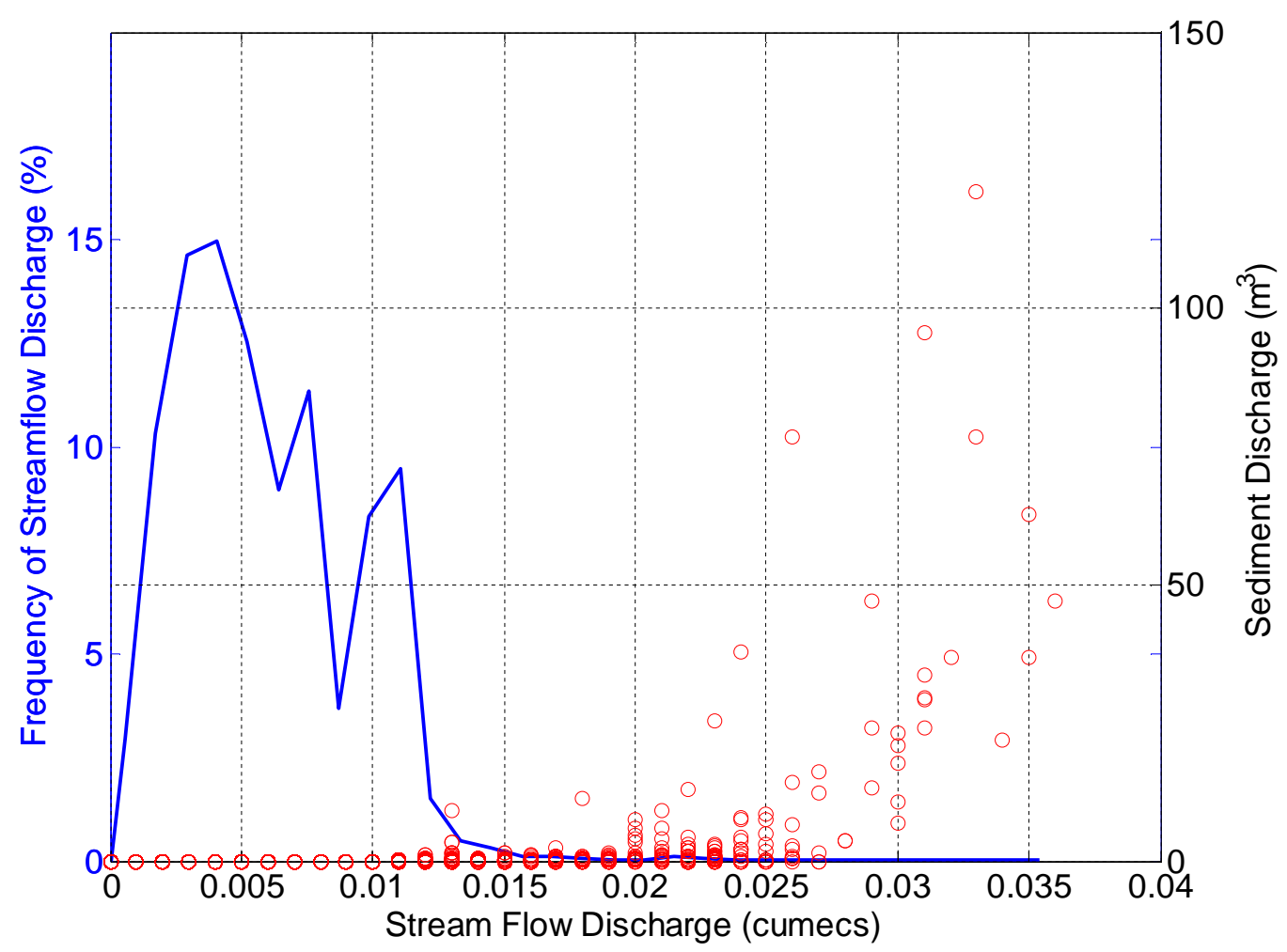

Figure 6.18: The relationship between the frequency of hourly flow discharges and the size of hourly sediment discharges generated by each hourly flow discharge under the altered climatic conditions model run.

The altered climatic conditions model run produced 40 sedimentation events. The amount of sediment discharged in each of these events is shown in Figure 6.19, while Table 6.5 shows the percentage of events in varying sediment discharge ranges. Three large events involving greater than $100 \mathrm{~m}^{3}$ of sediment were produced. These three events make up 7.5 percent of the events that occurred. The largest event discharged $684.993 \mathrm{~m}^{3}$ of sediment, just over five times higher than the largest sediment discharge event produced under the current conditions model run. Both of the other sedimentation events greater than $100 \mathrm{~m}^{3}$ produced in this model run were also larger than the largest event produced under the current conditions model run. The smallest sedimentation event that was produced was $0.007 \mathrm{~m}^{3}$.

The cumulative frequency of sedimentation events equal to or greater than a particular sediment discharge magnitude is shown in Figure 6.20 and Table 6.6. 42.5 percent (17 out of the 40) of the events that occurred under this rainfall regime contained less than 1 $\mathrm{m}^{3}$ of sediment. Four sediment discharge events contained between 1 to $2 \mathrm{~m}^{3}$ of sediment, which was 10 percent of the events. 47.5 percent of the events that occurred 
were greater than or equal $2 \mathrm{~m}^{3}$ of discharged sediment. Of this, 22.5 percent ( 6 events) of the events contained greater than or equal to $10 \mathrm{~m}^{3}$ of sediment.

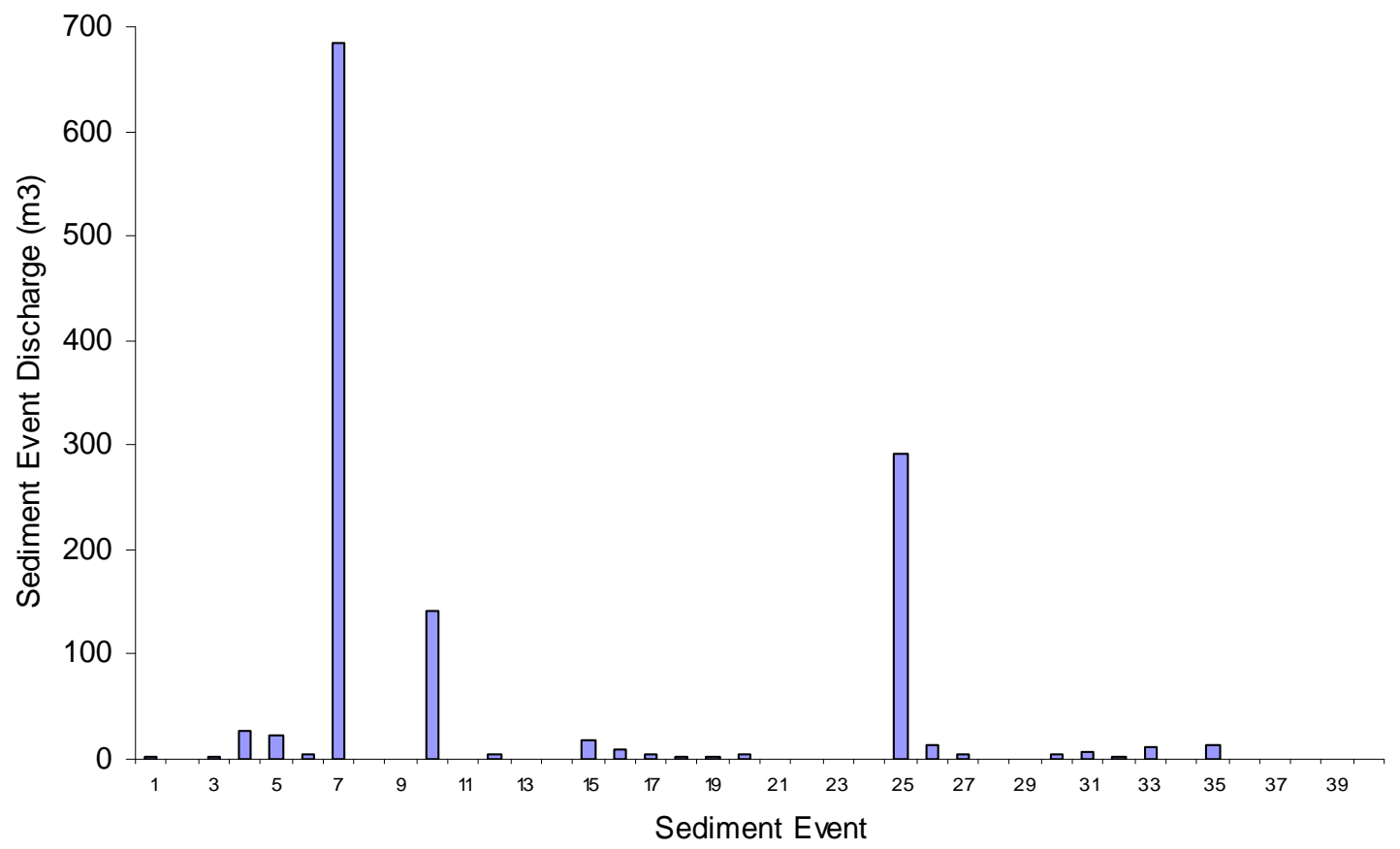

Figure 6.19: The size of the sediment discharge events produced for ten years in the altered climatic conditions model run.

Table 6.5: The percentage of events of varying size ranges produced using the 2071 rainfall data

\begin{tabular}{|c|c|c|}
\hline Sedimentation Event Size & Number of Events & Percentage of Events \\
\hline$<1 \mathrm{~m}^{3}$ & 17 & 42.5 \\
\hline 1 to $2 \mathrm{~m}^{3}$ & 4 & 10 \\
\hline 2 to $5 \mathrm{~m}^{3}$ & 8 & 20 \\
\hline 5 to $10 \mathrm{~m}^{3}$ & 2 & 5 \\
\hline 10 to $100 \mathrm{~m}^{3}$ & 6 & 15 \\
\hline$>100 \mathrm{~m}^{3}$ & 3 & 7.5 \\
\hline Total & 40 & 100 \\
\hline
\end{tabular}




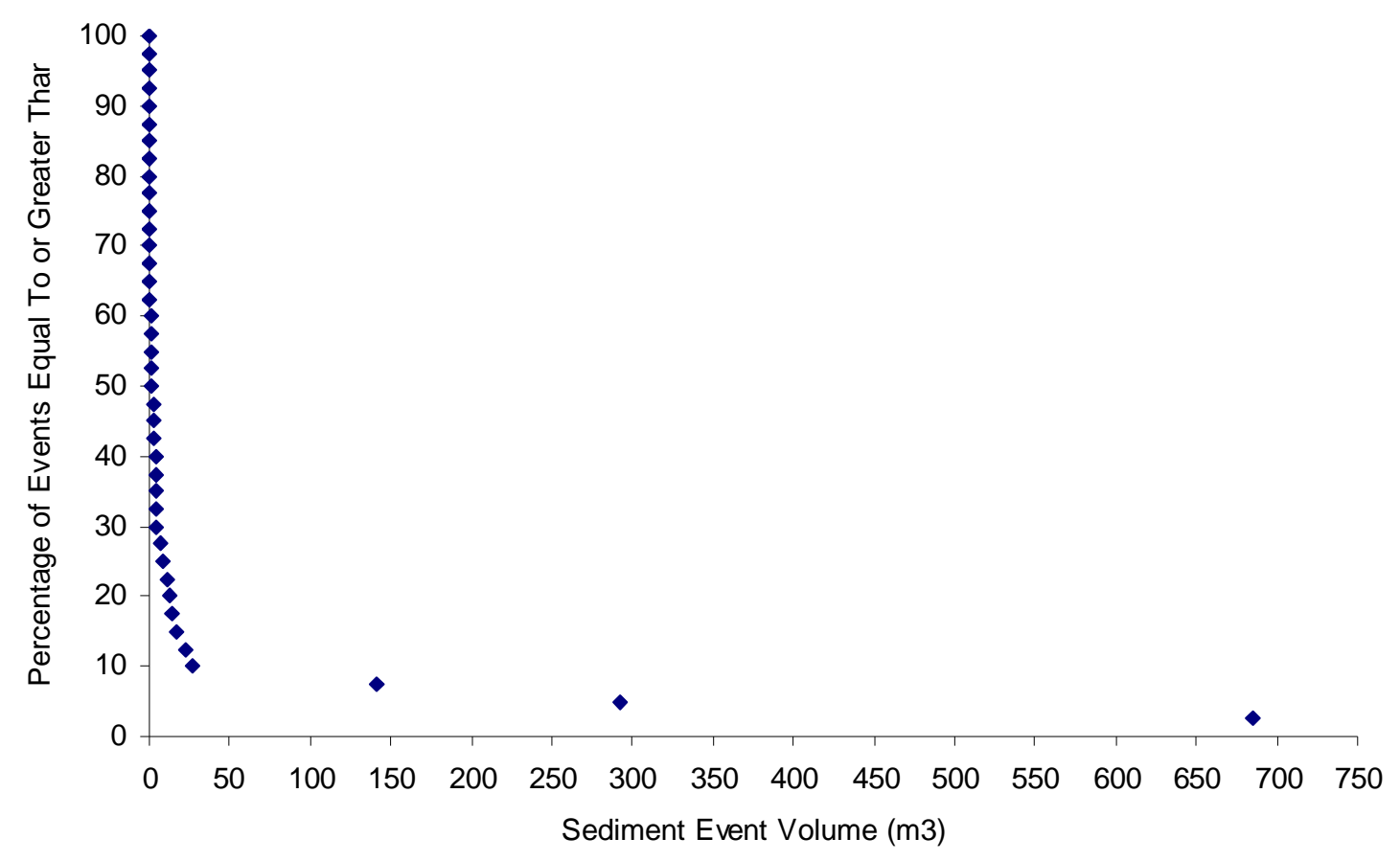

Figure 6.20: Cumulative frequency of sediment events equal to or greater than a selected sediment event volume for events produced from the altered climatic conditions model run.

Table 6.6: Cumulative frequency of sediment discharge events greater than or equal to varying event magnitudes.

\begin{tabular}{|c|c|c|}
\hline $\begin{array}{c}\text { Sedimentation } \\
\text { Event Size }\end{array}$ & $\begin{array}{c}\text { Cumulative Number of } \\
\text { Events }\end{array}$ & Cumulative Percentage of Events \\
\hline$>0 \mathrm{~m}^{3}$ & 40 & 100 \\
\hline$\geq 1 \mathrm{~m}^{3}$ & 23 & 57.5 \\
\hline$\geq 2 \mathrm{~m}^{3}$ & 19 & 47.5 \\
\hline$\geq 5 \mathrm{~m}^{3}$ & 11 & 27.5 \\
\hline$\geq 10 \mathrm{~m}^{3}$ & 9 & 22.5 \\
\hline$\geq 100 \mathrm{~m}^{3}$ & 3 & 7.5 \\
\hline
\end{tabular}

\section{Sedimentation Rates}

The total volume of sediment discharged from Catchment 2 under the Climatically Altered Conditions model run was $1275.20 \mathrm{~m}^{3}$. This total volume included both the suspended sediment and bed load sediment that was discharged from the catchment.

The average annual sedimentation rate of the total volume of sediment discharged for the ten years of the Climatically Altered Conditions model run was calculated. An average annual sedimentation rate of $127.520 \mathrm{~m}^{3}$ per year was discharge from Catchment 


\section{Chapter 7 \\ Interpretation and Discussion}

\subsection{Introduction}

The results of the methods undertaken were presented in chapters 5 and 6 . This chapter aims to provide a discussion of the results, making comparisons and considering the meaning of the results, their uncertainty and validity, and suggests implications for the occurrence of hazardous sediment events onto the alluvial fans. This chapter is divided into four main sections. Section 7.2 will examine where areas of sediment erosion within the catchment are likely to originate from. Section 7.3 discusses possible sedimentation rates onto the surface of Fan 2. Possible alterations to the frequency of the hazardous events are discussed in section 7.4. Finally section 7.5 considers the implications these results could have for the occurrence of hazardous sedimentation events onto these fans and their management.

\subsection{Likely Areas of Erosion}

\subsubsection{Longitudinal Profiles}

The longitudinal profile of the unnamed stream within Catchment 2 revealed no evidence of a knickpoint migrating through the catchment in 2008. Further, no knickpoint was evident within the longitudinal profile of the longer southern branch of the Kawauiti Stream within Catchment 1. If a knickpoint had been present within the catchments due to the modification of the alluvial fans for the State Highway and the constant reshaping of the fan surface and channel, as seems likely given the reported (Thomson, 1969) degradation, it is possible that the knickpoint has migrated through the entire length of the stream channel to the back of each of the catchments, indicating that the stream channel has already readjusted itself to the artificial alterations in base level. The catchments are small and the stream channels within them are short. The length of 
the longitudinal profile of the stream in Catchment 2 was $2.076 \mathrm{~km}$, while the profile of the southern branch of the Kawauiti Stream was $2.786 \mathrm{~km}$ long. Both streams would have probably extended past the end point of the profiles for several hundred metres. Additionally, knickpoints can become less obvious within the stream profile as they migrate through the catchment due to the slope of the knickpoint reducing. The fords across the fans were put in place 53 years ago and so it is possible for the knickpoints generated from their placement into the fan surface to have either dissipated as the slope of the knickpoint decreased or to have finished migrating through the catchment since the Marlborough Catchment Board report, 40 years ago.

It is important to note that the longitudinal profiles were completed after the occurrence of the two large rainfall events of July and August 2008. A large amount of sediment was deposited onto the three alluvial fans during these events. Any knickpoint that was present, if at all, along the longitudinal profiles prior these events may have been buried during the two events. This may also explain why no knickpoint was evident in the profile and is possible, given the large amount of sediment which was deposited onto the fans.

Several small artificial and natural steps were evident within the profiles of both catchments, although as these were not enough to affect the overall profile and gradient of the stream channels; for the purposes of this study they were not considered to be knickpoints. The natural steps were caused by boulders, vegetation debris or small landslides blocking the stream channel, behind which sediment had built up. Most of the natural steps were less than a metre high. Two artificial steps located on the fan were evident in the longitudinal profiles of both streams. The first step is the vertical drop produced by the downstream side of the State Highway 1 ford. The initial insertion of the concrete ford into the fan surface could have initiated a knickpoint migration up the stream channel, as the fan surface was cut into. Once this knickpoint has migrated through the catchment, the insertion of the ford will no longer have an effect on the longitudinal profile of the stream channel. The second step evident within both longitudinal profiles is produced from the regular clearing of the stream channel on the upper fan, which leaves a steep ramp near the apex of the fan. This artificial ramp is not considered to be a knickpoint. 
Mitigating actions after the occurrence of the 2008 rainfall events, however, may lead to a new knickpoint being initiated. After the rainfall events the stream channel on the fan above the road was cleared of sediment to a certain point near the apex of the fan. This left a steep ramp at this location (Figures 5.4 and 5.6), which given time and the occurrence of rainfall events large enough for sediment transport, would lead to the initiation of knickpoint migration into the catchment.

The presence or absence of a knickpoint migrating through the longitudinal profiles of stream channels can be used as an indication of where sediment inputs for fluvial sediment transport are originating from. Due to the steeper characteristic of knickpoints compared to the surrounding sections of the stream profile, stream flow has more potential energy to carry out erosion at the site of knickpoints. Erosion is, therefore, generally concentrated at the stream channel bed as a knickpoint migrates through the catchment (Charlton, 2008). The absence of any knickpoints located within the stream channel profiles of Catchments 1 and 2 indicates that there is no particular point within the stream channel where erosion of sediment is any greater than at other points within the stream channel. This suggests that the redistribution of sediment through the stream channel appears to broadly be in a steady state, implying that a large proportion of the sediment deposited onto these two alluvial fans is originating from the catchment canyon walls rather than the stream channel itself being the dominant contributor.

However, while undertaking the measurement of the longitudinal profiles within both catchments some evidence of a small amount of stream channel degradation near to outlet of both catchments, which occurred from the July and August 2008 rainfall events, was noted (Figure 7.1). Normally, the Kawauiti Stream and the unnamed stream have no stream flow in them, allowing for sediment eroded from the catchment canyon walls between discharge events to be stored within the stream channel. The channel degradation noted during field work after the 2008 rainfall events would be from this stored sediment, which originated from the catchment canyon walls, being transported through the catchment onto the alluvial fans. 


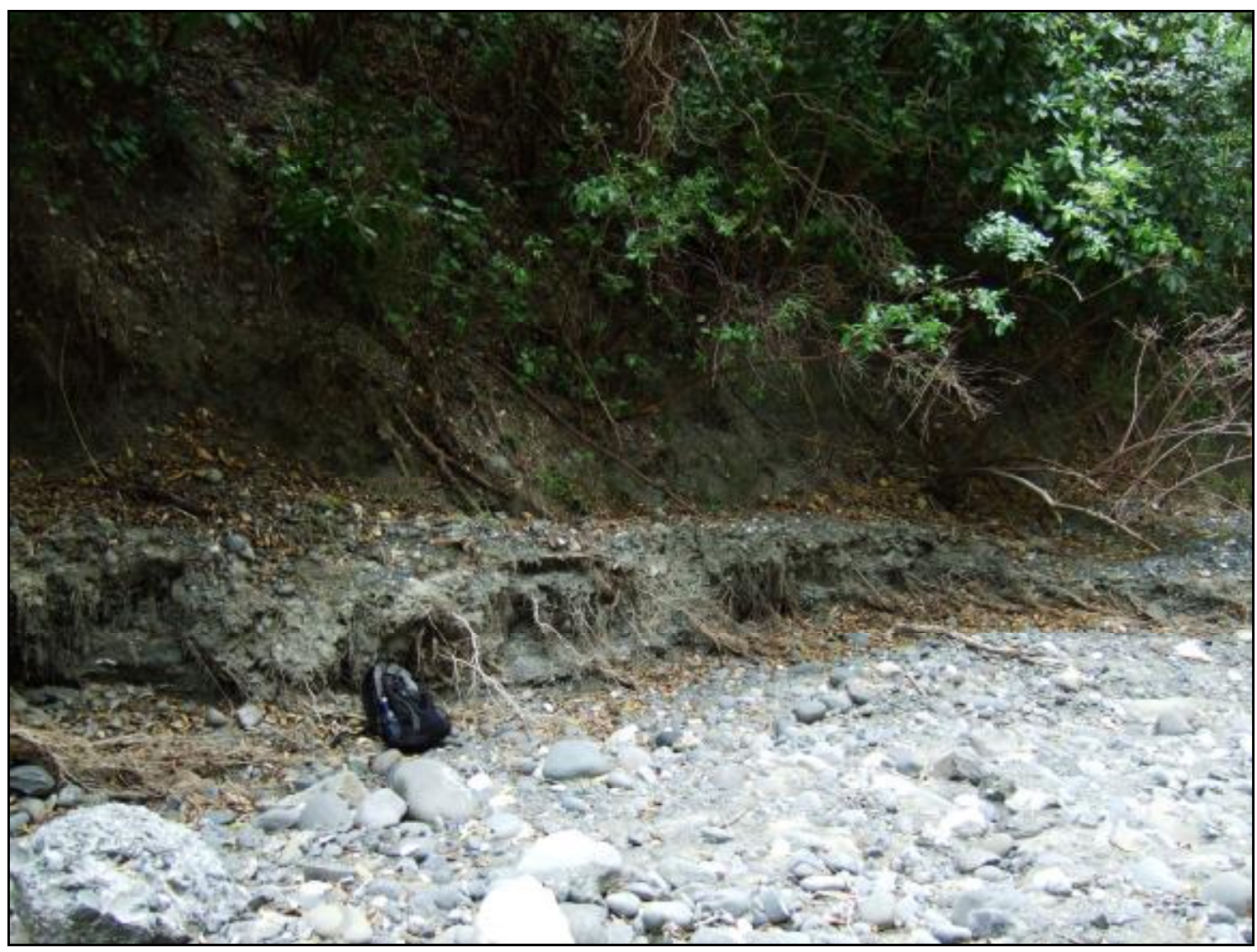

Figure 7.1: Evidence of the small channel degradation which occurred in the lower part of the stream channel in Catchment 2 during the July and August 2008 rainfall events. The backpack is for scale.

\subsubsection{Stream Power}

Sediment eroded from the canyon walls within Catchment 2 needs to be transported through the stream channel to be deposited onto the surface of the fan. This can only be carried out by the stream if the required amount of stream power is generated by the flow of water through the stream channel. Stream power calculations at ten locations along the stream channel of the unnamed stream flowing through Catchment 2 indicate that under stream discharge events equivalent to events with 10- and 23-year return periods there is a high amount of potential energy available within the stream channel to carry out sediment entrainment and transport. Stream power values for both return periods (see Table 5.14) display a general downstream trend of steadily increasing stream power. Stream power alters in response to changes to discharge and the gradient of the stream channel. The increasing trend evident in the stream power values for 
Catchment 2 is to be expected as discharge increases closer to the catchment outlet due to a greater catchment area being able to contribute runoff into the main stream channel.

Stream power values at the outlets of two sub-catchments, $G$ and $H$, appear to be anomalously high compared to the rest of the stream power values determined for the unnamed stream. This indicates that it is probable that higher amounts of sediment entrainment and transport are likely to occur at these two locations than in other locations along the stream due to more potential energy being available. The high stream power values at the outlets of sub-catchments $\mathrm{G}$ and $\mathrm{H}$ can be attributed to an increase in the gradient of the stream channel at these two locations. The outlet of subcatchment $\mathrm{G}$ has the steepest channel gradient of the ten sub-catchments at 0.18 metres per metre, while the outlet of sub-catchment $\mathrm{H}$ has the next steepest channel gradient at 0.14 metres per metre. It is unlikely that the two high stream power values, as a result of the higher channel gradients, are evidence of a knickpoint within the stream channel. This change in channel gradient is only small and is not clearly recognisable as knickpoint in the longitudinal profile of Catchment 2 (see Figure 5.4). Additionally knickpoints generally only cover a short horizontal section of the longitudinal profile. The channel gradient was determined from a 20 to 25 metre "horizontal slice" upstream of the outlet of sub-catchments $\mathrm{G}$ and $\mathrm{H}$, a distance which would be too long to show evidence of a knickpoint.

Unit stream power removes the effect of scale allowing for easier comparison of stream power between the different locations. Unit stream power was calculated for subcatchments A, E, G, I and J. Generally the values of unit stream power indicate that there is a constant amount of potential energy available per unit area of the stream channel to carry out work, such as sediment entrainment and transport. This trend can be explained by the width of the stream channel increasing downstream as the stream power additionally increases downstream, resulting in stream power being evenly distributed across the stream channel width down the length of the channel and indicates that erosion can occur evenly along the entire length of the stream.

Unit stream power values for the outlets of sub-catchments $G$ and $J$ do not follow this trend however. Unit stream power at $\mathrm{G}$ is $788 \mathrm{~W} / \mathrm{m}^{2}$ and $1012.5 \mathrm{~W} / \mathrm{m}^{2}$ for the $10-$ and 
23-year return period events respectively. These values are 3.9 times higher than the unit stream power values determined for sub-catchment $\mathrm{E}$ under both return periods. The high value of unit stream power at $\mathrm{G}$ can be explained due to the high stream power value determined for this location, as noted above, and due to the channel narrowing to 5.3 metres in width at this location. This produces higher potential for sediment erosion, entrainment and transport per unit area of the stream channel at this location as the stream flow (and thus the available energy within it) is concentrated over a smaller area than it would be in a wider channel.

At location $\mathrm{J}$, unit stream power for the 10 - and 23 -year return period is $109.6 \mathrm{~W} / \mathrm{m}^{2}$ and $141.4 \mathrm{~W} / \mathrm{m}^{2}$ respectively. These values are lower than the rest of the unit stream power values calculated for the unnamed stream in Catchment 2, indicating that there is less potential energy available per unit area of the stream channel at this location to carry out erosion. The outlet of sub-catchment $\mathbf{J}$ is located at the outlet of Catchment 2 , where the stream discharges onto Fan 2. Two main requirements for fan formation is an environment in which a stream becomes unconfined as it flows out of the catchment onto an open, gentler sloping surface and a means of sediment deposition (Bull, 1977; Blair and McPherson, 1994; Davies and McSaveney, 2008). The width of the stream channel at location $\mathrm{J}$ rapidly becomes wider, increasing from 11.8 metres to 21.5 metres in approximately the 100 metres between locations I and J. The lower unit stream power at this location is due to the channel becoming unconfined as the stream flow spreads out over the wider stream channel. This leads to a decrease in the amount of energy that can entrain and transport sediment at this location. This, in turn, can potentially result in larger clasts not being able to be entrained or transported, thus resulting in the larger clasts being deposited at this location due to a lack of energy available to transport them at the apex of Fan 2.

\subsubsection{Likely Areas of Sediment Entrainment}

Clasts can become entrained by water flow when the threshold of motion is met. This occurs when the boundary shear stress acting on a stream bed is greater than or equal to the critical shear stress required by certain sediment sizes (Leopold et al., 1964; Knighton, 1998). A comparison of the boundary shear stress and the critical shear stress 
values calculated for selected clast sizes present at the outlet of five sub-catchments along the unnamed stream in Catchment 2 has been made (See Tables 5.17 and 5.18). These results show that all clasts for which critical shear stress values were determined $(-6 \Phi,-5 \Phi,-4 \Phi,-3 \Phi,-2 \Phi,-1 \Phi, 1 \Phi$ and $3 \Phi)$ could potentially be entrained under a 10 and 23-year return period flood event. This was to be expected as flood events with either a 10- and 23-year return period are large, high magnitude flood events. This comparison implies that all of the clasts present at each of these locations can potentially be entrained by $10-$ and $23-$ year return period flood events, further implying that large amounts of sediment will be deposited onto Fan 2 as a result of discharge events of this frequency.

The calculation of critical shear stress assumed that the clasts were of equal size and were of a spherical shape. Clasts in natural streams rarely exhibit these properties, however, and this can affect the packing of clasts in the stream channel, controlling how easily they can be entrained. The sediment samples at all five locations have a large range of clast sizes present and are moderately to poorly sorted. The voids between the larger clasts, for example very large pebbles or small cobbles (-5.5Ф to $-6 \Phi)$, are infilled by the smaller pebbles, granules and sands present at each location. This can produce a tighter packing than was assumed here. Additionally smaller clasts can be protected by the larger clasts and non-spherical clasts can interlock with each other, restricting the entrainment of individual clasts. These variations from the assumptions made about the size and shape of the clasts present at each of the sub-catchment outlets give reason to believe that the actual critical shear stress values required for the initiation of entrainment of the clasts may in fact be slightly higher than has been determined. The boundary shear stress values for the 10- and 23-year return periods for the unnamed stream in Catchment 2, however, are sufficiently higher than the critical shear stress values, so that if an increase in critical shear stress values, due to tighter packing of the clasts, were to occur, then entrainment of all the clast sizes is still likely to occur (See tables 5.17 and 5.18). 


\subsection{Sedimentation Rates}

Due to the characteristics of the three alluvial fans, high rates of sediment accumulation onto the alluvial fans can be expected. Unfortunately no records of past sedimentation events have been taken, either for the date of occurrence, or for the amount of water and sediment which were discharged from the catchments of the three alluvial fans. This gives rise to difficulty when trying to determine the reliability and validity of the calculated results.

The average annual geological accumulation rate of $181.07 \mathrm{~m}^{3}$ of sediment onto Fan 2 is likely to be a slight underestimation of the actual average annual rate, due to an unknown amount of sediment being removed from the fan over the years, to be used in road works. By comparison the average annual geological sediment accumulation rate onto Fan 4 is much smaller. The catchment of Fan 4 has similar lithology, slope, vegetation and tectonic characteristics as the catchment of Fan 2, although it is much smaller in size. For this reason Fan 4 is also much smaller than Fan 2. The amount of sediment stored within the catchment which is able to be transported to Fan 4 would additionally be smaller for this reason. Despite this, the rate at which sediment is deposited onto Fan 4 should be broadly similar to that of Fan 2. This being said, the estimated sedimentation rate of $23.41 \mathrm{~m}^{3}$ of sediment per year is less than the estimated rate for Fan 2. The difference can be accounted for by the smaller total runoff generated within Fan 4's smaller catchment, which in turn, reduces the capacity for sediment to be transported out of the catchment. The rate of sediment accumulation on Fan 4 is likely to be more accurate than the rate estimated for Fan 2 as there has been no anthropogenic removal of sediment from the fan surface. Further, no control works have been required for Fan 4 as State Highway 1 and the Main South Island Trunk Rail line do not cross over this fan due to its smaller size.

The estimated annual geological sedimentation rate for Fan 2 can be compared with the sedimentation rate determined for the July and August 2008 events. These two rainfall events triggered large amounts of sediment to be transported onto the alluvial fans. Local landowners near the fans have commented that these two sedimentation events 
were the largest that have occurred for some years (pers. comm. Jeremy Stace, 16 Nov 2008), although there has been no records taken for any sedimentation events in the past with which to objectively compare these two events. As determined from the height of the buried fence posts, approximately $1158.50 \mathrm{~m}^{3}$ of sediment was transported and deposited onto Fan 2. This amount is just over six times larger than the calculated average annual geological sedimentation rate for Fan 2.

Sedimentation events onto alluvial fans do not occur regularly in time and the size of each individual event can vary greatly. Based on the anecdotal evidence, it is probable that these two events were examples of large, high magnitude events which occur rarely. In some years, or indeed periods, a few small sediment events or no sediment events may have occurred. Or, sediment may have been generated and stored in the catchment rather than being exported to the fan. In other years very large sediment events, such as the two 2008 events, may occur, transporting the sediment onto the fan, including that which had been stored in the catchment during the years where few sedimentation events occurred. The annual geological sedimentation rate calculated here for Fan 2 is a mean value of all the sediment deposited onto the fan surface since its formation approximately 6000 years ago. It has averaged out the volume of sediment transported by the few less frequent, large events which occurred in some years, with the more frequent events consisting of a smaller volume of sediment in other years and the years in which no sediment events occurred at all. This explains why the estimated 2008 event sedimentation rate in higher than the annual sedimentation rate calculated for Fan 2.

It is feasible that the 2008 sediment accumulation rate is an underestimation of the amount of sediment that was actually deposited onto Fan 2 in 2008. The height of the buried fence posts indicated the depth of sediment to at least bury the fence posts. The depth of sediment deposited onto Fan 2 may have in fact been much higher than the height of the fence posts and so a much large volume of sediment is therefore likely to have been deposited onto Fan 2. The area of the stream channel prior to the two sedimentation events was utilized to determine the volume of sediment deposited onto Fan 2. During these events the stream channel was eroded and as a result widened allowing for sediment deposition to spread over a wider area. At some locations on Fan 
2 sediment overtopped the stream channel allowing sediment to be deposited on areas which had previously been rendered inactive by engineering works. Further some sediment may have been transported away from the fan by the sea. These factors were not incorporated into the calculation to estimate the event sedimentation rate for 2008, indicating that the actual volume of sediment deposited onto Fan 2 during the two 2008 sediment events could have been higher than estimated. The annual rate of sediment deposition will be the sum of all of the individual discrete events which occurred in the year and so may be higher than the event rate determined for the two events which occurred in July and August 2008.

Annual sedimentation rates determined from the two CAESAR model runs were both lower than the estimated average annual geological sedimentation rate. The sediment accumulation rate calculated for the current conditions model run was $51.8 \mathrm{~m}^{3}$ of sediment per year - 28.6 percent of the average annual geological sedimentation rate. The rate calculated for the altered climatic conditions was $127.5 \mathrm{~m}^{3}$ of sediment per year - 70.4 percent of the average annual geological sedimentation rate. While both of these values may be representative of periods where very few high magnitude events occurred, it is more likely that these low average annual sedimentation rates have resulted from the limitations, uncertainties and errors associated with the use of CAESAR, which are discussed in section 7.4.2 below. The average annual rates of sediment accumulation generated by the CAESAR model runs are therefore difficult to reliably and realistically compare with the average annual geological sedimentation rate.

Nevertheless, a comparison between the two CAESAR model run average annual sediment accumulation rates indicated that under a changed rainfall regime, as can be expected from future climate change projections, the average annual amount of sediment discharge onto Fan 2 is likely to increase as a generally larger amount of sediment is contained within each sedimentation event. An increase in the mean amount of sediment deposited onto Fan 2 would shift the hypothetical sediment event magnitude-frequency curve to the right resulting in events containing larger amounts of sediment occurring more frequently than those which are currently occurring (Figure 7.2). 


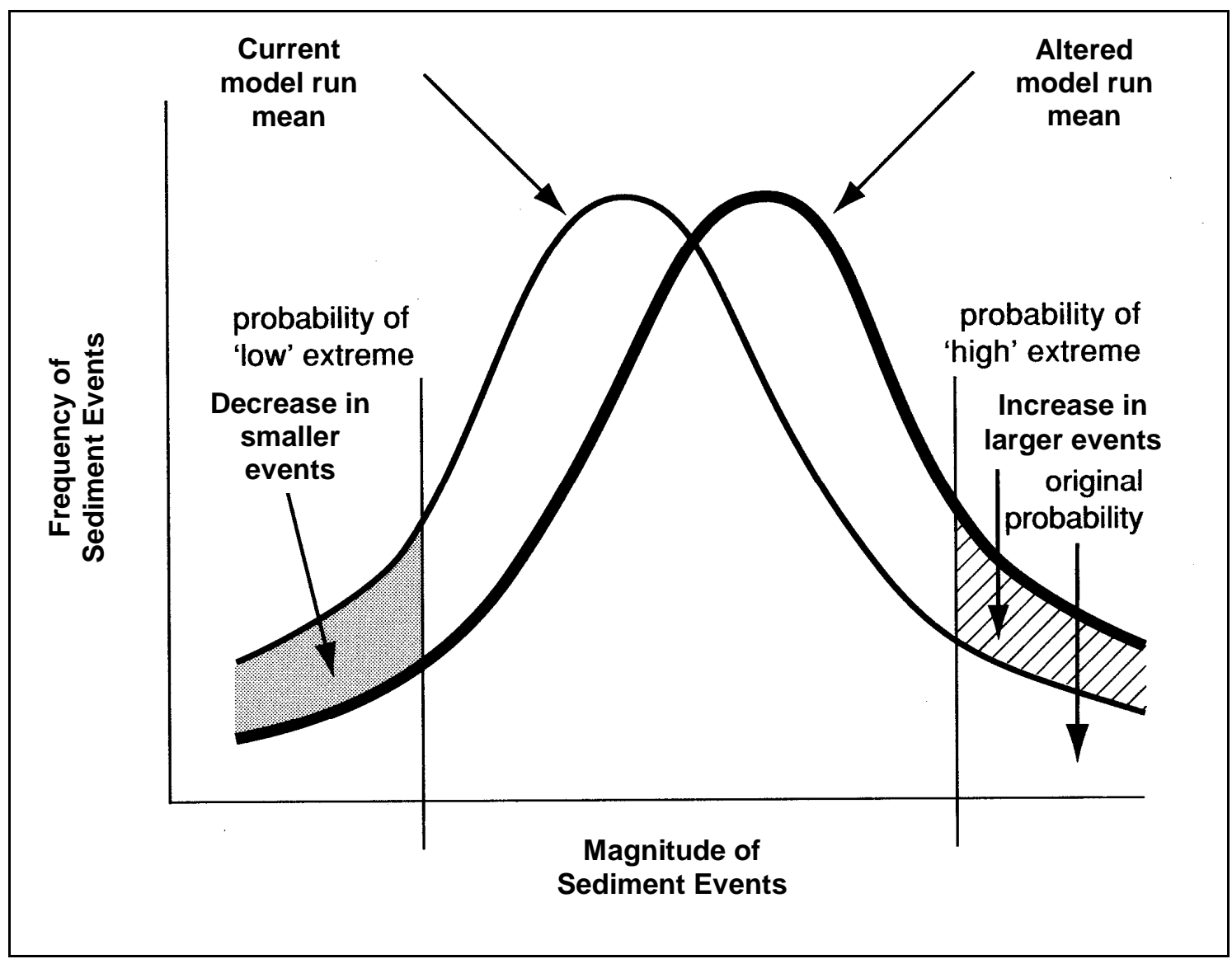

Figure 7.2: An increase in the mean amount of sediment, as indicated by the altered climatic conditions model run, would lead to a shift right of the hypothetical magnitude frequency curve, leading to an increased frequency of larger sediment events (modified from Smith, 1996).

\subsection{Sediment Event Frequency}

\subsubsection{Comparison of Sedimentation Event Occurrences}

The modelled occurrence of sedimentation events generated in the current conditions model run has been compared with the sedimentation events generated in the altered climatic conditions model run. This comparison is important for investigating potential changes to the frequency and magnitude of the hazard present on alluvial Fan 2.

The data generated by the two model runs imply that the frequency of sediment events being deposited on Fan 2 is likely to decrease if the current trend in projected climate change continues. Forty sediment events were generated under the altered climatic 
conditions model run, which used a rainfall data set based on the projected future A2 emissions scenario. This is less than the 69 sediment events which were generated under the current conditions model run. However, while less sediment events were generated under the altered climate situation, the data also suggest that when sediment events under this altered climate situation do occur, they will be of a larger magnitude. Generally events of a smaller magnitude contribute a smaller percentage towards the total number of events that occurred under the altered climatic conditions model run than under the current conditions model run, with events of a larger magnitude occurring more often.

Sediment events in which less than $1 \mathrm{~m}^{3}$ of sediment was involved were the most common sized event under both model runs, although the frequency of sediment events of this size decreased 16.21 percent from the current conditions model run to the altered climatic conditions model run. A similar decrease in the frequency of sediment events containing between $1 \mathrm{~m}^{3}$ and $2 \mathrm{~m}^{3}$ of sediment is shown. Events of this size decreased from 14.49 percent in the current climatic conditions model run to 10 percent in the altered climatic conditions model run - a total decrease of 31 percent.

Sediment events of a magnitude greater than $2 \mathrm{~m}^{3}$ of sediment generally occurred at a greater frequency under the altered climatic conditions model run when compared to the current climatic conditions model run. However, with closer examination, this is due to large increases in the frequency of two sediment event size ranges. The frequency of sediment events involving $2 \mathrm{~m}^{3}$ to $5 \mathrm{~m}^{3}$ of sediment displayed an increase of 244.8 percent of the total number of events generated by the current climatic conditions model run to the altered climatic conditions model run. Events of this size made up only 5.8 percent of the total events which occurred in the current conditions model run, but 20 percent of the total events which occurred in the altered climatic conditions model run.

Sediment events containing greater than or equal to $100 \mathrm{~m}^{3}$ of sediment also displayed an increase in frequency under an altered climate. Only one event of this magnitude $\left(136.5 \mathrm{~m}^{3}\right)$ was generated by the current conditions model run, which represented 1.45 percent of the total number of events that were generated. Three events of this magnitude $\left(140.8 \mathrm{~m}^{3}, 292.4 \mathrm{~m}^{3}\right.$ and $\left.685 \mathrm{~m}^{3}\right)$ were generated under the altered climatic 
model run - a tripling of the number of events which where generated by the currents conditions model run. The three events represented 7.5 percent of the total sediment events; an increase of 417.2 percent. All three of these events were larger than the single large event generated under the current conditions, with the largest of the three events being five times bigger, suggesting that the frequency of extreme events (those equal to or greater than $100 \mathrm{~m}^{3}$ ) are likely to increase as a result of future climate change. Sediment events with $5 \mathrm{~m}^{3}$ to $10 \mathrm{~m}^{3}$ and $10 \mathrm{~m}^{3}$ to $100 \mathrm{~m}^{3}$ of sediment both display decreases of 42.5 and 20.4 percent respectively.

Further, a similar change in the magnitude of hourly sediment discharge occurred under the altered climatic conditions model run, compared to the current climatic conditions. This is particularly evident when the hourly sediment discharge is plotted against hourly water discharge (see figures 6.14 and 6.18). A greater number of hourly sediment discharges occur under the altered climate than under the current climatic conditions. Generally hourly sediment events are larger under mid to high hourly water flow discharges. There is also a high concentration of hourly sediment events containing less than $5 \mathrm{~m}^{3}$ of sediment, even under varying water flow discharges. Both graphs display a high amount of hysteresis in the amount of sediment deposited when compared to the water discharge event which deposited it. This hysteresis could be due to the amount of sediment available within the catchment at the time of the rainfall/runoff event which triggered the sediment discharge. As discussed in section 7.3 sedimentation events may occur in some years, or in fact periods, and not in others. If no sediment event occurs for several years then there is likely to be a large amount of sediment available sediment stored within the catchment which could be transported in the next event, given sufficient water discharge. On the other hand, if two sediment events occur within a close time span of each other and are triggered by rainfall events of a similar magnitude, the second event may only discharge a small amount of sediment. This is due to the most of the sediment which was available in the catchment prior to the two events being transported onto the fan by the first event, i.e. supply constraint. This would lead to some water flow discharges having a high sediment discharge, while other water flow discharges of the same magnitude have a much smaller sediment discharge, as is shown in Figures 6.14 and 6.18. Additionally, hysteresis may be produced as a result of different volumes of sediment being entrained on the rising and falling limbs of the 
hydrograph during single rainfall/runoff events. This hysteresis of hourly sediment events leads to difficulty in determining a relationship between hourly sediment discharge and the frequency of hourly water flow discharge. This makes it difficult to determine a single most common geomorphically effective hourly discharge event under either climatic regime for Catchment 2.

One of the main conditions required for fan development is the occurrence of high intensity rainfall (Blair and McPherson, 1994; Davies and McSaveney, 2008). Alterations to the occurrence of these high intensity rainfall events, such as are projected to occur with climate change, can lead to alterations in the frequency and magnitude of sedimentation events discharged onto an alluvial fan. The rainfall data set input into the altered climatic conditions model run represents possible climate changes likely to occur in the area of the field site, and illustrates a drier climate with less total rainfall (see Figure 6.9). However, when high intensity rainfall events do occur, they are likely to be more intense. This alteration in rainfall events results in less frequent stream discharges, but a higher stream discharge capable of transporting greater amounts of sediment when they do occur, within Catchment 2, which in turn leads to less frequent but higher magnitude events as shown by the generated data.

Changes in the occurrence of high intensity rainfall events further have an effect on another of the main conditions required for fan development. Alluvial fans require an available sediment store within the catchment (Blair and McPherson, 1994; Davies and McSaveney, 2008) for their development. Less frequent high intensity rainfall events, and hence less frequent sediment discharge events allows for a greater amount of sediment to be accumulated and stored within the catchment. Therefore a greater amount of sediment is available to be transported onto the fan by the next high intensity rainfall event. Further the higher stream discharges are more able to transport this greater amount of sediment, generating sediment events of a greater magnitude. It is tempting to suggest that this has been demonstrated by the general increase in the volume of sediment involved in each of the sediment events generated under the altered climatic conditions model run, although CAESAR does not explicitly model this. 


\subsubsection{Model Projection Limitations, Errors and Uncertainties}

The use of CAESAR to model sedimentation events has been valuable in providing a guide to how the temporal frequency of potential hazardous sedimentation events may alter in relation to projected future climatic changes. The results are only projections of what may or may not actually occur in the future and are therefore not deterministic answers. This sub-section provides a discussion of the possible limitations, errors and uncertainties of CAESAR, the input data and the results.

\section{Model Limitations and Uncertainties}

CAESAR was originally designed for use in simulating catchments located in the United Kingdom (Coulthard and Van De Wiel, Date unknown). Generally these catchments exhibit very different characteristics from catchments located in New Zealand. The UK catchments generally consist of harder sandstone and mudstone lithology, which are much less easily eroded than the lithology in New Zealand. The UK does not experience the high tectonic activity which is present in New Zealand, which can result in the highly fractured lithology common in New Zealand. This, together with the higher proportion of intense rainfall and other weather, e.g. wind and snow, which New Zealand receives from being located in the "roaring forties", can give rise to the high amount of landsliding and other sedimentation events commonly experienced in New Zealand which is not so commonly experienced in the UK.

Due to this a number of limitations associated with the use of CAESAR and the way in which CAESAR simulates a New Zealand catchment have been identified. The characteristics of the actual real world catchment and the processes that operate within both the catchment and the stream channel are simplified by CAESAR which can lead to the real world catchment not being accurately simulated in the model runs. Three key limitations which are relevant to the simulation of Catchment 2 are recognised. These are the way in which the vegetation, the bed rock and lithology of the catchment (and as a result the ease with which the catchment is eroded) and the stream flow type are represented by CAESAR. 
Firstly, the vegetation cover within Catchment 2 is not realistically represented by CAESAR. Three different vegetation cover types have been identified within Catchment 2 (forest, 65.4 percent of the catchment; pasture, 16.05 percent; bare soil and rock, 18.55 percent. These differing vegetation covers are not recognised within CAESAR, with only a grass layer being allowed to grow over the surface layer of the catchment. This is largely controlled by the grass grow parameter which allows the time for grass growth maturity within the catchment to occur to be set. Vegetation cover has a very important role in determining the processes which occur in the catchment and when they can occur and it seems that this is not considered by CAESAR, or at least not within current versions of it. The type of vegetation cover present has an effect on the rate at which rainfall is able to run off the surface of the catchment and into the stream channel, with areas with vegetation generally exhibiting a slower runoff rate than unvegetated areas. As only a grass growth layer is recognised within CAESAR, the runoff rates simulated for Catchment 2 are not realistic, with runoff potentially being higher than is simulated for the bare soil and rock areas and lower for the forested areas of the catchment. Vegetation further affects the stability of slopes, which is especially important in Catchment 2, due to nearly 20 percent of the catchment not being vegetated. These unvegetated areas are generally located on steep slopes and so are much more likely to fail than steep slopes which are vegetated.

Secondly, the highly erosive nature of Catchment 2 is not realistically represented in CAESAR. The catchment consists of Great Marlborough Conglomerate, which, as noted during field work, is easily eroded by running water and can be chipped away by hand. It is not a consolidated lithology like the sandstones and mudstones present in catchments in the UK, for which CAESAR was designed. Due to this high erodibilty of the lithology, landslide and other mass movement processes are, in reality, likely to potentially occur more often in Catchment 2 than CAESAR allows for by scanning the entire catchment for landslides only once every 100 iterations. Further, stream flows are likely to erode a much larger amount of sediment from within the stream channel and the stream banks and canyon walls than is projected by CAESAR in each of the model runs, increasing the total amount of sediment discharged in each event. This is due to the high erodibilty of the lithology that makes the stream banks and canyon walls. 
Thirdly, the stream within Catchment 2 is an ephemeral stream, only containing surface water flow during intense or prolonged rainfall events. CAESAR, however, is designed to model perennial streams and so assumes that there is water flowing through the stream channel continually. Sediment, particularly finer clasts such as small gravels, sands and silts, can be regularly transported in perennial streams, with only the larger clasts able to be stored in the stream channel. Conversely in ephemeral streams all sediment which is deposited into the stream channel between flows is stored and can only be transported out of the catchment and out onto the alluvial fan when there is a surface flow in the stream channel as sedimentation events. In the case of Catchment 2 , this only occurs during intense or prolonged rainfall. CAESAR treating the unnamed stream in Catchment 2 as a perennial stream could result in an uncertainty in the number and size of the sedimentation events generated by each of the model runs. A high number of small sedimentation events (those containing less than $0.5 \mathrm{~m}^{3}$ of sediment) could occur, as noted in both of the model runs carried out for Catchment 2, due to the finer sediments being able to be transported more often in the continual flow than would be the case if the stream was treated as an ephemeral stream.

\section{Input Data Uncertainties}

There is some uncertainty surrounding the rainfall data used in both of the CAESAR model runs. Both the 1971 to 2000 control rainfall data set and the 2071 to 2100 future rainfall data set were produced by Regional Climate Model (RCM) simulations run by NIWA. While the 1971 to 2000 control rainfall data set was modelled around actual rainfall data, the data set is not the exact rainfall which occurred for this time period.

It is also important to note that the 2071 to 2100 future rainfall data set is only a future projection and may not be representative of the actual rainfall that will occur for this time period. It is based around the 'worst-case' A2 emissions scenario. Differing rainfall situations are predicted under each of the different emission scenarios and it is not yet clear which emission scenario is most likely to best represent the future climate. As a result the 2071 to 2100 rainfall data set generated from the RCM that is used here is only one possibility of a range of rainfall situations that may occur and, indeed, is only an estimation of the of the actual rainfall which may occur at the field site in the future. The results produced from CAESAR are therefore only at best a guide, 
particularly for the altered climatic conditions model run, of how an altered climate may affect sedimentation rates.

\section{Result Errors}

Due to no records of past events, both in the occurrence of events and of the amount of water and sediment discharged during each event, an amount of difficulty is introduced in determining how realistic and reliable the results generated from CAESAR are. Additionally, the above model and input data limitations and uncertainties add to the difficulty in determining how reliable the results are. However, when the results are compared to the memory of occurrences by locals in the area and the very small number of occurrences of events while this study was carried out, it is highly unlikely that the results generated from CAESAR are realistic. Two key anomalies have been noted in the results output from CAESAR:

- A limit below which a high proportion of the stream discharge occurs.

- The occurrence and magnitude of sedimentation events in both model runs reducing through time.

\section{$\underline{\text { Stream Discharge }}$}

A clear line below which a large proportion of the stream flow discharge occurs is evident across both of the stream flow discharge graphs (Figure 7.3). This occurs at approximately $0.01 \mathrm{~m}^{3} / \mathrm{s}$ on both graphs. This anomaly is unlikely to be caused by the rainfall data due to the line occurring at the same value on both stream discharge graphs, even though the two model runs were carried out using different rainfall data sets representing the current climatic conditions and possible future climatic conditions and it is evident from the water flow discharge frequency distribution (Figures 6.14 and 6.18) that a threshold may be present. 
A
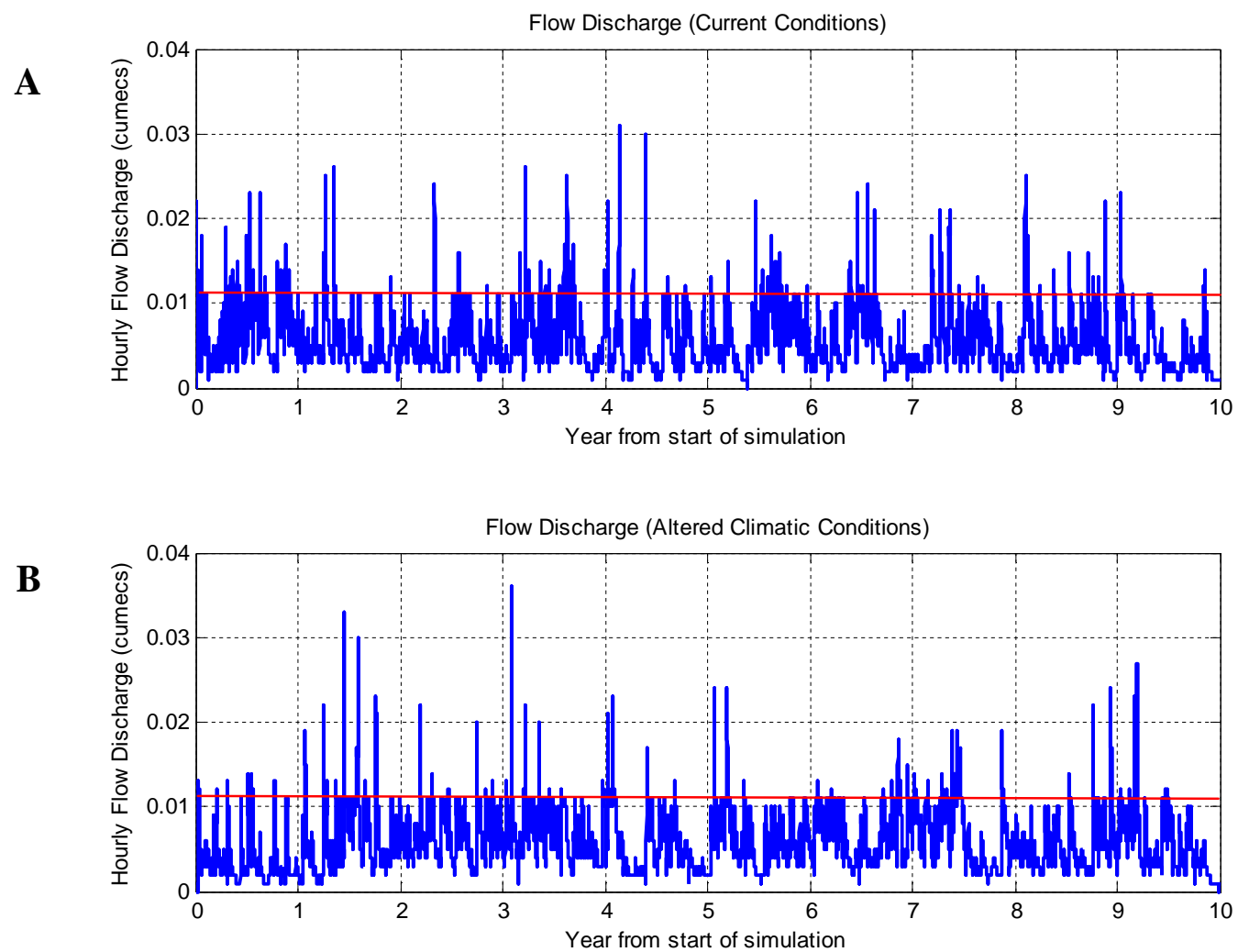

Figure 7.3: The water flow discharges produced in both CAESAR model runs, with the red line indicating the anomaly in the flow discharge. A: The current conditions model run and B: the altered climatic conditions model run.

\section{The Occurrence and Magnitude of Sedimentation Events}

The occurrence and magnitude of sediment events, in both the current conditions and the altered climatic conditions model runs, reduces as time in the model run passes. A high majority of the sediment events occurred in the first six years (years 1 to 6 ) of the simulations. Of the small number of events which did occur in the last four years (years 7 to 10 ) of the model simulations, none of the events contained greater than $0.5 \mathrm{~m}^{3}$ of sediment (see Figures 6.15 and 6.19). Table 7.1 displays the number and size range of the sediment events which occurred in each year of the model simulation. It is accepted that the occurrence of sediment events can naturally vary in time and in size; nevertheless, it is at least worthy of comment that both model run results display a similar pattern. This indicates that it is almost certainly a problem associated with the model and/or the parameters used for the model runs. 
Table 7.1: Number of sedimentation events per year of the model run for the current and altered climatic conditions model runs. In brackets is the size range of the events which occurred each year.

\begin{tabular}{|c|c|c|}
\hline $\begin{array}{c}\text { Year from Start of Model } \\
\text { Run }\end{array}$ & \multicolumn{2}{|c|}{ Number of Sedimentation Events Per Year } \\
\cline { 2 - 3 } & $\begin{array}{c}\text { Current Conditions Model } \\
\text { Run }\end{array}$ & $\begin{array}{c}\text { Altered Climatic } \\
\text { Conditions Model Run }\end{array}$ \\
\hline 1 & $20(0.084-136.539)$ & $2(0.028-1.778)$ \\
\hline 2 & $4(2.013-38.905)$ & $14(0.077-684.993)$ \\
\hline 3 & $4(0.007-19.256)$ & $6(0.019-3.719)$ \\
\hline 4 & $12(0.001-30.391)$ & $6(0.012-292.367)$ \\
\hline 5 & $8(0.019-18.014)$ & $4(0.052-6.83)$ \\
\hline 6 & $4(0.178-13.686)$ & $4(0.016-13.2)$ \\
\hline 7 & $4(0.247-0.352)$ & 0 \\
\hline 8 & $7(0.05-0.298)$ & $1(0.007)$ \\
\hline 9 & $4(0.11-0.276)$ & 0 \\
\hline 10 & $2(0.08-0.138)$ & $3(0.011-0.216)$ \\
\hline
\end{tabular}

These anomalies in the distribution and size of the sediment discharge events in both of the model simulations cannot be attributed to natural variations within the rainfall data sets. High hourly rainfall and stream flow discharge still occur (see Figures 6.10, 6.11, 6.13A and 6.17A) during the last four years of the data set and so there should be sediment events occurring at these times still. Again, it is tempting to infer something about catchment behaviour in this observation. CAESAR may be exhausting the sediment supply available within Catchment 2 to be discharged onto the fan. However, we could find no record of any parameter or process within CAESAR which could restrict the total amount of sediment that can be eroded and discharged from the catchment. The "Max Erode Limit" parameter limits the amount of erosion which can occur in each cell per model iteration (Coulthard et al., 2003) but this has no effect on the total amount of sediment which can be eroded. In addition to this, there is a large difference in the total amount of sediment that was discharged from the two model simulations. $518.1 \mathrm{~m}^{3}$ and $1,275.20 \mathrm{~m}^{3}$ of sediment were discharged from Catchment 2 under the current conditions model and the altered climatic conditions model run respectively. Due to the same parameters being set, except for the rainfall data set used, it can be expected that the total sediment discharges would be the same if CAESAR was exhausting the available sediment that could be discharged.

Despite considerable effort, we were unable to resolve the cause of this anomaly. It is acknowledged that it is highly likely to be an error associated with the model set up and 
parameters, and as a result inferences from modelling should only be based on only the first six years of both model simulations.

\subsubsection{Model Projections Summary}

Due to the limitations, errors and uncertainties associated with the use of CAESAR, the input data and the results output from the model runs it cannot be concluded that CAESAR is a suitable model to use for modelling sedimentation events within Catchment 2. The size and timing of the actual events produced by CAESAR are not necessarily accurate or representative of what could actually be occurring or occur in the future, resulting largely from errors with the model set up and parameters. This being said, however, the general pattern of sediment events occurring less frequently under an altered climatic regime, but of a larger magnitude when they do occur is an important observation and worthwhile noting.

\subsection{Implications for Potential Hazardous Events}

The results presented in chapters 5 and 6 and the comparison and discussion given in the current chapter have several key implications for the potential hazardous events which occur on Fan 2. Fans 1 and 3 and their respective catchments have similar geology, climate, vegetation and land use characteristics to that of Fan 2. Thus, the results gathered and the related implications for the occurrence of potentially hazardous events for Fan 2 will be broadly relevant for Fans 1 and 3 also.

Comparison of sediment events generated by the current climatic conditions model run and future climatic conditions suggested that the frequency of the events will decrease but that the events will generally be of a greater magnitude when they do occur. This implies that the potential hazard of fluvial sediment transport onto the alluvial fans is likely to remain unchanged or increase in future affecting State Highway 1 and the South Island Main Trunk Rail Line which pass over these fans. The hazard associated with the large sediment events is likely to increase as they could occur more often under an altered climate, while the hazard from the smaller events is unlikely to change. 
The longitudinal profiles of the stream channel indicated that the sediment transported onto the alluvial fans was originating from the catchment and canyon walls, and that the catchment sediment supply is likely to be in a steady state. The catchment and canyon walls provide an easily eroded source of conglomerate, which is unlikely to be exhausted in the near geological future. The suggested decrease in the frequency of the sediment events onto the alluvial fans would allow for a longer time interval between events for available sediment to be weathered and eroded from the canyon walls and to be stored within the stream channel.

Currently stream flow discharge events with a return period of 10- and 23-years occurring within the stream channel are competent to transport the current amounts of sediment which is stored in the stream channel once it has been eroded from the canyon walls. Throughout the stream channel, high stream power values indicate that there is a high amount of energy available for work to be carried out to transport sediment. Boundary shear stresses in these discharge events are capable of overcoming the critical shear stress of a large range of sediment calibres and initiating sediment transport. It is projected that rainfall events are likely to become more intense due to changes in the climatic situation, as is evident from the 2071 rainfall data set. Accordingly stream flow discharges will have greater available energy to carry out sediment entrainment and be able to transport large calibre sediment clasts. The stream flow will also be capable of transporting the larger amount of stored sediment onto the three fans.

Less sediment events are likely to occur as a result of an altered climatic regime. However this does not imply that the bypass bridges will be used less. The hazard presented to State Highway 1 and the South Island Main Trunk Rail Line by the three alluvial fans is likely to remain the same or increase. Small sediment events do not present a high degree of hazard to this key infrastructure, as they contain only small amounts of sediment and are less likely to reach the road or rail line. However it is suggested that when sediment events do occur, they will be of a larger magnitude. The number of sediment events able to reach the State Highway and the rail line is therefore likely to increase as larger events are able to travel further down the fan. This should be of concern when regarding the potential for future hazard to the sections of the road and rail crossing these fans. The State Highway fords and the bypass bridges, or 
alternatively the proposed culverts, which would replace the fords and bypass bridges, would need to be able to cope with a larger volume of sediment contained within the sediment events. 


\section{Chapter 8}

\section{Conclusions}

The three large alluvial fans situated along the northeast coast of the South Island, New Zealand between the settlement of Kekerengu and the mouth of the Clarence River flow from highly erosive catchments which are regularly active owing to the steep slopes and varying degrees of vegetated areas or bare rock and exposed sediment. Sediment events discharged from the catchments out onto the alluvial fans present obvious potential hazards to the key transport infrastructure, specifically State Highway 1 and the South Island Main Trunk Rail Line, and their users. Yet little record has been kept of the sediment event occurrences and little research has been conducted on these fans and their respective catchments. The underlying purpose of this study is centred on the hazard posed by fluvial sediment transport onto the three alluvial fans and how this may alter.

\subsection{Aims}

Three aims were developed, each with their own objectives established. The three stated aims of this study were:

Aim 1: Spatially define the locations from which the erosion hazard originates, within the catchments of the alluvial fans.

Aim 2: To understand the rates of sediment accumulation, in terms of both contemporary and geological sediment rates onto the alluvial fans.

Aim 3: Investigate the likely changes to potential hazard on the alluvial fans, in relation to changes in climate.

Each of these aims will be addressed in the following three sections. 


\subsection{Characterising the Hazard}

Objective 1: Construct longitudinal profiles of the stream channels to determine whether there is any evidence of the stream channel profiles altering as a result of artificial changes to base level.

To fulfil the first objective of aim 1, two longitudinal profiles were surveyed along the stream channels of the Kawauiti Stream and the unnamed stream in Catchments 1 and 2 respectively. These longitudinal profiles revealed no knickpoints to be migrating along either stream channel. This suggests that, currently in 2008, the stream profiles of Catchments 1 and 2 are not altering as a result of artificial changes to the streams' base level due to the insertion of the State Highway 1 fords and the continual reshaping of the fan stream channel. It is important to note that the longitudinal profile surveys were carried out after the occurrence of two large sediment events during July and August 2008, which may have removed any evidence of a knickpoint within the stream channels. This has lead to the recognition of the potential for a new knickpoint to be initiated as a result of an artificial step being created due to the clearing of the stream channel upstream of the State Highway on both Fans 1 and 2.

The absence of a knickpoint within the stream channel longitudinal profiles further implies that the source of sediment which is transported onto the alluvial fans during sediment events is not dominantly from the stream channel, but rather it is originating from the catchment canyon walls. The stream channel is well connected with the catchment walls, which consist predominantly of Great Marlborough Conglomerate. This sediment is eroded from the walls of the catchment and deposited into the stream channel, where it is likely to be stored until the occurrence of a stream discharge event capable of transporting it out of the catchment.

Objective 2: Evaluate which areas within the stream channels have the fluvial conditions required for sediment entrainment and transport of the sediment present within the stream channel out of catchment and onto the alluvial fans at times when flow discharges are present in the stream channels. 
To address the second objective of aim 1, through employing the longitudinal profiles and the rational method, stream power and unit stream power values for ten locations along the main stream channel of Catchment 2 were calculated to determine which areas of the stream channel had enough energy for sediment erosion to occur. Each location expressed high values of potential stream power under both 10- and 23-year return period events; with a general trend of increasing stream power towards the outlet of Catchment 2. This indicated that stream flows of this size have sufficiently high amounts of potential energy available to carry out erosion within the stream channel of Catchment 2. Unit stream power values indicated that there is generally a constant amount of energy available per unit area of the stream channel bed over the entire length of the stream channel due to the width of the channel increasing as stream power increases downstream.

In addition, comparison of boundary shear stress with calculated critical shear stress values determined for eight different calibres of clasts indicated that under both a 10 and 23-year return period flow discharge event, it is possible for all sediment within the stream channel at each of the five locations to be entrained and transported through the stream channel towards the fan. This suggested that under these flow conditions that a large amount of sediment could be deposited onto Fan 2 producing a hazard for the key transport routes.

\subsection{Rates of Sediment Accumulation}

Objective 1: Estimate the volume of material in the fans and the geological rates of sediment accumulation.

Objective 2: Estimate the amount of sediment deposited on the fans during the July and August 2008 rainfall events.

Average annual geological sediment accumulation rates and current event sediment accumulation rates were determined for Fan 2 through morphological interpretation of the field site and the surrounding area. An estimated average annual rate of $181.07 \mathrm{~m}^{3}$ 
per year of sediment has accumulated on Fan 2 since its formation approximately 6000 years ago. A high accumulation rate, similar to this, is to be expected and is a believable accumulation rate for this fan, as the catchment consists of easily eroded Great Marlborough Conglomerate with areas of absent vegetation on steep slopes. Additionally the catchment is located on a section of coast line which can receive intense rainfall events to trigger sediment movement. Actual event sediment accumulation rates onto the fan can be much higher than the average annual rate, as was highlighted by the two recent large sediment events in July and August 2008. Fence posts which were buried by the sediment discharged in these events were useful in directly interpreting the depth of sediment, and hence the volume of sediment deposited onto Fan 2 in these events. It is assumed that these two events were of a low frequency and high magnitude, with a total of at least $1,158.5 \mathrm{~m}^{3}$ of sediment deposited. However due to no records of sediment events onto these fans being kept, it is difficult to determine how accurate the average annual sediment accumulation and the 2008 event rates are.

Further, possible future rates of sediment accumulation onto Fan 2 were projected using the spatially distributed sediment transport model CAESAR. While these results are not accurate or reliable due to limitations and errors associated with CAESAR and the resulting output, as discussed in Chapter 7, a general comparison between the average annual sedimentation rates of the modelled current climatic conditions and the future climatic conditions indicates that it is likely that the average annual sediment accumulation rate will increase. This implies that generally sediment events of a larger magnitude will occur more often as a result of projected changes to the climate.

\subsection{Changes to Potential Hazard in Relation to Changes in Climate}

Objective 1: Estimate the potential change in frequency of sediment movement onto the alluvial fans as a result of a future rainfall/runoff regime, based on predicted climate change and by applying a spatially distributed sediment transport model. 
The spatially distributed sediment transport model CAESAR was employed to model sedimentation events onto Fan 2 under a current rainfall/runoff regime and a climate change altered rainfall/ runoff regime to investigate how the temporal frequency of sediment events may change as a result of projected climate changes. The occurrence of sediment events decreased under the altered climatic conditions model run, with 69 sediment events occurring in the current conditions model run and 40 events occurring in the altered climatic conditions model run. However, again due to the limitations, uncertainties and errors associated with CAESAR and the resulting output, the exact number of sediment events may be unreliable and not realistic. The general change in pattern between the two model runs indicates that sediment events will occur less frequently under an altered climatic regime, but when they do occur, events of a higher magnitude are likely.

This general pattern can be explained by the projected change in the rainfall regime due to climate change. Less rainfall is expected by occur in the east of the South Island, with a projected decrease of 7.5 percent by 2090 (MfE, 2008) over the area of the field site. Additionally rainfall events are projected to be of a higher intensity. This alters two of the main conditions required for fan development, allowing for longer time intervals between sediment events for sediment to build up within the catchment and higher stream flows with greater potential energy to transport the sediment onto the fan.

\subsection{Implications}

This study has proposed a set of possibilities for how the frequency of sediment transport onto Fan 2 could potentially alter in relation to a changing climate, resulting in potential changes to hazardous events on the fan. It has furthermore identified current and possible future locations of erosion, entrainment and transport of sediment within the catchment and along the stream channel of the unnamed stream. In general, currently in 2008 and possibly well into the future, a large proportion of sediment appears to be originating from the highly erosive catchment and canyon walls, and is stored within the stream channel. Under high stream flow discharge events this sediment is readily able to be entrained and transported out of the catchment onto the 
alluvial fan. The frequency of occurrence of these events is generally likely to decrease as rainfall regimes alter due to projected climatic changes. When these events do occur, however, it is proposed that more events of a larger magnitude will occur. These results indicate that the hazard presented to State Highway 1, the South Island Main Trunk Rail Line and their users is likely to stay unchanged or increase due to less sediment events occurring but a higher chance of larger events reaching the road and rail line.

The three large alluvial fans located on the northeast coast of the South Island, New Zealand between the settlement of Kekerengu and the Clarence River mouth have similar characteristics, allowing the gathered results and the their implications for Fan 2 and its catchment to be broadly relevant for Fans 1 and 3 and the respective catchments.

\subsection{Recommendations for Future Studies}

A number of future studies could be undertaken to further understand the potential hazard of these alluvial fans and how it may alter in the future. Studies on the geomorphic effect that the engineering of the fan surfaces have in relation to likely areas of erosion and the potential hazard would be important in further assessing the hazard presented to the State Highway and railway line and establishing if feedback mechanisms are present as a result of these anthropogenic changes. In particular this would include an assessment on the effects that the clearing of the stream channel on the fan has on sediment generation, for example through the generation of a knickpoint. This would require extending the longitudinal surveys up the tributaries and locating bedrock knickpoints underneath the alluvium. Further, studies on the geomorphic effects of the proposed replacement of the fords with culverts in relation to erosion and the potential hazard would be relevant.

A better understanding of the frequency and magnitude of sediment events onto the alluvial fans is needed to better project how the occurrence of sediment events may alter due to changes in the climatic regime. This has led to the need for records of sediment events onto the alluvial fans being recognised, particularly as two key transport routes cross over these fans. However, until a lengthy record of sediment events has been 
gathered, simulating sediment events through cellular modelling must be relied on. It is further recognised that a means of validating CAESAR to these catchments is required, or indeed, that a model better than CAESAR is required, which can more accurately model and reflect these catchments and the occurrence sediment transport through them. Model simulations over larger time periods and incorporating the differing projections of possible rainfall scenarios, resulting from other rainfall models and emission scenarios, would aid in better understanding how the frequency and magnitude of these. 


\section{References}

Abbott, P.L., 2008. Natural disasters. $6^{\text {th }}$ Edition, McGraw-Hill, Boston, 510pp

Allen, J.R.L., 1985. Principles of physical sedimentology. George Allen and Unwin Publishers, London, 271pp

Anderson, H.W., 1957. Relating sediment yield to watershed variables. Transactions of American Geophysical Union, Vol. 38 (6), pp. 921

Anderson, R., 1988. Alluvial fan morphometry: a true reflection of the source area morphology. Unpublished Honours Research Paper, Victoria University of Wellington

Ballard, J., 2008. SH1 shingle fan improvements scheme assessment report. Draft, Opus International Consultants, Christchurch

Bell, D.H., 1976. High intensity rainstorms and geological hazards: Cyclone Alison, March 1975, Kaikoura, New Zealand. Bulletin of the International Association of Engineering Geology, No. 14, pp 189-200

Blair, T. and McPherson, J., 1994, Alluvial fan processes and forms. In Abrahams, A. and Parsons, A. (Eds.), Geomorphology of the dessert environments. ChapmanHill, London, pp 354-402

Bovis, M.J. and Jakob, M., 1999. The role of debris supply conditions in predicting debris flow activity. Earth Surface Processes and Landforms, Vol. 24, pp10391054

Brennan, R.F., 2007. Alluvial fans: the influence of climate on deposition processes and hazards on alluvial fan. Unpublished Honours Thesis, University of Otago

Browne, G.H., 1992. The northeastern portion of the Clarence Fault: tectonic implications for the late evolution of Marlborough, New Zealand. New Zealand Journal of Geology and Geophysics, Vol. 35, pp 437-445

Browne, G.H., 1995. Sedimentation patterns during the Neogene in Marlborough, New Zealand. Journal of the Royal Society of New Zealand, Vol. 25 (4), pp 459-483

Bull, W.B., 1977. The alluvial fan environment. Progress in Physical Geography, Vol. 1 , pp 222-270

Bull, W.B., 1979. Thresholds of critical power in streams. Bulletin of the Geological Society of America, Vol. 90, pp 453-464

Bull, W.B., 1991. Geomorphic response to climate change. Oxford University Press, Oxford

Burton, I. and Kates, R.W., 1964. The perception of natural hazards in resource management. Natural Resources Journal, Vol. 3, pp 412-441

Chapman, D., 1994. Natural hazards. Oxford University Press, Melbourne, 174pp

Charlton, R., 2008. Fundamentals of fluvial geomorphology. Routledge, London, 234pp

Chow, V.T., 1964. Handbook of applied hydrology. McGraw-Hill, New York

Church, M. and Ryder, J.M., 1972. Paraglacial sedimentation, a consideration of fluvial processes conditioned by glaciation. Bulletin of the Geological Society of America, Vol. 83, pp 3059-3072

Church, M. and Slaymaker, O., 1989. Disequilibrium of Holocene sediment yield in glaciated British Columbia. Nature, Vol. 337, pp 452-454

Corominas, J., Remondo, J., Estevao, M., Zezere, J., Dias de Teran, J. Dikau, R., Schrott, L., Moya, J. and Gonzales, A., 1996. Debris flows. In Dikau, R., Brunsden, D., Schrott, L. and Ibsen, M. (Eds.), Landslide recognition identification, movement and causes, Wiley, pp 161-180 
Coulthard, T.J., 1999. Modelling upland catchment response to Holocene environmental change. Unpublished PhD Thesis, School of Geography, University of Leeds, U.K., 181pp

Coulthard, T.J., 2001. Landscape evolution models: a software review. Hydrological Processes, Vol. 15, pp 165-173

Coulthard, T.J., Dennis, I. and Foster, G., 2003. Instructions for using visual CAESAR/TRACER. Electronic address: www.coulthard.org.uk/downloads/visualcaesar.htm

Coulthard, T.J., Hicks, D.M. and Van De Wiel, M.J., 2007. Cellular modelling of river catchments and reaches: advantages, limitations and prospects. Geomorphology, Vol. 90, pp 192-207

Coulthard, T.J., Kirkby, M.J. and Macklin, M.G., 2000. Modelling geomorphic response to environmental change in an upland catchment. Hydrological Processes, Vol. 14, pp 2031-2045

Coulthard, T.J., Lewin, J. and Macklin, M.G., 2005. Modelling differential catchment response to environmental change. Geomorphology, Vol. 69, pp 222-241

Coulthard, T.J., Macklin, M.J. and Kirkby, M.J., 2002. A cellular model of Holocene upland river basin and alluvial fan evolution. Earth Surface Processes and Landforms, Vol. 27, pp 269-288

Coulthard, T.J. and Van De Wiel, M.J., Date unknown. The cellular automation evolutionary slope and river model (CASEAR). Instruction manual, Electronic address: www.coulthard.org.uk/downloads/visualcaesar.htm

Coulthard, T.J. and Van De Wiel, M.J., 2006. A cellular model of river meandering. Earth Surface Processes and Landforms, Vol. 31, pp 123-132

Crosta, G.B. and Frattini, P., 2004. Controls on modern alluvial fan processes in the Central Alps, Northern Italy. Earth Surface Processes and Landforms, Vol. 29, pp 267-293

Crozier, M.J., 1996. Magnitude / frequency issues in landslide hazard assessment. In. Mausbachor, R. and Schutte, A. (Eds.), Beitrage zur Physiogreographies Barsch Festschr., Heidelberger Greographische Arbeiten 104; pp 221-236

Crozier, M.J., 1999. The frequency and magnitude of geomorphic processes and landform behaviour. Zeitschrift fur Geomorphologie, Supplementband 115, pp $35-50$

Crozier, M.J. and Glade, T., 1999. Frequency and magnitude of landsliding: fundamental research issues. Zeitschrift fur Geomorphologie, Supplementband 115, pp 141-155

Crozier, M.J. and Glade, T., 2005. Landslide hazard and risk: issues, concepts and approach. In. Glade, T., Anderson, M. and Crozier, M.J. (Eds.), Landslide hazard and risk. John Wiley and Sons, England, pp 1-40

Davidson Ayson, 1996. Review of stormwater design criteria for Wellington City Council Report prepared for Wellington City Council

Davies, T.R., 1997. Long-term management of facilities on an active alluvial fan Waiho River Fan, Westland, New Zealand. Journal of Hydrology (NZ), Vol. 36 (2), pp 127-145

Davies, T.R. and Korup, O., 2007. Persistent alluvial fanhead trenching resulting from large, infrequent sediment input. Earth Surface Processes and Landforms, Vol. 32, pp 725-742

Davies, T.R. and McSaveney, M.J., 2008. Principles of sustainable development on fans Journal of Hydrology (NZ), Vol. 47 (1), pp 43-65 
De Scally, F.A. and Owens, I.F., 2004. Morphometric controls and geomorphic responses on fans in the Southern Alps, New Zealand. Earth Surface Processes and Landforms, Vol. 29, pp 311-322

De Scally, F.A. and Owens, I.F., 2005. Depositional processes and particle characteristics on fans in the Southern Alps, New Zealand. Geomorphology, Vol. 69, pp 46-56

Dean, S., 8 June 2009. Personal communication, National Institute of Water and Atmospheric Research Ltd.

Dorn, R.I., 1994. The role of climate change in alluvial fan development. In. Abrahams, A. and Parsons, A. (Eds.), Geomorphology of desert environments. ChapmanHill, London, pp 593-615

Drew, F., 1873. Alluvial and lacustrine deposits and glacial records of the Upper Indus Basin. Geological Society of London Quarterly Journal, Vol. 29, pp 441-471

EBA Engineering Consultants Ltd and Graham Rawlings Consulting Ltd, 1997. Geotechnical report No. 1 on hazards, risks and mitigative measures for Glencoe Stream catchment at Mount Cook/ Aoraki Village. New Zealand Department of Conservation

Folk, R. and Ward, W., 1957. Brazos River bar: a study in the significance of grain size parameters. Journal of Sedimentary Petrology, Vol. 27, pp 3-36

Frevert, R.K., Schwab, G.O., Edminster, T.W. and Barnes, K.K, 1955. Soil and water conservation engineering. John Wilely and Sons, New York, $479 \mathrm{pp}$

Fryirs, K.A. and Brierley, G.T., 2001. An introduction to fluvial geomorphology. Department of Physical Geography, Macquarie University, New South Wales, $124 \mathrm{pp}$

Fryirs, K.A., Brierley, G.J., Preston, N.J. and Kasai, M., 2007. Buffers, barriers and blankets: the (dis)connectivity of catchment-scale sediment cascades. Catena, Vol. 70, pp 49-67

Garfi, G., Bruno, D.E., Calcaterra, D. And Parise, M., 2007. Fan morphodynamics and slope instability in the Mucone Rive basin (Sila Massif, Southern Italy): significance of weathering and role of land use changes. Catena, Vol. 69, pp 181-196

Gibbs, H.S. and Beggs, J.P., 1953. Soils and agriculture of Awatere, Kaikoura and part of Marlborough counties. Department of Scientific and Industrial Research Soil Bureau Bulletin 9

Gregory, K.J. and Walling, D.E.; 1973; Drainage Basin Form and Process; John Wiley and Sons, New York, 456pp

Herschy, R.W., 2009. Streamflow measurement. $3^{\text {rd }}$ Edition, Routledge, London, 507pp

Hjulstrom, F., 1935. Studies of the morphological activity of rivers as illustrated by the River Fryris. Bulletin of the Geological Institute University of Uppsala, Vol. 25, pp 221-527

IPCC, International Panel on Climate Change, 2000. Special report on emissions scenarios. Nakicenovic, N. And Swart, R. (Eds.), Cambridge University Press, Cambridge

Jackson, L.E. Jr., Kostaschuk, R.A. and MacDonald, G.M., 1987. Identification of debris flow hazard on alluvial fans in the Canadian Rocky Mountains. Reviews in Engineering Geology VII, pp 115-124

Jain, V., Preston, N., Fryirs, K. And Brierley, G., 2006. Comparative assessment of three approaches for deriving stream power plots along long profiles in the 
Upper Hunter River catchment, New South Wales, Australia. Geomorphology, Vol. 74, pp 297-317

Kinsella, Y. and McGuire, F., 2006. Climate change uncertainty and the state highway network: a moving target. Transit New Zealand

Knighton, D., 1998. Fluvial forms and processes: a new perspective. Arnold, London, $383 \mathrm{pp}$

Lamb, S.H. and Bibby, H.M., 1988. The last 25 Ma of rotational deformation in part of the New Zealand plate-boundary zone. Journal of Structural Geology. Vol. 11 (4), 473-492

Leopold, L.B., Laird, M.G. and Millar, J.P., 1964. Fluvial processes in geomorphology. Freeman and Company, San Francisco, 522pp

Lewis, D.W., Laird, M.G. and Powell, R.D., 1980. Debris flow deposits of early Miocene age, Deadman Stream, Marlborough, New Zealand. Sedimentary Geology, Vol. 27, pp 83-118

LINZ, Land Information New Zealand, 2009. Aerial photograph BS28 (2004/2005). Electronic address: www.linz.govt.nz/topography/aerial_images/nztmgeo/bs28/index.aspx

Marchi, L., Pasuto, A. And Tecca, P.R., 1993. Flow processes on alluvial fans in the Eastern Italian Alps. Zeitschrift fur Geomorphologie, Vol. 37, pp 447-458

Martel, C., 2005. Standardisation of design flows for coastal catchments in New Zealand. Land Transport New Zealand, Research Report No. 272, 38pp

McArthur, I.L., 1987. The characteristics, classification and origin of late Pleistocene fan deposits in the Cass basin, Canterbury, New Zealand. Sedimentology, Vol. 34, pp 459-471

McSaveney, M.J., Davies, T.R.H. and Gough, J.D., 1995. Natural hazard assessment for Mount Cook/ Aoraki Village and environs. Unpublished report to the Mount Cook Village Development Sterring Group/ DoC, IGNS client report

McSaveney, M.J. and Whitehouse, I.E., 1989. Hazards on Fans. Streamland 73, DSIR Publishing, Wellington

MfE, Ministry for the Environment, 2002. Climate change impacts on New Zealand. Report ME396, Ministry for the Environment, Wellington, 39pp

MfE, Ministry for the Environment, 2008. Climate change effects and impacts assessment: a guidance manual for local government in New Zealand. $2^{\text {nd }}$ Edition, Mullan, B., Wratt, D., Dean, S., Hollis, M., Allan, S., Williams, T., Kenny, G. and MfE, Ministry for the Environment, Wellington, xvii + 149pp

Miller, M.C., McCave, I.N. and Komar, P.D., 1977. Threshold of sediment motion under unidirectional currents. Sedimentology, Vol 24, pp 507-527

Mullan, B., Reisinger, A., Manning, M., Wratt, D. And Nottage, R. (Compliers), 2009. Adaptation conference climate change scenarios information. Climate Change Adaptation Conference 2009, New Zealand Climate Change Centre

Murray, J., 23 January 2008.personal communication with current owner of Matariki Farm, the farm to the south of the fans and behind the catchments

NIWA, National Institute of Water and Atmospheric Research, 2009. Cliflo: the national climate database. Electronic address: http://cliflo.niwa.co.nz/

Opus International Consultants, 2008, SH1 shingle fan improvements scheme assessment report: preliminary geotechnical appraisal report. Appendix F. In. Ballard, J., SH1 shingle fan improvement scheme assessment report (Draft), Opus International Consultants, Christchurch 
Pascoe, R.M., 1983. The climate and weather of Marlborough. New Zealand Meteorological Service, Misc. Pub. 115 (12)

Pye, K. (Ed.), 1994. Sediment transport and depositional processes. Blackwell Scientific Publications, Oxford, 397pp

Rattenbury, M.S., Townsend, D.B., Johnston, M.R. (Compilers), 2006. Geology of the Kaikoura area. Institute of Geological and Nuclear Sciences, 1:250,000 geological map sheet, 1 sheet + 70pp, GNS Lower Hutt, New Zealand

Richards, K., 1999. The magnitude-frequency concept in fluvial geomorphology: a component of a degenerating research programme?. Zeitschrift fur Geomorphologie, Supplementband 115, pp 1-18

Robert, A., 1990. Boundary roughness in coarse-grained channels. Progress in Physical Geography, Vol. 14, pp 42-70

Selby, M.J., 1974. Dominant geomorphic events in landform evolution. Bulletin of the International Association of Engineering Geology, Vol. 9, pp 85-89

Selby, M.J., 1982. Hillslope materials and processes. Oxford University Press, Oxford, $264 \mathrm{pp}$

Selby, M.J., 1993. Hillslope materials and processes. $2^{\text {nd }}$ Edition, Oxford University Press, Oxford, 451pp

Sherrad, J.M., 1966. Kaikoura: a history of the district. Caxton Press, Christchurch, 373 $\mathrm{pp}$

Shields, A., 1936. Anwendung der Ahnlichkeitsmechanik und der Turbulenz-forschung auf die Geschiebebewegung. Mitteilung der preussischen Uersusanstalt fur Wasserbau and Schiffbau, Vol. 26, Berlin

Skermer, N.A., Rawlings, G.E. and Hurley, A.J., 2002. Debris flow defences at Aoraki Mount Cook Village New Zealand. Quarterly Journal of Engineering Geology and Hydrogeology, Vol. 35, pp 19-24

Smith, K., 1996. Environmental hazards: assessing risk and reducing disaster. $2^{\text {nd }}$ Edition, Routledge, New York, 389pp

Sorriso-Valvo, M., Antronico, L. and La Pera, E., 1998. Controls on fan morphology in Calabria, southern Italy. Geomorphology, Vol. 24, pp 169-187

Stace, J., 16 November 2008. Personal communication with land owner to the north of fans

Statham, I., 1977. Earth surface sediment transport. Clarendon Press, Oxford, 181pp

Strahler, A.N., 1975. Physical geography. $4^{\text {th }}$ Edition, Wiley, Canada, 643 pp

Strahler, A.N., 1957. Quantitative analysis of watershed geomorphology. Transactions of American Geophysical Union, Vol. 38, pp 913-920

$\mathrm{Su}$, A., 10 October 2008. Personal communication, graduate engineer at the New Zealand Transport Agency (formerly Transit New Zealand), Christchurch

Summerfield, M.A., 1991. Global geomorphology. Longman, Singapore, 537pp

Thomson, P.A., 1969. Kekerengu shingle fans. Unpublished Marlborough catchment Board Report, 7pp

Tomlinson, A.I., 1975. Cyclone Alison. Technical Information Circular, No. 148, New Zealand Meteorological Service, Wellington

Transit New Zealand, 2007. Transit New Zealand's 10 year state highway plan and forecast for 2007/08 to 2016/17: incorporating Transits 2007/08 land transport programme. Transit New Zealand, Wellington

Transit New Zealand, 2008a. Transit New Zealand's 10 year state highway plan and forecast for 2008/09 to 2017/18: incorporating Transits 2008/09 land transport programme. Transit New Zealand Wellington 
Transit New Zealand, 2008b. Photographs of the state highway 1 fords passing over the alluvial fan during the 31 July rainfall event

Turner, A.K., 1960. Rainfall losses in relation to runoff for small catchments. The Journal of the Institution of Engineers, Australia, Vol. 32 (1-2), pp 1-6

Van De Wiel, M.J., Coulthard, T.J., Macklin, M.G. and Lewin, J., 2007. Embedding reach-scale fluvial dynamics within the CAESAR cellular automation landscape evolution model. Geomorphology, Vol. 90, pp 283-301

Van Dissen, R. and Yeats, R.S., 1991. Hope Fault, Jordan Thrust, and uplift of the Seaward Kaikoura Range, New Zealand. Geology, Vol. 19, pp 393-396

Vickery, S. and Lamb, S., 1995. Large tectonic rotations since the Early Miocene in a convergent plate-boundary zone, South Island, New Zealand. Earth and Planetary Sciences Letters, Vol. 136, pp 43-59

Whetton, P., Mullan, A.B. and Pittock, A.B., 1994. Climate change scenarios for Australia and New Zealand. In, Bouma, W.J., Pearman, G.I. and Manning, M. (Eds.), Greenhouse '94: coping with climate change. Melbourne, CSIRO DAR 145-168

Wolman, M.G. and Millar, J.P., 1960. Magnitude and frequency of forces in geomorphic processes. Journal of Geology, Vol. 68 (1), pp 54-74

Worthy, M., 2005. High-resolution total stream power estimation for the Cotter River, Namadgi National Park, Australian Capital Territory. In, Roach, I.C., Regolith 2005 - ten years of CRC LEME. CRC LEME, pp 338-343 
APPENDIX I

Longitudinal Profile Collection Data 


\section{Profile Calculation Equations}

Calculation of the Distance between the engineering level and the staff:

(Upper staff reading - Lower staff reading) X 100

\section{Calculation of Cumulative Distance:}

The first value equals zero.

For each new back site point the cumulative distance equals the cumulative distance of the point above.

All others equal:

Cumulative distance point above + (Previous distance point - Current distance point)

Calculation of Reduced Level:

The first value equals zero.

Each new back site point equals zero.

All others equal:

Previous middle staff reading - Current middle staff reading

\section{Calculation of Collimation Height:}

The first value equals zero.

All others equal:

Collimation height point above - Current reduced level point 
Southern Branch of Kawauiti Stream, Catchment 1 Stream Channel Longitudinal Profile

\begin{tabular}{|c|c|c|c|c|c|c|c|c|c|c|}
\hline \multicolumn{3}{|c|}{ Backsight } & \multicolumn{3}{|c|}{ Foresight } & \multirow{2}{*}{ Comments } & \multirow{2}{*}{ Distance } & \multirow{2}{*}{$\begin{array}{c}\text { Cumulative } \\
\text { Distance }\end{array}$} & \multirow{2}{*}{$\begin{array}{c}\text { Reduced } \\
\text { Level }\end{array}$} & \multirow{2}{*}{$\begin{array}{c}\text { Collimation } \\
\text { Height }\end{array}$} \\
\hline $\mathbf{U}$ & $\mathbf{M}$ & $\mathbf{L}$ & $\mathbf{U}$ & M & $\mathbf{L}$ & & & & & \\
\hline & 4.97 & 4.49 & & & & Start of profile, centre of channel, west side of rail & 96 & 0 & 0 & 0 \\
\hline 4.44 & 4.14 & 3.84 & & & & Bottom egde of channel & 60 & 36 & 0.83 & 0.83 \\
\hline 3.98 & 3.69 & 3.4 & & & & Top of channel & 58 & 38 & 0.45 & 1.28 \\
\hline 2.92 & 2.76 & 2.6 & & & & & 32 & 64 & 0.93 & 2.21 \\
\hline \multirow[t]{2}{*}{1.5} & 1.5 & 1.5 & & & & Dumpy height & 0 & 96 & 1.26 & 3.47 \\
\hline & & & 1.06 & 0.96 & 0.86 & FS back to dumpy & 20 & 116 & 0.54 & 4.01 \\
\hline 4.56 & 4.33 & 4.1 & & & & & 46 & 116 & 0 & 4.01 \\
\hline \multirow[t]{2}{*}{1.6} & 1.6 & 1.6 & & & & Dumpy height & 0 & 162 & 0.83 & 6.74 \\
\hline & & & 1.17 & 1.145 & 1.12 & FS back to dumpy & 5 & 167 & 0.455 & 7.195 \\
\hline 3.65 & 3.45 & 3.25 & & & & & 40 & 167 & 0 & 7.195 \\
\hline 2.42 & 2.32 & 2.22 & & & & & 20 & 187 & 1.13 & 8.325 \\
\hline \multirow[t]{4}{*}{1.59} & 1.59 & 1.59 & & & & Dumpy height & 0 & 207 & 0.73 & 9.055 \\
\hline & & & 1.05 & 1.02 & 0.99 & Base of road ford east side, FS back to dumpy & 6 & 213 & 0.57 & 9.625 \\
\hline & & & 0.43 & 0.39 & 0.35 & Top of road ford east side, FS back to dumpy & 8 & 215 & 0.63 & 10.255 \\
\hline & & & 0.29 & 0.21 & 0.13 & West side of road, FS back to dumpy & 16 & 223 & 0.18 & 10.435 \\
\hline 4.6 & 4.25 & 3.9 & & & & BS to fence & 70 & 227 & 0 & 10.235 \\
\hline 3.04 & 2.88 & 2.72 & & & & & 32 & 265 & 1.37 & 11.605 \\
\hline \multirow[t]{3}{*}{1.44} & 1.44 & 1.44 & & & & Dumpy height & 0 & 297 & 1.44 & 13.045 \\
\hline & & & 0.39 & 0.28 & 0.17 & FS back to dumpy & 22 & 319 & 1.16 & 14.205 \\
\hline & 4.91 & 4.62 & & & & & 58 & 319 & 0 & 14.205 \\
\hline 2.9 & 2.8 & 2.7 & & & & & 20 & 357 & 2.11 & 16.315 \\
\hline \multirow[t]{2}{*}{1.54} & 1.54 & 1.54 & & & & Dumpy height & 0 & 377 & 1.26 & 17.575 \\
\hline & & & 1.04 & 0.99 & 0.94 & Base of bulldozed slope, FS back to dumpy & 10 & 387 & 0.55 & 18.125 \\
\hline 4.87 & 4.69 & 4.51 & & & & BS to base of bulldozed slope & 36 & 387 & 0 & 18.125 \\
\hline 3.27 & 3.12 & 2.97 & & & & & 30 & 393 & 1.57 & 19.695 \\
\hline \multirow[t]{2}{*}{1.52} & 1.52 & 1.52 & & & & Dumpy height & 0 & 423 & 1.6 & 21.295 \\
\hline & & & 0.65 & 0.55 & 0.45 & Top of fan, channel split into 2, FS back to dumpy & 20 & 443 & 0.97 & 22.265 \\
\hline 4 & 3.8 & 3.6 & & & & South channel, BS to mid point of channel split & 40 & 443 & 0 & 22.265 \\
\hline 2.68 & 2.6 & 2.52 & & & & & 16 & 467 & 1.2 & 23.465 \\
\hline \multirow[t]{2}{*}{1.54} & 1.54 & 1.54 & & & & Dumpy height & 0 & 483 & 1.06 & 24.525 \\
\hline & & & 0.18 & 0.05 & & FS back to dumpy & 26 & 509 & 1.49 & 26.015 \\
\hline 4.15 & 3.95 & 3.75 & & & & & 40 & 509 & 0 & 26.015 \\
\hline
\end{tabular}




\begin{tabular}{|c|c|c|c|c|c|c|c|c|c|c|}
\hline \multicolumn{3}{|c|}{ Backsight } & \multicolumn{3}{|c|}{ Foresight } & \multirow{2}{*}{ Comments } & \multirow{2}{*}{ Distance } & \multirow{2}{*}{$\begin{array}{c}\text { Cumulative } \\
\text { Distance }\end{array}$} & \multirow{2}{*}{$\begin{array}{c}\text { Reduced } \\
\text { Level }\end{array}$} & \multirow{2}{*}{$\begin{array}{c}\text { Collimation } \\
\text { Height }\end{array}$} \\
\hline $\mathbf{U}$ & M & $\mathbf{L}$ & $\mathbf{U}$ & M & $\mathbf{L}$ & & & & & \\
\hline 2.58 & 2.49 & 2.4 & & & & & 18 & 531 & 1.46 & 27.475 \\
\hline \multirow[t]{2}{*}{1.58} & 1.58 & 1.58 & & & & Dumpy height & 0 & 549 & 0.91 & 28.385 \\
\hline & & & 0.71 & 0.59 & 0.47 & FS back to dumpy & 24 & 573 & 0.99 & 29.375 \\
\hline 3.65 & 3.51 & 3.37 & & & & & 28 & 573 & 0 & 29.375 \\
\hline 2.09 & 2.04 & 1.99 & & & & & 10 & 591 & 1.47 & 30.845 \\
\hline \multirow[t]{2}{*}{1.6} & 1.6 & 1.6 & & & & Dumpy height & 0 & 601 & 0.44 & 31.285 \\
\hline & & & 0.47 & 0.37 & 0.27 & FS back to dumpy & 20 & 621 & 1.23 & 32.515 \\
\hline 2.75 & 2.695 & 2.64 & & & & & 11 & 621 & 0 & 32.515 \\
\hline 2.5 & 2.425 & 2.35 & & & & Top of channel & 15 & 617 & 0.27 & 32.785 \\
\hline 2.62 & 2.555 & 2.49 & & & & In channel & 13 & 619 & -0.13 & 32.655 \\
\hline 1.98 & 1.935 & 1.89 & & & & Top of channel & 9 & 623 & 0.62 & 33.275 \\
\hline \multirow[t]{2}{*}{1.51} & 1.51 & 1.51 & & & & Dumpy height & 0 & 632 & 0.425 & 33.7 \\
\hline & & & 0.68 & 0.595 & 0.51 & FS back to dumpy & 17 & 649 & 0.915 & 34.615 \\
\hline 1.79 & 1.7675 & 1.745 & & & & & 4.5 & 649 & 0 & 34.615 \\
\hline \multirow[t]{2}{*}{1.34} & 1.34 & 1.34 & & & & Dumpy height & 0 & 653.5 & 0.4275 & 35.0425 \\
\hline & & & 0.21 & 0.145 & 0.08 & In channel, FS back to dumpy & 13 & 666.5 & 1.195 & 36.2375 \\
\hline 2.335 & 2.285 & 2.235 & & & & & 10 & 666.5 & 0 & 36.2375 \\
\hline \multirow[t]{2}{*}{1.51} & 1.51 & 1.51 & & & & Dumpy height & 0 & 676.5 & 0.775 & 37.0125 \\
\hline & & & 0.59 & 0.5 & 0.41 & FS back to dumpy & 18 & 694.5 & 1.01 & 38.0225 \\
\hline 3.69 & 3.55 & 3.41 & & & & & 28 & 694.5 & 0 & 38.0225 \\
\hline \multirow[t]{2}{*}{1.62} & 1.62 & 1.62 & & & & Dumpy height & 0 & 722.5 & 1.93 & 39.9525 \\
\hline & & & 0.54 & 0.41 & 0.28 & FS back to dumpy & 26 & 748.5 & 1.21 & 41.1625 \\
\hline 2.34 & 2.29 & 2.2 & & & & & 14 & 748.5 & 0 & 41.1625 \\
\hline \multirow[t]{2}{*}{1.58} & 1.58 & 1.58 & & & & Dumpy height & 0 & 762.5 & 0.71 & 41.8725 \\
\hline & & & 0.16 & 0.105 & 0.05 & FS back to dumpy & 11 & 773.5 & 1.475 & 43.3475 \\
\hline 1.99 & 1.95 & 1.91 & & & & & 8 & 773.5 & 0 & 43.3475 \\
\hline \multirow[t]{2}{*}{1.44} & 1.44 & 1.44 & & & & Dumpy height & 0 & 781.5 & 0.51 & 43.8575 \\
\hline & & & 0.42 & 0.31 & 0.2 & FS back to dumpy & 22 & 803.5 & 1.13 & 44.9875 \\
\hline 1.9 & 1.865 & 1.83 & & & & & 7 & 803.5 & 0 & 44.9875 \\
\hline \multirow[t]{2}{*}{1.53} & 1.53 & 1.53 & & & & Dumpy height & 0 & 810.5 & 0.335 & 45.3225 \\
\hline & & & 0.98 & 0.915 & 0.85 & FS back to dumpy & 13 & 823.5 & 0.615 & 45.9375 \\
\hline 3.75 & 3.62 & 3.49 & & & & & 26 & 823.5 & 0 & 45.9375 \\
\hline \multirow[t]{2}{*}{1.53} & 1.53 & 1.53 & & & & Dumpy height & 0 & 849.5 & 2.09 & 48.0275 \\
\hline & & & 0.435 & 0.36 & 0.285 & FS back to dumpy & 15 & 864.5 & 1.17 & 49.1975 \\
\hline 2.175 & 2.1225 & 2.07 & & & & & 10.5 & 864.5 & 0 & 49.1975 \\
\hline 1.62 & 1.62 & 1.62 & & & & Dumpy height & 0 & 875 & 0.5025 & 49.7 \\
\hline
\end{tabular}




\begin{tabular}{|c|c|c|c|c|c|c|c|c|c|c|}
\hline \multicolumn{3}{|c|}{ Backsight } & \multicolumn{3}{|c|}{ Foresight } & \multirow{2}{*}{ Comments } & \multirow{2}{*}{ Distance } & \multirow{2}{*}{$\begin{array}{l}\text { Cumulative } \\
\text { Distance }\end{array}$} & \multirow{2}{*}{$\begin{array}{l}\text { Reduced } \\
\text { Level }\end{array}$} & \multirow{2}{*}{$\begin{array}{c}\text { Collimation } \\
\text { Height }\end{array}$} \\
\hline $\mathbf{U}$ & $\mathbf{M}$ & $\mathbf{L}$ & $\mathbf{U}$ & $\mathbf{M}$ & $\mathbf{L}$ & & & & & \\
\hline & & & 0.47 & 0.4 & 0.33 & FS back to dumpy & 14 & 889 & 1.22 & 50.92 \\
\hline 3.78 & 3.64 & 3.5 & & & & & 28 & 889 & 0 & 50.92 \\
\hline 2.89 & 2.73 & 2.67 & & & & In channel & 22 & 895 & 0.91 & 51.83 \\
\hline \multirow[t]{2}{*}{1.56} & 1.56 & 1.56 & & & & Dumpy height & 0 & 917 & 1.17 & 53 \\
\hline & & & 1.18 & 1.125 & 1.05 & Base of blockage, FS back to dumpy & 13 & 930 & 0.435 & 53.435 \\
\hline 4.31 & 4.255 & 4.2 & & & & & 11 & 930 & 0 & 53.435 \\
\hline 1.6625 & 1.65 & 1.6425 & & & & Top of blockage & 2 & 939 & 2.605 & 56.04 \\
\hline \multirow[t]{2}{*}{1.59} & 1.59 & 1.59 & & & & Dumpy height & 0 & 941 & 0.06 & 56.1 \\
\hline & & & 1.07 & 0.99 & 0.91 & FS back to dumpy & 16 & 957 & 0.6 & 56.7 \\
\hline 2.52 & 2.405 & 2.29 & & & & Landslide on south bank & 23 & 957 & 0 & 56.7 \\
\hline \multirow[t]{2}{*}{1.49} & 1.49 & 1.49 & & & & Dumpy height & 0 & 980 & 0.915 & 57.615 \\
\hline & & & 1.055 & 1.025 & 0.995 & Around small fan on south side of channel, FS back to dumpy & 6 & 986 & 0.465 & 58.08 \\
\hline 2.38 & 2.32 & 2.25 & & & & Around small fan on south side of channel & 13 & 986 & 0 & 58.08 \\
\hline \multirow[t]{2}{*}{1.51} & 1.51 & 1.51 & & & & Dumpy height & 0 & 999 & 0.81 & 58.89 \\
\hline & & & 1.205 & 1.175 & 1.145 & FS back to dumpy & 6 & 1005 & 0.335 & 59.225 \\
\hline 2.435 & 2.4 & 2.365 & & & & & 7 & 1005 & 0 & 59.225 \\
\hline \multirow[t]{2}{*}{1.52} & 1.52 & 1.52 & & & & Dumpy height & 0 & 1012 & 0.88 & 60.105 \\
\hline & & & 0.55 & 0.51 & 0.47 & FS back to dumpy & 8 & 1020 & 1.01 & 61.115 \\
\hline 3.21 & 3.08 & 2.95 & & & & & 26 & 1020 & 0 & 61.115 \\
\hline \multirow[t]{2}{*}{1.58} & 1.58 & 1.58 & & & & Dumpy height & 0 & 1046 & 1.5 & 62.615 \\
\hline & & & 0.28 & 0.22 & 0.16 & FS back to dumpy & 12 & 1058 & 1.36 & 63.975 \\
\hline 3.66 & 3.545 & 3.43 & & & & & 23 & 1058 & 0 & 63.975 \\
\hline \multirow[t]{2}{*}{1.48} & 1.48 & 1.48 & & & & Dumpy height & 0 & 1081 & 2.065 & 66.04 \\
\hline & & & 0.4775 & 0.425 & 0.3775 & FS back to dumpy & 10 & 1091 & 1.055 & 67.095 \\
\hline 2.83 & 2.75 & 2.67 & & & & & 16 & 1091 & 0 & 67.095 \\
\hline \multirow[t]{4}{*}{1.57} & 1.57 & 1.57 & & & & Dumpy height & 0 & 1107 & 1.18 & 68.275 \\
\hline & & & 1.49 & 1.46 & 1.43 & Bottom of step, FS back to dumpy & 6 & 1113 & 0.11 & 68.385 \\
\hline & & & 0.79 & 0.755 & 0.72 & Top of step, FS back to dumpy & 7 & 1114 & 0.705 & 69.09 \\
\hline & & & 0.36 & 0.29 & 0.22 & FS back to dumpy & 14 & 1121 & 0.465 & 69.555 \\
\hline 4.38 & 4.24 & 4.1 & & & & & 28 & 1121 & 0 & 69.555 \\
\hline 3.185 & 3.11 & 3.035 & & & & & 15 & 1134 & 1.13 & 70.685 \\
\hline \multirow[t]{2}{*}{1.48} & 1.48 & 1.48 & & & & Dumpy height & 0 & 1149 & 1.63 & 72.315 \\
\hline & & & 0.89 & 0.83 & 0.77 & FS back to dumpy & 12 & 1161 & 0.65 & 72.965 \\
\hline 2.59 & 2.515 & 2.44 & & & & & 15 & 1161 & 0 & 72.965 \\
\hline 1.66 & 1.66 & 1.66 & & & & Dumpy height & 0 & 1176 & 0.855 & 73.82 \\
\hline
\end{tabular}




\begin{tabular}{|c|c|c|c|c|c|c|c|c|c|c|}
\hline \multicolumn{3}{|c|}{ Backsight } & \multicolumn{3}{|c|}{ Foresight } & \multirow{2}{*}{ Comments } & \multirow{2}{*}{ Distance } & \multirow{2}{*}{$\begin{array}{c}\text { Cumulative } \\
\text { Distance }\end{array}$} & \multirow{2}{*}{$\begin{array}{c}\text { Reduced } \\
\text { Level }\end{array}$} & \multirow{2}{*}{$\begin{array}{c}\text { Collimation } \\
\text { Height }\end{array}$} \\
\hline $\mathbf{U}$ & $\mathbf{M}$ & $\mathbf{L}$ & $U$ & $\mathbf{M}$ & $\mathbf{L}$ & & & & & \\
\hline & & & 0.68 & 0.62 & 0.56 & FS back to dumpy & 12 & 1188 & 1.04 & 74.86 \\
\hline 2.815 & 2.74 & 2.665 & & & & & 15 & 1188 & 0 & 74.86 \\
\hline \multirow[t]{2}{*}{1.56} & 1.56 & 1.56 & & & & Dumpy height & 0 & 1203 & 1.18 & 76.04 \\
\hline & & & 0.79 & 0.72 & 0.65 & FS back to dumpy & 14 & 1217 & 0.84 & 76.88 \\
\hline 2.45 & 2.4 & 2.35 & & & & & 10 & 1217 & 0 & 76.88 \\
\hline \multirow[t]{2}{*}{1.66} & 1.66 & 1.66 & & & & Dumpy height & 0 & 1227 & 0.74 & 77.62 \\
\hline & & & 0.18 & 0.095 & 0.01 & FS back to dumpy & 17 & 1244 & 1.565 & 79.185 \\
\hline 2.71 & 2.62 & 2.53 & & & & & 18 & 1244 & 0 & 79.185 \\
\hline \multirow[t]{2}{*}{1.49} & 1.49 & 1.49 & & & & Dumpy height & 0 & 1262 & 1.13 & 80.315 \\
\hline & & & 0.78 & 0.725 & 0.69 & FS back to dumpy & 9 & 1271 & 0.765 & 81.08 \\
\hline 2.51 & 2.455 & 2.39 & & & & & 12 & 1271 & 0 & 81.08 \\
\hline \multirow[t]{2}{*}{1.62} & 1.62 & 1.62 & & & & Dumpy height & 0 & 1283 & 0.835 & 81.915 \\
\hline & & & 1.265 & 1.205 & 1.145 & FS back to dumpy & 12 & 1295 & 0.415 & 82.33 \\
\hline 2.82 & 2.76 & 2.7 & & & & Bottom of step & 12 & 1295 & 0 & 82.33 \\
\hline 2.41 & 2.355 & 2.3 & & & & Top of step & 11 & 1296 & 0.405 & 82.735 \\
\hline \multirow[t]{2}{*}{1.57} & 1.57 & 1.57 & & & & Dumpy height & 0 & 1307 & 0.785 & 83.52 \\
\hline & & & 0.44 & 0.375 & 0.31 & FS back to dumpy & 13 & 1320 & 1.195 & 84.715 \\
\hline 2.76 & 2.72 & 2.68 & & & & & 8 & 1320 & 0 & 84.715 \\
\hline \multirow[t]{2}{*}{1.55} & 1.55 & 1.55 & & & & Dumpy height & 0 & 1328 & 1.17 & 85.885 \\
\hline & & & 0.18 & 0.09 & 0 & FS back to dumpy & 18 & 1346 & 1.46 & 87.345 \\
\hline 2.71 & 2.65 & 2.58 & & & & & 13 & 1346 & 0 & 87.345 \\
\hline \multirow[t]{2}{*}{1.49} & 1.49 & 1.49 & & & & Dumpy height & 0 & 1359 & 1.16 & 88.505 \\
\hline & & & 0.86 & 0.8 & 0.74 & FS back to dumpy & 12 & 1371 & 0.69 & 89.195 \\
\hline 3.005 & 2.935 & 2.865 & & & & & 14 & 1371 & 0 & 89.195 \\
\hline 2.1325 & 2.125 & 2.1175 & & & & Bottom of step & 1.5 & 1383.5 & 0.81 & 90.005 \\
\hline 1.66 & 1.655 & 1.65 & & & & Top of step & 1 & 1384 & 0.47 & 90.475 \\
\hline \multirow[t]{2}{*}{1.56} & 1.56 & 1.56 & & & & Dumpy height & 0 & 1385 & 0.095 & 90.57 \\
\hline & & & 0.26 & 0.195 & 0.13 & FS back to dumpy & 13 & 1398 & 1.365 & 91.935 \\
\hline 2.555 & 2.475 & 2.395 & & & & & 16 & 1398 & 0 & 91.935 \\
\hline \multirow[t]{2}{*}{1.62} & 1.62 & 1.62 & & & & Dumpy height & 0 & 1414 & 0.855 & 92.79 \\
\hline & & & 0.3 & 0.225 & 0.15 & FS back to dumpy & 15 & 1429 & 1.395 & 94.185 \\
\hline 2.385 & 2.3375 & 2.29 & & & & & 9.5 & 1429 & 0 & 94.185 \\
\hline \multirow[t]{2}{*}{1.58} & 1.58 & 1.58 & & & & Dumpy height & 0 & 1438.5 & 0.7575 & 94.9425 \\
\hline & & & 0.65 & 0.58 & 0.51 & FS back to dumpy & 14 & 1452.5 & 1 & 95.9425 \\
\hline 2.91 & 2.83 & 2.75 & & & & & 16 & 1452.5 & 0 & 95.9425 \\
\hline 1.53 & 1.53 & 1.53 & & & & Dumpy height & 0 & 1468.5 & 1.3 & 97.2425 \\
\hline
\end{tabular}




\begin{tabular}{|c|c|c|c|c|c|c|c|c|c|c|}
\hline \multicolumn{3}{|c|}{ Backsight } & \multicolumn{3}{|c|}{ Foresight } & \multirow{2}{*}{ Comments } & \multirow{2}{*}{ Distance } & \multirow{2}{*}{$\begin{array}{c}\text { Cumulative } \\
\text { Distance }\end{array}$} & \multirow{2}{*}{$\begin{array}{c}\text { Reduced } \\
\text { Level }\end{array}$} & \multirow{2}{*}{$\begin{array}{c}\text { Collimation } \\
\text { Height }\end{array}$} \\
\hline $\mathbf{U}$ & $\mathbf{M}$ & $\mathbf{L}$ & $\mathbf{U}$ & $\mathbf{M}$ & $\mathbf{L}$ & & & & & \\
\hline & & & 0.315 & 0.26 & 0.205 & FS back to dumpy & 11 & 1479.5 & 1.27 & 98.5125 \\
\hline 2.685 & 2.58 & 2.475 & & & & & 21 & 1479.5 & 0 & 98.5125 \\
\hline \multirow[t]{2}{*}{1.52} & 1.52 & 1.52 & & & & Dumpy height & 0 & 1500.5 & 1.06 & 99.5725 \\
\hline & & & 0.515 & 0.45 & 0.385 & Tributary 1 on north side, FS back to dumpy & 13 & 1513.5 & 1.07 & 100.6425 \\
\hline 2.45 & 2.38 & 2.31 & & & & & 14 & 1513.5 & 0 & 100.6425 \\
\hline \multirow[t]{2}{*}{1.37} & 1.37 & 1.37 & & & & Dumpy height & 0 & 1527.5 & 1.01 & 101.6525 \\
\hline & & & 0.33 & 0.225 & 0.11 & FS back to dumpy & 22 & 1549.5 & 1.145 & 102.7975 \\
\hline 2.345 & 2.27 & 2.195 & & & & & 15 & 1549.5 & 0 & 102.7975 \\
\hline \multirow[t]{2}{*}{1.52} & 1.52 & 1.52 & & & & Dumpy height & 0 & 1564.5 & 0.75 & 103.5475 \\
\hline & & & 0.435 & 0.39 & 0.345 & FS back to dumpy & 9 & 1573.5 & 1.13 & 104.6775 \\
\hline 3.02 & 2.94 & 2.86 & & & & & 16 & 1573.5 & 0 & 104.6775 \\
\hline 2.38 & 2.33 & 2.28 & & & & & 10 & 1579.5 & 0.61 & 105.2875 \\
\hline \multirow[t]{2}{*}{1.51} & 1.51 & 1.51 & & & & Dumpy height & 0 & 1589.5 & 0.82 & 106.1075 \\
\hline & & & 0.96 & 0.91 & 0.86 & FS back to dumpy & 10 & 1599.5 & 0.6 & 106.7075 \\
\hline 2.845 & 2.75 & 2.655 & & & & & 19 & 1599.5 & 0 & 106.7075 \\
\hline \multirow[t]{2}{*}{1.56} & 1.56 & 1.56 & & & & Dumpy height & 0 & 1618.5 & 1.19 & 107.8975 \\
\hline & & & 0.5 & 0.42 & 0.34 & Tributary 2 on north side, FS back to dumpy & 16 & 1634.5 & 1.14 & 109.0375 \\
\hline 3.53 & 3.42 & 3.31 & & & & & 22 & 1634.5 & 0 & 109.0375 \\
\hline \multirow[t]{2}{*}{1.58} & 1.58 & 1.58 & & & & Dumpy height & 0 & 1656.5 & 1.84 & 110.8775 \\
\hline & & & 0.51 & 0.315 & & FS back to dumpy & 39 & 1695.5 & 1.265 & 112.1425 \\
\hline 2.935 & 2.8575 & 2.78 & & & & & 15.5 & 1695.5 & 0 & 112.1425 \\
\hline \multirow[t]{2}{*}{1.63} & 1.63 & 1.63 & & & & Dumpy height & 0 & 1711 & 1.2275 & 113.37 \\
\hline & & & 0.575 & 0.445 & 0.315 & FS back to dumpy & 26 & 1737 & 1.185 & 114.555 \\
\hline 3.73 & 3.59 & 3.45 & & & & & 28 & 1737 & 0 & 114.555 \\
\hline \multirow[t]{2}{*}{1.49} & 1.49 & 1.49 & & & & Dumpy height & 0 & 1765 & 2.1 & 116.655 \\
\hline & & & 0.73 & 0.65 & 0.57 & FS back to dumpy & 16 & 1781 & 0.84 & 117.495 \\
\hline 3.555 & 3.44 & 3.325 & & & & & 23 & 1781 & 0 & 117.495 \\
\hline 2.395 & 2.365 & 2.335 & & & & Bottom of step & 6 & 1798 & 1.075 & 118.57 \\
\hline 1.91 & 1.88 & 1.85 & & & & Top of step & 6 & 1798 & 0.485 & 119.055 \\
\hline \multirow[t]{2}{*}{1.55} & 1.55 & 1.55 & & & & Dumpy height & 0 & 1804 & 0.33 & 119.385 \\
\hline & & & 0.69 & 0.61 & 0.53 & FS back to dumpy & 16 & 1820 & 0.94 & 120.325 \\
\hline 2.6 & 2.535 & 2.47 & & & & & 13 & 1820 & 0 & 120.325 \\
\hline \multirow[t]{2}{*}{1.55} & 1.55 & 1.55 & & & & Dumpy height & 0 & 1833 & 0.985 & 121.31 \\
\hline & & & 0.46 & 0.37 & 0.28 & FS back to dumpy & 18 & 1851 & 1.18 & 122.49 \\
\hline 2.86 & 2.785 & 2.71 & & & & & 15 & 1851 & 0 & 122.49 \\
\hline 1.5 & 1.5 & 1.5 & & & & Dumpy height & 0 & 1866 & 1.285 & 123.775 \\
\hline
\end{tabular}




\begin{tabular}{|c|c|c|c|c|c|c|c|c|c|c|}
\hline \multicolumn{3}{|c|}{ Backsight } & \multicolumn{3}{|c|}{ Foresight } & \multirow{2}{*}{ Comments } & \multirow{2}{*}{ Distance } & \multirow{2}{*}{$\begin{array}{c}\text { Cumulative } \\
\text { Distance }\end{array}$} & \multirow{2}{*}{$\begin{array}{c}\text { Reduced } \\
\text { Level }\end{array}$} & \multirow{2}{*}{$\begin{array}{c}\text { Collimation } \\
\text { Height }\end{array}$} \\
\hline $\mathbf{U}$ & $\mathbf{M}$ & $\mathbf{L}$ & $\mathbf{U}$ & $\mathbf{M}$ & $\mathbf{L}$ & & & & & \\
\hline & & & 0.43 & 0.385 & 0.34 & FS back to dumpy & 9 & 1875 & 1.115 & 124.89 \\
\hline 2.54 & 2.46 & 2.38 & & & & & 16 & 1875 & 0 & 124.89 \\
\hline \multirow[t]{2}{*}{1.62} & 1.62 & 1.62 & & & & Dumpy height & 0 & 1891 & 0.84 & 125.73 \\
\hline & & & 0.84 & 0.77 & 0.69 & FS back to dumpy & 15 & 1906 & 0.85 & 126.58 \\
\hline 3 & 2.91 & 2.82 & & & & & 18 & 1906 & 0 & 126.58 \\
\hline \multirow[t]{2}{*}{1.59} & 1.59 & 1.59 & & & & Dumpy height & 0 & 1924 & 1.32 & 127.9 \\
\hline & & & 0.72 & 0.655 & 0.59 & FS back to dumpy & 13 & 1937 & 0.935 & 128.835 \\
\hline 2.04 & 1.995 & 1.95 & & & & & 9 & 1937 & 0 & 128.835 \\
\hline \multirow[t]{2}{*}{1.53} & 1.53 & 1.53 & & & & Dumpy height & 0 & 1946 & 0.465 & 129.3 \\
\hline & & & 0.215 & 0.115 & 0.015 & FS back to dumpy & 20 & 1966 & 1.415 & 130.715 \\
\hline 2.425 & 2.3825 & 2.34 & & & & & 8.5 & 1966 & 0 & 130.715 \\
\hline 2.115 & 2.105 & 2.095 & & & & Edge of landslide, bottom & 2 & 1972.5 & 0.2775 & 130.9925 \\
\hline 1.77 & 1.76 & 1.75 & & & & Top of landslide & 2 & 1972.5 & 0.345 & 131.3375 \\
\hline \multirow[t]{2}{*}{1.54} & 1.54 & 1.54 & & & & Dumpy height & 0 & 1974.5 & 0.22 & 131.5575 \\
\hline & & & 0.39 & 0.31 & 0.23 & FS back to dumpy & 16 & 1990.5 & 1.23 & 132.7875 \\
\hline 2.64 & 2.57 & 2.5 & & & & & 14 & 1990.5 & 0 & 132.7875 \\
\hline \multirow[t]{2}{*}{1.37} & 1.37 & 1.37 & & & & Dumpy height & 0 & 2004.5 & 1.2 & 133.9875 \\
\hline & & & 0.99 & 0.945 & 0.9 & FS back to dumpy & 9 & 2013.5 & 0.425 & 134.4125 \\
\hline 3.22 & 3.16 & 3.1 & & & & & 12 & 2013.5 & 0 & 134.4125 \\
\hline \multirow[t]{2}{*}{1.68} & 1.68 & 1.68 & & & & Dumpy height & 0 & 2025.5 & 1.48 & 135.8925 \\
\hline & & & 0.51 & 0.475 & 0.44 & FS back to dumpy & 7 & 2032.5 & 1.205 & 137.0975 \\
\hline 2.45 & 2.36 & 2.27 & & & & & 18 & 2032.5 & 0 & 137.0975 \\
\hline \multirow[t]{2}{*}{1.49} & 1.49 & 1.49 & & & & Dumpy height & 0 & 2050.5 & 0.87 & 137.9675 \\
\hline & & & 0.7825 & 0.7 & 0.6175 & FS back to dumpy & 16.5 & 2067 & 0.79 & 138.7575 \\
\hline 2.32 & 2.27 & 2.22 & & & & & 10 & 2067 & 0 & 138.7575 \\
\hline \multirow[t]{4}{*}{1.51} & 1.51 & 1.51 & & & & Dumpy height & 0 & 2077 & 0.76 & 139.5175 \\
\hline & & & 0.84 & 0.8 & & Bottom of step, FS back to dumpy & 8 & 2085 & 0.71 & 140.2275 \\
\hline & 3.0175 & 2.93 & & & & & 17.5 & 2085 & 0 & 140.2275 \\
\hline & 2.47 & 2.39 & & & & Top of step & 16 & 2086.5 & 0.5475 & 140.775 \\
\hline \multirow[t]{2}{*}{1.43} & 1.43 & 1.43 & & & & Dumpy height & 0 & 2102.5 & 1.04 & 141.815 \\
\hline & & & 0.69 & 0.595 & 0.5 & FS back to dumpy & 19 & 2121.5 & 0.835 & 142.65 \\
\hline 2.25 & 2.215 & 2.18 & & & & & 7 & 2121.5 & 0 & 142.65 \\
\hline \multirow[t]{2}{*}{1.5} & 1.5 & 1.5 & & & & Dumpy height & 0 & 2128.5 & 0.715 & 143.365 \\
\hline & & & 0.325 & 0.22 & & FS back to dumpy & 21 & 2149.5 & 1.28 & 144.645 \\
\hline 3.07 & 2.97 & 2.87 & & & & & 20 & 2149.5 & 0 & 144.645 \\
\hline 2.7 & 2.68 & 2.66 & & & & Bottom of step & 4 & 2165.5 & 0.29 & 144.935 \\
\hline
\end{tabular}




\begin{tabular}{|c|c|c|c|c|c|c|c|c|c|c|}
\hline \multicolumn{3}{|c|}{ Backsight } & \multicolumn{3}{|c|}{ Foresight } & \multirow{2}{*}{ Comments } & \multirow{2}{*}{ Distance } & \multirow{2}{*}{$\begin{array}{c}\text { Cumulative } \\
\text { Distance }\end{array}$} & \multirow{2}{*}{$\begin{array}{l}\text { Reduced } \\
\text { Level }\end{array}$} & \multirow{2}{*}{$\begin{array}{l}\text { Collimation } \\
\text { Height }\end{array}$} \\
\hline $\mathbf{U}$ & $\mathbf{M}$ & $\mathbf{L}$ & $U$ & $\mathbf{M}$ & $\mathbf{L}$ & & & & & \\
\hline 2.005 & 1.99 & 1.975 & & & & Top of step & 3 & 2166.5 & 0.69 & 145.625 \\
\hline \multirow[t]{2}{*}{1.42} & 1.42 & 1.42 & & & & Dumpy height & 0 & 2169.5 & 0.57 & 146.195 \\
\hline & & & 0.73 & 0.68 & 0.63 & Tributary 3, FS back to dumpy & 10 & 2179.5 & 0.74 & 146.935 \\
\hline 2.31 & 2.25 & 2.19 & & & & & 12 & 2179.5 & 0 & 146.935 \\
\hline \multirow[t]{2}{*}{1.52} & 1.52 & 1.52 & & & & Dumpy height & 0 & 2191.5 & 0.73 & 147.665 \\
\hline & & & 0.59 & 0.5 & 0.41 & FS back to dumpy & 18 & 2209.5 & 1.02 & 148.685 \\
\hline 2.82 & 2.775 & 2.73 & & & & & 9 & 2209.5 & 0 & 148.685 \\
\hline \multirow[t]{2}{*}{1.56} & 1.56 & 1.56 & & & & Dumpy height & 0 & 2218.5 & 1.215 & 149.9 \\
\hline & & & 0.44 & 0.38 & 0.32 & FS back to dumpy & 12 & 2230.5 & 1.18 & 151.08 \\
\hline 3.69 & 3.62 & 3.55 & & & & Tributary enters channel between this point and $\mathrm{DH}$ & 14 & 2230.5 & 0 & 151.08 \\
\hline \multirow[t]{2}{*}{1.39} & 1.39 & 1.39 & & & & Dumpy height & 0 & 2244.5 & 2.23 & 153.31 \\
\hline & & & 1.1075 & 1.0325 & 0.9575 & FS back to dumpy & 15 & 2259.5 & 0.3575 & 153.6675 \\
\hline 2.645 & 2.58 & 2.515 & & & & & 13 & 2259.5 & 0 & 153.6675 \\
\hline 1.63 & 1.63 & 1.63 & & & & Dumpy height & 0 & 2272.5 & 0.95 & 154.6175 \\
\hline \multirow[t]{3}{*}{1.56} & 1.56 & 1.56 & & & & $\begin{array}{l}\text { Dumpy height, tributary just behind on north side and another } \\
\text { just in front on north side }\end{array}$ & 0 & 2290.5 & 1.49 & 157.2475 \\
\hline & & & 0.99 & 0.9 & 0.81 & FS back to dumpy & 18 & 2308.5 & 0.66 & 157.9075 \\
\hline & & & 0.93 & 0.825 & 0.72 & FS back to dumpy & 21 & 2311.5 & 0.075 & 157.9825 \\
\hline 3.36 & 3.28 & 3.2 & & & & & 16 & 2311.5 & 0 & 157.9825 \\
\hline \multirow[t]{2}{*}{1.62} & 1.62 & 1.62 & & & & Dumpy height, tributary on north side just behind & 0 & 2327.5 & 1.66 & 159.6425 \\
\hline & & & 0.73 & 0.67 & 0.61 & FS back to dumpy & 12 & 2339.5 & 0.95 & 160.5925 \\
\hline 2.8 & 2.725 & 2.65 & & & & & 15 & 2339.5 & 0 & 160.5925 \\
\hline \multirow[t]{2}{*}{1.59} & 1.59 & 1.59 & & & & Dumpy height & 0 & 2354.5 & 1.135 & 161.7275 \\
\hline & & & 0.8025 & 0.7575 & 0.7125 & FS back to dumpy & 9 & 2363.5 & 0.8325 & 162.56 \\
\hline 2.86 & 2.77 & 2.68 & & & & & 18 & 2363.5 & 0 & 162.56 \\
\hline \multirow[t]{2}{*}{1.71} & 1.71 & 1.71 & & & & Dumpy height & 0 & 2381.5 & 1.06 & 163.62 \\
\hline & & & 0.705 & 0.67 & 0.635 & FS back to dumpy & 7 & 2388.5 & 1.04 & 164.66 \\
\hline 3.07 & 3.005 & 2.94 & & & & & 13 & 2388.5 & 0 & 164.66 \\
\hline \multirow[t]{2}{*}{1.6} & 1.6 & 1.6 & & & & Dumpy height & 0 & 2401.5 & 1.405 & 166.065 \\
\hline & & & 0.59 & 0.545 & 0.5 & FS back to dumpy & 9 & 2410.5 & 1.055 & 167.12 \\
\hline 3.115 & 3.025 & 2.935 & & & & Bottom of step & 18 & 2410.5 & 0 & 167.12 \\
\hline 1.815 & 1.745 & 1.675 & & & & Top of step & 14 & 2414.5 & 1.28 & 168.4 \\
\hline \multirow[t]{2}{*}{1.49} & 1.49 & 1.49 & & & & Dumpy height & 0 & 2428.5 & 0.255 & 168.655 \\
\hline & & & 0.785 & 0.74 & 0.695 & FS back to dumpy & 9 & 2437.5 & 0.75 & 169.405 \\
\hline 1.99 & 1.96 & 1.93 & & & & & 6 & 2437.5 & 0 & 169.405 \\
\hline 1.52 & 1.52 & 1.52 & & & & Dumpy height & 0 & 2443.5 & 0.44 & 169.845 \\
\hline
\end{tabular}




\begin{tabular}{|c|c|c|c|c|c|c|c|c|c|c|}
\hline \multicolumn{3}{|c|}{ Backsight } & \multicolumn{3}{|c|}{ Foresight } & \multirow{2}{*}{ Comments } & \multirow{2}{*}{ Distance } & \multirow{2}{*}{$\begin{array}{c}\text { Cumulative } \\
\text { Distance }\end{array}$} & \multirow{2}{*}{$\begin{array}{c}\text { Reduced } \\
\text { Level }\end{array}$} & \multirow{2}{*}{$\begin{array}{c}\text { Collimation } \\
\text { Height }\end{array}$} \\
\hline $\mathbf{U}$ & $\mathbf{M}$ & $\mathbf{L}$ & $\mathrm{U}$ & $\mathbf{M}$ & $\mathbf{L}$ & & & & & \\
\hline & & & 1.055 & 1.02 & 0.985 & FS back to dumpy & 7 & 2450.5 & 0.5 & 170.345 \\
\hline 2.125 & 2.085 & 2.045 & & & & & 8 & 2450.5 & 0 & 170.345 \\
\hline \multirow[t]{2}{*}{1.58} & 1.58 & 1.58 & & & & Dumpy height & 0 & 2458.5 & 0.505 & 170.85 \\
\hline & & & 0.5 & 0.46 & 0.42 & FS back to dumpy & 8 & 2466.5 & 1.12 & 171.97 \\
\hline 2.21 & 2.145 & 2.08 & & & & & 13 & 2466.5 & 0 & 171.97 \\
\hline \multirow[t]{2}{*}{1.46} & 1.46 & 1.46 & & & & Dumpy height & 0 & 2479.5 & 0.685 & 172.655 \\
\hline & & & 1.195 & 1.155 & 1.115 & FS back to dumpy & 8 & 2487.5 & 0.305 & 172.96 \\
\hline 2.91 & 2.83 & 2.75 & & & & & 16 & 2487.5 & 0 & 172.96 \\
\hline \multirow[t]{2}{*}{1.53} & 1.53 & 1.53 & & & & Dumpy height & 0 & 2503.5 & 1.3 & 174.26 \\
\hline & & & 0.66 & 0.6 & 0.54 & FS back to dumpy & 12 & 2515.5 & 0.93 & 175.19 \\
\hline 3.33 & 3.24 & 3.15 & & & & & 18 & 2515.5 & 0 & 175.19 \\
\hline \multirow[t]{2}{*}{1.48} & 1.48 & 1.48 & & & & Dumpy height & 0 & 2533.5 & 1.76 & 176.95 \\
\hline & & & 0.645 & 0.6 & 0.555 & FS back to dumpy & 9 & 2542.5 & 0.88 & 177.83 \\
\hline 1.605 & 1.595 & 1.585 & & & & & 2 & 2542.5 & 0 & 177.83 \\
\hline \multirow[t]{2}{*}{1.33} & 1.33 & 1.33 & & & & Dumpy height & 0 & 2544.5 & 0.265 & 178.095 \\
\hline & & & 0.54 & 0.5 & 0.46 & FS back to dumpy & 8 & 2552.5 & 0.83 & 178.925 \\
\hline 2.46 & 2.41 & 2.36 & & & & & 10 & 2552.5 & 0 & 178.925 \\
\hline \multirow[t]{2}{*}{1.63} & 1.63 & 1.63 & & & & Dumpy height & 0 & 2562.5 & 0.78 & 179.705 \\
\hline & & & 0.62 & 0.605 & 0.59 & Top of boulder, FS back to dumpy & 3 & 2565.5 & 1.025 & 180.73 \\
\hline 2.305 & 2.275 & 2.245 & & & & & 6 & 2565.5 & 0 & 180.73 \\
\hline \multirow[t]{2}{*}{1.44} & 1.44 & 1.44 & & & & Dumpy height & 0 & 2571.5 & 0.835 & 181.565 \\
\hline & & & 0.685 & 0.625 & 0.585 & FS back to dumpy & 10 & 2581.5 & 0.815 & 182.38 \\
\hline 2.67 & 2.635 & 2.6 & & & & & 7 & 2581.5 & 0 & 182.38 \\
\hline 2.065 & 2.06 & 2.055 & & & & Back of log jam & 1 & 2587.5 & 0.575 & 182.955 \\
\hline \multirow[t]{2}{*}{1.48} & 1.48 & 1.48 & & & & Dumpy height & 0 & 2588.5 & 0.58 & 183.535 \\
\hline & & & 1.07 & 1.05 & 1.03 & FS back to dumpy & 4 & 2592.5 & 0.43 & 183.965 \\
\hline 2.62 & 2.57 & 2.52 & & & & & 10 & 2592.5 & 0 & 183.965 \\
\hline \multirow[t]{2}{*}{1.57} & 1.57 & 1.57 & & & & Dumpy height & 0 & 2602.5 & 1 & 184.965 \\
\hline & & & 1.03 & 0.99 & 0.95 & FS back to dumpy & 8 & 2610.5 & 0.58 & 185.545 \\
\hline 2.54 & 2.48 & 2.42 & & & & & 12 & 2610.5 & 0 & 185.545 \\
\hline \multirow[t]{2}{*}{1.57} & 1.57 & 1.57 & & & & Dumpy height & 0 & 2622.5 & 0.91 & 186.455 \\
\hline & & & 0.98 & 0.935 & 0.89 & FS back to dumpy & 9 & 2631.5 & 0.635 & 187.09 \\
\hline 2.6 & 2.54 & 2.48 & & & & & 12 & 2631.5 & 0 & 187.09 \\
\hline 1.69 & 1.69 & 1.69 & & & & Dumpy height & 0 & 2643.5 & 0.85 & 187.94 \\
\hline 2.72 & 2.67 & 2.62 & & & & South channel & 10 & 2655.5 & 0 & 188.52 \\
\hline 1.47 & 1.47 & 1.47 & & & & Dumpy height & 0 & 2665.5 & 1.2 & 189.72 \\
\hline
\end{tabular}




\begin{tabular}{|c|c|c|c|c|c|c|c|c|c|c|}
\hline \multicolumn{3}{|c|}{ Backsight } & \multicolumn{3}{|c|}{ Foresight } & \multirow{2}{*}{ Comments } & \multirow{2}{*}{ Distance } & \multirow{2}{*}{$\begin{array}{l}\text { Cumulative } \\
\text { Distance }\end{array}$} & \multirow{2}{*}{$\begin{array}{l}\text { Reduced } \\
\text { Level }\end{array}$} & \multirow{2}{*}{$\begin{array}{l}\text { Collimation } \\
\text { Height }\end{array}$} \\
\hline $\mathbf{U}$ & $\mathbf{M}$ & $L$ & $U$ & M & $L$ & & & & & \\
\hline & & & 1.17 & 1.11 & 1.05 & $\begin{array}{l}\text { Stream disects into two channels. South channel is flatter, } \\
\text { North is slightly larger. End of survey points, FS back to dumpy }\end{array}$ & 12 & 2655.5 & 0.58 & 188.52 \\
\hline & & & 0.32 & 0.255 & 0.19 & FS back to dumpy & 13 & 2678.5 & 1.215 & 190.935 \\
\hline 2.48 & 2.435 & 2.39 & & & & & 9 & 2678.5 & 0 & 190.935 \\
\hline \multirow[t]{2}{*}{1.53} & 1.53 & 1.53 & & & & Dumpy height & 0 & 2687.5 & 0.905 & 191.84 \\
\hline & & & 0.545 & 0.48 & 0.415 & Bottom of step, FS back to dumpy & 13 & 2700.5 & 1.05 & 192.89 \\
\hline 3.6 & 3.53 & 3.46 & & & & & 14 & 2700.5 & 0 & 192.89 \\
\hline 2.98 & 2.9 & 2.82 & & & & Top of step & 16 & 2698.5 & 0.63 & 193.52 \\
\hline 2.905 & 2.865 & 2.825 & & & & Bottom of step & 8 & 2706.5 & 0.035 & 193.555 \\
\hline 1.98 & 1.96 & 1.94 & & & & Top of step, tributary & 4 & 2710.5 & 0.905 & 194.46 \\
\hline \multirow[t]{2}{*}{1.58} & 1.58 & 1.58 & & & & Dumpy height & 0 & 2714.5 & 0.38 & 194.84 \\
\hline & & & 0.625 & 0.57 & 0.515 & Tributary, FS bacl to dumpy & 11 & 2725.5 & 1.01 & 195.85 \\
\hline 2.895 & 2.84 & 2.785 & & & & & 11 & 2725.5 & 0 & 195.85 \\
\hline \multirow[t]{2}{*}{1.53} & 1.53 & 1.53 & & & & Dumpy height & 0 & 2736.5 & 1.31 & 197.16 \\
\hline & & & 0.43 & 0.38 & 0.33 & FS back to dumpy & 10 & 2746.5 & 1.15 & 198.31 \\
\hline 3.165 & 3.13 & 3.095 & & & & & 7 & 2746.5 & 0 & 198.31 \\
\hline \multirow[t]{2}{*}{1.57} & 1.57 & 1.57 & & & & Dumpy height & 0 & 2753.5 & 1.56 & 199.87 \\
\hline & & & 0.83 & 0.76 & 0.69 & FS back to dumpy & 14 & 2767.5 & 0.81 & 200.68 \\
\hline 2.23 & 2.18 & 2.13 & & & & & 10 & 2767.5 & 0 & 200.68 \\
\hline \multirow[t]{2}{*}{1.54} & 1.54 & 1.54 & & & & Dumpy height & 0 & 2777.5 & 0.64 & 201.32 \\
\hline & & & 0.75 & 0.71 & 0.67 & $\begin{array}{l}\text { Start of landslide and vegetation blocking path, FS back to } \\
\text { dumpy }\end{array}$ & 8 & 2785.5 & 0.83 & 202.15 \\
\hline
\end{tabular}


Unnamed Stream, Catchment 2 Stream Channel Longitudinal Profile

\begin{tabular}{|c|c|c|c|c|c|c|c|c|c|c|c|}
\hline \multicolumn{3}{|c|}{ Backsight } & \multicolumn{3}{|c|}{ Foresight } & \multirow{2}{*}{ Comments } & \multirow{2}{*}{ Distance } & \multirow{2}{*}{$\begin{array}{c}\text { Cumulative } \\
\text { Distance }\end{array}$} & \multirow{2}{*}{$\begin{array}{c}\text { Reduced } \\
\text { Level }\end{array}$} & \multirow{2}{*}{$\begin{array}{c}\text { Collimation } \\
\text { Height }\end{array}$} & \multirow{2}{*}{$\begin{array}{l}\text { Catchment } \\
\text { Information }\end{array}$} \\
\hline $\mathbf{U}$ & M & $\mathbf{L}$ & $\mathbf{U}$ & $\mathbf{M}$ & $\mathbf{L}$ & & & & & & \\
\hline 4.22 & 3.88 & 3.54 & & & & Start of profile, centre of channel, west side of rail & 68 & 0 & 0 & 0 & Start of profile \\
\hline 3.52 & 3.28 & 3.04 & & & & & 48 & 20 & 0.6 & 0.6 & \\
\hline 2.52 & 2.4 & 2.28 & & & & & 24 & 44 & 0.88 & 1.48 & \\
\hline \multirow[t]{4}{*}{1.48} & 1.48 & 1.48 & & & & Dumpy height & 0 & 68 & 0.92 & 2.4 & \\
\hline & & & 0.55 & 0.46 & 0.37 & FS back to dumpy & 18 & 86 & 1.02 & 3.42 & \\
\hline & & & 0.14 & 0.01 & & FS back to dumpy & 26 & 94 & 0.45 & 3.87 & \\
\hline & 4.81 & 4.47 & & & & & 68 & 94 & 0 & 3.87 & \\
\hline 3.15 & 2.96 & 2.77 & & & & & 38 & 124 & 1.85 & 5.72 & \\
\hline \multirow[t]{3}{*}{1.5} & 1.5 & 1.5 & & & & Dumpy height & 0 & 162 & 1.46 & 7.18 & \\
\hline & & & 1.15 & 1.095 & 1.04 & FS back to dumpy & 11 & 173 & 0.405 & 7.585 & \\
\hline & & & 0.385 & 0.28 & 0.175 & FS back to dumpy & 21 & 183 & 0.815 & 8.4 & \\
\hline 4.99 & 4.75 & 4.51 & & & & Base of road ford east side & 48 & 183 & 0 & 8.4 & \\
\hline 4.09 & 3.88 & 3.67 & & & & Top of road ford east side & 42 & 189 & 0.87 & 9.27 & \\
\hline 3.91 & 3.73 & 3.55 & & & & West side of road & 36 & 195 & 0.15 & 9.42 & \\
\hline 3.89 & 3.745 & 3.6 & & & & Fence & 29 & 202 & -0.015 & 9.405 & \\
\hline 2.56 & 2.495 & 2.43 & & & & & 13 & 218 & 1.25 & 10.655 & \\
\hline \multirow[t]{2}{*}{1.57} & 1.57 & 1.57 & & & & Dumpy height & 0 & 231 & 0.925 & 11.58 & \\
\hline & & & 0.77 & 0.71 & 0.65 & FS back to dumpy & 12 & 243 & 0.86 & 12.44 & \\
\hline 4.37 & 4.2 & 4.03 & & & & & 34 & 243 & 0 & 12.44 & \\
\hline 2.735 & 2.665 & 2.595 & & & & & 14 & 263 & 1.535 & 13.975 & \\
\hline \multirow[t]{2}{*}{1.56} & 1.56 & 1.56 & & & & Dumpy height & 0 & 277 & 1.105 & 15.08 & \\
\hline & & & 0.515 & 0.44 & 0.365 & FS back to dumpy & 15 & 292 & 1.12 & 16.2 & \\
\hline 4.71 & 4.51 & 4.31 & & & & & 40 & 292 & 0 & 16.2 & \\
\hline 2.885 & 2.81 & 2.735 & & & & & 15 & 317 & 1.7 & 17.9 & \\
\hline \multirow[t]{2}{*}{1.635} & 1.635 & 1.635 & & & & Dumpy height & 0 & 332 & 1.175 & 19.075 & \\
\hline & & & 0.71 & 0.645 & 0.58 & FS back to dumpy & 13 & 345 & 0.99 & 20.065 & \\
\hline 4.185 & 4.085 & 3.985 & & & & & 20 & 345 & 0 & 20.065 & \\
\hline 3.665 & 3.59 & 3.515 & & & & Bottom of bulldozed ramp & 15 & 350 & 0.495 & 20.56 & \\
\hline 2.29 & 2.24 & 2.19 & & & & Top of bulldozed ramp & 10 & 355 & 1.35 & 21.91 & \\
\hline \multirow[t]{2}{*}{1.46} & 1.46 & 1.46 & & & & Dumpy height & 0 & 365 & 0.78 & 22.69 & \\
\hline & & & 0.455 & 0.38 & 0.305 & FS back to dumpy & 15 & 380 & 1.08 & 23.77 & \\
\hline 4.55 & 4.38 & 4.21 & & & & & 34 & 380 & 0 & 23.77 & \\
\hline 2.78 & 2.7 & 2.62 & & & & & 16 & 398 & 1.68 & 25.45 & \\
\hline 1.48 & 1.48 & 1.48 & & & & Dumpy height & 0 & 414 & 1.22 & 26.67 & \\
\hline
\end{tabular}




\begin{tabular}{|c|c|c|c|c|c|c|c|c|c|c|c|}
\hline \multicolumn{3}{|c|}{ Backsight } & \multicolumn{3}{|c|}{ Foresight } & \multirow{2}{*}{ Comments } & \multirow{2}{*}{ Distance } & \multirow{2}{*}{$\begin{array}{c}\text { Cumulative } \\
\text { Distance }\end{array}$} & \multirow{2}{*}{$\begin{array}{c}\text { Reduced } \\
\text { Level }\end{array}$} & \multirow{2}{*}{$\begin{array}{c}\text { Collimation } \\
\text { Height }\end{array}$} & \multirow{2}{*}{$\begin{array}{l}\text { Catchmen } \\
\text { Informatior }\end{array}$} \\
\hline $\mathbf{U}$ & $M$ & $\mathbf{L}$ & $\mathbf{U}$ & $\mathbf{M}$ & $\mathbf{L}$ & & & & & & \\
\hline & & & 0.15 & 0.07 & & FS back to dumpy & 16 & 430 & 1.41 & 28.08 & \\
\hline 4.73 & 4.54 & 4.35 & & & & & 38 & 430 & 0 & 28.08 & Catchment J \\
\hline 2.99 & 2.9 & 2.81 & & & & & 18 & 450 & 1.64 & 29.72 & \\
\hline \multirow[t]{2}{*}{1.47} & 1.47 & 1.47 & & & & Dumpy height & 0 & 468 & 1.43 & 31.15 & \\
\hline & & & 0.26 & 0.18 & 0.1 & FS back to dumpy & 16 & 484 & 1.29 & 32.44 & \\
\hline 4.63 & 4.47 & 4.31 & & & & & 32 & 484 & 0 & 32.44 & \\
\hline 3.57 & 3.47 & 3.37 & & & & & 20 & 496 & 1 & 33.44 & \\
\hline 2.83 & 2.77 & 2.71 & & & & & 12 & 504 & 0.7 & 34.14 & \\
\hline 2.21 & 2.18 & 2.15 & & & & & 6 & 510 & 0.59 & 34.73 & \\
\hline \multirow[t]{6}{*}{1.63} & 1.63 & 1.63 & & & & Dumpy height & 0 & 516 & 0.55 & 35.28 & \\
\hline & & & 0.87 & 0.82 & 0.77 & FS back to dumpy & 10 & 526 & 0.81 & 36.09 & \\
\hline & & & 0.825 & 0.76 & 0.695 & Edge of main channel, FS back to dumpy & 13 & 529 & 0.06 & 36.15 & \\
\hline & & & 0.695 & 0.615 & 0.535 & Middle of main channel, FS back to dumpy & 16 & 532 & 0.145 & 36.295 & \\
\hline & & & 0.34 & 0.255 & 0.17 & Edge of main channel, FS back to dumpy & 17 & 533 & 0.36 & 36.655 & \\
\hline & 4.95 & 4.74 & & & & & 42 & 533 & 0 & 36.655 & Catchment I \\
\hline 4.01 & 3.86 & 3.71 & & & & Edge of main channel & 30 & 545 & 1.09 & 37.745 & \\
\hline 4.24 & 4.1 & 3.96 & & & & Bottom of main channel & 28 & 547 & -0.24 & 37.505 & \\
\hline 3.96 & 3.84 & 3.72 & & & & Bottom of main channel & 24 & 551 & 0.26 & 37.765 & \\
\hline 3.615 & 3.495 & 3.375 & & & & Top of main channel & 24 & 551 & 0.345 & 38.11 & \\
\hline 2.74 & 2.67 & 2.6 & & & & & 14 & 561 & 0.825 & 38.935 & \\
\hline \multirow[t]{3}{*}{1.48} & 1.48 & 1.48 & & & & Dumpy height & 0 & 575 & 1.19 & 40.125 & \\
\hline & & & 0.59 & 0.53 & 0.47 & FS back to dumpy & 12 & 587 & 0.95 & 41.075 & \\
\hline & & & 0.4 & 0.32 & 0.24 & FS back to dumpy & 16 & 591 & 0.21 & 41.285 & \\
\hline 2.82 & 2.73 & 2.64 & & & & Whole channel becomes the main channel & 18 & 591 & 0 & 41.285 & \\
\hline 2.2 & 2.135 & 2.07 & & & & & 13 & 596 & 0.595 & 41.88 & \\
\hline 2.305 & 2.25 & 2.195 & & & & & 11 & 598 & -0.115 & 41.765 & \\
\hline 1.925 & 1.9 & 1.875 & & & & & 5 & 604 & 0.35 & 42.115 & \\
\hline \multirow[t]{4}{*}{1.57} & 1.57 & 1.57 & & & & Dumpy height & 0 & 609 & 0.33 & 42.445 & \\
\hline & & & 0.82 & 0.79 & 0.76 & FS back to dumpy & 6 & 615 & 0.78 & 43.225 & \\
\hline & & & 0.49 & 0.44 & 0.39 & FS back to dumpy & 10 & 619 & 0.35 & 43.575 & \\
\hline & & & 0.28 & 0.21 & 0.14 & FS back to dumpy & 14 & 623 & 0.23 & 43.805 & \\
\hline 3.595 & 3.46 & 3.325 & & & & & 27 & 623 & 0 & 43.805 & \\
\hline 2.61 & 2.53 & 2.45 & & & & Top of channel & 16 & 634 & 0.93 & 44.735 & \\
\hline 2.835 & 2.765 & 2.695 & & & & Bottom if channel & 14 & 636 & -0.235 & 44.5 & \\
\hline 2.445 & 2.39 & 2.335 & & & & Middle of channel & 11 & 639 & 0.375 & 44.875 & \\
\hline 2.14 & 2.095 & 2.05 & & & & Middle of channel & 9 & 641 & 0.295 & 45.17 & \\
\hline
\end{tabular}




\begin{tabular}{|c|c|c|c|c|c|c|c|c|c|c|c|}
\hline \multicolumn{3}{|c|}{ Backsight } & \multicolumn{3}{|c|}{ Foresight } & \multirow{2}{*}{ Comments } & \multirow{2}{*}{ Distance } & \multirow{2}{*}{$\begin{array}{c}\text { Cumulative } \\
\text { Distance }\end{array}$} & \multirow{2}{*}{$\begin{array}{c}\text { Reduced } \\
\text { Level }\end{array}$} & \multirow{2}{*}{$\begin{array}{c}\text { Collimation } \\
\text { Height }\end{array}$} & \multirow{2}{*}{$\begin{array}{l}\text { Catchment } \\
\text { Information }\end{array}$} \\
\hline $\mathbf{U}$ & M & $\mathbf{L}$ & $\bar{U}$ & $\mathbf{M}$ & $\mathbf{L}$ & & & & & & \\
\hline 1.98 & 1.96 & 1.94 & & & & Middle of channel & 4 & 646 & 0.135 & 45.305 & \\
\hline 1.67 & 1.655 & 1.64 & & & & & 3 & 647 & 0.305 & 45.61 & \\
\hline \multirow[t]{3}{*}{1.56} & 1.56 & 1.56 & & & & Dumpy height & 0 & 650 & 0.095 & 45.705 & \\
\hline & & & 0.36 & 0.31 & 0.26 & FS back to dumpy & 10 & 660 & 1.25 & 46.955 & \\
\hline & & & 0.23 & 0.17 & 0.11 & FS back to dumpy & 12 & 662 & 0.14 & 47.095 & \\
\hline 2.84 & 2.765 & 2.69 & & & & Edge of channel & 15 & 662 & 0 & 47.095 & \\
\hline 2.465 & 2.4 & 2.335 & & & & Top of channel & 13 & 664 & 0.365 & 47.46 & \\
\hline 2.17 & 2.11 & 2.05 & & & & & 12 & 665 & 0.29 & 47.75 & \\
\hline 1.74 & 1.7 & 1.66 & & & & & 8 & 669 & 0.41 & 48.16 & \\
\hline 1.535 & 1.515 & 1.495 & & & & Top of channel & 4 & 673 & 0.185 & 48.345 & \\
\hline \multirow[t]{5}{*}{1.49} & 1.49 & 1.49 & & & & Dumpy height & 0 & 677 & 0.025 & 48.37 & \\
\hline & & & 0.98 & 0.95 & 0.93 & FS back to dumpy & 5 & 682 & 0.54 & 48.91 & \\
\hline & & & 0.92 & 0.885 & 0.85 & Mid channel, FS back to dumpy & 7 & 684 & 0.065 & 48.975 & \\
\hline & & & 0.5 & 0.425 & 0.35 & FS back to dumpy & 15 & 692 & 0.46 & 49.435 & \\
\hline & & & & 0.17 & 0.08 & FS back to dumpy & 18 & 695 & 0.255 & 49.69 & \\
\hline 3.45 & 3.35 & 3.25 & & & & & 20 & 695 & 0 & 49.69 & \\
\hline 2.63 & 2.565 & 2.5 & & & & & 13 & 702 & 0.785 & 50.475 & \\
\hline 1.845 & 1.825 & 1.805 & & & & & 4 & 711 & 0.74 & 51.215 & \\
\hline \multirow[t]{3}{*}{1.46} & 1.46 & 1.46 & & & & Dumpy height & 0 & 715 & 0.365 & 51.58 & \\
\hline & & & 0.44 & 0.38 & 0.32 & FS back to dumpy & 12 & 727 & 1.08 & 52.66 & Catchment $\mathrm{H}$ \\
\hline & & & 0.24 & 0.18 & 0.12 & FS back to dumpy & 12 & 727 & 0.2 & 52.86 & \\
\hline 2.395 & 2.345 & 2.295 & & & & & 10 & 727 & 0 & 52.86 & \\
\hline \multirow[t]{2}{*}{1.35} & 1.35 & 1.35 & & & & Dumpy height & 0 & 737 & 0.995 & 53.855 & \\
\hline & & & 0.61 & 0.575 & 0.54 & FS back to dumpy & 7 & 744 & 0.775 & 54.63 & \\
\hline 3.18 & 3.14 & 3.1 & & & & & 8 & 744 & 0 & 54.63 & \\
\hline \multirow[t]{2}{*}{1.52} & 1.52 & 1.52 & & & & Dumpy height & 0 & 752 & 1.62 & 56.25 & \\
\hline & & & 1.24 & 1.195 & 1.15 & FS back to dumpy & 9 & 761 & 0.325 & 56.575 & \\
\hline 3.12 & 3.04 & 2.96 & & & & & 16 & 761 & 0 & 56.575 & \\
\hline 2.28 & 2.24 & 2.2 & & & & & 8 & 769 & 0.8 & 57.375 & \\
\hline \multirow[t]{2}{*}{1.43} & 1.43 & 1.43 & & & & Dumpy height & 0 & 777 & 0.81 & 58.185 & \\
\hline & & & 0.73 & 0.685 & 0.64 & FS back to dumpy & 9 & 786 & 0.745 & 58.93 & \\
\hline 1.7 & 1.67 & 1.64 & & & & & 6 & 786 & 0 & 58.93 & \\
\hline \multirow[t]{2}{*}{1.28} & 1.28 & 1.28 & & & & Dumpy height & 0 & 792 & 0.39 & 59.32 & \\
\hline & & & 0.705 & 0.675 & 0.645 & FS back to dumpy & 6 & 798 & 0.605 & 59.925 & \\
\hline 2.52 & 2.495 & 2.47 & & & & & 5 & 798 & 0 & 59.925 & \\
\hline 1.6 & 1.6 & 1.6 & & & & Dumpy height & 0 & 803 & 0.895 & 60.82 & \\
\hline
\end{tabular}




\begin{tabular}{|c|c|c|c|c|c|c|c|c|c|c|c|}
\hline \multicolumn{3}{|c|}{ Backsight } & \multicolumn{3}{|c|}{ Foresight } & \multirow{2}{*}{ Comments } & \multirow{2}{*}{ Distance } & \multirow{2}{*}{$\begin{array}{l}\text { Cumulative } \\
\text { Distance }\end{array}$} & \multirow{2}{*}{$\begin{array}{c}\text { Reduced } \\
\text { Level }\end{array}$} & \multirow{2}{*}{$\begin{array}{c}\text { Collimation } \\
\text { Height }\end{array}$} & \multirow{2}{*}{$\begin{array}{l}\text { Catchmen } \\
\text { Information }\end{array}$} \\
\hline $\mathbf{U}$ & $\mathbf{M}$ & $\mathbf{L}$ & $\mathbf{U}$ & $\mathbf{M}$ & $\mathbf{L}$ & & & & & & \\
\hline & & & 0.53 & 0.49 & 0.45 & FS back to dumpy & 8 & 811 & 1.11 & 61.93 & \\
\hline & & & 0.5 & 0.44 & 0.38 & FS back to dumpy & 12 & 815 & 0.05 & 61.98 & \\
\hline 2.86 & 2.8 & 2.75 & & & & & 11 & 815 & 0 & 61.98 & \\
\hline \multirow[t]{2}{*}{1.45} & 1.45 & 1.45 & & & & Dumpy height & 0 & 826 & 1.35 & 63.33 & \\
\hline & & & 0.55 & 0.5 & 0.45 & FS back to dumpy & 10 & 836 & 0.95 & 64.28 & \\
\hline 3.88 & 3.81 & 3.73 & & & & & 15 & 836 & 0 & 64.28 & \\
\hline 2.645 & 2.6 & 2.565 & & & & Tributary 1 & 8 & 843 & 1.21 & 65.49 & \\
\hline \multirow[t]{3}{*}{1.53} & 1.53 & 1.53 & & & & Dumpy height & 0 & 851 & 1.07 & 66.56 & \\
\hline & & & 0.815 & 0.76 & 0.705 & FS back to dumpy & 11 & 862 & 0.77 & 67.33 & Catchment G \\
\hline & & & 0.305 & 0.225 & 0.145 & FS back to dumpy & 16 & 867 & 0.535 & 67.865 & \\
\hline 4.02 & 3.965 & 3.91 & & & & & 11 & 867 & 0 & 67.865 & \\
\hline 2.48 & 2.46 & 2.44 & & & & Tributary 2 & 4 & 874 & 1.505 & 69.37 & \\
\hline \multirow[t]{2}{*}{1.56} & 1.56 & 1.56 & & & & Dumpy height & 0 & 878 & 0.9 & 70.27 & \\
\hline & & & 0.17 & 0.1 & 0.03 & FS back to dumpy & 14 & 892 & 1.46 & 71.73 & \\
\hline 2.65 & 2.55 & 2.45 & & & & & 20 & 892 & 0 & 71.73 & \\
\hline 2.23 & 2.15 & 2.07 & & & & Edge of channel & 16 & 896 & 0.4 & 72.13 & \\
\hline 1.89 & 1.85 & 1.81 & & & & Mid channel & 8 & 904 & 0.3 & 72.43 & \\
\hline 2.03 & 2.01 & 1.99 & & & & & 4 & 908 & -0.16 & 72.27 & \\
\hline \multirow[t]{2}{*}{1.56} & 1.56 & 1.56 & & & & Dumpy height & 0 & 912 & 0.45 & 72.72 & \\
\hline & & & 0.54 & 0.48 & 0.42 & FS back to dumpy & 12 & 924 & 1.08 & 73.8 & \\
\hline 3.325 & 3.275 & 3.225 & & & & & 10 & 924 & 0 & 73.8 & \\
\hline 2.73 & 2.705 & 2.68 & & & & Bottom of huge boulder & 5 & 929 & 0.57 & 74.37 & \\
\hline 1.315 & 1.295 & 1.275 & & & & Top of boulder & 4 & 930 & 1.41 & 75.78 & \\
\hline \multirow[t]{2}{*}{1.5} & 1.5 & 1.5 & & & & Dumpy height & 0 & 934 & -0.205 & 75.575 & \\
\hline & & & 1.04 & 1 & 0.96 & Tributary 3, FS back to dumpy & 8 & 942 & 0.5 & 76.075 & \\
\hline 4.68 & 4.55 & 4.42 & & & & & 26 & 942 & 0 & 76.075 & \\
\hline 3.52 & 3.445 & 3.36 & & & & & 16 & 952 & 1.105 & 77.18 & \\
\hline 2.29 & 2.25 & 2.21 & & & & & 8 & 960 & 1.195 & 78.375 & \\
\hline 2.01 & 2 & 1.99 & & & & Bottom of channel & 2 & 966 & 0.25 & 78.625 & \\
\hline 1.74 & 1.735 & 1.73 & & & & & 1 & 967 & 0.265 & 78.89 & \\
\hline \multirow[t]{3}{*}{1.55} & 1.55 & 1.55 & & & & Dumpy height & 0 & 968 & 0.185 & 79.075 & \\
\hline & & & 0.83 & 0.8 & 0.77 & FS back to dumpy & 6 & 974 & 0.75 & 79.825 & \\
\hline & & & 0.13 & 0.06 & & FS back to dumpy & 14 & 982 & 0.74 & 80.565 & \\
\hline 4.38 & 4.235 & 4.08 & & & & & 30 & 982 & 0 & 80.565 & \\
\hline 3.09 & 2.98 & 2.87 & & & & & 22 & 990 & 1.255 & 81.82 & \\
\hline 2.5 & 2.44 & 2.38 & & & & & 12 & 1000 & 0.54 & 82.36 & \\
\hline
\end{tabular}




\begin{tabular}{|c|c|c|c|c|c|c|c|c|c|c|c|}
\hline \multicolumn{3}{|c|}{ Backsight } & \multicolumn{3}{|c|}{ Foresight } & \multirow{2}{*}{ Comments } & \multirow{2}{*}{ Distance } & \multirow{2}{*}{$\begin{array}{l}\text { Cumulative } \\
\text { Distance }\end{array}$} & \multirow{2}{*}{$\begin{array}{c}\text { Reduced } \\
\text { Level }\end{array}$} & \multirow{2}{*}{$\begin{array}{c}\text { Collimation } \\
\text { Height }\end{array}$} & \multirow{2}{*}{$\begin{array}{l}\text { Catchmen } \\
\text { Information }\end{array}$} \\
\hline $\mathbf{U}$ & $\mathbf{M}$ & $\mathbf{L}$ & $\mathbf{U}$ & $\mathbf{M}$ & $\mathbf{L}$ & & & & & & \\
\hline \multirow[t]{2}{*}{1.6} & 1.6 & 1.6 & & & & Dumpy height & 0 & 1012 & 0.84 & 83.2 & \\
\hline & & & 0.18 & 0.08 & & FS back to dumpy & 20 & 1032 & 1.52 & 84.72 & \\
\hline 2.4 & 2.36 & 2.32 & & & & & 8 & 1032 & 0 & 84.72 & \\
\hline \multirow[t]{2}{*}{1.45} & 1.45 & 1.45 & & & & Dumpy height & 0 & 1040 & 0.91 & 85.63 & \\
\hline & & & 0.58 & 0.53 & 0.48 & Last point before vege block, FS back to dumpy & 10 & 1050 & 0.92 & 86.55 & \\
\hline 2.6 & 2.55 & 2.5 & & & & & 10 & 1050 & 0 & 86.55 & \\
\hline 2.11 & 2.08 & 2.05 & & & & & 6 & 1054 & 0.47 & 87.02 & \\
\hline \multirow[t]{3}{*}{1.55} & 1.55 & 1.55 & & & & Dumpy height & 0 & 1060 & 0.53 & 87.55 & \\
\hline & & & 0.68 & 0.65 & 0.62 & FS back to dumpy & 6 & 1066 & 0.9 & 88.45 & \\
\hline & & & 0.36 & 0.31 & 0.26 & Blockage of rocks, FS back to dumpy & 10 & 1070 & 0.34 & 88.79 & \\
\hline 3.09 & 3.04 & 2.99 & & & & & 10 & 1070 & 0 & 88.79 & \\
\hline 2.9 & 2.86 & 2.82 & & & & & 8 & 1072 & 0.18 & 88.97 & \\
\hline \multirow[t]{3}{*}{1.53} & 1.53 & 1.53 & & & & Dumpy height sharp bend in channel & 0 & 1080 & 1.33 & 90.3 & \\
\hline & & & 0.85 & 0.835 & 0.82 & Bottom of step, FS back to dumpy & 3 & 1083 & 0.695 & 90.995 & \\
\hline & & & 0.64 & 0.62 & 0.6 & Top of step, FS back to Dumpy & 4 & 1084 & 0.215 & 91.21 & \\
\hline 2.29 & 2.255 & 2.22 & & & & & 7 & 1084 & 0 & 91.21 & \\
\hline 1.71 & 1.68 & 1.65 & & & & & 6 & 1085 & 0.575 & 91.785 & Catchment $\mathrm{F}$ \\
\hline \multirow[t]{2}{*}{1.53} & 1.53 & 1.53 & & & & Dumpy height & 0 & 1091 & 0.15 & 91.935 & \\
\hline & & & 0.96 & 0.94 & 0.92 & FS back to dumpy & 4 & 1095 & 0.59 & 92.525 & \\
\hline 2.59 & 2.54 & 2.49 & & & & In channel & 10 & 1095 & 0 & 92.525 & \\
\hline 2.37 & 2.335 & 2.3 & & & & Bottom edge of channel & 7 & 1098 & 0.205 & 92.73 & \\
\hline 1.8 & 1.77 & 1.75 & & & & Top of channel & 5 & 1100 & 0.565 & 93.295 & \\
\hline \multirow[t]{2}{*}{1.44} & 1.44 & 1.44 & & & & Dumpy height & 0 & 1105 & 0.33 & 93.625 & \\
\hline & & & 1.02 & 1 & 0.98 & Bottom of rock, FS back to dumpy & 4 & 1109 & 0.44 & 94.065 & \\
\hline 2.94 & 2.91 & 2.88 & & & & & 6 & 1109 & 0 & 94.065 & \\
\hline 1.91 & 1.895 & 1.88 & & & & Top of rock & 3 & 1112 & 1.015 & 95.08 & \\
\hline \multirow[t]{3}{*}{1.52} & 1.52 & 1.52 & & & & Dumpy height & 0 & 1115 & 0.375 & 95.455 & \\
\hline & & & 0.55 & 0.52 & 0.49 & Edge of channel, FS back to dumpy & 6 & 1121 & 1 & 96.455 & \\
\hline & & & 0.76 & 0.71 & 0.66 & In channel, FS back to dumpy & 10 & 1125 & -0.19 & 96.265 & \\
\hline 2.36 & 2.31 & 2.26 & & & & & 10 & 1125 & 0 & 96.265 & \\
\hline \multirow[t]{3}{*}{1.49} & 1.49 & 1.49 & & & & Dumpy height & 0 & 1135 & 0.82 & 97.085 & \\
\hline & & & 0.92 & 0.86 & 0.8 & In channel, FS back to dumpy & 12 & 1147 & 0.63 & 97.715 & \\
\hline & & & 0.38 & 0.3 & 0.22 & FS back to dumpy & 16 & 1151 & 0.56 & 98.275 & \\
\hline 3.42 & 3.315 & 3.21 & & & & Tributary 4 just above point, FS back to dumpy & 21 & 1151 & 0 & 98.275 & \\
\hline \multirow[t]{2}{*}{1.46} & 1.46 & 1.46 & & & & Dumpy height & 0 & 1172 & 1.855 & 100.13 & \\
\hline & & & 0.68 & 0.63 & 0.58 & FS back to dumpy & 10 & 1182 & 0.83 & 100.96 & \\
\hline
\end{tabular}




\begin{tabular}{|c|c|c|c|c|c|c|c|c|c|c|c|}
\hline \multicolumn{3}{|c|}{ Backsight } & \multicolumn{3}{|c|}{ Foresight } & \multirow{2}{*}{ Comments } & \multirow{2}{*}{ Distance } & \multirow{2}{*}{$\begin{array}{l}\text { Cumulative } \\
\text { Distance }\end{array}$} & \multirow{2}{*}{$\begin{array}{c}\text { Reduced } \\
\text { Level }\end{array}$} & \multirow{2}{*}{$\begin{array}{c}\text { Collimation } \\
\text { Height }\end{array}$} & \multirow{2}{*}{$\begin{array}{l}\text { Catchmen } \\
\text { Information }\end{array}$} \\
\hline $\mathbf{U}$ & $\mathbf{M}$ & $\mathbf{L}$ & $\mathbf{U}$ & $\mathbf{M}$ & $\mathbf{L}$ & & & & & & \\
\hline 2.86 & 2.81 & 2.76 & & & & & 10 & 1182 & 0 & 100.96 & \\
\hline 2.8 & 2.76 & 2.72 & & & & Bottom of channel & 8 & 1184 & 0.05 & 101.01 & \\
\hline 2.07 & 2.03 & 1.99 & & & & Top of channel & 8 & 1184 & 0.73 & 101.74 & \\
\hline \multirow[t]{2}{*}{1.49} & 1.49 & 1.49 & & & & Dumpy height & 0 & 1192 & 0.54 & 102.28 & \\
\hline & & & 0.48 & 0.44 & 0.4 & FS back to dumpy & 8 & 1200 & 1.05 & 103.33 & \\
\hline 3.22 & 3.14 & 3.06 & & & & Bottom of step & 16 & 1200 & 0 & 103.33 & \\
\hline 2.66 & 2.58 & 2.5 & & & & Top of step & 16 & 1200 & 0.56 & 103.89 & \\
\hline \multirow[t]{2}{*}{1.55} & 1.55 & 1.55 & & & & Dumpy height & 0 & 1216 & 1.03 & 104.92 & \\
\hline & & & 1.06 & 1.01 & 0.96 & Tributary 5 , FS back to dumpy & 10 & 1226 & 0.54 & 105.46 & \\
\hline 3.9 & 3.82 & 3.74 & & & & & 16 & 1226 & 0 & 105.46 & \\
\hline 3.31 & 3.275 & 3.24 & & & & Bottom of step & 7 & 1235 & 0.545 & 106.005 & \\
\hline 2.84 & 2.81 & 2.78 & & & & Top of step & 6 & 1236 & 0.465 & 106.47 & \\
\hline \multirow[t]{2}{*}{1.44} & 1.44 & 1.44 & & & & Dumpy height & 0 & 1242 & 1.37 & 107.84 & \\
\hline & & & 0.32 & 0.23 & 0.14 & FS back to dumpy & 18 & 1260 & 1.21 & 109.05 & Catchment E \\
\hline 4.09 & 3.98 & 3.87 & & & & & 22 & 1260 & 0 & 109.05 & \\
\hline 2.22 & 2.2 & 2.18 & & & & Bottom of step & 4 & 1278 & 1.78 & 110.83 & \\
\hline 1.55 & 1.53 & 1.51 & & & & Top of step & 4 & 1278 & 0.67 & 111.5 & \\
\hline \multirow[t]{4}{*}{1.46} & 1.46 & 1.46 & & & & Dumpy height & 0 & 1282 & 0.07 & 111.57 & \\
\hline & & & 1.47 & 1.46 & 1.45 & Bottom of step, FS back to dumpy & 2 & 1284 & 0 & 111.57 & \\
\hline & & & 0.68 & 0.67 & 0.66 & Top of step, FS back to Dumpy & 2 & 1284 & 0.79 & 112.36 & \\
\hline & & & 0.48 & 0.44 & 0.4 & Bottom of step, FS back to dumpy & 8 & 1290 & 0.23 & 112.59 & \\
\hline 2.62 & 2.55 & 2.48 & & & & BS to bottom of step & 14 & 1290 & 0 & 112.59 & \\
\hline 2.04 & 1.97 & 1.9 & & & & Top of step & 14 & 1290 & 0.58 & 113.17 & \\
\hline \multirow[t]{2}{*}{1.54} & 1.54 & 1.54 & & & & Dumpy height & 0 & 1304 & 0.43 & 113.6 & \\
\hline & & & 0.79 & 0.72 & 0.65 & In channel, tributary 6 , FS back to dumpy & 14 & 1318 & 0.82 & 114.42 & \\
\hline 3.29 & 3.19 & 3.09 & & & & & 20 & 1318 & 0 & 114.42 & \\
\hline \multirow[t]{2}{*}{1.56} & 1.56 & 1.56 & & & & Dumpy height & 0 & 1338 & 1.63 & 116.05 & \\
\hline & & & 0.66 & 0.6 & 0.54 & To stake, FS back to dumpy & 12 & 1350 & 0.96 & 117.01 & \\
\hline 2.32 & 2.25 & 2.18 & & & & Back to stake & 14 & 1350 & 0 & 117.01 & \\
\hline \multirow[t]{2}{*}{1.66} & 1.66 & 1.66 & & & & Dumpy height & 0 & 1364 & 0.59 & 117.6 & \\
\hline & & & 0.27 & 0.24 & 0.21 & FS back to dumpy & 6 & 1370 & 1.42 & 119.02 & \\
\hline 2.58 & 2.49 & 2.4 & & & & & 18 & 1370 & 0 & 119.02 & \\
\hline \multirow[t]{2}{*}{1.6} & 1.6 & 1.6 & & & & Dumpy height & 0 & 1388 & 0.89 & 119.91 & \\
\hline & & & 0.49 & 0.42 & 0.35 & FS back to dumpy & 14 & 1402 & 1.18 & 121.09 & \\
\hline 2.44 & 2.4 & 2.36 & & & & & 8 & 1402 & 0 & 121.09 & \\
\hline 1.54 & 1.54 & 1.54 & & & & Dumpy height, 20 degree change to left & 0 & 1410 & 0.86 & 121.95 & \\
\hline
\end{tabular}




\begin{tabular}{|c|c|c|c|c|c|c|c|c|c|c|c|}
\hline \multicolumn{3}{|c|}{ Backsight } & \multicolumn{3}{|c|}{ Foresight } & \multirow{2}{*}{ Comments } & \multirow{2}{*}{ Distance } & \multirow{2}{*}{$\begin{array}{c}\text { Cumulative } \\
\text { Distance }\end{array}$} & \multirow{2}{*}{$\begin{array}{c}\text { Reduced } \\
\text { Level }\end{array}$} & \multirow{2}{*}{$\begin{array}{c}\text { Collimation } \\
\text { Height }\end{array}$} & \multirow{2}{*}{$\begin{array}{l}\text { Catchmen } \\
\text { Informatior }\end{array}$} \\
\hline $\mathbf{U}$ & $M$ & $\mathbf{L}$ & $\mathbf{U}$ & $\mathbf{M}$ & $\mathbf{L}$ & & & & & & \\
\hline & & & 0.225 & 0.17 & 0.115 & FS back to dumpy & 11 & 1421 & 1.37 & 123.32 & \\
\hline 2.62 & 2.545 & 2.47 & & & & Tributary 7 & 15 & 1421 & 0 & 123.32 & \\
\hline \multirow[t]{2}{*}{1.59} & 1.59 & 1.59 & & & & Dumpy height & 0 & 1436 & 0.955 & 124.275 & \\
\hline & & & 0.61 & 0.56 & 0.51 & FS back to dumpy & 10 & 1446 & 1.03 & 125.305 & \\
\hline 2.66 & 2.61 & 2.56 & & & & & 10 & 1446 & 0 & 125.305 & \\
\hline \multirow[t]{2}{*}{1.66} & 1.66 & 1.66 & & & & Dumpy height & 0 & 1456 & 0.95 & 126.255 & Catchment D \\
\hline & & & 0.52 & 0.45 & 0.38 & FS back to dumpy & 14 & 1470 & 1.21 & 127.465 & \\
\hline 2.78 & 2.69 & 2.6 & & & & & 18 & 1470 & 0 & 127.465 & \\
\hline \multirow[t]{2}{*}{1.6} & 1.6 & 1.6 & & & & Dumpy height & 0 & 1488 & 1.09 & 128.555 & \\
\hline & & & 0.71 & 0.66 & 0.61 & FS back to dumpy & 10 & 1498 & 0.94 & 129.495 & \\
\hline 3.09 & 2.995 & 2.8 & & & & & 29 & 1498 & 0 & 129.495 & \\
\hline \multirow[t]{2}{*}{1.61} & 1.61 & 1.61 & & & & Dumpy height & 0 & 1527 & 1.385 & 130.88 & \\
\hline & & & 0.59 & 0.535 & 0.48 & FS back to dumpy & 11 & 1538 & 1.075 & 131.955 & \\
\hline 2.61 & 2.555 & 2.5 & & & & & 11 & 1538 & 0 & 131.955 & \\
\hline \multirow[t]{2}{*}{1.5} & 1.5 & 1.5 & & & & Dumpy height & 0 & 1549 & 1.055 & 133.01 & \\
\hline & & & 0.74 & 0.7 & 0.66 & FS back to dumpy & 8 & 1557 & 0.8 & 133.81 & \\
\hline 2.96 & 2.9 & 2.84 & & & & & 12 & 1557 & 0 & 133.81 & \\
\hline \multirow[t]{2}{*}{1.49} & 1.49 & 1.49 & & & & Dumpy height, tributary 8 & 0 & 1569 & 1.41 & 135.22 & \\
\hline & & & 0.62 & 0.51 & 0.4 & FS back to dumpy & 22 & 1591 & 0.98 & 136.2 & \\
\hline 2.88 & 2.81 & 2.74 & & & & & 14 & 1591 & 0 & 136.2 & \\
\hline \multirow[t]{2}{*}{1.53} & 1.53 & 1.53 & & & & Dumpy height, 60 degree left & 0 & 1605 & 1.28 & 137.48 & \\
\hline & & & 0.51 & 0.43 & 0.35 & Narrow, deeply incised, FS back to dumpy & 16 & 1621 & 1.1 & 138.58 & \\
\hline 2.99 & 2.89 & 2.79 & & & & Narrow, deeply incised & 20 & 1621 & 0 & 138.58 & \\
\hline \multirow[t]{2}{*}{1.61} & 1.61 & 1.61 & & & & Dumpy height, narrow, deeply incised & 0 & 1641 & 1.28 & 139.86 & \\
\hline & & & 0.96 & 0.9 & 0.84 & Base of log dam, narrow, deeply incised, FS back to dumpy & 12 & 1653 & 0.71 & 140.57 & \\
\hline 3.55 & 3.45 & 3.35 & & & & & 20 & 1653 & 0 & 140.57 & \\
\hline 2.41 & 2.315 & 2.22 & & & & Top of log dam & 19 & 1654 & 1.135 & 141.705 & \\
\hline \multirow[t]{2}{*}{1.55} & 1.55 & 1.55 & & & & Dumpy height & 0 & 1673 & 0.765 & 142.47 & \\
\hline & & & 1.09 & 1.055 & 1.02 & FS back to dumpy & 7 & 1680 & 0.495 & 142.965 & \\
\hline 3.1 & 3 & 2.9 & & & & & 20 & 1680 & 0 & 142.965 & \\
\hline \multirow[t]{2}{*}{1.73} & 1.73 & 1.73 & & & & Dumpy height & 0 & 1700 & 1.27 & 144.235 & \\
\hline & & & 0.51 & 0.47 & 0.43 & FS back to dumpy & 8 & 1708 & 1.26 & 145.495 & \\
\hline 2.74 & 2.675 & 2.61 & & & & Tributary 9 & 13 & 1708 & 0 & 145.495 & \\
\hline \multirow[t]{2}{*}{1.65} & 1.65 & 1.65 & & & & Dumpy height & 0 & 1721 & 1.025 & 146.52 & \\
\hline & & & 0.95 & 0.91 & 0.87 & FS back to dumpy & 8 & 1729 & 0.74 & 147.26 & \\
\hline 4.33 & 4.19 & 4.05 & & & & & 28 & 1729 & 0 & 147.26 & \\
\hline
\end{tabular}




\begin{tabular}{|c|c|c|c|c|c|c|c|c|c|c|c|}
\hline \multicolumn{3}{|c|}{ Backsight } & \multicolumn{3}{|c|}{ Foresight } & \multirow{2}{*}{ Comments } & \multirow{2}{*}{ Distance } & \multirow{2}{*}{$\begin{array}{c}\text { Cumulative } \\
\text { Distance }\end{array}$} & \multirow{2}{*}{$\begin{array}{c}\text { Reduced } \\
\text { Level }\end{array}$} & \multirow{2}{*}{$\begin{array}{c}\text { Collimation } \\
\text { Height }\end{array}$} & \multirow{2}{*}{$\begin{array}{l}\text { Catchment } \\
\text { Information }\end{array}$} \\
\hline $\mathbf{U}$ & M & $\mathbf{L}$ & $\mathrm{U}$ & $\mathbf{M}$ & $\mathbf{L}$ & & & & & & \\
\hline \multirow[t]{2}{*}{1.59} & 1.59 & 1.59 & & & & Dumpy height & 0 & 1757 & 2.6 & 149.86 & \\
\hline & & & 1.05 & 0.99 & 0.93 & FS back to dumpy & 12 & 1769 & 0.6 & 150.46 & \\
\hline 3.44 & 3.32 & 3.2 & & & & Tributary 10 & 24 & 1769 & 0 & 150.46 & \\
\hline \multirow{2}{*}{1.66} & 1.66 & 1.66 & & & & Dumpy height, tributary 11 & 0 & 1793 & 1.66 & 152.12 & \\
\hline & & & 0.42 & 0.35 & 0.28 & FS back to dumpy & 14 & 1807 & 1.31 & 153.43 & \\
\hline 3.56 & 3.48 & 3.4 & & & & & 16 & 1807 & 0 & 153.43 & \\
\hline \multirow[t]{2}{*}{1.55} & 1.55 & 1.55 & & & & Dumpy height & 0 & 1823 & 1.93 & 155.36 & Catchment C \\
\hline & & & 0.44 & 0.38 & 0.32 & FS back to dumpy & 12 & 1835 & 1.17 & 156.53 & \\
\hline 3.45 & 3.38 & 3.31 & & & & & 14 & 1835 & 0 & 156.53 & \\
\hline \multirow[t]{2}{*}{1.56} & 1.56 & 1.56 & & & & Dumpy height & 0 & 1849 & 1.82 & 158.35 & \\
\hline & & & 0.57 & 0.52 & 0.47 & Bottom of landslide blockage, FS back to dumpy & 10 & 1859 & 1.04 & 159.39 & \\
\hline 2.77 & 2.68 & 2.59 & & & & & 18 & 1859 & 0 & 159.39 & \\
\hline 1.14 & 1.08 & 1.02 & & & & Top of landslide blockage & 12 & 1865 & 1.6 & 160.99 & \\
\hline 2.16 & 2.12 & 2.08 & & & & Tributary 12 & 8 & 1869 & -1.04 & 159.95 & \\
\hline \multirow[t]{2}{*}{1.5} & 1.5 & 1.5 & & & & Dumpy height & 0 & 1877 & 0.62 & 160.57 & \\
\hline & & & 1.04 & 1 & 0.96 & FS back to dumpy & 8 & 1885 & 0.5 & 161.07 & \\
\hline 2.53 & 2.475 & 2.42 & & & & & 11 & 1885 & 0 & 161.07 & \\
\hline \multirow{2}{*}{1.52} & 1.52 & 1.52 & & & & Dumpy height & 0 & 1896 & 0.955 & 162.025 & \\
\hline & & & 0.85 & 0.82 & 0.79 & FS back to dumpy & 6 & 1902 & 0.7 & 162.725 & \\
\hline 3.31 & 3.235 & 3.16 & & & & & 15 & 1902 & 0 & 162.725 & \\
\hline \multirow[t]{2}{*}{1.6} & 1.6 & 1.6 & & & & Dumpy height & 0 & 1917 & 1.635 & 164.36 & \\
\hline & & & 1.78 & 1.77 & 1.76 & FS back to dumpy & 2 & 1919 & -0.17 & 164.19 & \\
\hline 2.86 & 2.82 & 2.78 & & & & & 8 & 1919 & 0 & 164.19 & \\
\hline \multirow[t]{2}{*}{1.42} & 1.42 & 1.42 & & & & Dumpy height & 0 & 1927 & 1.4 & 165.59 & \\
\hline & & & 0.88 & 0.82 & 0.76 & FS back to dumpy & 12 & 1939 & 0.6 & 166.19 & \\
\hline 2.14 & 2.11 & 2.08 & & & & & 6 & 1939 & 0 & 166.19 & \\
\hline \multirow[t]{2}{*}{1.63} & 1.63 & 1.63 & & & & Dumpy height & 0 & 1945 & 0.48 & 166.67 & \\
\hline & & & 0.96 & 0.93 & 0.9 & FS back to dumpy & 6 & 1951 & 0.7 & 167.37 & Catchment B \\
\hline 3.45 & 3.38 & 3.31 & & & & & 14 & 1951 & 0 & 167.37 & \\
\hline \multirow[t]{3}{*}{1.64} & 1.64 & 1.64 & & & & Dumpy height & 0 & 1965 & 1.74 & 169.11 & \\
\hline & & & 0.4 & 0.355 & 0.31 & FS back to dumpy & 9 & 1974 & 1.285 & 170.395 & \\
\hline & & & 0.23 & 0.17 & 0.11 & Tributary $13, \mathrm{FS}$ back to dumpy & 12 & 1977 & 0.185 & 170.58 & \\
\hline 2.83 & 2.79 & 2.75 & & & & Base of big landslide block channel, tributary 14 & 8 & 1977 & 0 & 170.58 & \\
\hline \multirow[t]{2}{*}{1.57} & 1.57 & 1.57 & & & & Dumpy height, end of survey point reading taken & 0 & 1985 & 1.22 & 171.8 & \\
\hline & & & 0.31 & 0.255 & 0.2 & FS back to dumpy & 11 & 1996 & 1.315 & 173.115 & \\
\hline
\end{tabular}




\begin{tabular}{|c|c|c|c|c|c|c|c|c|c|c|c|}
\hline \multicolumn{3}{|c|}{ Backsight } & \multicolumn{3}{|c|}{ Foresight } & \multirow{2}{*}{ Comments } & \multirow{2}{*}{ Distance } & \multirow{2}{*}{$\begin{array}{l}\text { Cumulative } \\
\text { Distance }\end{array}$} & \multirow{2}{*}{$\begin{array}{c}\text { Reduced } \\
\text { Level }\end{array}$} & \multirow{2}{*}{$\begin{array}{c}\text { Collimation } \\
\text { Height }\end{array}$} & \multirow{2}{*}{$\begin{array}{l}\text { Catchment } \\
\text { Information }\end{array}$} \\
\hline $\mathbf{U}$ & $\mathbf{M}$ & $\mathbf{L}$ & $\bar{U}$ & $M$ & $\mathbf{L}$ & & & & & & \\
\hline & 2.68 & 2.61 & & & & & 14 & 1996 & 0 & 173.115 & \\
\hline \multirow[t]{3}{*}{1.45} & 1.45 & 1.45 & & & & Dumpy height & 0 & 2010 & 1.23 & 174.345 & \\
\hline & & & 0.79 & 0.73 & 0.67 & FS back to dumpy & 12 & 2022 & 0.72 & 175.065 & \\
\hline & 3.32 & 3.21 & & & & & 22 & 2022 & 0 & 175.065 & \\
\hline \multirow[t]{2}{*}{1.54} & 1.54 & 1.54 & & & & Dumpy height & 0 & 2044 & 1.78 & 176.845 & \\
\hline & & & 0.6 & 0.555 & 0.51 & FS back to dumpy & 9 & 2053 & 0.985 & 177.83 & Catchment A \\
\hline 2.21 & 2.175 & 2.14 & & & & & 7 & 2053 & 0 & 177.83 & \\
\hline \multirow[t]{2}{*}{1.48} & 1.48 & 1.48 & & & & Dumpy height & 0 & 2060 & 0.695 & 178.525 & \\
\hline & & & 0.13 & 0.05 & & Main channel split into 2 tributaries & 16 & 2076 & 1.43 & 179.955 & End of profile \\
\hline
\end{tabular}




\section{APPENDIX II}

Rainfall Intensity Data for Rational Method Calculations 


\section{$\underline{\text { Time of Concentration Calculations }}$}

\section{Maximum Rainfall Totals For Each Duration $(\mathrm{mm})$ Converted To Intensities (mm/hr)}

Note no data was recorded for these durations in 1985 so this year has been omitted from the rest of the calculations

\begin{tabular}{|c|c|c|c|c|c|c|c|c|c|c|}
\hline Year & $10 \min T$ & $10 \mathrm{~min}$ In & $20 \min T$ & $20 \mathrm{~min}$ In & $30 \min T$ & $30 \mathrm{~min}$ In & $60 \min T$ & $60 \min I n$ & $120 \min T$ & $120 \mathrm{~min}$ In \\
\hline 1968 & 11.2 & 67.2 & 16.8 & 50.4 & 21.1 & 42.2 & 29.5 & 29.5 & 42.2 & 21.1 \\
\hline 1969 & 4.6 & 27.6 & 7.1 & 21.3 & 8.4 & 16.8 & 16.3 & 16.3 & 25.4 & 12.7 \\
\hline 1970 & 5.1 & 30.6 & 7.9 & 23.7 & 9.1 & 18.2 & 11.4 & 11.4 & 15.5 & 7.75 \\
\hline 1971 & 4.8 & 28.8 & 5.2 & 15.6 & 7.1 & 14.2 & 12.2 & 12.2 & 19.6 & 9.8 \\
\hline 1972 & 5 & 30 & 8.6 & 25.8 & 9.4 & 18.8 & 13.8 & 13.8 & 21.6 & 10.8 \\
\hline 1973 & 5.3 & 31.8 & 6.8 & 20.4 & 8.7 & 17.4 & 14.3 & 14.3 & 19.5 & 9.75 \\
\hline 1975 & 12.7 & 76.2 & 21.3 & 63.9 & 31.4 & 62.8 & 53.2 & 53.2 & 74.3 & 37.15 \\
\hline 1976 & 4.1 & 24.6 & 7.3 & 21.9 & 10.7 & 21.4 & 19.3 & 19.3 & 32.3 & 16.15 \\
\hline 1977 & 9.6 & 57.6 & 11.3 & 33.9 & 13.1 & 26.2 & 15.2 & 15.2 & 20.9 & 10.45 \\
\hline 1978 & 5.6 & 33.6 & 10.3 & 30.9 & 14.9 & 29.8 & 27.4 & 27.4 & 53.2 & 26.6 \\
\hline 1979 & 5 & 30 & 7.8 & 23.4 & 11.5 & 23 & 18.3 & 18.3 & 27.9 & 13.95 \\
\hline 1984 & 5.1 & 30.6 & 7.8 & 23.4 & 8.2 & 16.4 & 11.5 & 11.5 & 16.5 & 8.25 \\
\hline \multicolumn{11}{|l|}{1985} \\
\hline 1986 & 6 & 36 & 8.1 & 24.3 & 10 & 20 & 15 & 15 & 27.1 & 13.55 \\
\hline 1987 & 5.7 & 34.2 & 7.8 & 23.4 & 8 & 16 & 10.5 & 10.5 & 14.3 & 7.15 \\
\hline 1988 & 4.4 & 26.4 & 5.6 & 16.8 & 6.7 & 13.4 & 9.9 & 9.9 & 15 & 7.5 \\
\hline 1989 & 3.6 & 21.6 & 7 & 21 & 10.2 & 20.4 & 20.2 & 20.2 & 35.8 & 17.9 \\
\hline 1990 & 3 & 18 & 5 & 15 & 7.1 & 14.2 & 11.4 & 11.4 & 20.7 & 10.35 \\
\hline
\end{tabular}

Each maximum rainfall total for the differing duration time periods was converted into rainfall intensities for mm/hr. For example the 10 min rainfall totals were multiplied by 6 and the 120 min rainfall totals were divided by 2 . 


\section{$\underline{\text { Time of Concentration Calculations }}$}

\section{Return Period (Frequency) For Each Intensity (Magnitude)}

Note 1985 has been removed due to incomplete data sets

$R P=n+1 / m$

\begin{tabular}{|c|c|c|c|c|c|c|c|c|c|c|c|c|c|c|}
\hline \multicolumn{3}{|c|}{10 min Intensity } & \multicolumn{3}{|c|}{20 min Intensity } & \multicolumn{3}{|c|}{30 min Intensity } & \multicolumn{3}{|c|}{60 min Intensity } & \multicolumn{3}{|c|}{120 min Intnesity } \\
\hline Mag & Intensity & $\mathbf{R P}$ & Mag & Intensity & $\mathbf{R P}$ & Mag & Intensity & $\mathbf{R P}$ & Mag & Intensity & $\mathbf{R P}$ & Mag & Intensity & $\mathbf{R P}$ \\
\hline 1 & 76.2 & 23 & 1 & 63.9 & 23 & 1 & 62.8 & 23 & 1 & 53.2 & 23 & 1 & 40.1 & 23 \\
\hline 2 & 67.2 & 11.5 & 2 & 50.7 & 11.5 & 2 & 50.6 & 11.5 & 2 & 45.4 & 11.5 & 2 & 37.2 & 11.5 \\
\hline 3 & 63.6 & 7.667 & 3 & 50.4 & 7.667 & 3 & 42.2 & 7.667 & 3 & 29.5 & 7.667 & 3 & 26.6 & 7.667 \\
\hline 4 & 57.6 & 5.75 & 4 & 33.9 & 5.75 & 4 & 29.8 & 5.75 & 4 & 27.4 & 5.75 & 4 & 21.1 & 5.75 \\
\hline 5 & 41.4 & 4.6 & 5 & 30.9 & 4.6 & 5 & 26.2 & 4.6 & 5 & 20.2 & 4.6 & 5 & 17.9 & 4.6 \\
\hline 6 & 36.0 & 3.833 & 6 & 28.2 & 3.833 & 6 & 23 & 3.833 & 6 & 19.3 & 3.833 & 6 & 16.2 & 3.833 \\
\hline 7 & 34.2 & 3.286 & 7 & 25.8 & 3.286 & 7 & 22.8 & 3.286 & 7 & 18.3 & 3.286 & 7 & 14.0 & 3.286 \\
\hline 8 & 33.6 & 2.875 & 8 & 24.3 & 2.875 & 8 & 21.4 & 2.875 & 8 & 16.3 & 2.875 & 8 & 13.6 & 2.875 \\
\hline 9 & 31.8 & 2.556 & 9 & 23.7 & 2.556 & 9 & 20.4 & 2.556 & 9 & 15.9 & 2.556 & 9 & 12.7 & 2.556 \\
\hline 10 & 30.6 & 2.3 & 10 & 23.4 & 2.3 & 10 & 20 & 2.3 & 10 & 15.2 & 2.3 & 10 & 12.1 & 2.3 \\
\hline 10 & 30.6 & 2.3 & 10 & 23.4 & 2.3 & 11 & 18.8 & 2.091 & 11 & 15 & 2.091 & 11 & 12 & 2.091 \\
\hline 12 & 30 & 1.917 & 10 & 23.4 & 2.3 & 12 & 18.2 & 1.917 & 12 & 14.7 & 1.917 & 12 & 10.8 & 1.917 \\
\hline 12 & 30 & 1.917 & 13 & 21.9 & 1.769 & 13 & 17.4 & 1.769 & 13 & 14.3 & 1.769 & 13 & 10.5 & 1.769 \\
\hline 14 & 28.8 & 1.643 & 14 & 21.3 & 1.643 & 14 & 17 & 1.643 & 14 & 13.9 & 1.643 & 14 & 10.4 & 1.643 \\
\hline 15 & 27.6 & 1.533 & 15 & 21 & 1.533 & 15 & 16.8 & 1.533 & 15 & 13.8 & 1.533 & 15 & 10.1 & 1.533 \\
\hline 16 & 26.4 & 1.438 & 16 & 20.4 & 1.438 & 16 & 16.4 & 1.438 & 16 & 12.2 & 1.438 & 16 & 9.8 & 1.438 \\
\hline 17 & 24.6 & 1.353 & 17 & 20.1 & 1.353 & 17 & 16 & 1.353 & 17 & 11.5 & 1.353 & 16 & 9.8 & 1.438 \\
\hline 17 & 24.6 & 1.353 & 18 & 19.2 & 1.278 & 18 & 15.6 & 1.278 & 18 & 11.4 & 1.278 & 18 & 8.9 & 1.278 \\
\hline 17 & 24.6 & 1.353 & 19 & 16.8 & 1.211 & 19 & 14.2 & 1.211 & 18 & 11.4 & 1.278 & 19 & 8.3 & 1.211 \\
\hline 20 & 22.8 & 1.15 & 20 & 16.2 & 1.15 & 19 & 14.2 & 1.211 & 20 & 10.5 & 1.15 & 20 & 7.8 & 1.15 \\
\hline 21 & 21.6 & 1.095 & 21 & 15.6 & 1.095 & 21 & 14.2 & 1.095 & 21 & 9.9 & 1.095 & 21 & 7.5 & 1.095 \\
\hline 22 & 18.0 & 1.045 & 22 & 15 & 1.045 & 22 & 11.6 & 1.045 & 21 & 9.9 & 1.095 & 22 & 7.2 & 1.045 \\
\hline
\end{tabular}

The rainfall intensity values for the 22 years under each time intensity are ranked in order if magnitude and assigned a return period value determined from the above equation. 
$\underline{\text { Time of Concentration Calculations }}$

Table For Constructing Frequency/ Magnitude Graph

\begin{tabular}{|c|c|c|c|c|c|}
\hline RP (x axis) & $10 \mathrm{~min}$ In & $20 \mathrm{~min}$ In & $30 \mathrm{~min} \ln$ & $60 \mathrm{~min}$ In & $120 \mathrm{~min}$ In \\
\hline 23 & 76.2 & 63.9 & 62.8 & 53.2 & 40.1 \\
\hline 11.5 & 67.2 & 50.7 & 50.6 & 45.4 & 37.2 \\
\hline 7.667 & 63.6 & 50.4 & 42.2 & 29.5 & 26.6 \\
\hline 5.75 & 57.6 & 33.9 & 29.8 & 27.4 & 21.1 \\
\hline 4.6 & 41.4 & 30.9 & 26.2 & 20.2 & 17.9 \\
\hline 3.833 & 36.0 & 28.2 & 23 & 19.3 & 16.2 \\
\hline 3.286 & 34.2 & 25.8 & 22.8 & 18.3 & 14.0 \\
\hline 2.875 & 33.6 & 24.3 & 21.4 & 16.3 & 13.6 \\
\hline 2.556 & 31.8 & 23.7 & 20.4 & 15.9 & 12.7 \\
\hline \multirow[t]{3}{*}{2.3} & 30.6 & 23.4 & 20 & 15.2 & 12.1 \\
\hline & 30.6 & 23.4 & & & \\
\hline & & 23.4 & & & \\
\hline 2.091 & & & 18.8 & 15 & 12 \\
\hline \multirow[t]{2}{*}{1.917} & 30 & & 18.2 & 14.7 & 10.8 \\
\hline & 30 & & & & \\
\hline 1.769 & & 21.9 & 17.4 & 14.3 & 10.5 \\
\hline 1.643 & 28.8 & 21.3 & 17 & 13.9 & 10.4 \\
\hline 1.533 & 27.6 & 21 & 16.8 & 13.8 & 10.1 \\
\hline \multirow[t]{2}{*}{1.438} & 26.4 & 20.4 & 16.4 & 12.2 & 9.8 \\
\hline & & & & & 9.8 \\
\hline \multirow[t]{3}{*}{1.353} & 24.6 & 20.1 & 16 & 11.5 & \\
\hline & 24.6 & & & & \\
\hline & 24.6 & & & & \\
\hline \multirow[t]{2}{*}{1.278} & & 19.2 & 15.6 & 11.4 & 8.9 \\
\hline & & & & 11.4 & \\
\hline \multirow[t]{2}{*}{1.211} & & 16.8 & 14.2 & & 8.3 \\
\hline & & & 14.2 & & \\
\hline 1.15 & 22.8 & 16.2 & & 10.5 & 7.8 \\
\hline \multirow[t]{2}{*}{1.095} & 21.6 & 15.6 & 14.2 & 9.9 & 7.5 \\
\hline & & & & 9.9 & \\
\hline 1.045 & 18.0 & 15 & 11.6 & & 7.2 \\
\hline
\end{tabular}

Rainfall intensity values are grouped into return periods and graphed

Intensity/ Duration Curve Table

\begin{tabular}{|r|r|r|}
\hline \multirow{2}{*}{$\begin{array}{c}\text { Duration } \\
\text { (min) }\end{array}$} & \multicolumn{2}{|c|}{ Intensity (yrs) RP } \\
\cline { 2 - 3 } & $\mathbf{1 0}$ & $\mathbf{2 3}$ \\
\hline $\mathbf{1 0}$ & 61.420 & 77.341 \\
\hline $\mathbf{2 0}$ & 47.065 & 59.392 \\
\hline $\mathbf{3 0}$ & 43.753 & 56.356 \\
\hline $\mathbf{6 0}$ & 36.661 & 47.818 \\
\hline $\mathbf{1 2 0}$ & 29.349 & 38.272 \\
\hline
\end{tabular}

Rainfall intensity values for selected return periods were read of the frequency/magnitude

curves for each duration. This was graphed as intensity duration curves from which the exceed intensity of a storm with a duration equal to the calculated time of concentration was determined 


\section{Frequency Magnitude Curves for Differing Rainfall Durations}

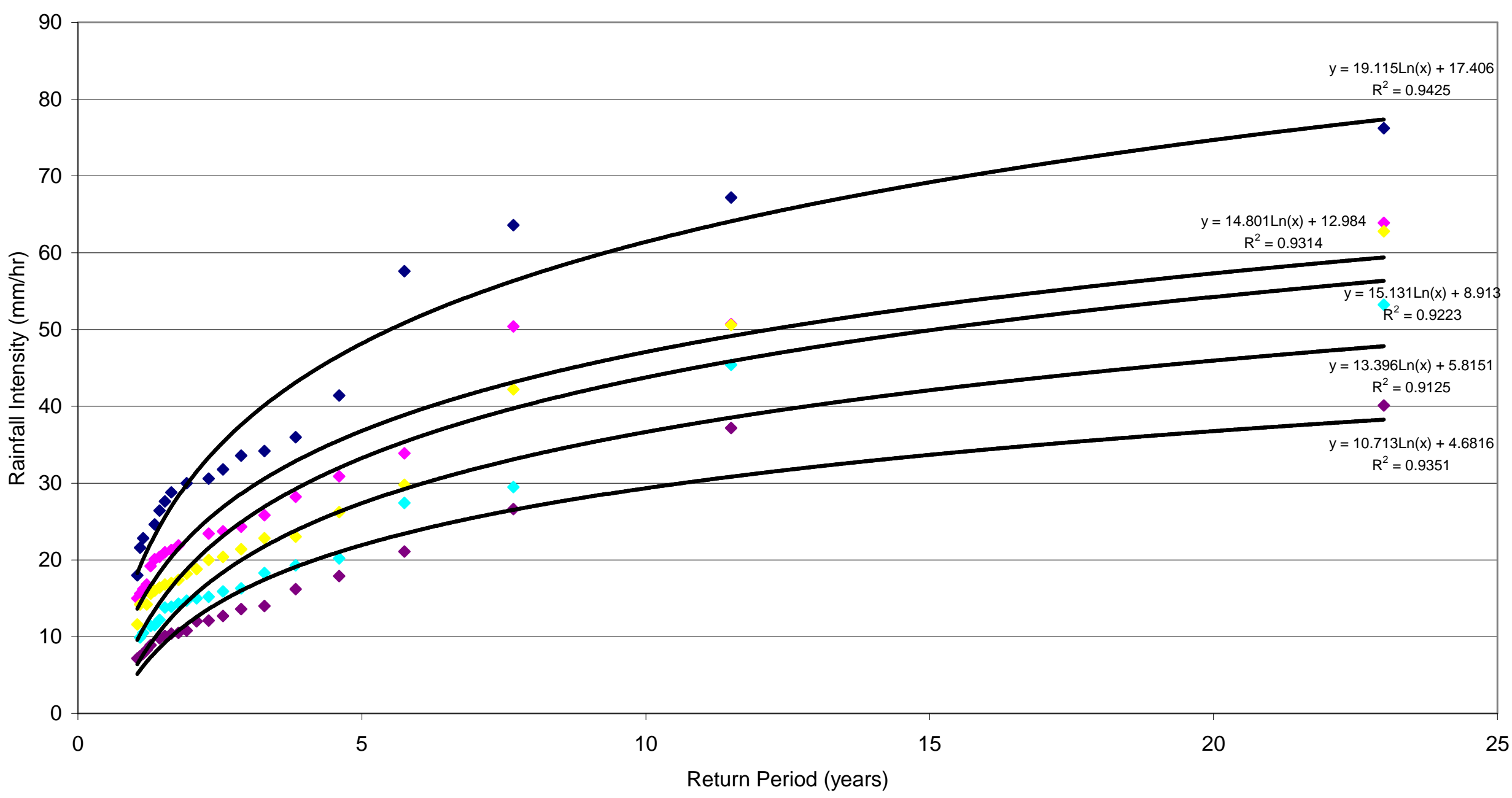

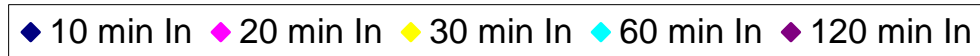




\section{Rainfall Intensity/ Duration Curve}

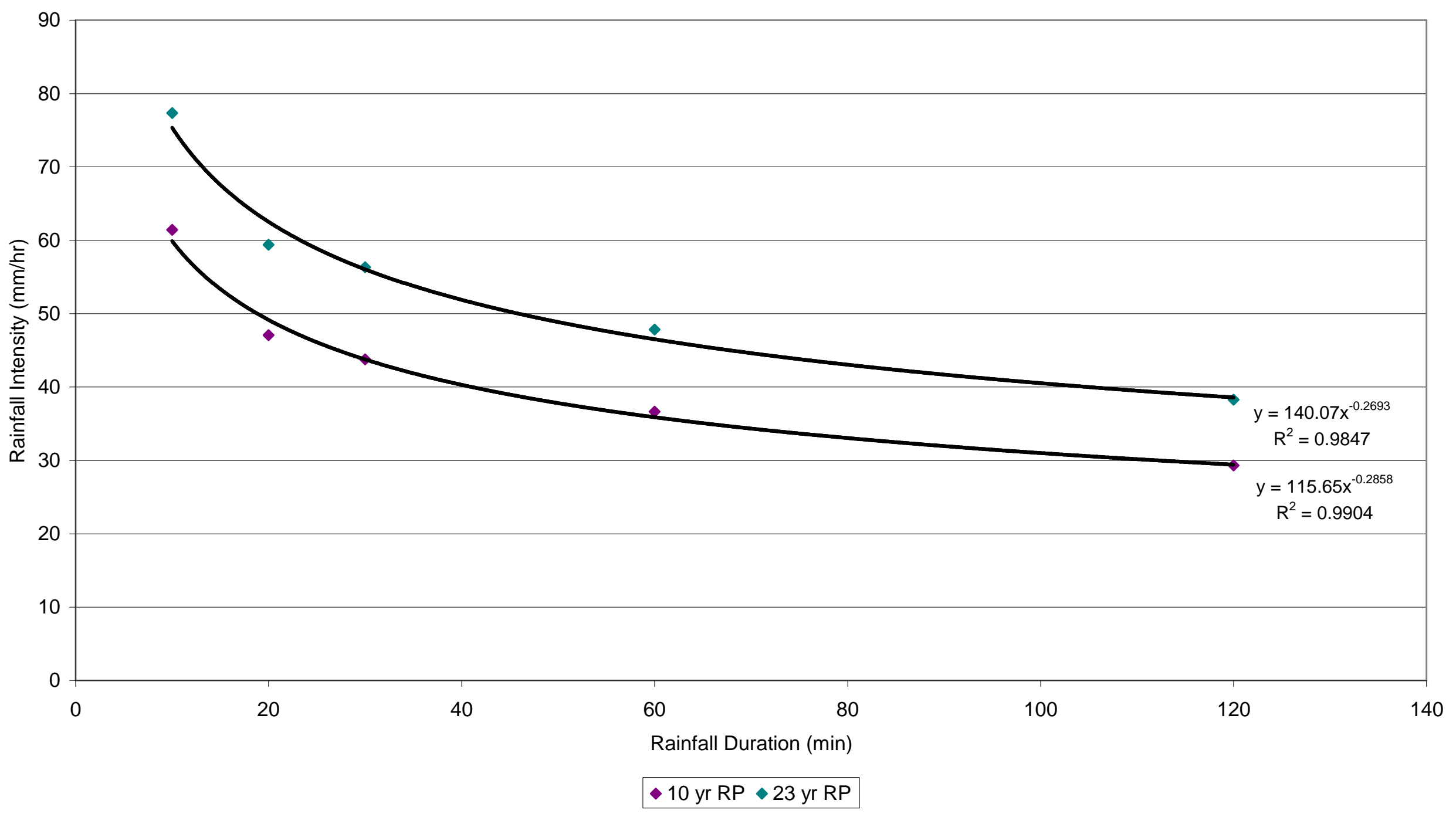




\section{APPENDIX III}

Grain Size 


\section{Sample 1}

Sample 1 was taken at the end of the longitudinal profile near the back of Catchment 2 . The stream channel was narrow (3.1 m wide) and moderately incised. The sample is composed of mainly large pebbles to cobbles $(86.7 \%,-4.5 \Phi$ to $-6 \Phi)$ with a mean grain size of $-5.42 \Phi$. Very small amounts of sand occur with silt almost absent. The median grain size of this sample is $-5.5 \Phi$ and is moderately sorted with a sorting value of 0.9 . This sample has a positive skewness of 0.3 .

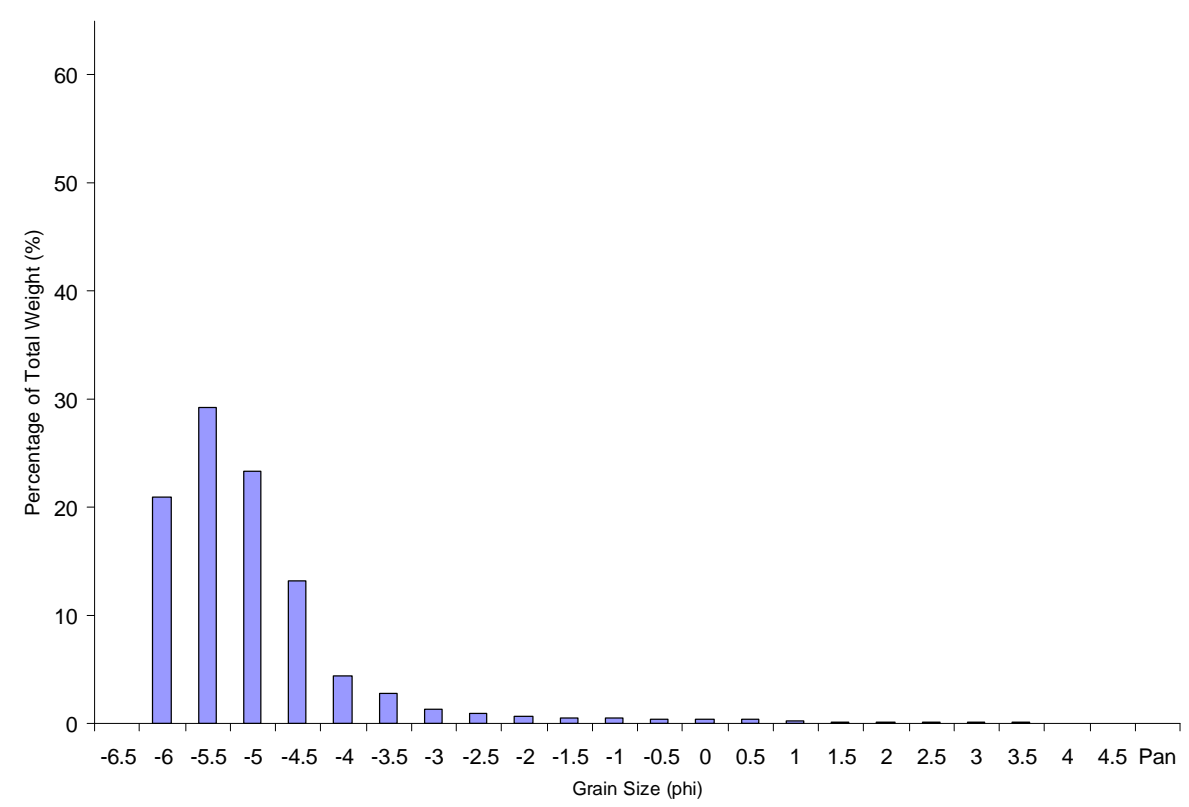

Percentage of each clast size present in Sample 1.

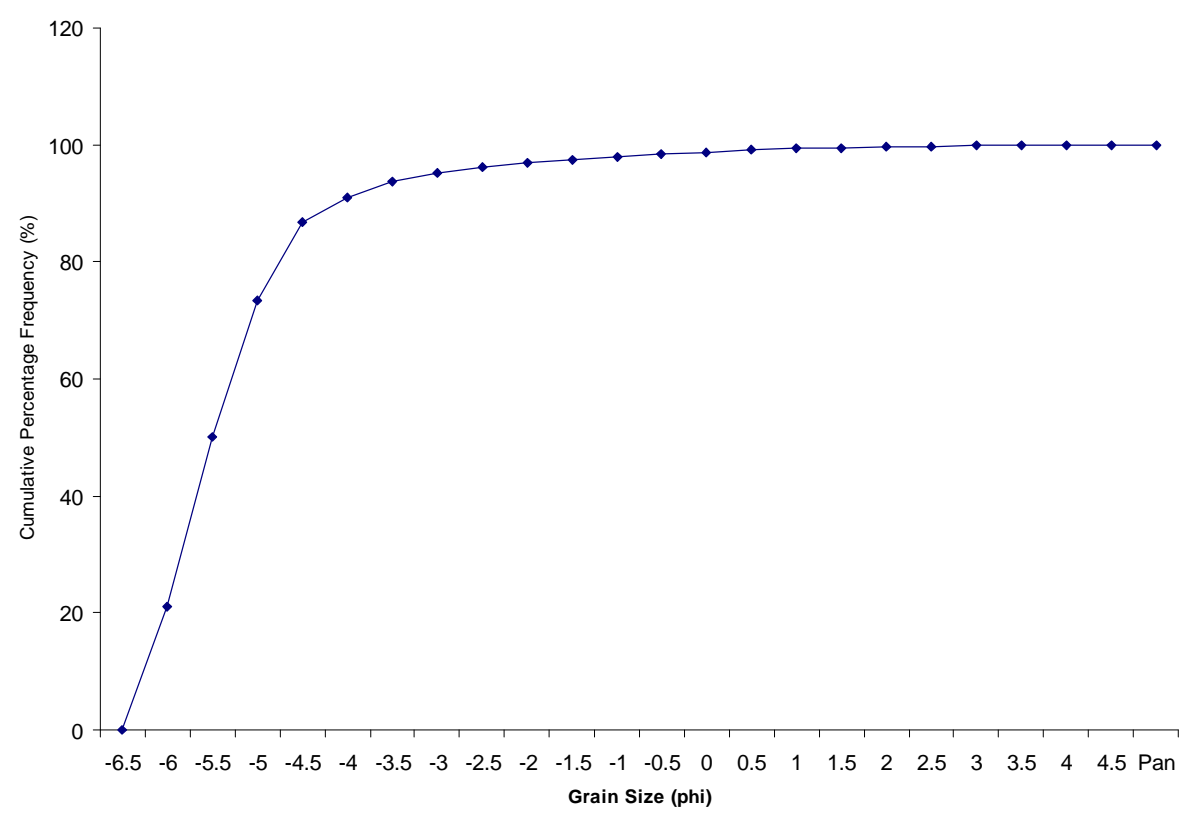

The cumulative frequency of each clast size in Sample 1. 


\section{Sample 2}

Sample 2 was taken near the middle of the longitudinal profile from a 9.12 metre wide section of the stream channel. Steep catchment walls on both sides of the channel formed the stream banks, allowing for sediment to be deposited directly into the stream channel. This sample consists of mainly large to medium pebbles $(82.3 \%,-3 \Phi$ to $5.5 \Phi)$. Small amounts of granules, sands and coarse silts also occur in this sample. The mean grain size is $-4.47 \Phi$, while 50 percent of the sample is coarser than $-4.9 \Phi$. Sample 2 has exhibits less moderate sorting than that evident in Sample 1, with a sorting value of 1.6. The sample also has a slightly more positive skewness of 0.9.

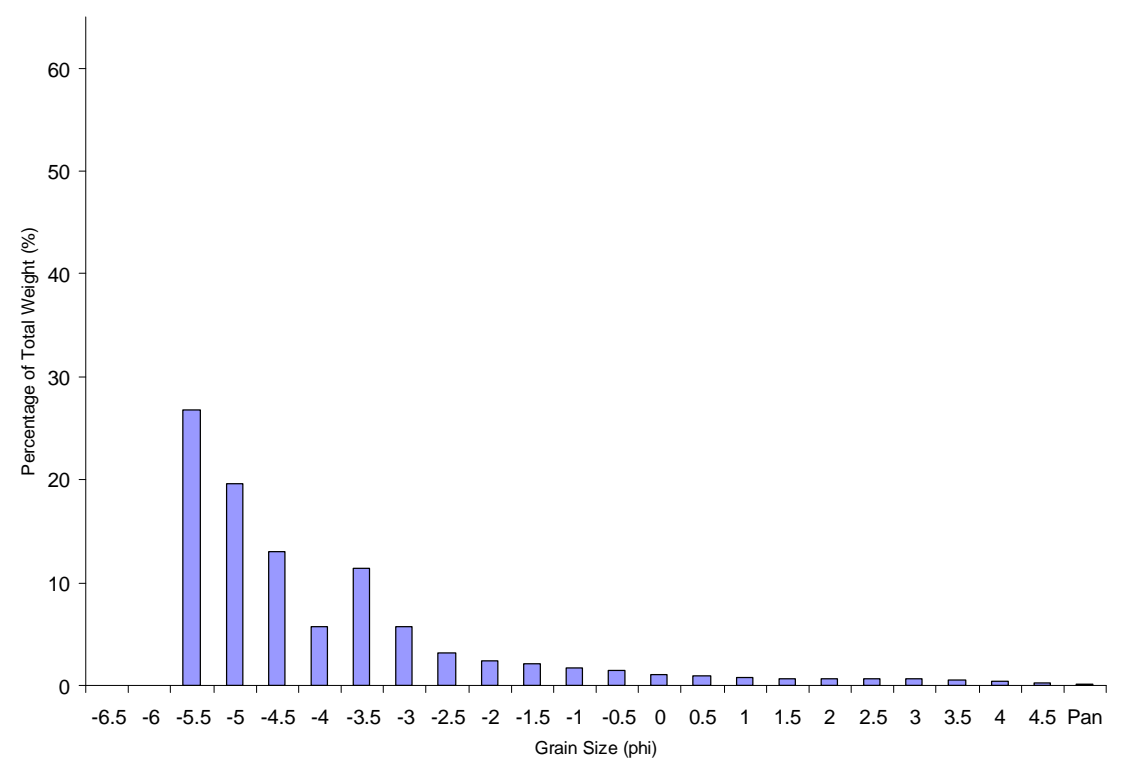

Percentage of each clast size present in Sample 2.

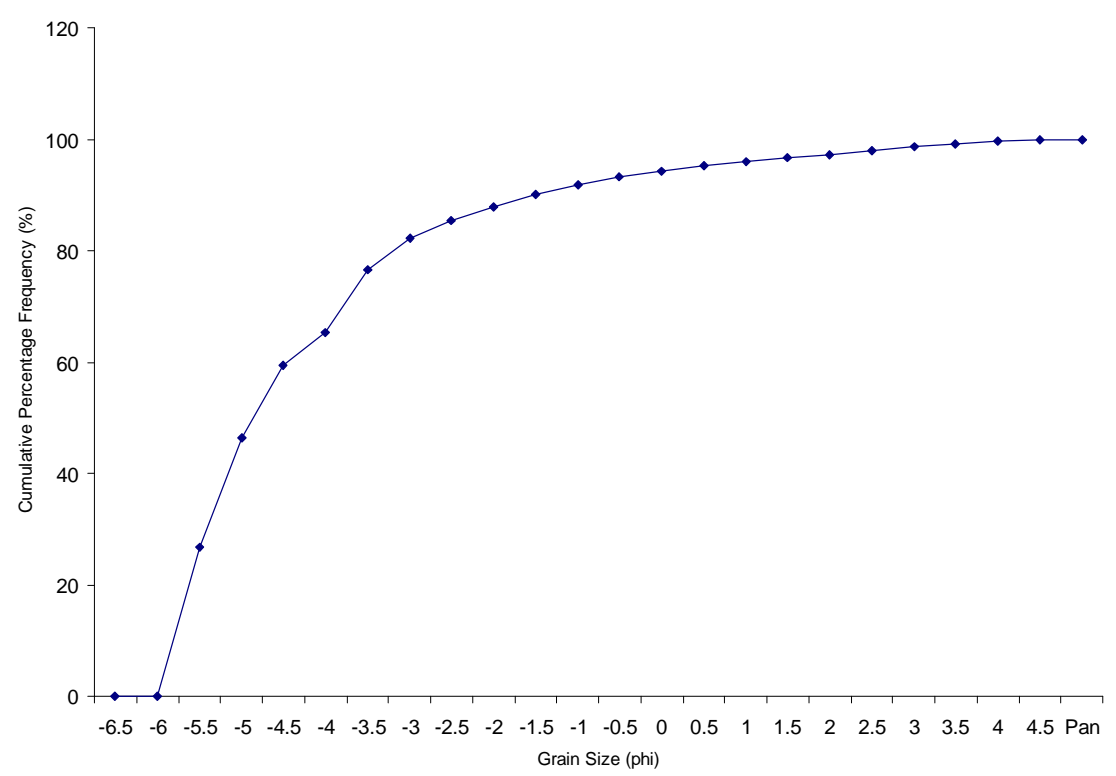

The cumulative frequency of each clast size in Sample 2. 


\section{Sample 3}

Sample 3 was taken from an 8.1 metre wide section of the stream channel. This section of channel covered the whole catchment floor, with moderately sloped vegetated stream banks. The sample is composed of gravels with small cobbles (-6 to $-6.4 \Phi)$ making up 59 percent of the total sample. Pebbles, granules and sands are present in the sample but each make up less than 10 percent, while silt is absent from the sample. Sample 3 has a mean grain size of $-4.7 \Phi$ but due to the high proportion of small cobbles, 50 percent of the sample is coarser than $-6.1 \Phi$. This sample is poorly sorted (2.08) and has a positive skewness of 0.9, similar to Sample 2.

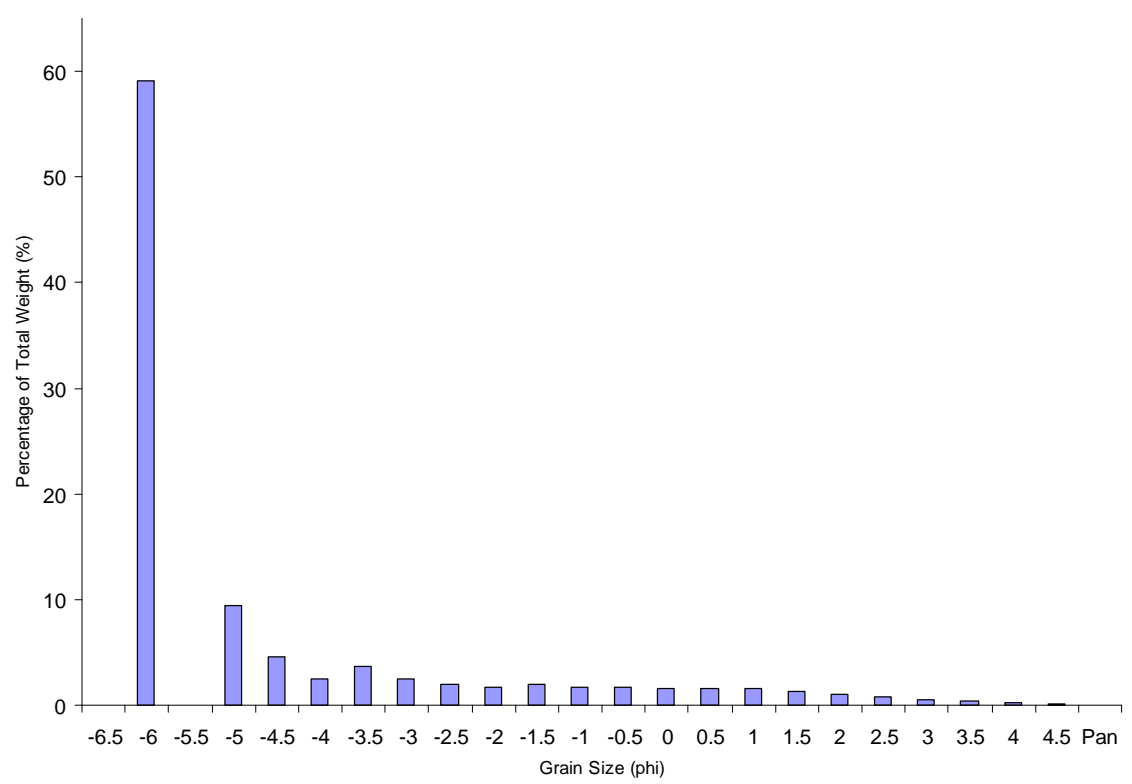

Percentage of each clast size present in Sample 3.

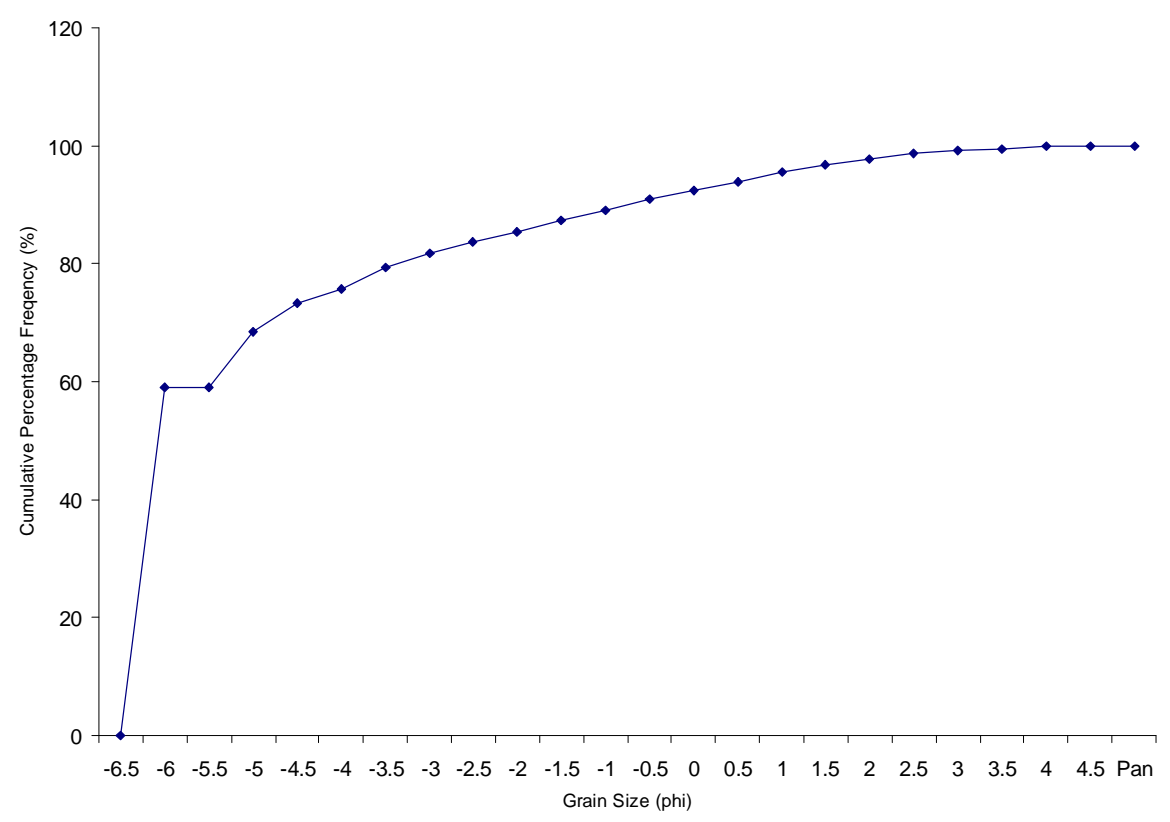

The cumulative frequency of each clast size in Sample 3. 


\section{Sample 4}

Sample 4 was taken from a 5.3 metre wide section of the stream channel with similar characteristics to the stream channel where sample 3 was taken. This sample consists of mainly very large pebbles to small cobbles $(86.2 \%,-5 \Phi$ to $-6 \Phi)$ with small amounts of pebbles and sand making up the rest of the sample. Overall sample 4 has a mean of 5.73 $\Phi$ and a median grain size of $-5.8 \Phi$. It is less moderately sorted than Sample 1, with a sorting value of 1.1 and has a positive skewness of 0.5 .

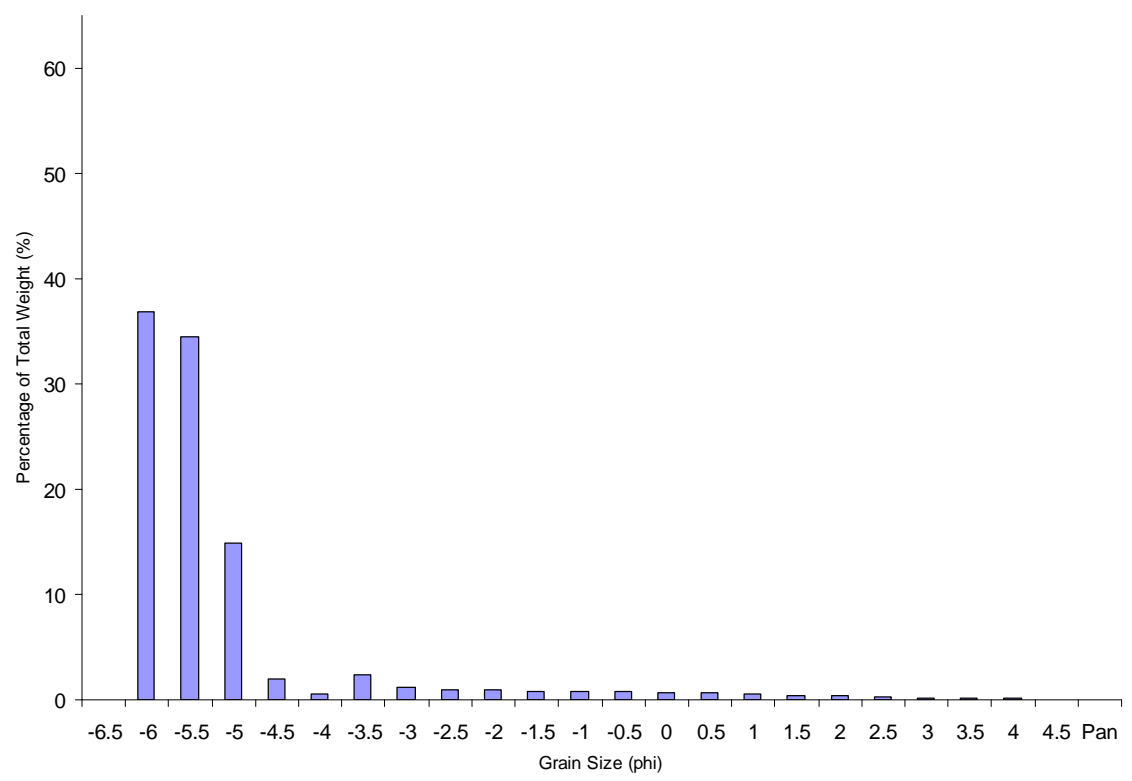

Percentage of each clast size present in Sample 4.

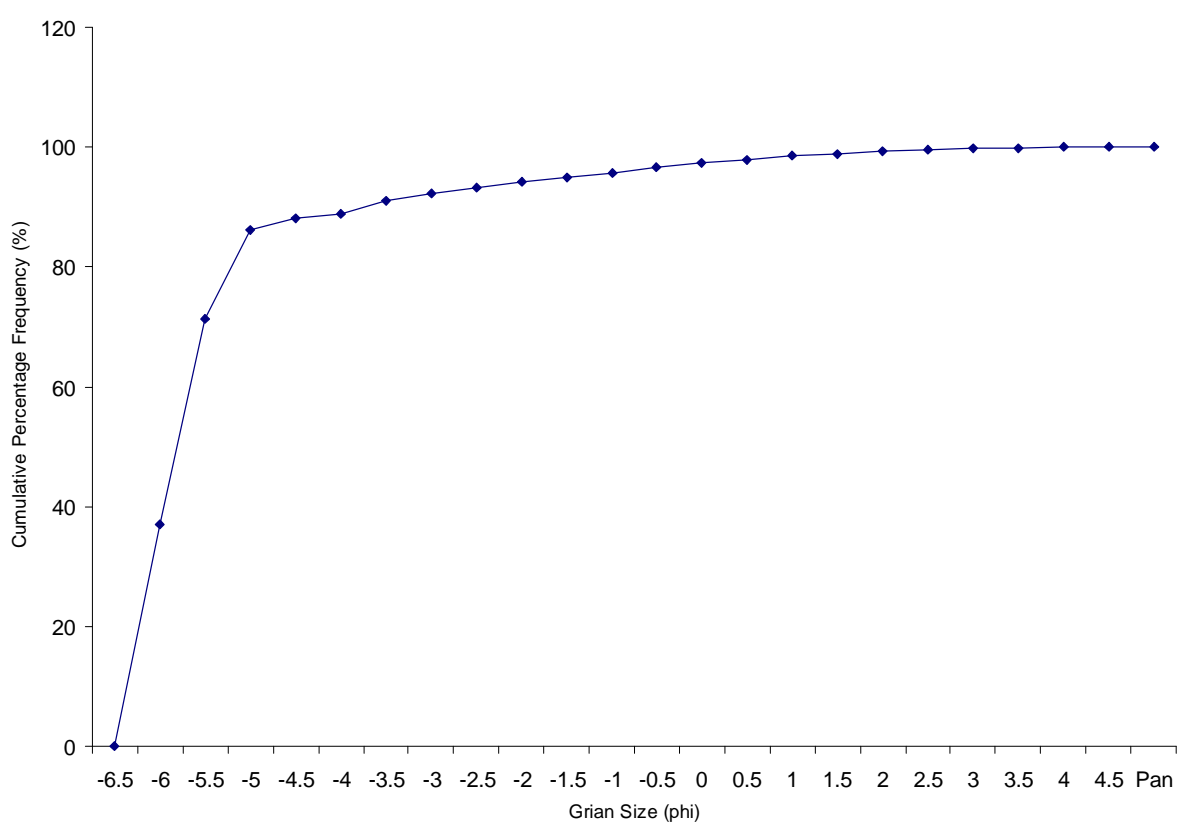

The cumulative frequency of each clast size in Sample 4. 


\section{Sample 5}

Sample 5 was located near the bottom of Catchment 2. At this location the stream channel begins to widen (11.8 metres wide) as the stream gets closer to the outlet of the catchment. This sample is composed mainly of large pebbles to small cobbles $(41.6 \%$, 4.5Фto $-5.5 \Phi)$ with the larges clasts seen in previous samples from further up the

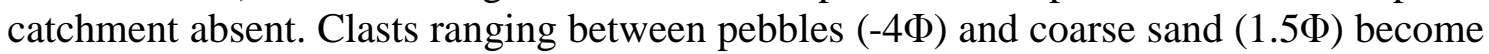
more prevalent in this sample and small amounts of silt are also evident, probably from a wider channel allowing deposition to start to occur from this point onwards. As a result sample 5 has a lower mean grain size and median. The mean grain size is $-3.22 \Phi$ and 50 percent of the clasts are coarser than $-3.8 \Phi$. The sample is poorly sorted with a sorting value of 2.1. Sample 5 has a positive skewness of 0.5 .

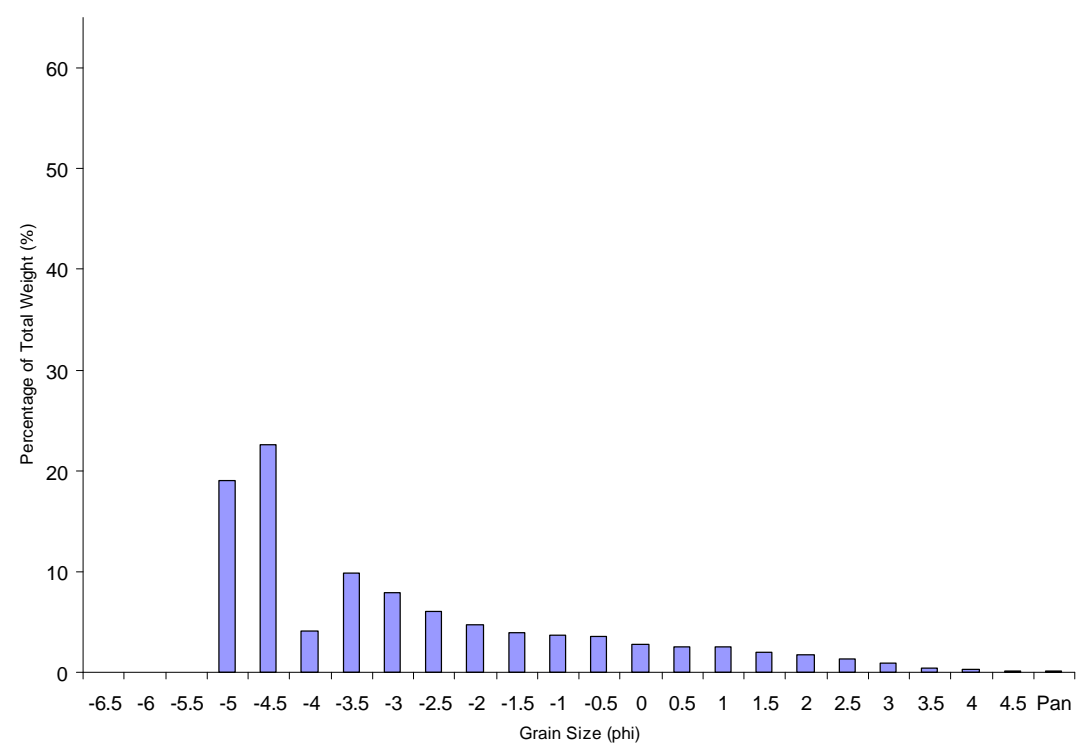

Percentage of each clast size present in Sample 5.

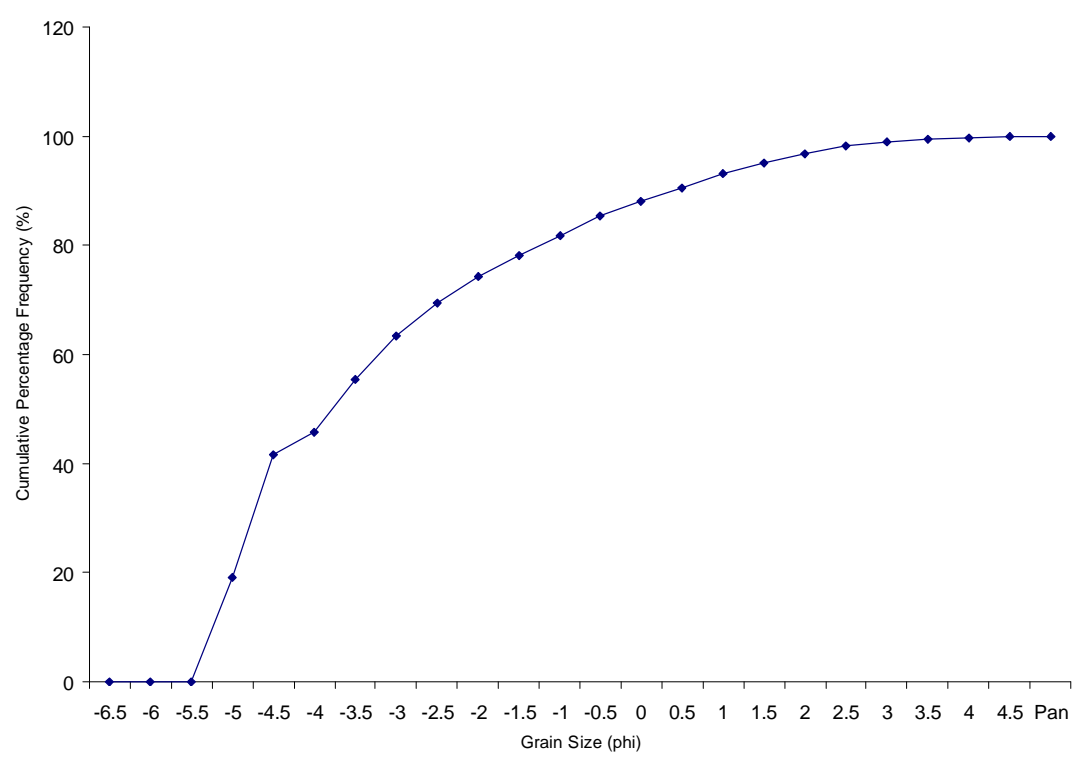

The cumulative frequency of each clast size in Sample 5. 


\section{Sample 6}

Sample 6 was taken near the fan apex at the catchment outlet. Between this sample and Sample 5 the stream channel has considerably widened and is 21.3 metres at this site. The channel is open, with patches of Kanuka (Kunzea spp.) scrub growing within the stream channel. This is also growing on the stream banks, as is grass. The sample is composed of large pebbles to small cobbles (-4.5Ф to $-5.5 \Phi)$ similar to Sample 5, although these size sediments make up a smaller percentage of the total sample (only $27.2 \%)$. Granule to fine sand sized clasts $(-1.5 \Phi$ to $3 \Phi)$ are more common in this sample, each contributing up to 7 percent of the total sample. Additionally there is a small amount of silt evident in this sample. This sample has the smallest mean grain size $(-1.92 \Phi)$ and the smallest median grain size with 50 percent of the sample coarser than $-1.85 \Phi$. Similar to Sample 5, Sample 6 is poorly sorted with a sorting value of 2.5Ф. This sample has skewness value of 0.0 .

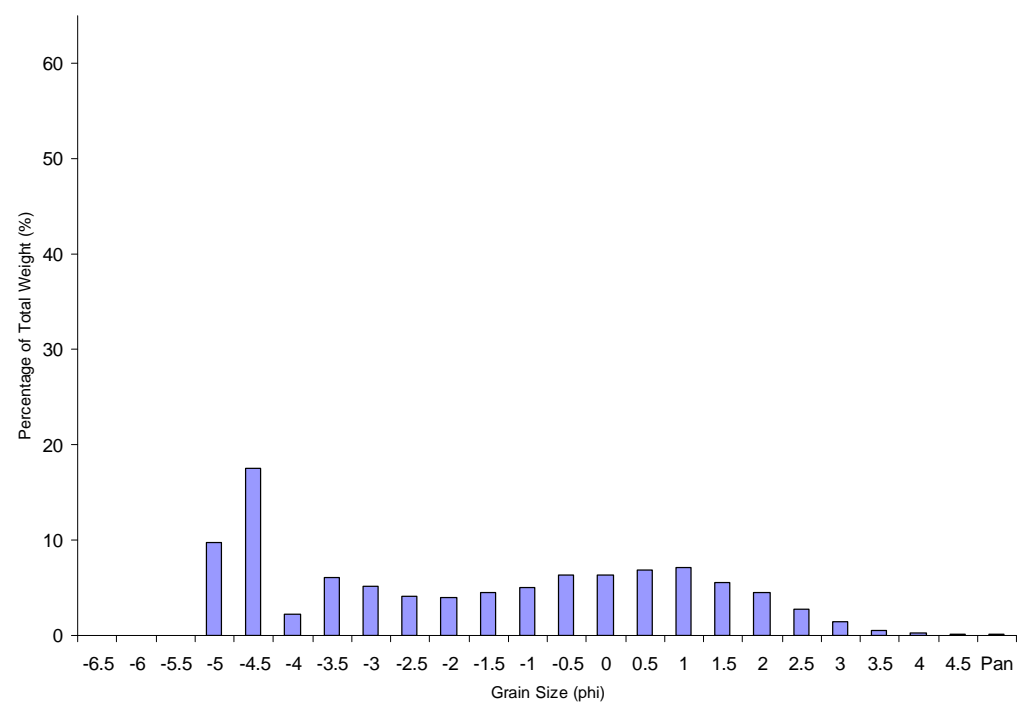

Percentage of each clast size present in Sample 6.

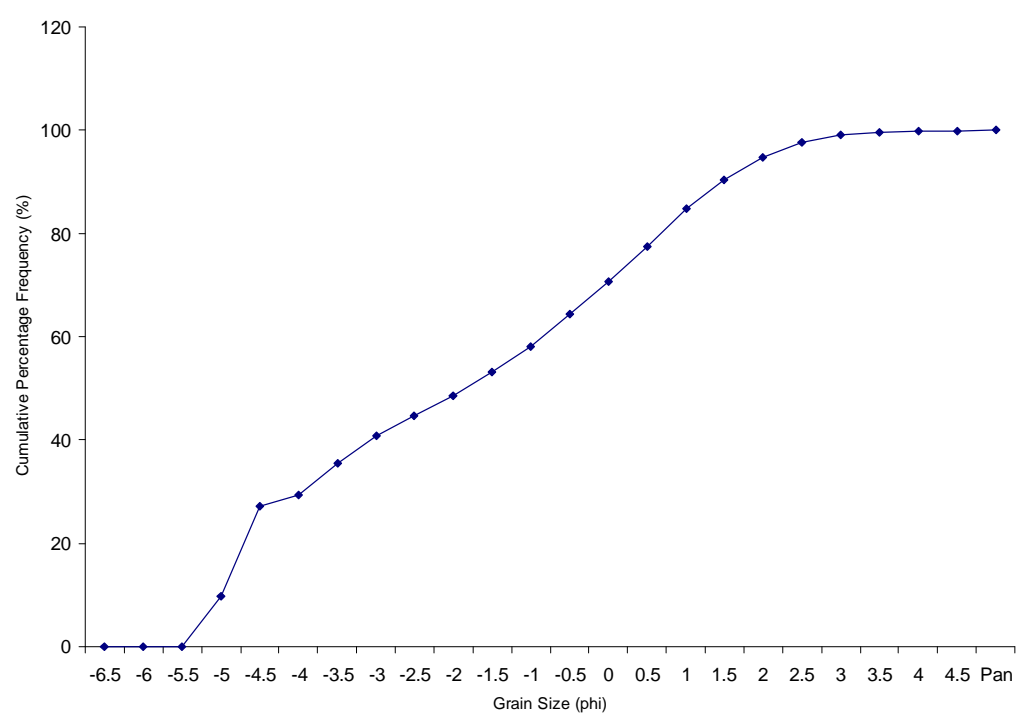

The cumulative frequency of each clast size in Sample 6. 


\section{Sample 7}

Sample 7 was located on the Fan 2 to the west of State Highway 1. The channel on the fan has been cleared of sediment and vegetation and is therefore artificially kept wide. The sediment has been bulldozed to the sides of the channels to form stop banks. At the site of the sample the stream channel was 22.7 metres wide. This sample consists of a range of mainly small pebbles to small cobbles $(74 \%,-2.5 \Phi$ to $-6 \Phi)$ with amounts of sands and silts contributing to the rest of the sample. The mean grain size is $-3.42 \Phi$ and 50 percent of the sample is coarser than $-4.55 \Phi$. This sample is poorly sorted $(2.6 \Phi)$ similar to the Samples 5 and 6 and has a positive skewness of 0.6.

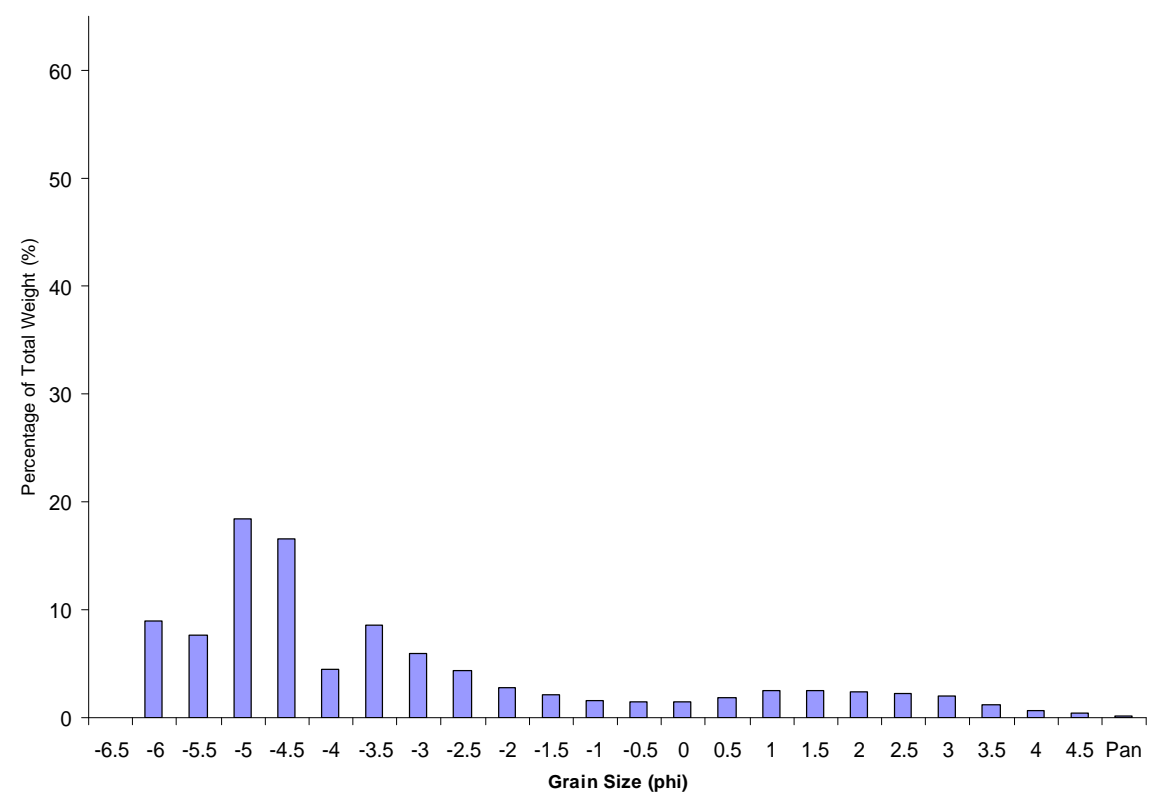

Percentage of each clast size present in Sample 7.

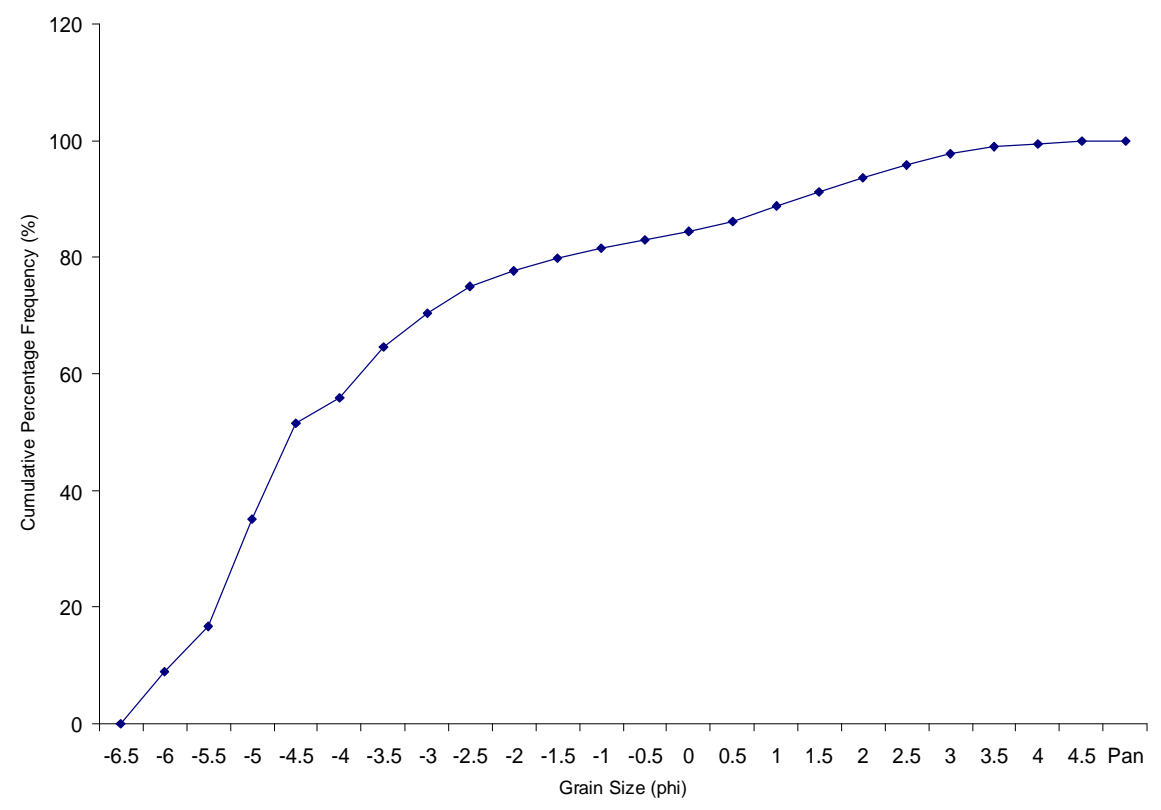

The cumulative frequency of each clast size in Sample 7. 


\section{Samples 8A and 8B}

Sample 8 was located on the lower fan to the east of State Highway 1. As with Sample 7 , the stream channel here has been artificially cleared and kept wide. The channel at this sample location was 22.3 metres wide. Two samples were taken at this location. Sample 8A exhibits less coarse sediment and more fines than Sample 8B as it was taken from an area where small surface water flows occur periodically, while sample 8B was to the side of this area. Sample 8A is similar to Sample 7. It consists of mainly pebbles $(60.4 \%,-2 \Phi$ to $-5-5 \Phi)$. Granules, sands and silts make up the rest of the sample. This sample has the highest percentage of silts compared to the other eight samples taken along the stream profile. The mean grain size for this sample is $-2.77 \Phi$ with 50 percent of the grains being coarser than $-2.85 \Phi$. It is poorly sorted with a sorting value of $2.8 \Phi$ and presents a positive skewness of 0.2 .

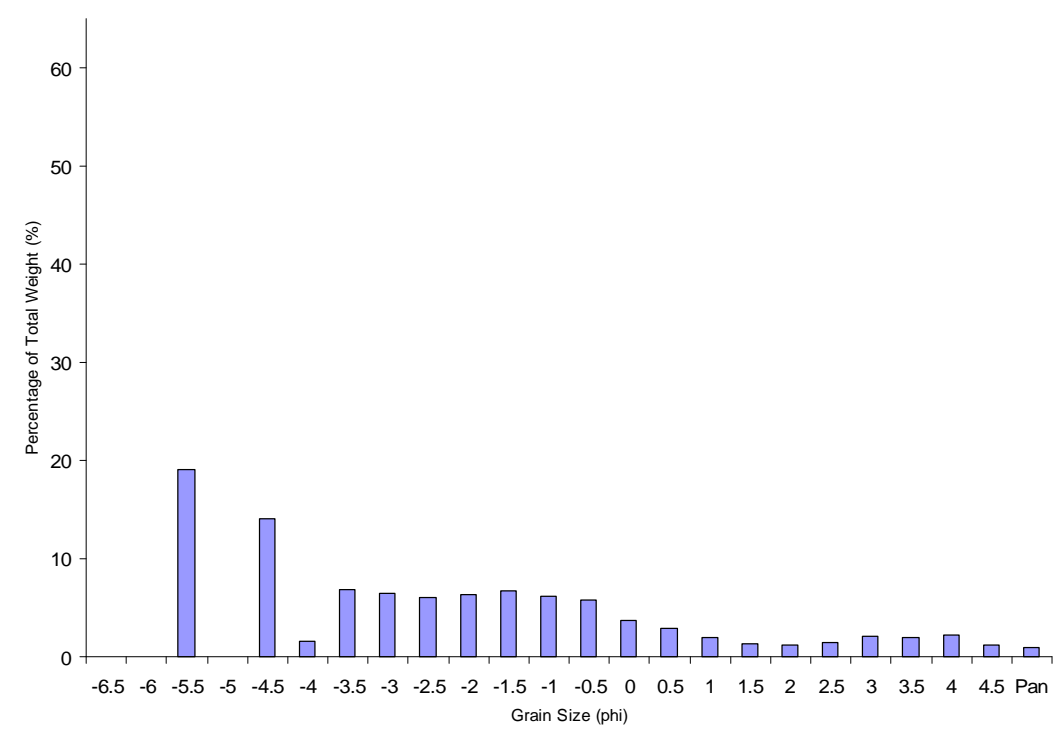

Percentage of each clast size present in Sample 8A.

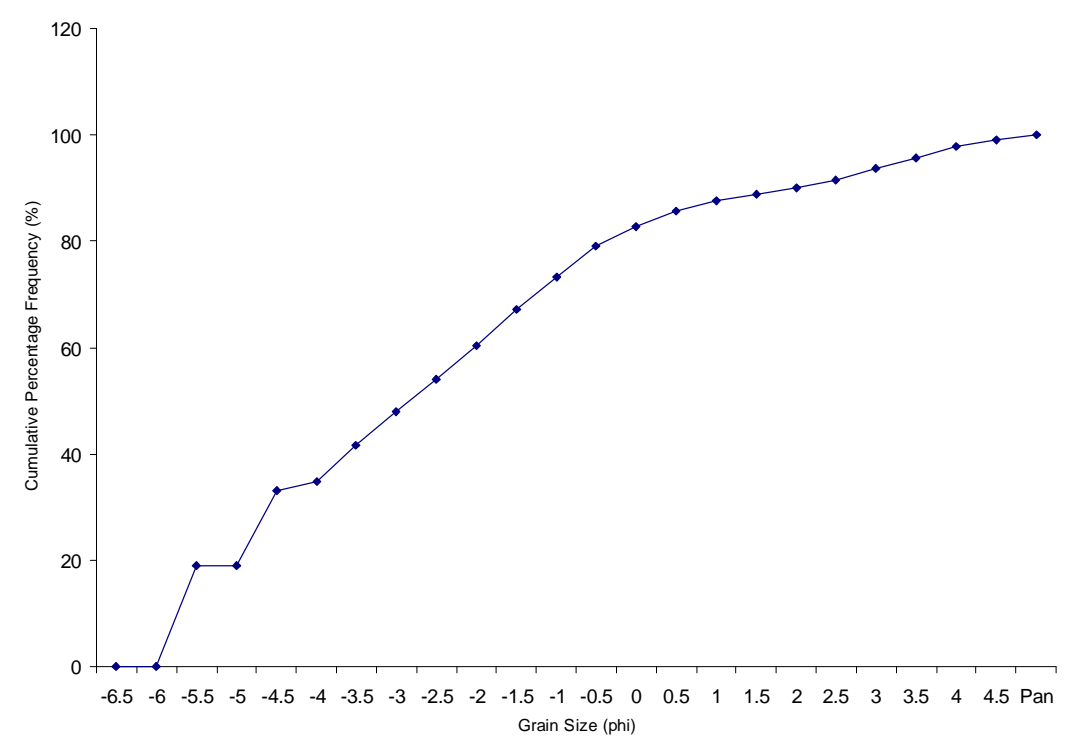

The cumulative frequency of each clast size in Sample 8A. 
Sample 8B has a large proportion of large to very large pebbles $(82.1 \%,-4.5 \Phi$ to $-5.5 \Phi)$ and only very small amounts of clasts ranging between medium pebbles and silt. This sample has a mean grain size of $-5.2 \Phi$ and a median grain size of $-5.4 \Phi$. It is moderately sorted $(1.0 \Phi)$ when compared to the other samples located on the fan and has a positive skewness of $0.6 \Phi$.

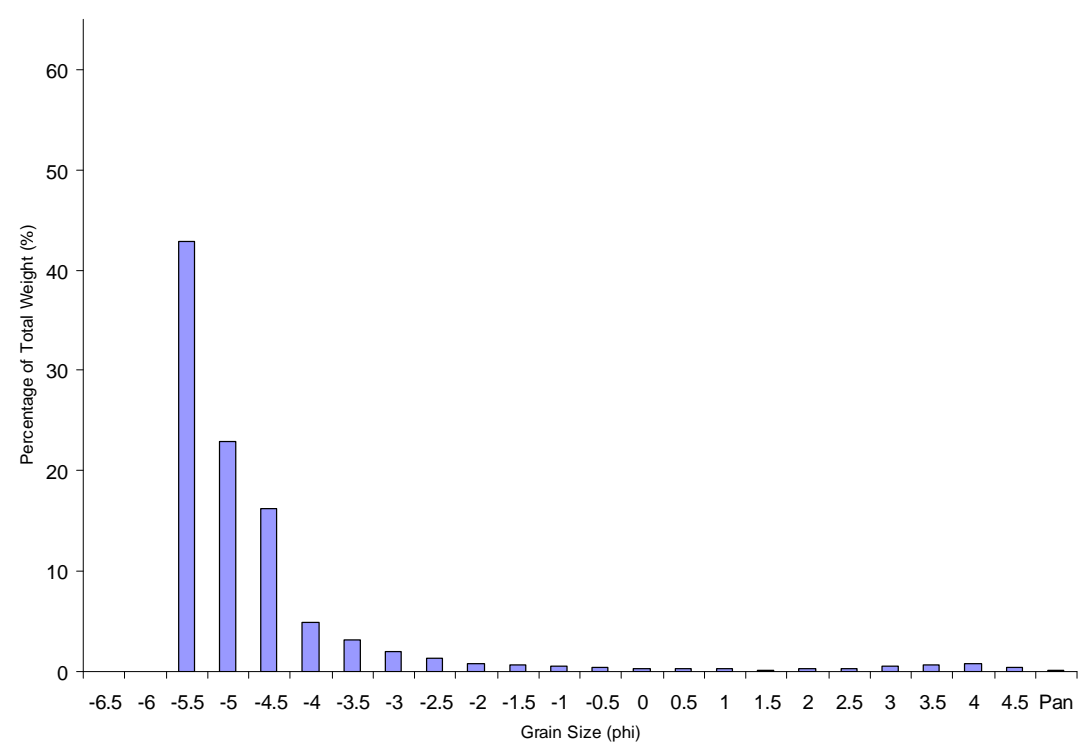

Percentage of each clast size present in Sample 8B.

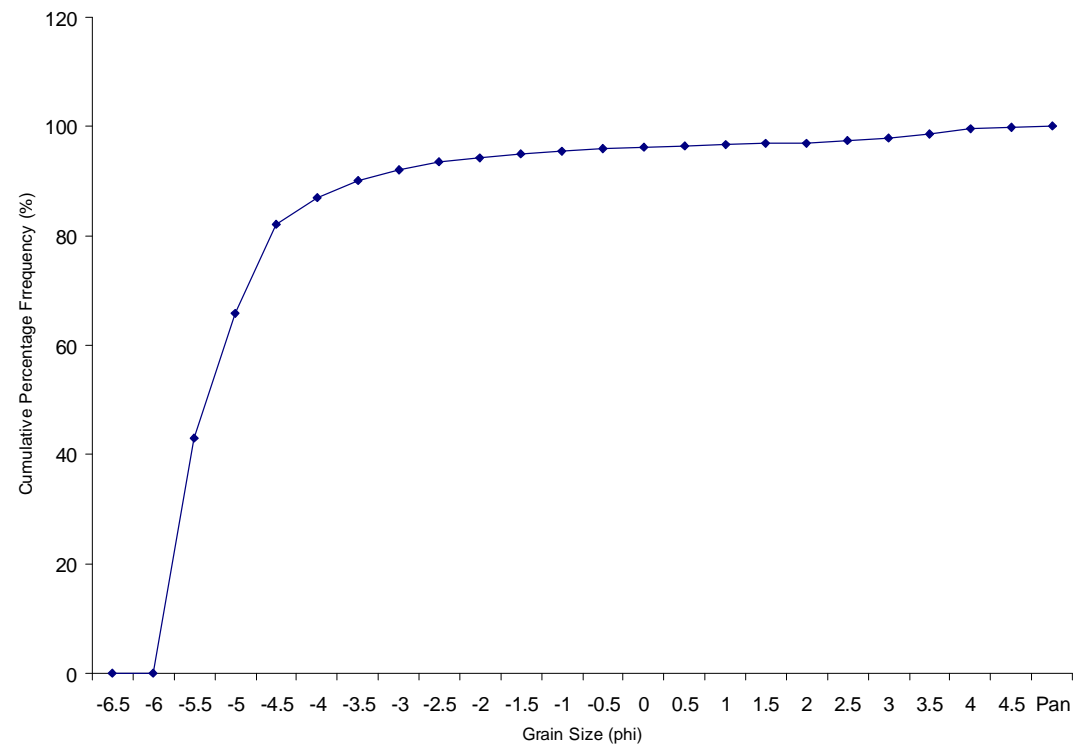

The cumulative frequency of each clast size in Sample 8B.

Due to the location of Samples 7, 8A and 8B on the part of the fan which has been artificially controlled, with the channel being bulldozed, the sediments deposited on the surface of the fan channel are likely to have been disturbed or removed completely, with larger sediments from the surrounding fan and stopbanks combined with the current deposit. The location of Sample 6, near the apex of the fan, had not been artificially cleared and is therefore more representative of sediments located within the stream channel of the fan. 


\section{Source Sediment Sample}

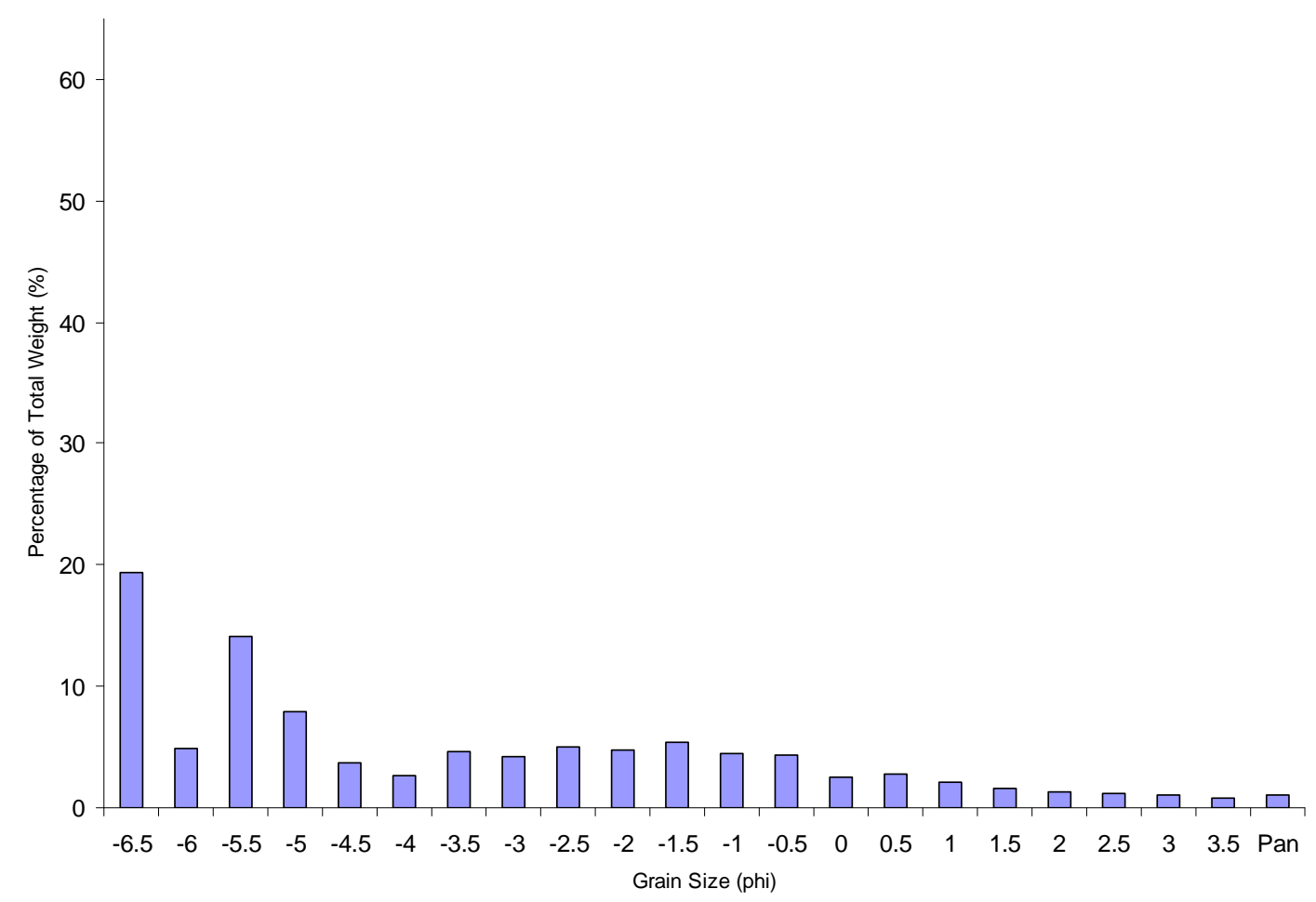

Percentage of each clast size present in the Source Sample.

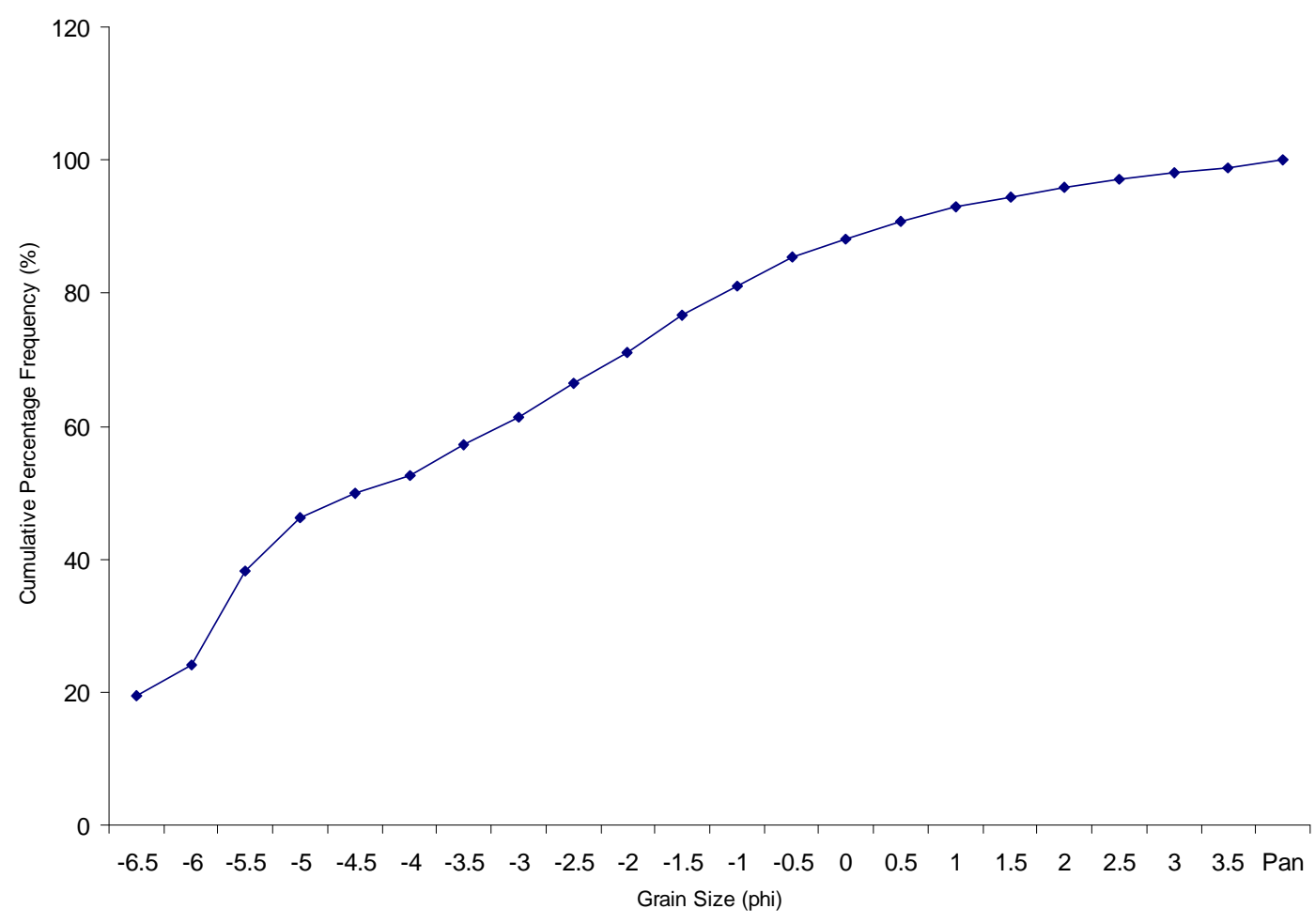

The cumulative frequency of each clast size in the Source Sample. 
Sample 1

Individually Measured Clasts

\begin{tabular}{|c|c|c|c|c|}
\hline A Axis & B Axis & C Axis & $\Phi$ Size & Weight \\
\hline 82 & 73 & 48 & -6 & 384.66 \\
\hline 67 & 62 & 28 & -5.5 & 180.56 \\
\hline 66 & 45 & 26 & -5.5 & 102.67 \\
\hline 53 & 45 & 25 & -5.5 & 84.77 \\
\hline 84 & 59 & 34 & -5.5 & 168.43 \\
\hline 74 & 44 & 43 & -5 & 206.39 \\
\hline 73 & 44 & 30 & -5 & 141.69 \\
\hline 42 & 34 & 24 & -5 & 46.1 \\
\hline 39 & 32 & 22 & -5 & 33.75 \\
\hline 42 & 28 & 18 & -4.5 & 31.12 \\
\hline \multicolumn{4}{|c|}{ Total Weight } & 1380.14 \\
\hline
\end{tabular}

Individually Measured Clasts from -4Ф Pan

\begin{tabular}{|c|c|c|c|c|}
\hline A Axis & B Axis & C Axis & $\Phi$ Size & Weight \\
\hline 44 & 22 & 21 & -4.5 & 22.39 \\
\hline 30 & 18 & 12 & -4 & 8.21 \\
\hline 36 & 28 & 28 & -4.5 & 18.18 \\
\hline 33 & 30 & 19 & -4.5 & 17.01 \\
\hline 38 & 20 & 18 & -4 & 14.44 \\
\hline 31 & 30 & 25 & -4 & 27.45 \\
\hline 38 & 26 & 19 & -4.5 & 18.78 \\
\hline 35 & 22 & 15 & -4.5 & 15.74 \\
\hline & & & & \\
\hline 28 & 28 & 12 & -4.5 & 14.93 \\
\hline 28 & 21 & 15 & -4 & 17.83 \\
\hline 28 & 22 & 18 & -4.5 & 11.15 \\
\hline 32 & 22 & 13 & -4.5 & 14.1 \\
\hline 36 & 23 & 18 & -4.5 & 29.53 \\
\hline 32 & 30 & 23 & -4.5 & 23.24 \\
\hline 34 & 27 & 17 & -4.5 & 12.91 \\
\hline 36 & 24 & 11 & -4.5 & 13.83 \\
\hline 32 & 20 & 20 & -4 & 12.15 \\
\hline \multicolumn{3}{|c|}{ Total Weight } & 291.87 \\
\hline
\end{tabular}

Sieved Sediment

\begin{tabular}{|c|r|}
\hline$\Phi$ Size & Weight \\
\hline-4 & 291.87 \\
\hline-3.5 & 50.64 \\
\hline-3 & 25.03 \\
\hline-2.5 & 17.5 \\
\hline-2 & 13.02 \\
\hline-1.5 & 10.16 \\
\hline-1 & 9.14 \\
\hline-0.5 & 8.24 \\
\hline 0 & 7.06 \\
\hline 0.5 & 6.31 \\
\hline 1 & 4.78 \\
\hline 1.5 & 3.16 \\
\hline 2 & 2.18 \\
\hline 2.5 & 1.6 \\
\hline 3 & 1.49 \\
\hline 3.5 & 1.26 \\
\hline 4 & 1.19 \\
\hline 4.5 & 1.1 \\
\hline Pan & 0.07 \\
\hline Total & 455.8 \\
\hline
\end{tabular}

Total Sediment Sample

\begin{tabular}{|c|c|c|c|}
\hline $\begin{array}{c}\boldsymbol{\Phi} \\
\text { Size }\end{array}$ & Weight & $\%$ & Cumulative $\%$ \\
\hline-6.5 & 0 & 0.000 & 0.000 \\
\hline-6 & 384.66 & 20.952 & 20.952 \\
\hline-5.5 & 536.43 & 29.218 & 50.170 \\
\hline-5 & 427.93 & 23.308 & 73.478 \\
\hline-4.5 & 242.91 & 13.231 & 86.709 \\
\hline-4 & 80.08 & 4.362 & 91.071 \\
\hline-3.5 & 50.64 & 2.758 & 93.829 \\
\hline-3 & 25.03 & 1.363 & 95.193 \\
\hline-2.5 & 17.5 & 0.953 & 96.146 \\
\hline-2 & 13.02 & 0.709 & 96.855 \\
\hline-1.5 & 10.16 & 0.553 & 97.408 \\
\hline-1 & 9.14 & 0.498 & 97.906 \\
\hline-0.5 & 8.24 & 0.449 & 98.355 \\
\hline 0 & 7.06 & 0.385 & 98.740 \\
\hline 0.5 & 6.31 & 0.344 & 99.083 \\
\hline 1 & 4.78 & 0.260 & 99.344 \\
\hline 1.5 & 3.16 & 0.172 & 99.516 \\
\hline 2 & 2.18 & 0.119 & 99.635 \\
\hline 2.5 & 1.6 & 0.087 & 99.722 \\
\hline 3 & 1.49 & 0.081 & 99.803 \\
\hline 3.5 & 1.26 & 0.069 & 99.871 \\
\hline 4 & 1.19 & 0.065 & 99.936 \\
\hline 4.5 & 1.1 & 0.060 & 99.996 \\
\hline Pan & 0.07 & 0.004 & 100.000 \\
\hline Total & 1835.94 & 100 & \\
\hline & & & \\
\hline
\end{tabular}


Individually Measured Clasts

\begin{tabular}{|c|c|c|c|c|}
\hline A Axis & B Axis & C Axis & $\Phi$ Size & Weight \\
\hline 63 & 46 & 28 & -5.5 & 122.26 \\
\hline 63 & 54 & 36 & -5.5 & 192.51 \\
\hline 57 & 53 & 30 & -5.5 & 111.2 \\
\hline 63 & 43 & 29 & -5 & 106.76 \\
\hline 50 & 41 & 31 & -5 & 62.52 \\
\hline 57 & 49 & 18 & -5.5 & 62.74 \\
\hline 59 & 44 & 8 & -5 & 31.84 \\
\hline 54 & 32 & 32 & -5 & 63.53 \\
\hline 46 & 37 & 28 & -5 & 63.28 \\
\hline 54 & 31 & 27 & -4.5 & 50.71 \\
\hline 48 & 18 & 18 & -4 & 24.45 \\
\hline 58 & 31 & 20 & -4.5 & 58.97 \\
\hline 38 & 31 & 17 & -4.5 & 26.77 \\
\hline 49 & 28 & 13 & -4.5 & 23.17 \\
\hline 37 & 30 & 18 & -4.5 & 28.37 \\
\hline 36 & 35 & 31 & -5 & 30.6 \\
\hline 36 & 30 & 16 & -4.5 & 15.22 \\
\hline \multicolumn{4}{|c|}{ Total Weight } & 1074.9 \\
\hline
\end{tabular}

Individually Measured Clasts from -4Ф Pan

\begin{tabular}{|c|c|c|c|c|}
\hline A Axis & B Axis & C Axis & $\Phi$ Size & Weight \\
\hline 22 & 20 & 20 & -4 & 17.05 \\
\hline 20 & 20 & 12 & -4 & 6.22 \\
\hline 28 & 22 & 15 & -4.5 & 12.51 \\
\hline 25 & 22 & 11 & -4.5 & 6.94 \\
\hline 25 & 19 & 14 & -4 & 8.06 \\
\hline 36 & 21 & 17 & -4 & 14.41 \\
\hline 34 & 22 & 16 & -4.5 & 15.17 \\
\hline 24 & 20 & 12 & -4 & 8.79 \\
\hline 24 & 20 & 12 & -4 & 7.29 \\
\hline 28 & 21 & 12 & -4 & 9.9 \\
\hline 24 & 18 & 17 & -4 & 8.97 \\
\hline \multicolumn{4}{|c|}{ Total Weight } & 115.31 \\
\hline
\end{tabular}

Sieved Sediment

\begin{tabular}{|c|c|}
\hline$\Phi$ Size & Weight \\
\hline-4 & 115.31 \\
\hline-3.5 & 207.88 \\
\hline-3 & 104.1 \\
\hline-2.5 & 58.52 \\
\hline-2 & 44.77 \\
\hline-1.5 & 38.73 \\
\hline-1 & 30.72 \\
\hline-0.5 & 26.29 \\
\hline 0 & 19.07 \\
\hline 0.5 & 15.88 \\
\hline 1 & 13.8 \\
\hline 1.5 & 12.76 \\
\hline 2 & 12.2 \\
\hline 2.5 & 12.33 \\
\hline 3 & 12.56 \\
\hline 3.5 & 9.25 \\
\hline 4 & 7.48 \\
\hline 4.5 & 5.4 \\
\hline Pan & 3.21 \\
\hline Total & 750.26 \\
\hline
\end{tabular}

Total Sediment Sample

\begin{tabular}{|c|c|c|c|}
\hline$\Phi$ Size & Weight & $\%$ & Cumulative $\%$ \\
\hline-6.5 & 0 & 0.000 & 0.000 \\
\hline-6 & 0 & 0.000 & 0.000 \\
\hline-5.5 & 488.71 & 26.776 & 26.776 \\
\hline-5 & 358.53 & 19.644 & 46.420 \\
\hline-4.5 & 237.83 & 13.031 & 59.451 \\
\hline-4 & 105.14 & 5.761 & 65.211 \\
\hline-3.5 & 207.88 & 11.390 & 76.601 \\
\hline-3 & 104.1 & 5.704 & 82.305 \\
\hline-2.5 & 58.52 & 3.206 & 85.511 \\
\hline-2 & 44.77 & 2.453 & 87.964 \\
\hline-1.5 & 38.73 & 2.122 & 90.086 \\
\hline-1 & 30.72 & 1.683 & 91.769 \\
\hline-0.5 & 26.29 & 1.440 & 93.209 \\
\hline 0 & 19.07 & 1.045 & 94.254 \\
\hline 0.5 & 15.88 & 0.870 & 95.124 \\
\hline 1 & 13.8 & 0.756 & 95.880 \\
\hline 1.5 & 12.76 & 0.699 & 96.579 \\
\hline 2 & 12.2 & 0.668 & 97.248 \\
\hline 2.5 & 12.33 & 0.676 & 97.923 \\
\hline 3 & 12.56 & 0.688 & 98.612 \\
\hline 3.5 & 9.25 & 0.507 & 99.118 \\
\hline 4 & 7.48 & 0.410 & 99.528 \\
\hline 4.5 & 5.4 & 0.296 & 99.824 \\
\hline Pan & 3.21 & 0.176 & 100.000 \\
\hline Total & 1825.16 & 100 & \\
\hline & & & \\
\hline
\end{tabular}


Sample 3

Individually Measured Clasts

\begin{tabular}{|c|c|c|c|c|}
\hline A Axis & B Axis & C Axis & $\Phi$ Size & Weight \\
\hline 132 & 68 & 43 & -6 & 588.23 \\
\hline 99 & 84 & 57 & -6 & 661.45 \\
\hline 54 & 33 & 19 & -5 & 43.56 \\
\hline 80 & 67 & 36 & -6 & 217.1 \\
\hline 70 & 40 & 32 & -5 & 126.86 \\
\hline 72 & 64 & 64 & -6 & 376.77 \\
\hline 47 & 35 & 24 & -5 & 52.15 \\
\hline 41 & 29 & 16 & -4.5 & 20.04 \\
\hline 45 & 35 & 24 & -5 & 39.1 \\
\hline 36 & 28 & 19 & -4.5 & 19.2 \\
\hline 36 & 25 & 10 & -4.5 & 7.15 \\
\hline 33 & 25 & 18 & -4.5 & 19.09 \\
\hline 32 & 23 & 15 & -4.5 & 12.8 \\
\hline 36 & 27 & 22 & -4.5 & 28.68 \\
\hline 38 & 38 & 17 & -5 & 33.73 \\
\hline 33 & 30 & 13 & -4.5 & 16.56 \\
\hline \multicolumn{5}{|c|}{ Total Weight } \\
\hline
\end{tabular}

Individually Measured Clasts from -4Ф Pan

\begin{tabular}{|c|c|c|c|c|}
\hline A Axis & B Axis & C Axis & Ф Size & Weight \\
\hline 26 & 23 & 12 & -4.5 & 10.76 \\
\hline 28 & 22 & 14 & -4.5 & 11.03 \\
\hline 26 & 18 & 14 & -4 & 10.01 \\
\hline 30 & 17 & 15 & -4 & 11.46 \\
\hline 29 & 17 & 14 & -4 & 10.32 \\
\hline 30 & 19 & 18 & -4 & 14.47 \\
\hline 36 & 21 & 14 & -4 & 13.75 \\
\hline 27 & 20 & 15 & -4 & 9.58 \\
\hline 25 & 20 & 15 & -4 & 6.71 \\
\hline \multicolumn{5}{|c|}{ Total Weight } \\
\hline \multicolumn{5}{|c}{} \\
\hline
\end{tabular}

Sieved Sediment

\begin{tabular}{|c|c|}
\hline$\Phi$ Size & Weight \\
\hline-4 & 98.09 \\
\hline-3.5 & 116.68 \\
\hline-3 & 77.10 \\
\hline-2.5 & 60.57 \\
\hline-2 & 52.85 \\
\hline-1.5 & 59.95 \\
\hline-1 & 53.16 \\
\hline-0.5 & 54.98 \\
\hline 0 & 47.45 \\
\hline 0.5 & 47.59 \\
\hline 1 & 47.32 \\
\hline 1.5 & 40.64 \\
\hline 2 & 32.28 \\
\hline 2.5 & 25.28 \\
\hline 3 & 17.54 \\
\hline 3.5 & 10.93 \\
\hline 4 & 8.96 \\
\hline 4.5 & 5.59 \\
\hline Pan & 0.69 \\
\hline Total & 857.65 \\
\hline
\end{tabular}

Total Sediment Sample

\begin{tabular}{|c|c|c|c|}
\hline$\Phi$ Size & Weight & $\%$ & Cumulative \% \\
\hline-6.5 & 0 & 0.000 & 0.000 \\
\hline-6 & 1843.55 & 59.086 & 59.086 \\
\hline-5.5 & 0 & 0.000 & 59.086 \\
\hline-5 & 295.4 & 9.468 & 68.553 \\
\hline-4.5 & 145.31 & 4.657 & 73.211 \\
\hline-4 & 76.3 & 2.445 & 75.656 \\
\hline-3.5 & 116.68 & 3.740 & 79.396 \\
\hline-3 & 77.1 & 2.471 & 81.867 \\
\hline-2.5 & 60.57 & 1.941 & 83.808 \\
\hline-2 & 52.85 & 1.694 & 85.502 \\
\hline-1.5 & 59.95 & 1.921 & 87.423 \\
\hline-1 & 53.16 & 1.704 & 89.127 \\
\hline-0.5 & 54.98 & 1.762 & 90.889 \\
\hline 0 & 47.45 & 1.521 & 92.410 \\
\hline 0.5 & 47.59 & 1.525 & 93.935 \\
\hline 1 & 47.32 & 1.517 & 95.452 \\
\hline 1.5 & 40.64 & 1.303 & 96.754 \\
\hline 2 & 32.28 & 1.035 & 97.789 \\
\hline 2.5 & 25.28 & 0.810 & 98.599 \\
\hline 3 & 17.54 & 0.562 & 99.161 \\
\hline 3.5 & 10.93 & 0.350 & 99.512 \\
\hline 4 & 8.96 & 0.287 & 99.799 \\
\hline 4.5 & 5.59 & 0.179 & 99.978 \\
\hline Pan & 0.69 & 0.022 & 100.000 \\
\hline Total & 3120.12 & 100 & \\
\hline & & & \\
\hline
\end{tabular}


Individually Measured Clasts

\begin{tabular}{|c|c|c|c|c|}
\hline A Axis & B Axis & C Axis & $\Phi$ Size & Weight \\
\hline 100 & 62 & 46 & -5.5 & 514.93 \\
\hline 124 & 70 & 37 & -6 & 482.7 \\
\hline 86 & 45 & 30 & -5.5 & 176.33 \\
\hline 80 & 42 & 62 & -5 & 287.67 \\
\hline 85 & 63 & 40 & -5.5 & 289.96 \\
\hline 113 & 87 & 49 & -6 & 565.28 \\
\hline 31 & 22 & 18 & -4.5 & 17.06 \\
\hline 42 & 32 & 19 & -5 & 35.94 \\
\hline 59 & 33 & 16 & -5 & 48.22 \\
\hline 41 & 34 & 24 & -5 & 49 \\
\hline 46 & 29 & 21 & -4.5 & 38.33 \\
\hline \multicolumn{4}{|c|}{ Total Weight } & 2505.42 \\
\hline
\end{tabular}

Individually Measured Clasts from -4Ф Pan

\begin{tabular}{|c|c|c|c|c|}
\hline A Axis & B Axis & C Axis & $\Phi$ Size & Weight \\
\hline 27 & 20 & 12 & -4 & 8.04 \\
\hline 27 & 18 & 13 & -4 & 8.73 \\
\hline \multicolumn{4}{|c|}{ Total Weight } & 16.77 \\
\hline
\end{tabular}

Sieved Sediment

\begin{tabular}{|c|c|}
\hline$\Phi$ Size & Weight \\
\hline-4 & 16.77 \\
\hline-3.5 & 66.05 \\
\hline-3 & 34.40 \\
\hline-2.5 & 26.96 \\
\hline-2 & 24.62 \\
\hline-1.5 & 22.98 \\
\hline-1 & 22.86 \\
\hline-0.5 & 23.19 \\
\hline 0 & 19.68 \\
\hline 0.5 & 18.26 \\
\hline 1 & 16.21 \\
\hline 1.5 & 12.27 \\
\hline 2 & 9.59 \\
\hline 2.5 & 7.72 \\
\hline 3 & 5.31 \\
\hline 3.5 & 3.48 \\
\hline 4 & 3.25 \\
\hline 4.5 & 1.7 \\
\hline Pan & 0.47 \\
\hline Total & 335.77 \\
\hline
\end{tabular}

Total Sediment Sample

\begin{tabular}{|c|c|c|c|}
\hline$\Phi$ Size & Weight & $\%$ & Cumulative $\%$ \\
\hline-6.5 & 0 & 0.000 & 0.000 \\
\hline-6 & 1047.98 & 36.885 & 36.885 \\
\hline-5.5 & 981.22 & 34.536 & 71.421 \\
\hline-5 & 420.83 & 14.812 & 86.233 \\
\hline-4.5 & 55.39 & 1.950 & 88.182 \\
\hline-4 & 16.77 & 0.590 & 88.772 \\
\hline-3.5 & 66.05 & 2.325 & 91.097 \\
\hline-3 & 34.4 & 1.211 & 92.308 \\
\hline-2.5 & 26.96 & 0.949 & 93.257 \\
\hline-2 & 24.62 & 0.867 & 94.123 \\
\hline-1.5 & 22.98 & 0.809 & 94.932 \\
\hline-1 & 22.86 & 0.805 & 95.737 \\
\hline-0.5 & 23.19 & 0.816 & 96.553 \\
\hline 0 & 19.68 & 0.693 & 97.246 \\
\hline 0.5 & 18.26 & 0.643 & 97.888 \\
\hline 1 & 16.21 & 0.571 & 98.459 \\
\hline 1.5 & 12.27 & 0.432 & 98.891 \\
\hline 2 & 9.59 & 0.338 & 99.228 \\
\hline 2.5 & 7.72 & 0.272 & 99.500 \\
\hline 3 & 5.31 & 0.187 & 99.687 \\
\hline 3.5 & 3.48 & 0.122 & 99.809 \\
\hline 4 & 3.25 & 0.114 & 99.924 \\
\hline 4.5 & 1.7 & 0.060 & 99.983 \\
\hline Pan & 0.47 & 0.017 & 100.000 \\
\hline Total & 2841.19 & 100 & \\
\hline & & & \\
\hline
\end{tabular}


Sample 5

Individually Measured Clasts

\begin{tabular}{|c|c|c|c|c|}
\hline A Axis & B Axis & C Axis & Ф Size & Weight \\
\hline 43 & 34 & 28 & -5 & 59.36 \\
\hline 46 & 43 & 31 & -5 & 79.71 \\
\hline 40 & 36 & 20 & -5 & 38.01 \\
\hline 49 & 39 & 32 & -5 & 76.04 \\
\hline 51 & 37 & 15 & -5 & 38.93 \\
\hline 42 & 37 & 29 & -5 & 51.78 \\
\hline 40 & 36 & 21 & -5 & 40 \\
\hline \multicolumn{5}{|c|}{ Total Weight } \\
\hline
\end{tabular}

Individually Measured Clasts from $-4 \Phi$

Pan

\begin{tabular}{|c|c|c|c|c|}
\hline A Axis & B Axis & C Axis & Ф Size & Weight \\
\hline 29 & 26 & 18 & -4.5 & 17.24 \\
\hline 28 & 20 & 16 & -4 & 10.43 \\
\hline 26 & 22 & 11 & -4.5 & 8.02 \\
\hline 65 & 24 & 18 & -4.5 & 36.64 \\
\hline 24 & 23 & 17 & -4.5 & 11.69 \\
\hline 28 & 27 & 13 & -4.5 & 17.44 \\
\hline 22 & 15 & 17 & -4 & 7.71 \\
\hline 26 & 22 & 17 & -4.5 & 13.21 \\
\hline 50 & 29 & 16 & -4.5 & 27.17 \\
\hline 32 & 27 & 16 & -4.5 & 18.36 \\
\hline 32 & 24 & 15 & -4.5 & 11.34 \\
\hline & & & & \\
33 & 26 & 22 & -4.5 & 20.22 \\
\hline 30 & 24 & 18 & -4.5 & 18.3 \\
\hline 44 & 22 & 19 & -4.5 & 29.13 \\
\hline 18 & 22 & 10 & -4.5 & 4.65 \\
\hline 25 & 21 & 18 & -4 & 10.81 \\
\hline 32 & 15 & 31 & -4 & 20.15 \\
\hline 18 & 23 & 21 & -4.5 & 11.04 \\
\hline 39 & 24 & 19 & -4.5 & 18.96 \\
\hline 27 & 25 & 16 & -4.5 & 14.75 \\
\hline 28 & 26 & 19 & -4.5 & 22.69 \\
\hline 30 & 30 & 19 & -4.5 & 19.45 \\
\hline 30 & 26 & 20 & -4.5 & 22.92 \\
\hline 35 & 23 & 16 & -4.5 & 20.29 \\
\hline 29 & 26 & 25 & -4.5 & 22.37 \\
\hline 42 & 22 & 13 & -4.5 & 9.73 \\
\hline 30 & 24 & 17 & -4.5 & 16.22 \\
\hline 26 & 19 & 15 & -4 & 10.85 \\
\hline 50 & 22 & 21 & -4.5 & 33.58 \\
\hline 26 & 26 & 14 & -4.5 & 10.5 \\
\hline 32 & 17 & 13 & -4 & 9.2 \\
\hline 29 & 21 & 18 & -4 & 12.54 \\
\hline & Total Weight & & 537.6 \\
\hline & & & & \\
\hline
\end{tabular}

Sieved Sediment

\begin{tabular}{|c|c|}
\hline$\Phi$ Size & Weight \\
\hline-4 & 537.6 \\
\hline-3.5 & 198.58 \\
\hline-3 & 159.47 \\
\hline-2.5 & 122.18 \\
\hline-2 & 94.95 \\
\hline-1.5 & 80.37 \\
\hline-1 & 74.23 \\
\hline-0.5 & 70.9 \\
\hline 0 & 55.28 \\
\hline 0.5 & 51.14 \\
\hline & \\
\hline 1 & 49.77 \\
\hline 1.5 & 40.72 \\
\hline 2 & 34.91 \\
\hline 2.5 & 27.55 \\
\hline 3 & 17.47 \\
\hline 3.5 & 8.42 \\
\hline 4 & 5.64 \\
\hline 4.5 & 3.44 \\
\hline Pan & 1.76 \\
\hline Total & 1634.38 \\
\hline
\end{tabular}

Total Sediment Sample

\begin{tabular}{|c|c|c|c|}
\hline $\begin{array}{c}\boldsymbol{\Phi} \\
\text { Size }\end{array}$ & Weight & $\%$ & Cumulative $\%$ \\
\hline-6.5 & 0 & 0.000 & 0.000 \\
\hline-6 & 0 & 0.000 & 0.000 \\
\hline-5.5 & 0 & 0.000 & 0.000 \\
\hline-5 & 383.83 & 19.018 & 19.018 \\
\hline-4.5 & 455.91 & 22.590 & 41.608 \\
\hline-4 & 81.69 & 4.048 & 45.656 \\
\hline-3.5 & 198.58 & 9.839 & 55.495 \\
\hline-3 & 159.47 & 7.902 & 63.397 \\
\hline-2.5 & 122.18 & 6.054 & 69.451 \\
\hline-2 & 94.95 & 4.705 & 74.155 \\
\hline-1.5 & 80.37 & 3.982 & 78.138 \\
\hline-1 & 74.23 & 3.678 & 81.816 \\
\hline-0.5 & 70.9 & 3.513 & 85.329 \\
\hline 0 & 55.28 & 2.739 & 88.068 \\
\hline 0.5 & 51.14 & 2.534 & 90.602 \\
\hline 1 & 49.77 & 2.466 & 93.068 \\
\hline 1.5 & 40.72 & 2.018 & 95.085 \\
\hline 2 & 34.91 & 1.730 & 96.815 \\
\hline 2.5 & 27.55 & 1.365 & 98.180 \\
\hline 3 & 17.47 & 0.866 & 99.046 \\
\hline 3.5 & 8.42 & 0.417 & 99.463 \\
\hline 4 & 5.64 & 0.279 & 99.742 \\
\hline 4.5 & 3.44 & 0.170 & 99.913 \\
\hline Pan & 1.76 & 0.087 & 100.000 \\
\hline Total & 2018.21 & 100 & \\
\hline & & & \\
\hline
\end{tabular}


Individually Measured Clasts

\begin{tabular}{|c|c|c|c|c|}
\hline A Axis & B Axis & C Axis & $\Phi$ Size & Weight \\
\hline 54 & 38 & 30 & -5 & 71.41 \\
\hline 39 & 31 & 18 & -4.5 & 29.04 \\
\hline 44 & 30 & 17 & -4.5 & 23.57 \\
\hline 30 & 32 & 16 & -5 & 22.64 \\
\hline 44 & 35 & 27 & -5 & 41.32 \\
\hline \multicolumn{5}{|c|}{ Total Weight } \\
\hline
\end{tabular}

Individually Measured Clasts from -4Ф Pan

\begin{tabular}{|c|c|c|c|c|}
\hline A Axis & B Axis & C Axis & $\Phi$ Size & Weight \\
\hline 49 & 24 & 21 & -4.5 & 34.59 \\
\hline 30 & 19 & 22 & -4 & 15.51 \\
\hline 54 & 27 & 16 & -4.5 & 25.93 \\
\hline 50 & 26 & 15 & -4.5 & 28.45 \\
\hline 22 & 25 & 16 & -4.5 & 12.89 \\
\hline 39 & 28 & 17 & -4.5 & 24.9 \\
\hline 40 & 27 & 15 & -4.5 & 22.51 \\
\hline 31 & 25 & 14 & -4.5 & 9.85 \\
\hline 30 & 27 & 13 & -4.5 & 11.03 \\
\hline 32 & 22 & 21 & -4.5 & 19.82 \\
\hline 29 & 18 & 10 & -4 & 7.84 \\
\hline 23 & 17 & 12 & -4 & 7.36 \\
\hline \multicolumn{5}{|c|}{ Total Weight } \\
\hline
\end{tabular}

Sieved Sediment

\begin{tabular}{|c|c|}
\hline$\Phi$ Size & Weight \\
\hline-4 & 220.68 \\
\hline-3.5 & 84.76 \\
\hline-3 & 71.57 \\
\hline-2.5 & 55.79 \\
\hline-2 & 55.21 \\
\hline-1.5 & 62.38 \\
\hline-1 & 69.01 \\
\hline-0.5 & 87.15 \\
\hline 0 & 87.55 \\
\hline 0.5 & 94.91 \\
\hline 1 & 99.49 \\
\hline 1.5 & 77.49 \\
\hline 2 & 62.4 \\
\hline 2.5 & 38.61 \\
\hline 3 & 19.79 \\
\hline 3.5 & 7.24 \\
\hline 4 & 3.46 \\
\hline 4.5 & 1.73 \\
\hline Pan & 0.94 \\
\hline Total & 1200.16 \\
\hline
\end{tabular}

Total Sediment Sample

\begin{tabular}{|c|c|c|c|}
\hline$\Phi$ Size & Weight & $\%$ & Cumulative \% \\
\hline-6.5 & 0 & 0.000 & 0.000 \\
\hline-6 & 0 & 0.000 & 0.000 \\
\hline-5.5 & 0 & 0.000 & 0.000 \\
\hline-5 & 135.37 & 9.752 & 9.752 \\
\hline-4.5 & 242.58 & 17.475 & 27.227 \\
\hline-4 & 30.71 & 2.212 & 29.439 \\
\hline-3.5 & 84.76 & 6.106 & 35.545 \\
\hline-3 & 71.57 & 5.156 & 40.701 \\
\hline-2.5 & 55.79 & 4.019 & 44.720 \\
\hline-2 & 55.21 & 3.977 & 48.698 \\
\hline-1.5 & 62.38 & 4.494 & 53.191 \\
\hline-1 & 69.01 & 4.971 & 58.163 \\
\hline-0.5 & 87.15 & 6.278 & 64.441 \\
\hline 0 & 87.55 & 6.307 & 70.748 \\
\hline 0.5 & 94.91 & 6.837 & 77.585 \\
\hline 1 & 99.49 & 7.167 & 84.752 \\
\hline 1.5 & 77.49 & 5.582 & 90.335 \\
\hline 2 & 62.4 & 4.495 & 94.830 \\
\hline 2.5 & 38.61 & 2.781 & 97.611 \\
\hline 3 & 19.79 & 1.426 & 99.037 \\
\hline 3.5 & 7.24 & 0.522 & 99.558 \\
\hline 4 & 3.46 & 0.249 & 99.808 \\
\hline 4.5 & 1.73 & 0.125 & 99.932 \\
\hline Pan & 0.94 & 0.068 & 100.000 \\
\hline Total & 1388.14 & 100 & \\
\hline & & & \\
\hline
\end{tabular}




\section{Sample 7}

Individually Measured Clasts

\begin{tabular}{|c|c|c|c|c|}
\hline A Axis & B Axis & C Axis & Ф Size & Weight \\
\hline 85 & 68 & 26 & -6 & 168.5 \\
\hline 56 & 54 & 35 & -5.5 & 142.89 \\
\hline 59 & 43 & 36 & -5 & 127.63 \\
\hline 48 & 39 & 25 & -5 & 66.64 \\
\hline 49 & 34 & 16 & -5 & 33.65 \\
\hline 44 & 40 & 19 & -5 & 51.35 \\
\hline 48 & 32 & 17 & -5 & 30.54 \\
\hline 35 & 32 & 24 & -5 & 36.05 \\
\hline 49 & 30 & 27 & -4.5 & 60.3 \\
\hline 35 & 28 & 26 & -4.5 & 31.92 \\
\hline 38 & 26 & 18 & -4.5 & 18.69 \\
\hline 50 & 27 & 26 & -4.5 & 44.79 \\
\hline \multicolumn{4}{|c|}{ Total Weight } & 812.95 \\
\hline
\end{tabular}

Individually Measured Clasts from -4Ф Pan

\begin{tabular}{|c|c|c|c|c|}
\hline A Axis & B Axis & C Axis & $\Phi$ Size & Weight \\
\hline 37 & 26 & 17 & -4.5 & 24.27 \\
\hline 30 & 22 & 19 & -4.5 & 9.91 \\
\hline 34 & 23 & 14 & -4.5 & 12.62 \\
\hline 32 & 19 & 17 & -4 & 13.93 \\
\hline 37 & 26 & 17 & -4.5 & 12.01 \\
\hline 33 & 28 & 25 & -4.5 & 27.15 \\
\hline 37 & 24 & 20 & -4.5 & 23.72 \\
\hline 26 & 25 & 17 & -4.5 & 12.09 \\
\hline 32 & 17 & 16 & -4 & 10.99 \\
\hline 23 & 20 & 14 & -4 & 9.76 \\
\hline 30 & 26 & 8 & -4.5 & 8.71 \\
\hline 37 & 23 & 13 & -4.5 & 13.63 \\
\hline 30 & 18 & 18 & -4 & 10.5 \\
\hline 36 & 18 & 18 & -4 & 12.33 \\
\hline 28 & 23 & 12 & -4.5 & 10.3 \\
\hline 28 & 18 & 13 & -4 & 9.94 \\
\hline 23 & 19 & 17 & -4 & 9.65 \\
\hline 21 & 17 & 17 & -4 & 6.77 \\
\hline
\end{tabular}

Sieved Sediment

\begin{tabular}{|c|c|}
\hline$\Phi$ Size & Weight \\
\hline-4 & 238.28 \\
\hline-3.5 & 161.59 \\
\hline-3 & 110.70 \\
\hline-2.5 & 82.67 \\
\hline-2 & 51.85 \\
\hline-1.5 & 40.20 \\
\hline-1 & 30.65 \\
\hline-0.5 & 28.3 \\
\hline 0 & 26.64 \\
\hline 0.5 & 34.21 \\
\hline 1 & 47.2 \\
\hline 1.5 & 46.6 \\
\hline 2 & 44.12 \\
\hline 2.5 & 40.99 \\
\hline 3 & 36.74 \\
\hline 3.5 & 22.15 \\
\hline 4 & 13.01 \\
\hline 4.5 & 7.13 \\
\hline Pan & 1.75 \\
\hline Total & 1064.78 \\
\hline
\end{tabular}

Total Sediment Sample

\begin{tabular}{|c|c|c|c|}
\hline$\Phi$ Size & Weight & $\%$ & Cumulative $\%$ \\
\hline-6.5 & 0 & 0.000 & 0.000 \\
\hline-6 & 168.5 & 8.974 & 8.974 \\
\hline-5.5 & 142.89 & 7.610 & 16.583 \\
\hline-5 & 345.86 & 18.419 & 35.002 \\
\hline-4.5 & 310.11 & 16.515 & 51.518 \\
\hline-4 & 83.87 & 4.467 & 55.984 \\
\hline-3.5 & 161.59 & 8.606 & 64.590 \\
\hline-3 & 110.7 & 5.895 & 70.485 \\
\hline-2.5 & 82.67 & 4.403 & 74.888 \\
\hline-2 & 51.85 & 2.761 & 77.649 \\
\hline-1.5 & 40.2 & 2.141 & 79.790 \\
\hline-1 & 30.65 & 1.632 & 81.422 \\
\hline-0.5 & 28.3 & 1.507 & 82.929 \\
\hline 0 & 26.64 & 1.419 & 84.348 \\
\hline 0.5 & 34.21 & 1.822 & 86.170 \\
\hline 1 & 47.2 & 2.514 & 88.684 \\
\hline 1.5 & 46.6 & 2.482 & 91.165 \\
\hline 2 & 44.12 & 2.350 & 93.515 \\
\hline 2.5 & 40.99 & 2.183 & 95.698 \\
\hline 3 & 36.74 & 1.957 & 97.655 \\
\hline 3.5 & 22.15 & 1.180 & 98.834 \\
\hline 4 & 13.01 & 0.693 & 99.527 \\
\hline 4.5 & 7.13 & 0.380 & 99.907 \\
\hline Pan & 1.75 & 0.093 & 100.000 \\
\hline Total & 1877.73 & 100 & \\
\hline & & & \\
\hline
\end{tabular}




\section{Sample 8A}

Individually Measured Clasts

\begin{tabular}{|c|c|c|c|c|}
\hline A Axis & B Axis & C Axis & $\Phi$ Size & Weight \\
\hline 77 & 50 & 42 & -5.5 & 246.87 \\
\hline 40 & 30 & 24 & -4.5 & 39.81 \\
\hline 43 & 25 & 23 & -4.5 & 29.6 \\
\hline 34 & 23 & 14 & -4.5 & 20.11 \\
\hline \multicolumn{4}{|c|}{ Total Weight } & 336.39 \\
\hline
\end{tabular}

Individually Measured Clasts from -4Ф Pan

\begin{tabular}{|c|c|c|c|c|}
\hline A Axis & B Axis & C Axis & $\Phi$ Size & Weight \\
\hline 44 & 26 & 17 & -4.5 & 28.33 \\
\hline 49 & 21 & 16 & -4 & 20.27 \\
\hline 37 & 23 & 16 & -4.5 & 18.89 \\
\hline 34 & 24 & 14 & -4.5 & 14.15 \\
\hline 27 & 26 & 16 & -4.5 & 8.59 \\
\hline 29 & 27 & 18 & -4.5 & 12.65 \\
\hline 32 & 22 & 11 & -4.5 & 10.04 \\
\hline \multicolumn{6}{|c|}{ Total Weight } & 112.92 \\
\hline
\end{tabular}

Sieved Sediment

\begin{tabular}{|c|c|}
\hline$\Phi$ Size & Weight \\
\hline-4 & 112.92 \\
\hline-3.5 & 89.2 \\
\hline-3 & 82.51 \\
\hline-2.5 & 77.73 \\
\hline-2 & 81.71 \\
\hline-1.5 & 87.30 \\
\hline-1 & 80.30 \\
\hline-0.5 & 74.88 \\
\hline 0 & 47.85 \\
\hline 0.5 & 36.83 \\
\hline 1 & 25.91 \\
\hline 1.5 & 16.32 \\
\hline 2 & 15.17 \\
\hline 2.5 & 19.24 \\
\hline 3 & 27.45 \\
\hline 3.5 & 25.05 \\
\hline 4 & 28.8 \\
\hline 4.5 & 15.56 \\
\hline Pan & 11.36 \\
\hline Total & 956.09 \\
\hline
\end{tabular}

Total Sediment Sample

\begin{tabular}{|c|c|c|c|}
\hline$\Phi$ Size & Weight & $\%$ & Cumulative $\%$ \\
\hline-6.5 & 0 & 0.000 & 0.000 \\
\hline-6 & 0 & 0.000 & 0.000 \\
\hline-5.5 & 246.87 & 19.100 & 19.100 \\
\hline-5 & 0 & 0.000 & 19.100 \\
\hline-4.5 & 182.17 & 14.095 & 33.195 \\
\hline-4 & 20.27 & 1.568 & 34.763 \\
\hline-3.5 & 89.2 & 6.901 & 41.665 \\
\hline-3 & 82.51 & 6.384 & 48.049 \\
\hline-2.5 & 77.73 & 6.014 & 54.063 \\
\hline-2 & 81.71 & 6.322 & 60.385 \\
\hline-1.5 & 87.3 & 6.754 & 67.139 \\
\hline-1 & 80.3 & 6.213 & 73.352 \\
\hline-0.5 & 74.88 & 5.794 & 79.146 \\
\hline 0 & 47.85 & 3.702 & 82.848 \\
\hline 0.5 & 36.83 & 2.850 & 85.697 \\
\hline 1 & 25.91 & 2.005 & 87.702 \\
\hline 1.5 & 16.32 & 1.263 & 88.965 \\
\hline 2 & 15.17 & 1.174 & 90.138 \\
\hline 2.5 & 19.24 & 1.489 & 91.627 \\
\hline 3 & 27.45 & 2.124 & 93.751 \\
\hline 3.5 & 25.05 & 1.938 & 95.689 \\
\hline 4 & 28.8 & 2.228 & 97.917 \\
\hline 4.5 & 15.56 & 1.204 & 99.121 \\
\hline Pan & 11.36 & 0.879 & 100.000 \\
\hline total & 1292.48 & 100 & \\
\hline & & & \\
\hline
\end{tabular}




\section{Sample 8B}

Individually Measured Clasts

\begin{tabular}{|c|c|c|c|c|}
\hline A Axis & B Axis & C Axis & $\Phi$ Size & Weight \\
\hline 100 & 61 & 45 & -5.5 & 385.84 \\
\hline 88 & 55 & 41 & -5.5 & 258.63 \\
\hline 80 & 43 & 40 & -5 & 168.05 \\
\hline 61 & 51 & 28 & -5.5 & 118.08 \\
\hline 56 & 44 & 33 & -5 & 120.16 \\
\hline 67 & 33 & 25 & -5 & 58.33 \\
\hline 59 & 26 & 25 & -4.5 & 53.49 \\
\hline 64 & 47 & 38 & -5.5 & 130.87 \\
\hline 44 & 32 & 20 & -5 & 46.24 \\
\hline 50 & 30 & 23 & -4.5 & 48.58 \\
\hline 43 & 32 & 23 & -5 & 37.49 \\
\hline 35 & 34 & 30 & -5 & 48.94 \\
\hline 44 & 25 & 20 & -4.5 & 26.4 \\
\hline 45 & 25 & 16 & -4.5 & 23.2 \\
\hline 31 & 24 & 21 & -4.5 & 22.94 \\
\hline 36 & 24 & 18 & -4.5 & 22.67 \\
\hline 32 & 25 & 21 & -4.5 & 24.11 \\
\hline 36 & 26 & 18 & -4.5 & 12.5 \\
\hline 40 & 21 & 14 & -4 & 23.04 \\
\hline 32 & 27 & 19 & -4.5 & 19.5 \\
\hline 38 & 22 & 11 & -4.5 & 21.75 \\
\hline & Total Weight & & 1670.81 \\
\hline & & & & \\
\hline
\end{tabular}

Individually Measured Clasts from -4Ф Pan

\begin{tabular}{|c|c|c|c|c|}
\hline A Axis & B Axis & C Axis & $\Phi$ Size & Weight \\
\hline 21 & 21 & 10 & -4 & 6.39 \\
\hline 17 & 17 & 17 & -4 & 7.24 \\
\hline 31 & 24 & 19 & -4.5 & 18.42 \\
\hline 30 & 19 & 16 & -4 & 12.95 \\
\hline 30 & 24 & 17 & -4.5 & 12.44 \\
\hline 40 & 21 & 14 & -4 & 17.57 \\
\hline 30 & 18 & 16 & -4 & 15.24 \\
\hline 25 & 20 & 16 & -4 & 10.79 \\
\hline 32 & 24 & 12 & -4.5 & 9.77 \\
\hline 32 & 23 & 15 & -4.5 & 13.48 \\
\hline 27 & 19 & 16 & -4 & 9.7 \\
\hline 30 & 23 & 11 & -4.5 & 8.71 \\
\hline \multicolumn{5}{|c|}{ Total Weight } \\
\hline
\end{tabular}

Sieved Sediment

\begin{tabular}{|c|c|}
\hline$\Phi$ Size & Weight \\
\hline-4 & 142.70 \\
\hline-3.5 & 64.68 \\
\hline-3 & 41.23 \\
\hline-2.5 & 28.05 \\
\hline-2 & 17.26 \\
\hline-1.5 & 14.14 \\
\hline-1 & 10.67 \\
\hline-0.5 & 9.00 \\
\hline 0 & 5.91 \\
\hline 0.5 & 4.83 \\
\hline 1 & 4.38 \\
\hline 1.5 & 3.83 \\
\hline 2 & 4.30 \\
\hline 2.5 & 6.06 \\
\hline 3 & 12.33 \\
\hline 3.5 & 14.77 \\
\hline 4 & 17.77 \\
\hline 4.5 & 7.19 \\
\hline Pan & 3.71 \\
\hline Total & 412.81 \\
\hline \multicolumn{2}{|c}{}
\end{tabular}

Total Sediment Sample

\begin{tabular}{|c|c|c|c|}
\hline$\Phi$ Size & Weight & $\%$ & Cumulative $\%$ \\
\hline-6.5 & 0 & 0.000 & 0.000 \\
\hline-6 & 0 & 0.000 & 0.000 \\
\hline-5.5 & 893.42 & 42.878 & 42.878 \\
\hline-5 & 479.21 & 22.999 & 65.877 \\
\hline-4.5 & 337.96 & 16.220 & 82.097 \\
\hline-4 & 102.92 & 4.939 & 87.037 \\
\hline-3.5 & 64.68 & 3.104 & 90.141 \\
\hline-3 & 41.23 & 1.979 & 92.119 \\
\hline-2.5 & 28.05 & 1.346 & 93.466 \\
\hline-2 & 17.26 & 0.828 & 94.294 \\
\hline-1.5 & 14.14 & 0.679 & 94.973 \\
\hline-1 & 10.67 & 0.512 & 95.485 \\
\hline-0.5 & 9 & 0.432 & 95.917 \\
\hline 0 & 5.91 & 0.284 & 96.200 \\
\hline 0.5 & 4.83 & 0.232 & 96.432 \\
\hline 1 & 4.38 & 0.210 & 96.642 \\
\hline 1.5 & 3.83 & 0.184 & 96.826 \\
\hline 2 & 4.3 & 0.206 & 97.033 \\
\hline 2.5 & 6.06 & 0.291 & 97.323 \\
\hline 3 & 12.33 & 0.592 & 97.915 \\
\hline 3.5 & 14.77 & 0.709 & 98.624 \\
\hline 4 & 17.77 & 0.853 & 99.477 \\
\hline 4.5 & 7.19 & 0.345 & 99.822 \\
\hline Pan & 3.71 & 0.178 & 100.000 \\
\hline Total & 2083.62 & 100 & \\
\hline & & & \\
\hline
\end{tabular}




\section{Source Sediment Sample}

Individually Measured Clasts

Individually measured clasts removed from sample before it was split

\begin{tabular}{|c|c|c|c|c|}
\hline A Axis & B Axis & C Axis & Ф Size & Weight \\
\hline 59 & 49 & 34 & -5.5 & 152.3 \\
\hline 107 & 62 & 60 & -5.5 & 540.54 \\
\hline 55 & 38 & 24 & -5 & 71.32 \\
\hline 147 & 91 & 55 & -6.5 & 1218.64 \\
\hline 61 & 36 & 38 & -5 & 129.46 \\
\hline 67 & 36 & 25 & -5 & 91.48 \\
\hline 41 & 37 & 25 & -5 & 44.24 \\
\hline 51 & 34 & 9 & -5 & 21.64 \\
\hline 43 & 35 & 25 & -5 & 56.09 \\
\hline 59 & 47 & 34 & -5.5 & 119 \\
\hline 45 & 36 & 23 & -5 & 48.1 \\
\hline 65 & 47 & 21 & -5.5 & 74.43 \\
\hline 103 & 69 & 39 & -6 & 302.94 \\
\hline & Total Weight & & 2870.18 \\
\hline
\end{tabular}

Individually Measured Clasts from -4Ф Pan

\begin{tabular}{|c|c|c|c|c|c|}
\hline Sub-Sample & A Axis & B Axis & C Axis & $\Phi$ Size & Weight \\
\hline \multirow{6}{*}{ A } & 15 & 20 & 36 & -4 & 13.63 \\
\hline & 32 & 32 & 17 & -5 & 17.95 \\
\hline & 37 & 21 & 10 & -4 & 12.17 \\
\hline & 34 & 32 & 12 & -5 & 16.08 \\
\hline & 35 & 25 & 21 & -4.5 & 23.61 \\
\hline & 29 & 22 & 19 & -4.5 & 13.91 \\
\hline \multirow{7}{*}{ B } & 34 & 21 & 16 & -4 & 15.06 \\
\hline & 27 & 22 & 15 & -4.5 & 14.01 \\
\hline & 35 & 22 & 17 & -4.5 & 17.43 \\
\hline & 25 & 25 & 16 & -4.5 & 10.97 \\
\hline & 25 & 21 & 13 & -4 & 8.29 \\
\hline & 32 & 20 & 17 & -4 & 9.46 \\
\hline & 29 & 17 & 18 & -4 & 9.57 \\
\hline C & 31 & 24 & 21 & -4.5 & 16.8 \\
\hline \multirow{5}{*}{$E$} & 39 & 18 & 16 & -4 & 15.55 \\
\hline & 39 & 22 & 16 & -4.5 & 19.78 \\
\hline & 28 & 24 & 10 & -4.5 & 6.35 \\
\hline & 17 & 17 & 14 & -4 & 5.22 \\
\hline & 40 & 17 & 13 & -4 & 10.62 \\
\hline \multirow{3}{*}{$\mathrm{F}$} & 32 & 25 & 14 & -4.5 & 9.21 \\
\hline & 36 & 20 & 13 & -4 & 14.38 \\
\hline & 39 & 31 & 21 & -4.5 & 26.66 \\
\hline \multirow{5}{*}{$\mathrm{G}$} & 34 & 26 & 30 & -4.5 & 18.03 \\
\hline & 25 & 24 & 17 & -4.5 & 15.35 \\
\hline & 26 & 20 & 8 & -4 & 3.9 \\
\hline & 31 & 21 & 16 & -4 & 13.63 \\
\hline & 40 & 25 & 15 & -4.5 & 14.13 \\
\hline \multirow{5}{*}{$\mathrm{H}$} & 40 & 22 & 17 & -4.5 & 18.89 \\
\hline & 25 & 24 & 10 & -4.5 & 5.32 \\
\hline & 30 & 20 & 15 & -4 & 13.65 \\
\hline & 28 & 20 & 14 & -4 & 8.49 \\
\hline & 21 & 17 & 13 & -4 & 5.24 \\
\hline 1 & 37 & 21 & 15 & -4 & 8.5 \\
\hline \multicolumn{5}{|c|}{ Total Weight } & 431.84 \\
\hline
\end{tabular}

Total Sediment Sample

Total of sieved samples $A$ to I and

individually measured clasts

\begin{tabular}{|c|c|c|c|}
\hline $\begin{array}{c}\Phi \\
\text { Size }\end{array}$ & Weight & $\%$ & $\begin{array}{c}\text { Cumulative } \\
\%\end{array}$ \\
\hline-6.5 & 1218.64 & 19.392 & 19.392 \\
\hline-6 & 302.94 & 4.821 & 24.213 \\
\hline-5.5 & 886.27 & 14.103 & 38.316 \\
\hline-5 & 496.36 & 7.899 & 46.215 \\
\hline-4.5 & 230.45 & 3.667 & 49.882 \\
\hline-4 & 167.36 & 2.663 & 52.545 \\
\hline-3.5 & 289.73 & 4.610 & 57.155 \\
\hline-3 & 263.73 & 4.197 & 61.352 \\
\hline-2.5 & 316.23 & 5.032 & 66.384 \\
\hline-2 & 301.9 & 4.804 & 71.188 \\
\hline-1.5 & 340.53 & 5.419 & 76.607 \\
\hline-1 & 284.39 & 4.525 & 81.133 \\
\hline-0.5 & 271.85 & 4.326 & 85.459 \\
\hline 0 & 159.23 & 2.534 & 87.993 \\
\hline 0.5 & 176.59 & 2.810 & 90.803 \\
\hline 1 & 132.64 & 2.111 & 92.913 \\
\hline 1.5 & 99.18 & 1.578 & 94.492 \\
\hline 2 & 86.67 & 1.379 & 95.871 \\
\hline 2.5 & 74.73 & 1.189 & 97.060 \\
\hline 3 & 69.05 & 1.099 & 98.159 \\
\hline 3.5 & 46.75 & 0.744 & 98.903 \\
\hline Pan & 68.96 & 1.097 & 100.000 \\
\hline Total & 6284.18 & 100 & \\
\hline
\end{tabular}




\section{APPENDIX IV}

CAESAR Settings 


\section{CAESAR Settings}

The sediment redistribution model CAESAR (version 5.9c) was employed to determine how the frequency of potential hazardous sedimentation events onto Fan 2 could alter as a result of altered climatic situations. This appendix identifies the parameters which were set in the model runs and outlines the operation of CAESAR.

\section{Parameters set in CAESAR to run the models}

There are ten tabs in CAESAR which contain differing parameters. The parameters set on each of the tabs for both of the model runs are identified below. Note ${ }^{1}$ denotes the current conditions model run and ${ }^{2}$ denotes the altered climatic conditions model run.

Files Tab

DEM data file:

Grain data file:

Bedrock data file:

Rainfall data file:

Variable $\mathrm{M}$ value file:

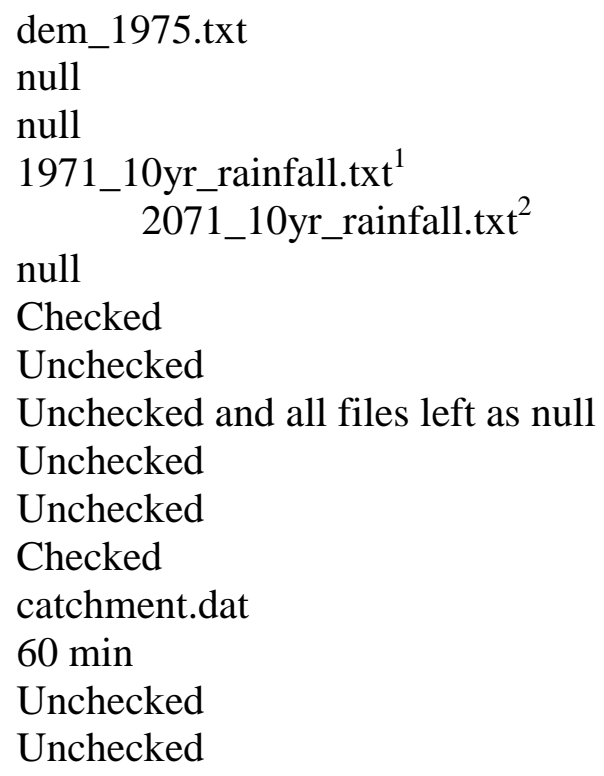

Checked

Unchecked

Unchecked and all files left as null

Unchecked

catchment.dat

Unchecked

Unchecked

Catchment mode:

Reach mode:

Tracer run:

Generate Avi file:

Generate Google Earth animation: Unchecked

Generate time series output: Checked

File name:

Save file every $*$ min: $\quad 60 \mathrm{~min}$

Generate tracer output:

Generate iteration output:

Lateral Erosion Tab

No lateral erosion:

Checked

All other options left unchecked

Numerical Tab

Memory limit:

5

Max \# of iterations:

Min time step (secs):

$100,000,000$

Max time step (secs)

0

Run start time (h):

3600

Max run duration (h):

0

Min Q depth for calc:

87660

0.01

Water depth threshold above which erosion can occur: $\quad 0.01$

Active layer thickness: $\quad 0.2$

WS smoothing radius: 1

Flow distribution width (cells): 2 
Initial discharge $\left(\mathrm{m}^{3} / \mathrm{s}\right)$ :

Evaporation rate $(\mathrm{m} / \mathrm{s})$ :

Init \# of scans:

Max erode limit:

Slope used to calc Tau:
Reach mode only so not required

0.0

20

0.02

Bedslope checked

$\underline{\text { Sediment Tab }}$

\begin{tabular}{|l|l|l|l|l|}
\hline & Grain Size $(\mathrm{m})$ & Proportion & Suspended? & Fall Velocity \\
\hline Size 1 & 0.000125 & 0.029 & Yes & 0.066 \\
\hline Size 2 & 0.00025 & 0.042 & Yes & 0.109 \\
\hline Size 3 & 0.0007 & 0.075 & Yes & 0.164 \\
\hline Size 4 & 0.002 & 0.143 & Yes & 0.237 \\
\hline Size 5 & 0.0057 & 0.098 & & \\
\hline Size 6 & 0.0011 & 0.088 & & \\
\hline Size 7 & 0.023 & 0.063 & & \\
\hline Size 8 & 0.045 & 0.220 & & \\
\hline Size 9 & 0.091 & 0.242 & & \\
\hline
\end{tabular}

Wilcock and Crowe equation:

Checked

Einstein equation:

Unchecked

Description Tab

No description entered for either model run

$\underline{\text { Grid Tab }}$

Override header file:

Checked

$\mathrm{X}$ coordinates:

171

Y coordinates:

157

Cell size:

10

Hydrology Tab

Inputs 1 to 8:

Left blank and unchecked

'm' value:

0.01

Vegetation Tab

Vegetation crit shear:

180.0

Grass maturity (yrs):

5

Contaminant Tab

Input 1:

Left blank and unchecked

Slope Processes

Creep rate:

0.0025

Slope failure threshold:

Soil erosion rate:

45

SIBERIA sub model?:

0.0

Unchecked and its parameters left blank 


\section{CAESAR Operation}

CAESAR was downloaded from:

http://www.coulthard.org.uk/downloads/visualcaesar.htm

The model needs to be stored in a new file for each model run, in which all other files (input and output files) for the model run will be stored. To operate CAESAR in 'catchment mode', CAESAR requires a DEM of the catchment and an hourly rainfall data set for the length of the model run. These files must be in ASCII .txt form and saved in the same file as the CAESAR model. Grain sizes of the catchment are also required.

Open CAESAR.

Select required parameters under each of the tabs.

Go to "Config File" $\rightarrow$ Save As $\rightarrow$ Save the parameter settings into the same files as the CAESAR model.

Click "Load Data" button

Check that CAESAR is in 'catchment' mode. A 1 should appear in the bottom left corner.

Click "Start"

The output files generated as CAESAR runs will be saved to the same file as the CAESAR model. 


\section{APPENDIX V \\ Hourly Rainfall Data for CAESAR}

\section{APPENDIX VI \\ CAESAR Results}




\section{Appendix V: Hourly Rainfall Data for CAESAR}

Due to the large amount of rainfall data required to be input into CAESAR, it is presented in digital form on the attached CD ROM. The file is called "CAESAR Rainfall Data" and contains both the 1971 ten year control rainfall data set and the 2071 ten year climatically altered rainfall data set. Each data set is on a separate spreadsheet and is saved in Microsoft Excel (version 2007).

The rainfall data are taken from a grid box located over the field site location, from a Regional Climate Model (RCM) provided from NIWA and is based around the IPCC's Special Report on Emissions Scenarios' A2 emission scenario. The 1971 data set is based on a normal 365 day Gregorian calendar, while the 2071 data set is based on a 360 day calendar. The rainfall data from the RCM has been rounded to 1 decimal place to be used in CAESAR. Only the rainfall column was used and converted into a text file to be used in CAESAR.

\section{Appendix VI: CAESAR Results - Output Files}

Each of the CAESAR model runs output five files. These files were:

- catchment.dat

- d50top.txt

- elev.txt

- elevdiff.txt

- grain.txt

Only the catchment.dat output file was required for analysing the results need for this study. This file contained 14 data columns. Column 1 is the model time step, column 2 is the water flow discharge, columns 3 and 4 represent nothing, column 5 is the total discharged sediment, and columns 6 to 14 are the amount of sediment discharged for each of the 9 grain size ranges.

Due to the large amount of data in the catchment.dat output files generated from the two model runs, it is presented in digital form on the attached CD ROM. The files are called "catchment_current" and "catchment_altered". Each output data set is stored in a separate Microsoft Excel (version 2007) file. Each file contains two spreadsheets. The "catchment.dat" spreadsheet contains the data from the catchment.dat file output from CAESAR. The "Sediment Events" spreadsheet displays the total sediment events which were generated by CAESAR under each climatic regime. 
